\title{
Mechanistic Understanding of Silver Sorbent Aging Processes in Off-Gas Treatment
}

Final Report: For the period October 1, 2016 - September 30, 2020

Prepared for:

U.S. Department of Energy Nuclear Energy University Program

NEUP Integration Office

Center for Advanced Energy Studies

P.O. Box 1625

Idaho Falls, ID 83415

Contract Number: NFE-16-10229

Program Manager: Stephanie Bruffey

Seungrag Choi

Yue Nan

Lawrence L. Tavlarides (PI)

Department of Biomedical and Chemical Engineering

Syracuse University

\section{Alexander I. Wiechert Ziheng Shen}

Sotira Yiacoumi (Co-PI)

School of Civil and Environmental Engineering

Georgia Institute of Technology

Austin P. Ladshaw

Costas Tsouris (Co-PI)

Oak Ridge National Laboratory

Submission date: December 29, 2020 


\section{Executive Summary}

The effect of aging in various off-gas streams including dry air, humid air, $1 \% \mathrm{NO} / \mathrm{N}_{2}, 2 \%$ $\mathrm{NO}_{2} /$ air, and a gas mixture consisting of $99.25 \%$ humid air (dew point: $-15{ }^{\circ} \mathrm{C}$ ), $0.25 \% \mathrm{NO} / \mathrm{N}_{2}$, and $0.5 \% \mathrm{NO}_{2}$ /air in terms of concentration on reduced silver exchanged mordenite $\left(\mathrm{Ag}^{0} \mathrm{Z}\right)$ and silver functionalized silica aerogel $\left(\mathrm{Ag}^{0}\right.$-aerogel $)$ were studied in this project.

Aged $\mathrm{Ag}^{0} \mathrm{Z}$ and $\mathrm{Ag}^{0}$-aerogel were prepared by exposing both $\mathrm{Ag}^{0} \mathrm{Z}$ and $\mathrm{Ag}^{0}$-aerogel to dry air, humid air (dew points: $-15{ }^{\circ} \mathrm{C}$ to $+15{ }^{\circ} \mathrm{C}$ ), $1 \% \mathrm{NO} / \mathrm{N}_{2}$ and $2 \% \mathrm{NO}_{2} /$ air at various aging temperatures $\left(100{ }^{\circ} \mathrm{C}-20{ }^{\circ} \mathrm{C}\right)$ for differing periods of time of up to 6 months. Additionally, both adsorbents were exposed to the above mentioned gas mixture at $150{ }^{\circ} \mathrm{C}$ for different aging times (10 minutes to 1 month). These aged samples were prepared using a continuous-flow aging system. Iodine capacity data were acquired from continuous-flow iodine adsorption systems using aged $\mathrm{Ag}^{0} \mathrm{Z}$ and $\mathrm{Ag}^{0}$-aerogel. For both $\mathrm{Ag}^{0} \mathrm{Z}$ and $\mathrm{Ag}^{0}$-aerogel, significant iodine loading capacity losses were observed when the adsorbents were exposed to the gas streams used in this study. Adsorbents aged in the $2 \% \mathrm{NO}_{2} /$ air gas stream experienced the most substantial iodine capacity losses, with $\mathrm{Ag}^{0} \mathrm{Z}$ losing $~ 90 \%$ of its initial iodine capacity after 5 hours and $\mathrm{Ag}^{0}$-aerogel losing $~ 80 \%$ of its initial iodine capacity after 2 weeks at $150^{\circ} \mathrm{C}$. Kinetic data obtained from these experiments also show that the iodine capacity losses from aging are more significant when the adsorbents are aged at higher temperatures and water conentrations.

Chemical and physical analyses and mechanisms for the aging of $\mathrm{Ag}^{0} \mathrm{Z}$ and $\mathrm{Ag}^{0}$-aerogel in dry air, humid air, $1 \% \mathrm{NO} / \mathrm{N}_{2}, 2 \% \mathrm{NO}_{2} /$ air, and the gas mixture are discussed in this report. It is proposed that the processes governing the aging of both $\mathrm{Ag}^{0} \mathrm{Z}$ and $\mathrm{Ag}^{0}$-aerogel involve the oxidation of the $\mathrm{Ag}^{0}$ particles present in both adsorbents. Based on available experimental data and sample analyses, kinetic models for $\mathrm{Ag}^{0} \mathrm{Z}$ and $\mathrm{Ag}^{0}$-aerogel aging are suggested. Pseudo ${ }^{\text {th }}$ order reversible and irreversible reaction models are used to describe experimental data for $\mathrm{Ag}^{0} \mathrm{Z}$ and $\mathrm{Ag}^{0}$-aerogel aged in all of the gas streams used in this study. The variables and parameters for these reaction models are provided in this report.

Molecular modeling and column simulations were also used to better describe the mechanisms of aging and assess the impact of aging on iodine adsorption, respectively. Preliminary studies were performed using density functional theory (DFT) as a tool for the investigation of the mechanisms governing adsorbent aging and iodine uptake. Quantum Espresso (QE), a molecular modeling software package, was the main program utilized in these DFT studies. For this analysis, QE was used to identify the optimized structure of a molecular system of interest and then to determine the electronic energy of the identified optimum structure. Considering the computational complexity of simulating metallic silver, a model nickel system based on published literature examining the decomposition of methane on a nickel (111) surface was initially considered to evaluate QE's capabilities. A nickel system was chosen because its crystalline structure is comparable to that of silver. Geometry optimization, frequency analyses, and transition state searches were performed on this model system to calculate activation energies for each elementary step. These finding were then used to determine the potential energy surface (PES) of the reaction pathway for methane decomposition on the nickel surface. The results of this analysis agreed well with the reference cases taken from the literature. A potential slab model for the $\mathrm{Ag}^{0}$ aerogel with a chemisorbed 1-propanethiolate molecule was also considered. Several aging 
reactions of for $\mathrm{Ag}^{0}$-aerogel were postulated. Once the PES of these postulated reactions is calculated, the reaction rate constants can be estimated based on simulated activation energies.

The adsorption of organic iodides in columns was also simulated using the Catalytic After Treatment System (CATS) modeling framework. CATS establishes and solves the mass and energy conservation equations needed to perform simulations of column adsorption. Kinetic information, including the reaction order and reaction rate constants, for various proposed aging and adsorption mechanisms were estimated based on data obtained from thin-bed experiments performed at ORNL. Deep-bed simulation for the same set of tests was also performed.

Utilizing simple and sophisticated experimental information combined with molecular and macroscopic mechanistic modeling, this project has significantly advanced the current understanding of aging for silver bearing adsorbents in nuclear-fuel-reprocessing off-gas streams. In addition, this project has produced models that can be utilized to predict the influence of adsorbent aging on the uptake kinetics and capacity of aged adsorbents for iodine and iodinecontaining organic compounds. The results of the study have been published in the open literature, and can be used to help DOE better predict the removal of radioactive gases from nuclear-fuelreprocessing off-gas streams. 


\section{Table of Contents}

Part 1: Aging Processes of Silver-Exchanged Mordenite and Silver-Functionalized Silica Aerogel in Different Off-Gas Components: Kinetics and Modeling .......................................... 1

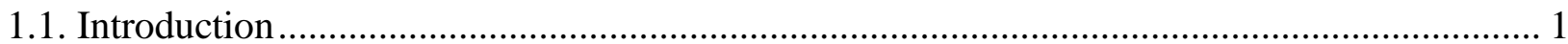

1.2. Experimental Setup, Conditions, and Materials ...................................................... 1

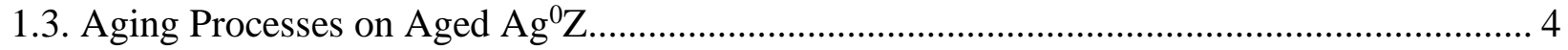

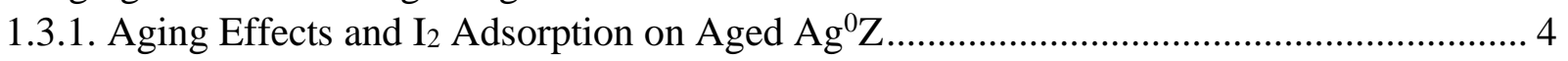

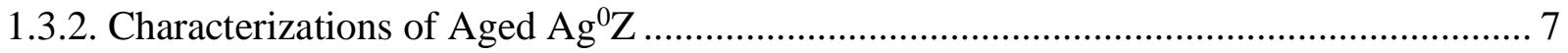

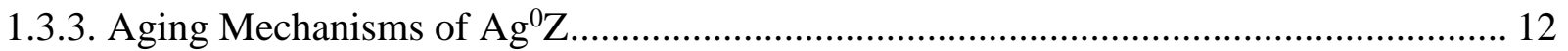

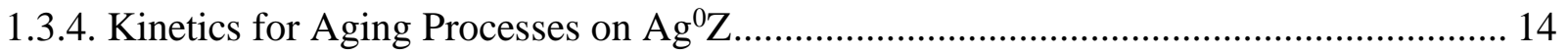

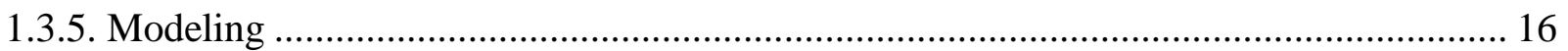

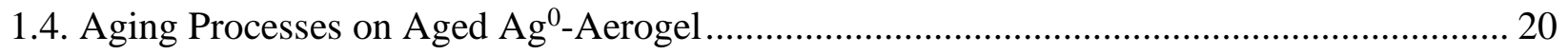

1.4.1. Aging Effects and $\mathrm{I}_{2}$ Adsorption on Aged $\mathrm{Ag}^{0}$-Aerogel ......................................... 20

1.4.2. Characterizations of Aged $\mathrm{Ag}^{0}$-Aerogel ................................................................... 22

1.4.3. Aging Mechanisms of $\mathrm{Ag}^{0}$-Aerogel ......................................................................... 25

1.4.4. Kinetics for Aging Processes on $\mathrm{Ag}^{0}$-Aerogel....................................................... 27

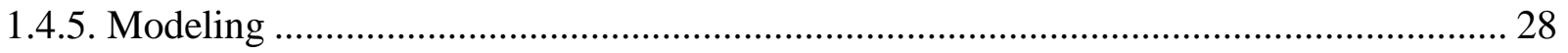

1.5. Aging Effects of Off-Gas Mixture on $\mathrm{Ag}^{0} \mathrm{Z}$ and $\mathrm{Ag}^{0}$-Aerogel ....................................... 31

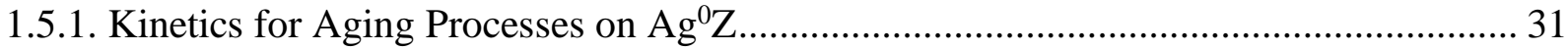

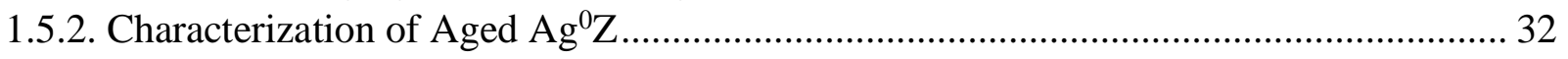

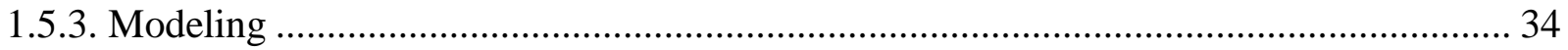

1.5.4. Kinetics for Aging Processes on Aged $\mathrm{Ag}^{0}$-Aerogel ............................................ 35

1.5.5. Characterization of Aged $\mathrm{Ag}^{0}$-Aerogel ................................................................. 35

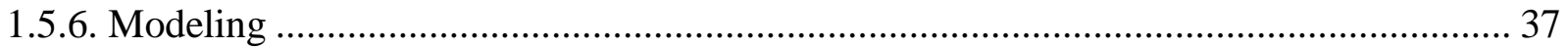

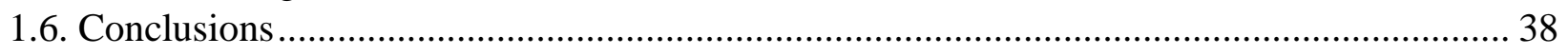

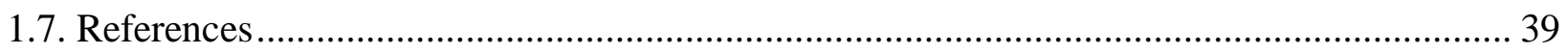

Part 2: Capture of Iodine from Nuclear-Fuel-Reprocessing Off-Gas: Influence of Aging on Reduced Silver Mordenite Adsorbent after Exposure to NO/NO2 ..................................... 43

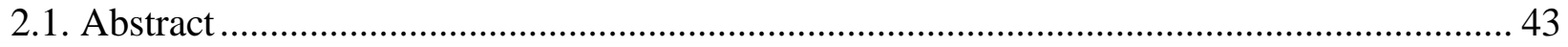

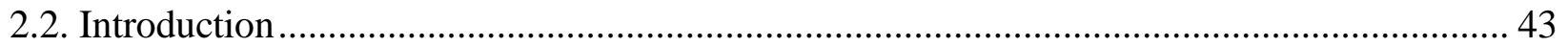

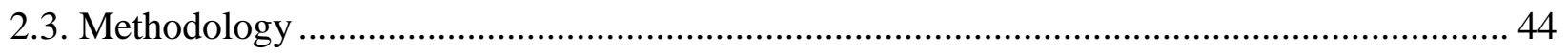

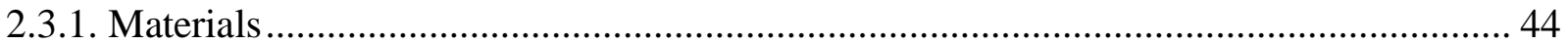

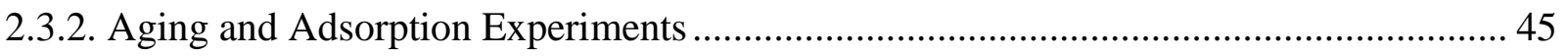

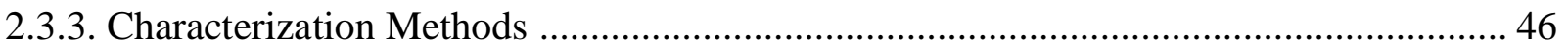

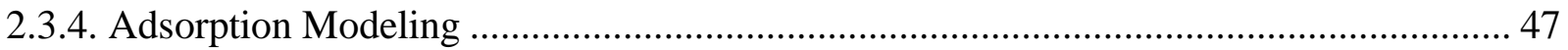

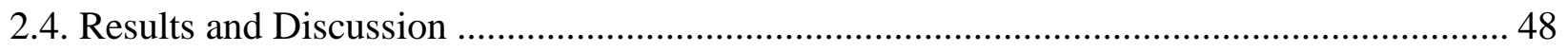

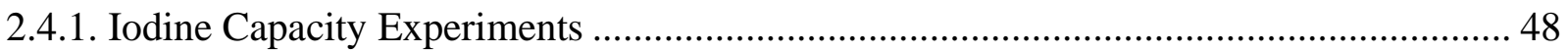

2.4.2. Adsorbent Characterization ................................................................................. 49

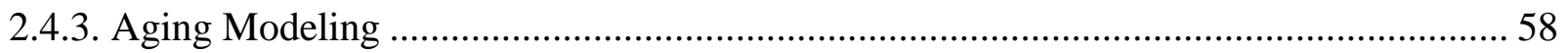

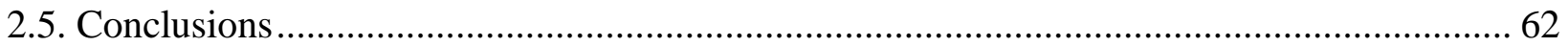

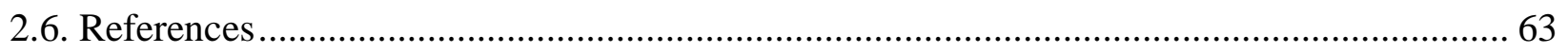


Part 3: Molecular Modeling ..............................................................................................68

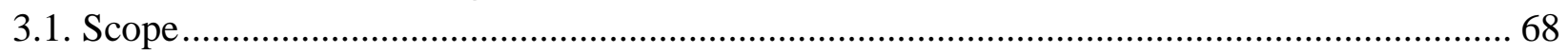

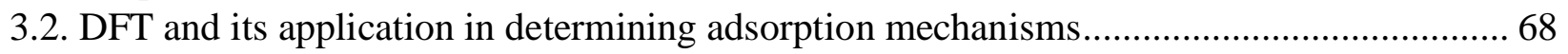

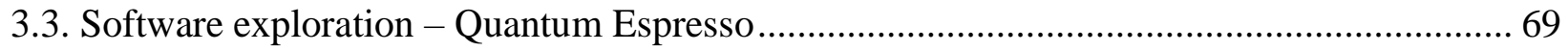

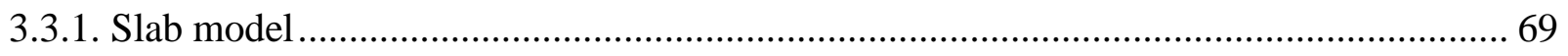

3.3.2. Potential Energy Surface Diagram ...................................................................... 70

3.3.3. Case study - Finding reaction mechanism of methane dissociation onto Ni (111) ....... 70

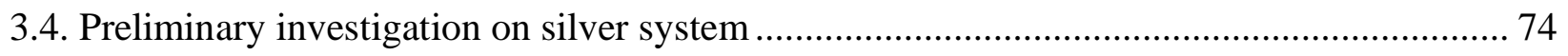

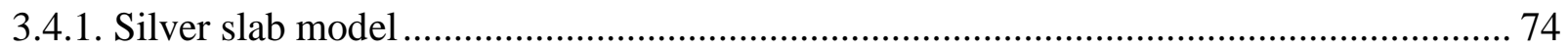

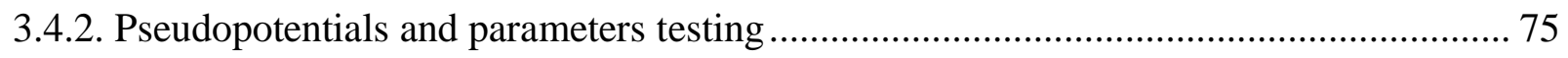

3.4.3. Preliminary test results .................................................................................... 75

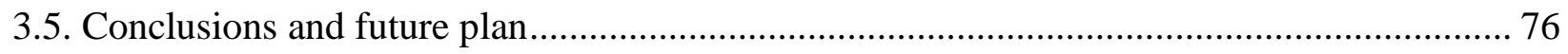

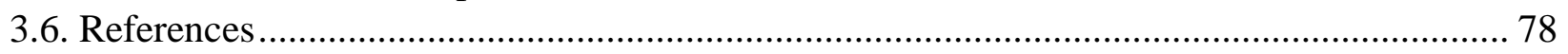

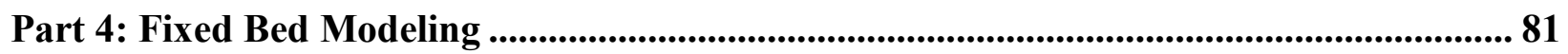

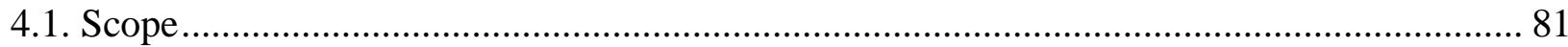

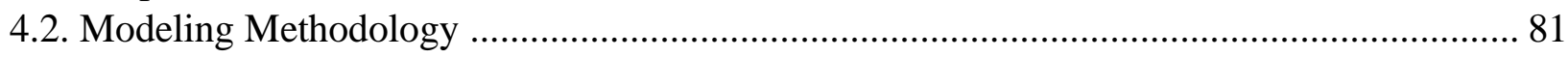

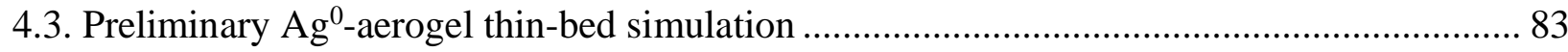

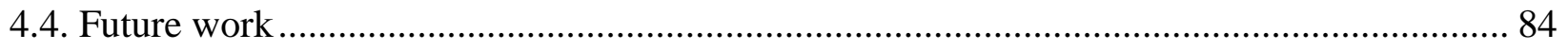

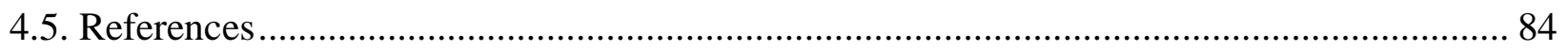

Part 5: List of Products .................................................................................................................... 86

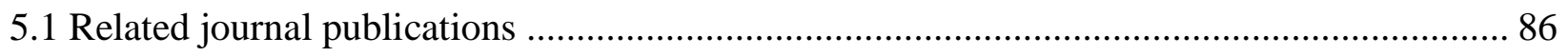

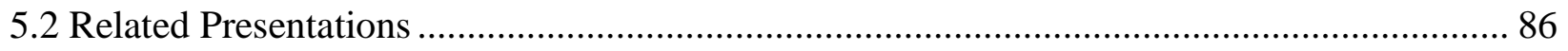

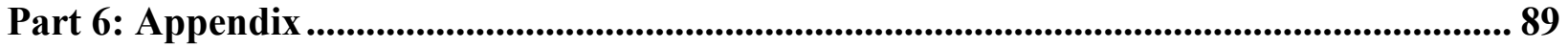

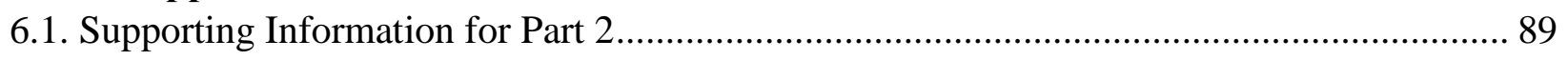




\section{Part 1: Aging Processes of Silver-Exchanged Mordenite and Silver-Functionalized Silica Aerogel in Different Off-Gas Components: Kinetics and Modeling}

\subsection{Introduction}

${ }^{129} \mathrm{I}$ is one of the volatile radioactive species produced during the reprocessing of spent nuclear fuel, and it is essential that ${ }^{129} \mathrm{I}$ be removed from the reprocessing off-gas stream due to its high mobility, long half-life, and its potential for bioaccumulation. Solid adsorbents have been suggested to effectively capture gaseous iodine. ${ }^{1,2} \mathrm{Ag}$-exchanged mordenite $\left(\mathrm{Ag}^{0} \mathrm{Z}\right)$ and $\mathrm{Ag}$ functionalized silica aerogel ( $\mathrm{Ag}^{0}$-aerogel) have been studied as outstanding adsorbents for the effective capture gaseous iodine. Various studies on $\mathrm{Ag}^{0} \mathrm{Z}^{3,4,14-21}$ and $\mathrm{Ag}^{0}$-aerogel ${ }^{5-13,18-20}$ have been reported. Among other points, these studies have investigated the mechanisms of iodine adsorption and the iodine capacities of $\mathrm{Ag}^{0} \mathrm{Z}$ and $\mathrm{Ag}^{0}$-aerogel.

In previous studies, many researchers investigated the deactivation of $\mathrm{Ag}$ in $\mathrm{Ag}^{0} \mathrm{Z}$ and $\mathrm{Ag}^{0}$ aerogel that resulted from long-term exposure of the adsorbents to off-gas streams containing $\mathrm{H}_{2} \mathrm{O}$, $\mathrm{NO}$, and $\mathrm{NO}_{2}$. In an effort to understand the long-term behavior of $\mathrm{Ag}^{0} \mathrm{Z}$ and $\mathrm{Ag}^{0}$-aerogel in spent nuclear fuel reprocessing off-gas, aging studies on $\mathrm{Ag}^{0} \mathrm{Z}^{14-21}$ and $\mathrm{Ag}^{0}$-aerogel ${ }^{7,9-13,18-20,} 22$ have been performed for extended periods of up to 6 months. These studies showed that aging $\operatorname{Ag}^{0} \mathrm{Z}$ and $\mathrm{Ag}^{0}$-aerogel in gas streams at $150^{\circ} \mathrm{C}$ for up to 6 months led to a decrease in the adsorbent's iodine loading capacity. For $\mathrm{Ag}^{0} \mathrm{Z}$, the adsorbent's iodine loading capacity dropped by $40 \%$ after it was exposed to dry air for 6 months ${ }^{14}$, by $60 \%$ after 4 months of exposure to humid air ${ }^{15}$, by $85 \%$ after 2 months exposure to $1 \% \mathrm{NO} /$ dry air, and by $30 \%$ after 2 months exposure to $2 \% \mathrm{NO}_{2} /$ dry air. In addition, $\mathrm{Ag}^{0}$-aerogel lost $22 \%$ of its iodine loading capacity when exposed to dry or humid air for 6 months, and it lost $43 \%$ and $15 \%$ of its iodine loading capacity after 2 months exposure to $1 \% \mathrm{NO}$ and $2 \% \mathrm{NO}_{2}$, respectively. ${ }^{9-13,18-20}$ However, it was not clear why the iodine loading capacity of the adsorbents decreased when exposed to these off-gas streams.

To understand the mechanisms of aging in $\mathrm{Ag}^{0} \mathrm{Z}$ and $\mathrm{Ag}^{0}$-aerogel, long-term aging experiments (up to 6 months), iodine adsorption experiments, and characterization studies were performed. Also, the kinetics of the aging processes on both $\mathrm{Ag}^{0} \mathrm{Z}$ and $\mathrm{Ag}^{0}$-aerogel were studied with proposed conditions including aging time (up to 6 months), temperature $\left(100^{\circ} \mathrm{C}\right.$ to $200^{\circ} \mathrm{C}$ ), and gas-stream water concentration (dew points: $-45^{\circ} \mathrm{C}$ to $+15^{\circ} \mathrm{C}$ ) to better understand the impact of off-gas streams on silver containing adsorbents. The kinetic data from aging and iodine adsorption experiments were obtained, and suitable reaction models were suggested to predict the aging impacts on adsorbents.

\subsection{Experimental Setup, Conditions, and Materials}

The $\mathrm{Ag}^{0} \mathrm{Z}$ used for this study was prepared by reducing commercially available $\mathrm{AgZ}$ (IONEX-Type, Ag-900 E16, Molecular Products) in a 4\% $\mathrm{H}_{2} / \mathrm{Ar}$ gas stream at $400{ }^{\circ} \mathrm{C}$ for 24 hours. ${ }^{23}$ These reduction conditions were determined from previous studies to be the optimal conditions needed to maximize the $\mathrm{Ag}^{0} \mathrm{Z}$ 's iodine loading capacity. ${ }^{23}$ The $\mathrm{AgZ}$ pellets were manufactured with $\mathrm{AgZ}$ crystals and a binder material and are cylindrical extrudates with an average diameter of $1.6 \mathrm{~mm}$. They contained $11.9 \mathrm{wt} . \%$ of $\mathrm{Ag}$ and had a silicon-aluminum ratio of 5:1. The $\mathrm{Ag}^{0}$-aerogel used in this study was provided by PNNL. The granules were black with yellow spots and had a bulk density of $477 \mathrm{~kg} / \mathrm{m}^{3}$. The silver content of the aerogel, estimated 
through $\mathrm{I}_{2}$ adsorption experiments, was about 36.5 wt.\%. Brunauer-Emmett-Teller (BET) characterization of the granules revealed a surface area of $103 \mathrm{~m}^{2} / \mathrm{g}$, adsorption/desorption pore size of $10 / 6 \mathrm{~nm}$, respectively. The $\mathrm{Ag}^{0}$-aerogel was also prepared by reducing the $\mathrm{Ag}$-aerogel (unreduced) in $2.7 \% \mathrm{H}_{2} / \mathrm{Ar}$ at $165{ }^{\circ} \mathrm{C}$ for 2 hours. Various gases used in this study, including compressed dry air (Ultra Zero Grade, dew point $<-70{ }^{\circ} \mathrm{C}$ ), $\mathrm{N}_{2}$ (Ultra High Purity), 4\% $\mathrm{H}_{2} / \mathrm{Ar}$ (Certified Standard Grade, $4 \% \mathrm{H}_{2}$ balanced in $\mathrm{Ar}$ ), $1 \% \mathrm{NO} / \mathrm{N}_{2}$, and $2 \% \mathrm{NO}_{2} /$ air were purchased from Airgas Inc.

To determine the impact of off-gas streams on $\mathrm{Ag}^{0} \mathrm{Z}$ and $\mathrm{Ag}^{0}$-aerogel, aging experiments were conducted with off-gas species including dry-air (dew point of $-70^{\circ} \mathrm{C}$ ), humid-air (dew point of $-40{ }^{\circ} \mathrm{C},-15{ }^{\circ} \mathrm{C}$, and $+15^{\circ} \mathrm{C}$ ), $1 \% \mathrm{NO} / \mathrm{N}_{2}$ and $2 \% \mathrm{NO}_{2}$ /air, respectively, using a continuous-flow aging system as shown in Figure 1. The $\mathrm{Ag}^{0} \mathrm{Z}$ and $\mathrm{Ag}^{0}$-aerogel were loaded into paired column sets in two ovens. Each column was divided into 4 column sections (inner diameter $2.5 \mathrm{~cm}$ ), and the columns were connected to one another with stainless steel gas tubing. Each column had four sections (height $7 \mathrm{~cm}$ ) for 4 different aging times (i.e. 1, 2, 4, and 6 months). Each pair of columns was connected with a gas line for dry-air, humid-air, $1 \% \mathrm{NO} / \mathrm{N}_{2}$, or $2 \% \mathrm{NO}_{2} /$ air. Thermocouples were placed at the inlet of each column in both ovens to monitor the gas temperature. Gas was passed into each column through the gas lines for the designed periods at $100-200{ }^{\circ} \mathrm{C}$. Flow rate was kept at $500 \mathrm{ml} / \mathrm{min}$ for dry and humid air, and $100 \mathrm{ml} / \mathrm{min}$ for $\mathrm{NO}$ and $\mathrm{NO}_{2}$ gases by a massflow controller. The humid gas stream was generated by controlling the flow rate of the dry air stream through a water vapor generator (Easidew, Michell Instruments) and was monitored using a dew point hygrometer. Aged $\mathrm{Ag}^{0} \mathrm{Z}$ and $\mathrm{Ag}^{0}$-aerogel samples were obtained at each desired aging time.

Additional aging experiments were conducted in a gas mixture containing $99.25 \%$ humidair (dew point of $-15^{\circ} \mathrm{C}$ ), $0.25 \% \mathrm{NO}$, and $0.5 \% \mathrm{NO}_{2}$ by diluting $1 \% \mathrm{NO} / \mathrm{N}_{2}$ and $2 \% \mathrm{NO}_{2} /$ air in humid air (d.p. $-15^{\circ} \mathrm{C}$ ) at $150{ }^{\circ} \mathrm{C}$ using a modified version of the aging system described above which is shown in Figure 2. The $\mathrm{Ag}^{0} \mathrm{Z}$ and $\mathrm{Ag}^{0}$-aerogel samples were aged for up to 1 month in the gas mixture. There were two columns (inner diameter: $2.5 \mathrm{~cm}$ ) in an oven corresponding to the gas mixture studied. Each column had three sections (height: $7 \mathrm{~cm}$ ) for measuring different aging times (i.e., 10 minutes, 30 minutes, 1 hour, and 5 hours for $\mathrm{Ag}^{0} \mathrm{Z}$ ). The mixed aging gas was passed through the columns at a constant flow rate $(200 \mathrm{ml} / \mathrm{min})$ using a mass-flow controller to ensure that the gas concentration was uniform throughout the columns.

Iodine adsorption experiments on the aged $\mathrm{Ag}^{0} \mathrm{Z}$ and $\mathrm{Ag}^{0}$-aerogel were performed by the continuous-flow adsorption system shown in Figure 4. A schematic diagram of one system is shown in Figure 3. Each of the systems was comprised of an iodine generation unit, a microbalance unit, a furnace and a data acquisition system. Molecular iodine vapors were generated by the dynacalibrators (VICI, Model 450 and 500). By controlling the temperature of the dynacalibrator and flow rates of the carrier and dilution streams, the concentration of iodine in the gas stream $(50 \mathrm{ppm})$ was precisely controlled. A microbalance with a sensitivity of $0.1 \mu \mathrm{g}$ was used in each system to measure the mass change of adsorbents. A stainless steel screen tray inside a glass adsorption column was suspended from the microbalance and loaded with a single-layer of adsorbents. The glass column (I.D.: 30mm) was wrapped with glass coils, through which the flowing gas stream was pre-heated. There were two thermocouples both inside and outside of the column to ensure the gas was preheated to the desired adsorption temperature. A furnace was used 
in each system for desired temperatures. Photographs of the iodine adsorption systems, and details of the adsorption column and the screen tray with adsorbents loaded are shown in Figure 4.

In addition, the aged $\mathrm{Ag}^{0} \mathrm{Z}$ and $\mathrm{Ag}^{0}$-aerogel samples were analyzed using various methods including scanning electron microscopy (SEM), X-ray powder diffraction (XRD), energy dispersive X-ray spectroscopy (EDS), X-ray photoelectron spectroscopy (XPS), and X-ray absorption fine structure (XAFS) to determine changes in physical structure, chemical composition, and oxidation states of $\mathrm{Ag}$ upon aging.

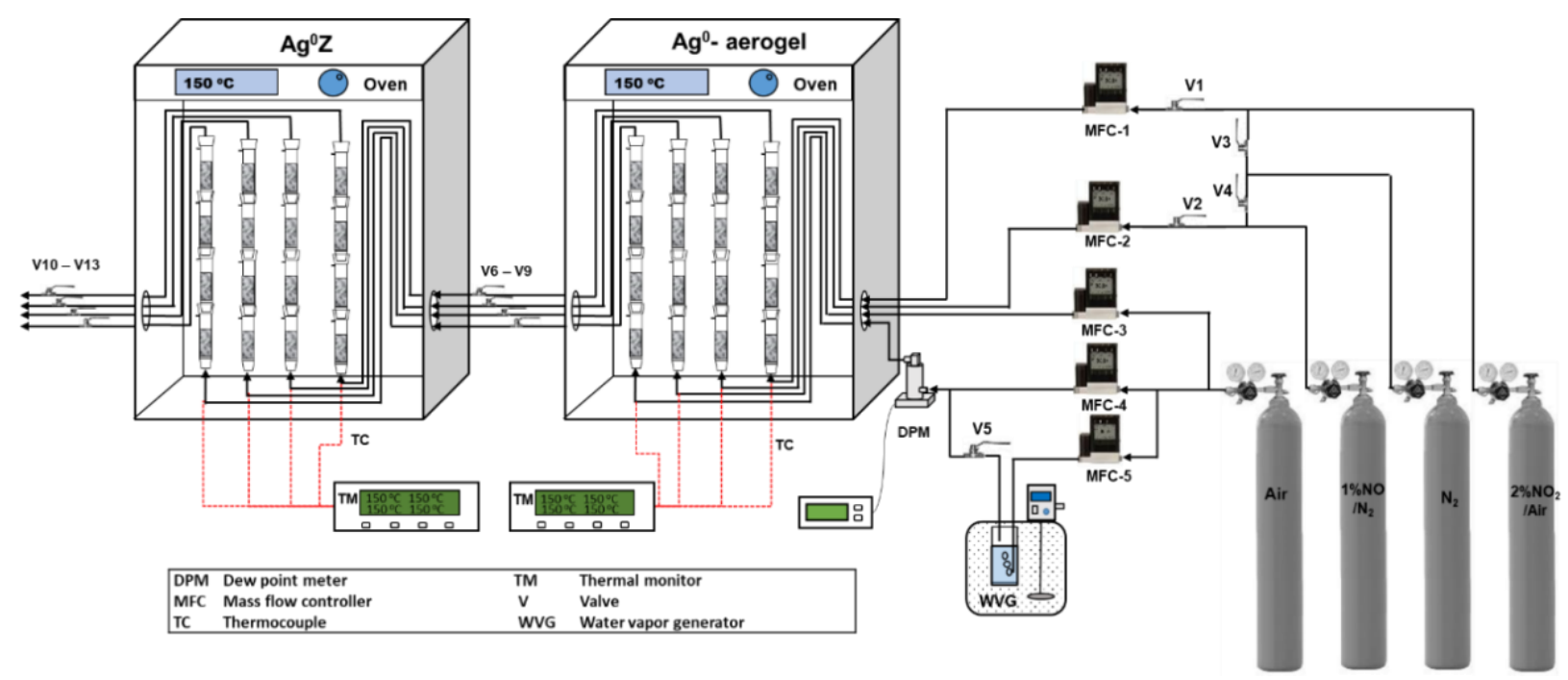

Figure 1. Schematic diagram of the continuous-flow aging system.

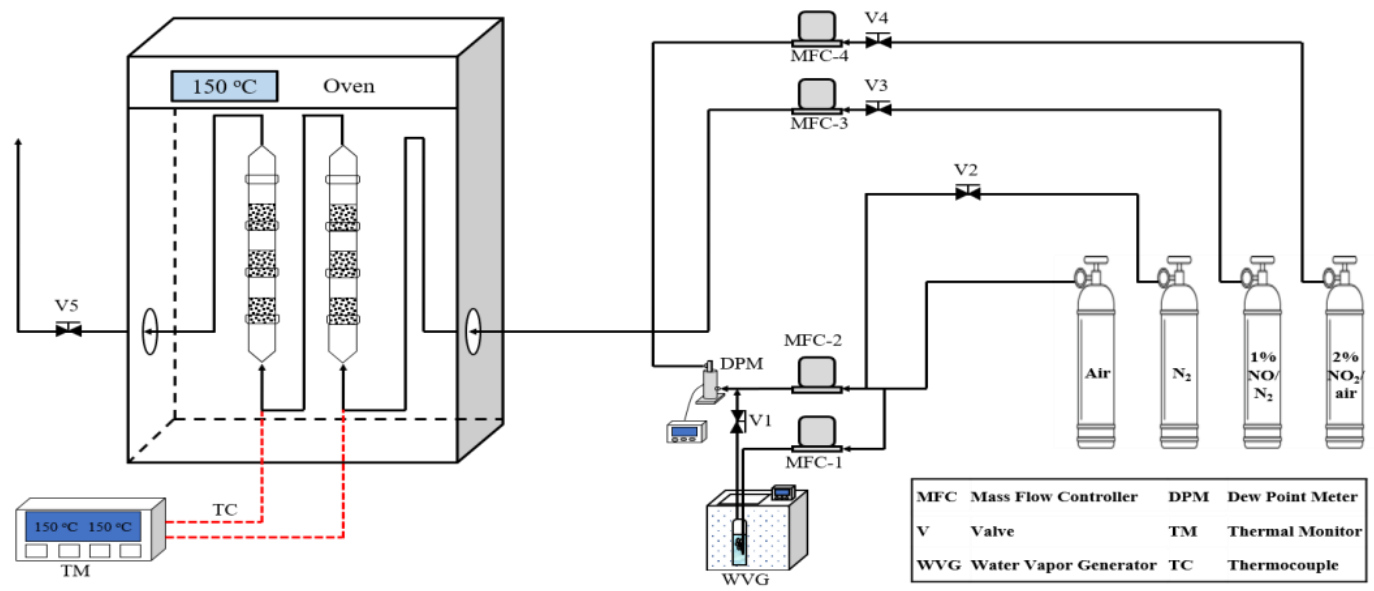

Figure 2. Schematic diagram of the continuous-flow aging system revised for gas mixture. 


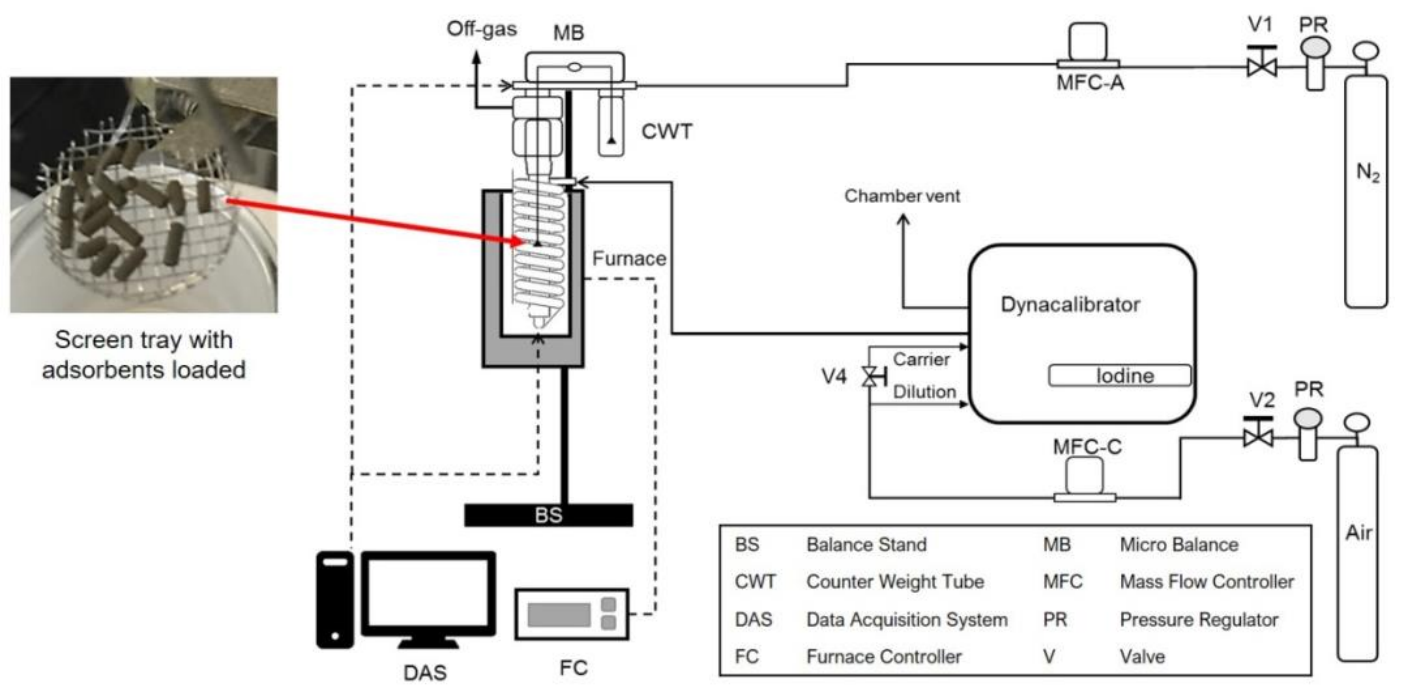

Figure 3. Schematic diagram of the continuous-flow adsorption system.

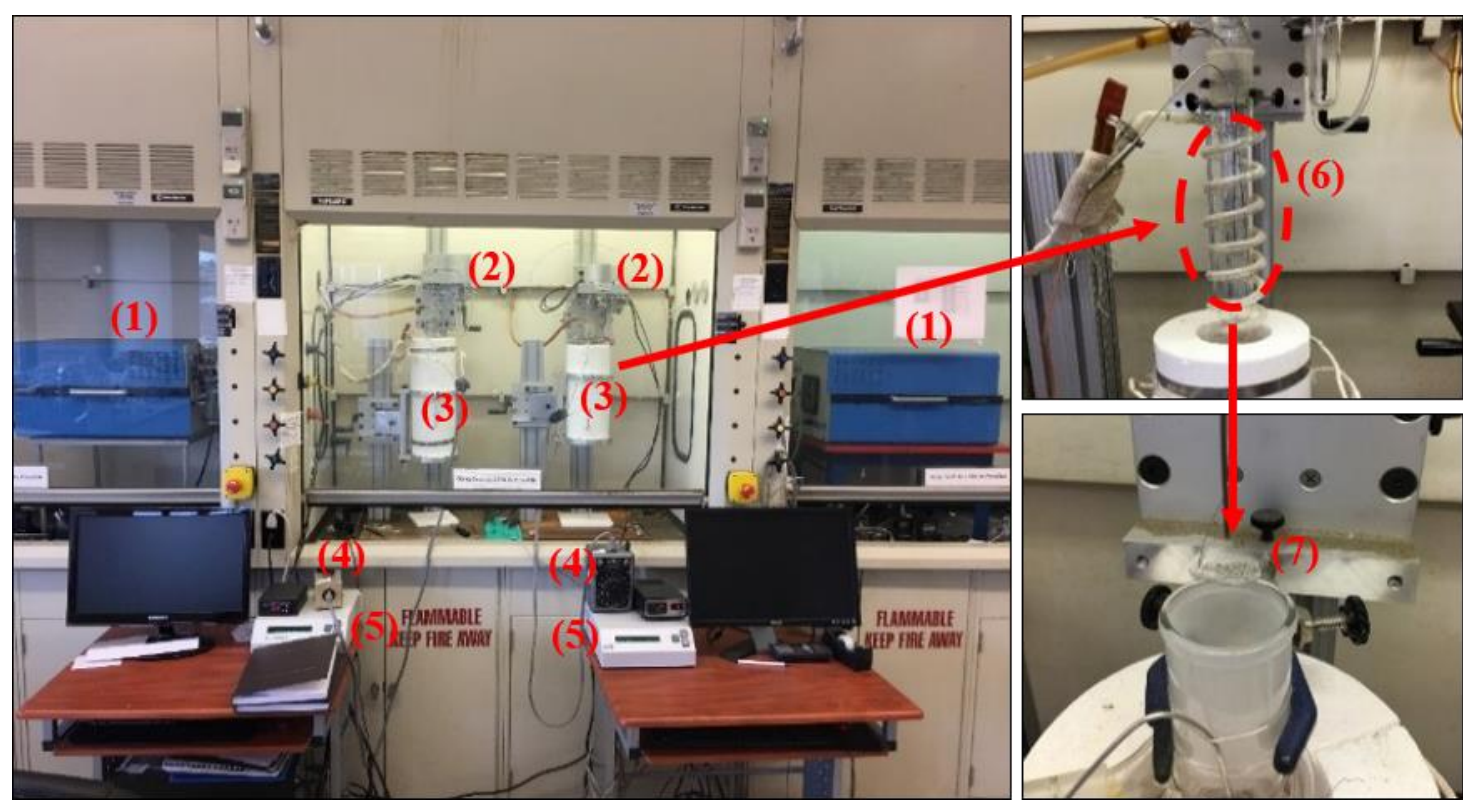

Figure 4. Photographs of the continuous-flow adsorption system; (1) Dynacalibrator; (2) Microbalance; (3) Furnace; (4) Temperature controller; (5) Data acquisition system; (6) Adsorption column; (7) Screen pan.

\subsection{Aging Processes on Aged $\mathrm{Ag}^{0} \mathrm{Z}$}

\subsubsection{Aging Effects and $I_{2}$ Adsorption on Aged $\mathbf{A g}^{0} \mathrm{Z}$}

Aged $\mathrm{Ag}^{0} \mathrm{Z}$ samples were obtained under the conditions described above. Photos of the original $\mathrm{AgZ}$ (unreduced) and $\mathrm{Ag}^{0} \mathrm{Z}$ (reduced) and aged $\mathrm{Ag}^{0} \mathrm{Z}$ samples are displayed in Figure 5. The photos indicate that there are no obvious physical changes to the $\mathrm{Ag}^{0} \mathrm{Z}$ samples aged in dry 
air and humid air for up to 6 months. However, the $\mathrm{Ag}^{0} \mathrm{Z}$ aged in $\mathrm{NO}$ and $\mathrm{NO}_{2}$ show a significant color change from dark brown to white/yellowish, which is similar to AgZ. This result suggests that $\mathrm{NO}$ and $\mathrm{NO}_{2}$ have a stronger aging effect than dry air and humid air on $\mathrm{Ag}^{0} \mathrm{Z}$. The comparison of the 5-hour aged samples in $\mathrm{NO}$ and $\mathrm{NO}_{2}$ leads to the conclusion that $2 \% \mathrm{NO}_{2} /$ air has greater impact than $1 \% \mathrm{NO} / \mathrm{N}_{2}$.

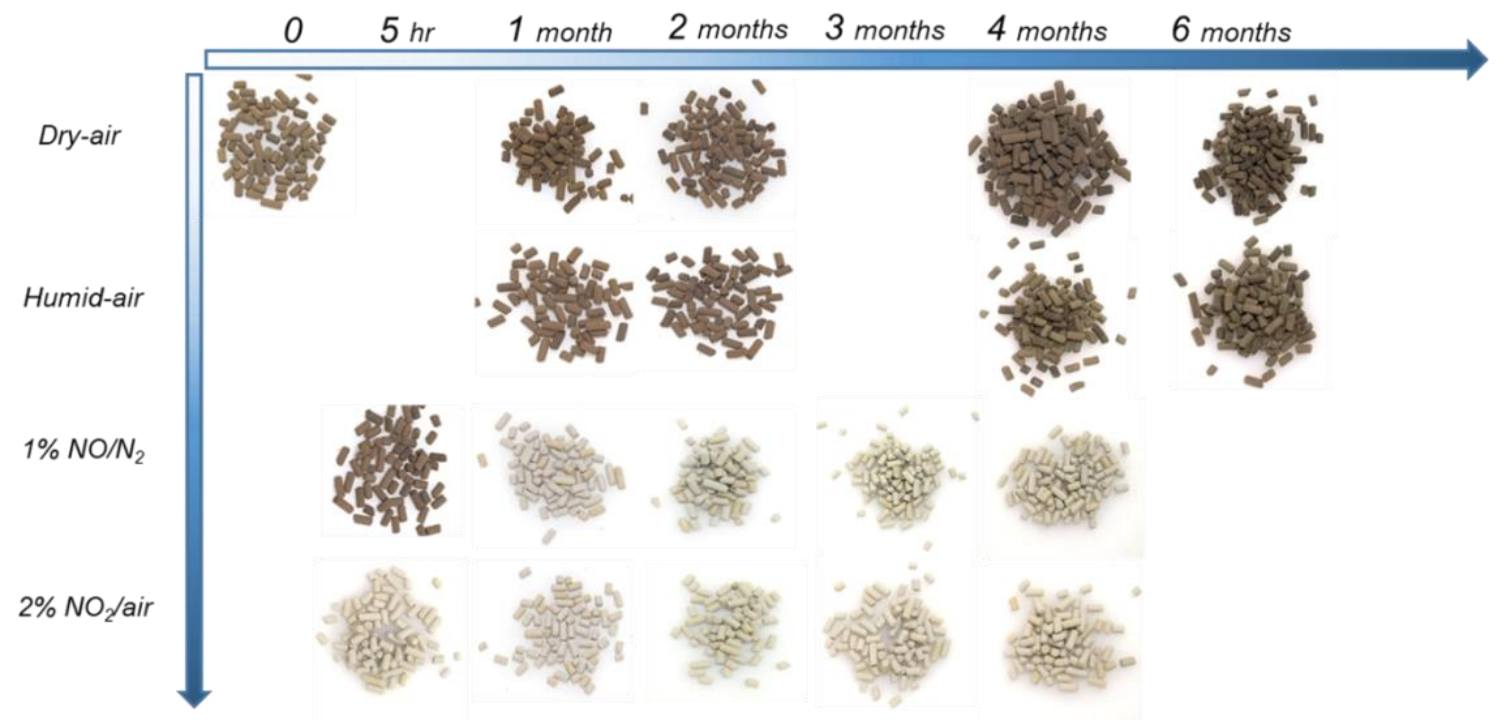

Figure 5. Pictures of non-aged $\mathrm{AgZ}$ and $\mathrm{Ag}^{0} \mathrm{Z}$ and aged $\mathrm{Ag}^{0} \mathrm{Z}$ in dry air (dew point of $-70{ }^{\circ} \mathrm{C}$ ), humid air (dew point of $-15^{\circ} \mathrm{C}$ ), $1 \% \mathrm{NO} / \mathrm{N}_{2}$ and $2 \% \mathrm{NO}_{2} /$ air for up to 6 months.

The $\mathrm{I}_{2}$ adsorption capacity of the aged $\mathrm{Ag}^{0} \mathrm{Z}$ samples is compared in Figure 6. Reduction in $\mathrm{I}_{2}$ adsorption capacity was observed with all the aged $\mathrm{Ag}^{0} \mathrm{Z}$ samples. In dry air, the chemisorption capacity dropped from about $12 \mathrm{wt} . \%$ to $\sim 7 \mathrm{wt} . \%$ after aging for 6 months; in humid air, it dropped to $\sim 5 \mathrm{wt} . \%$; in $\mathrm{NO}$ and $\mathrm{NO}_{2}$, it reduced to less than $1 \mathrm{wt} . \%$ after aging for 6 months. Changes to the capacity over time in the gas streams are summarized in the plot shown in Figure 7. It shows an aging effect of $\mathrm{NO}_{2}=\mathrm{NO}>$ humid air $>$ dry air (in terms of capacity loss), and an aging rate of $\mathrm{NO}_{2}>\mathrm{NO}>$ humid air $>$ dry air. It is noted that $\mathrm{Ag}^{0} \mathrm{Z}$ losses its capacity rapidly in the $2 \%$ $\mathrm{NO}_{2}$ /air stream; losing $60 \%$ of its capacity in 12 minutes and $90 \%$ of its capacity within 1 hour. This indicates that $\mathrm{NO}_{2}$ in the off-gas streams will be a significant issue and must be addressed when using $\mathrm{Ag}^{0} \mathrm{Z}$ column for iodine capture. 

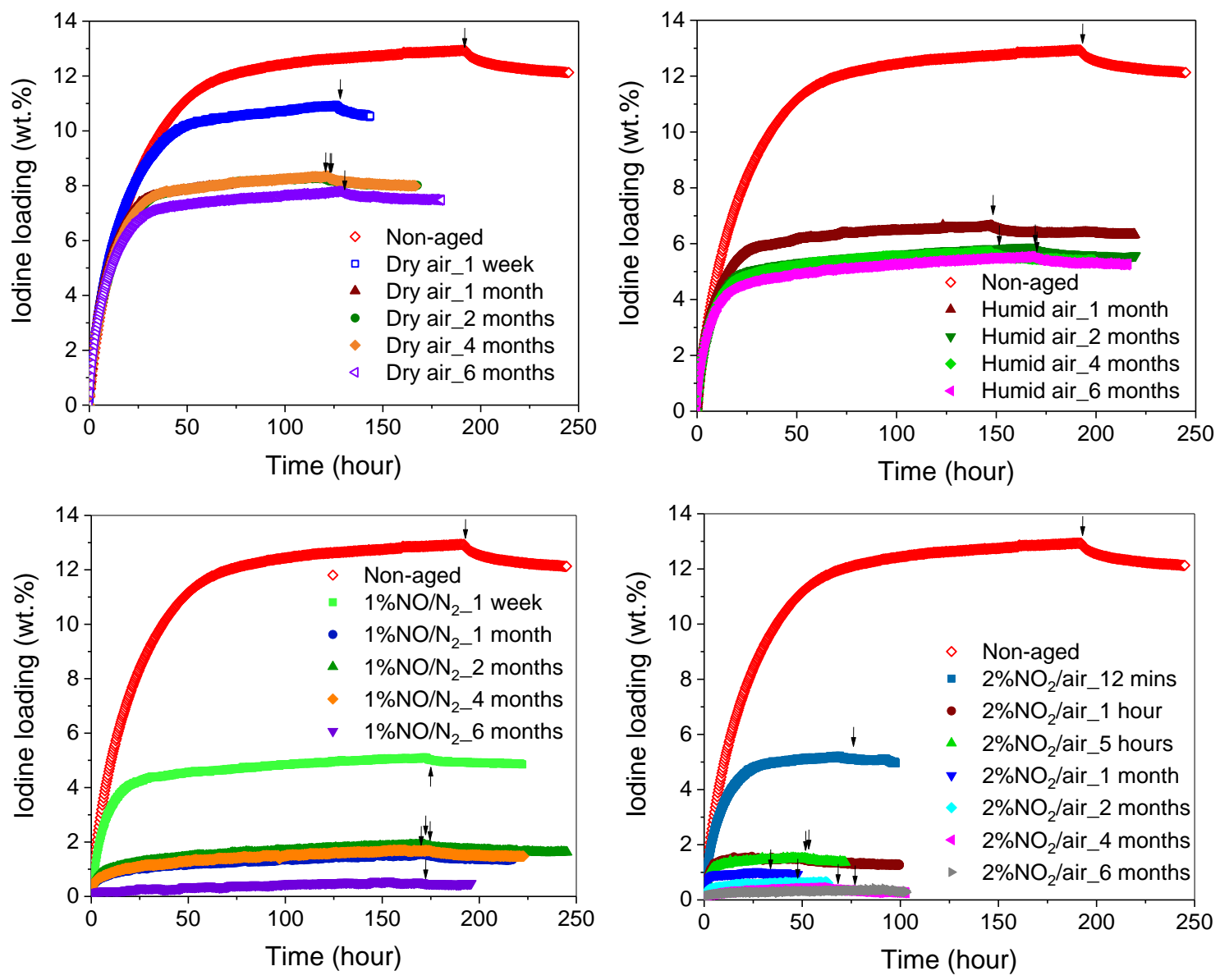

Figure 6. $\mathrm{I}_{2}$ adsorption on non-aged $\mathrm{Ag}^{0} \mathrm{Z}$ and $\mathrm{Ag}^{0} \mathrm{Z}$ aged in dry air, humid air, $1 \% \mathrm{NO} / \mathrm{N}_{2}$, and $2 \%$ $\mathrm{NO}_{2} /$ air for different times at $150{ }^{\circ} \mathrm{C}$. The arrows $(\downarrow$ or $\uparrow)$ indicate positions where $\mathrm{I}_{2}$ vapor was stopped to start desorption of $\mathrm{I}_{2}$.

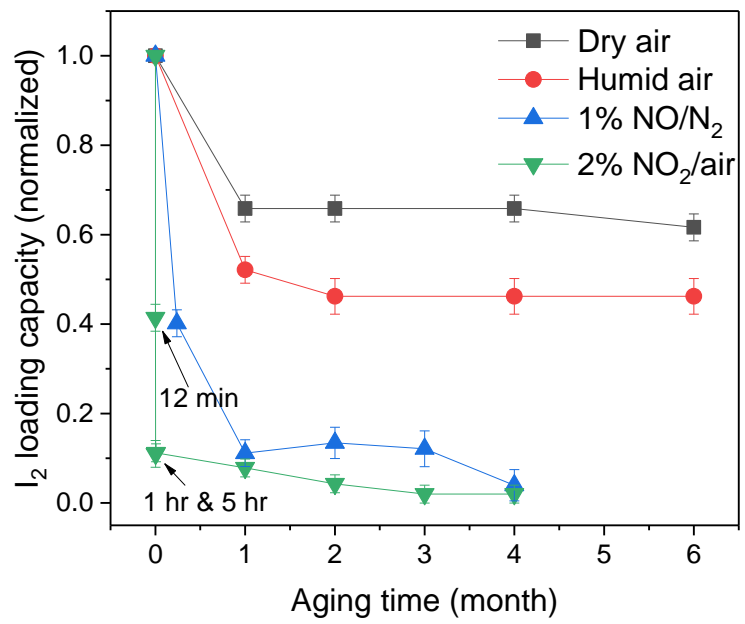

Figure 7. Change of $\mathrm{I}_{2}$ adsorption capacity of $\mathrm{Ag}^{0} \mathrm{Z}$ (normalized) over aging time at $150{ }^{\circ} \mathrm{C}$. The data for $\mathrm{NO}_{2}$ at $1 \mathrm{hr}$. and $5 \mathrm{hr}$. overlapped due to the large $x$-axis scale. 


\subsubsection{Characterizations of Aged $\mathrm{Ag}^{0} \mathrm{Z}$}

\subsubsection{X-ray Powder Diffraction}

The XRD patterns for the non-aged and aged $\mathrm{Ag}^{0} \mathrm{Z}$ samples are shown in Figure 8 . Comparing the patterns of $\mathrm{AgZ}$ and $\mathrm{Ag}^{0} \mathrm{Z}$, the $\mathrm{Ag}^{0} \mathrm{Z}$ pattern has two additional strong character peaks representing crystals of metallic $\mathrm{Ag}\left(\mathrm{Ag}^{0}\right)$, which is the result of the reduction of $\mathrm{Ag}^{+}$to $\mathrm{Ag}^{0}$ and consequent formation of $\mathrm{Ag}^{0}$ particles on the mordenite crystal surface. A decrease in the intensity of the $\mathrm{Ag}^{0}$ peaks was observed when $\mathrm{Ag}^{0} \mathrm{Z}$ was exposed to the aging gases. And the degree of the decrease in different gases follows the sequence of $\mathrm{NO}_{2}=\mathrm{NO}>$ humid air $>$ dry air, which is consistent with that observed in Figure 6.

The decrease in $\mathrm{Ag}^{0}$ should be due to the oxidation of $\mathrm{Ag}^{0}$ to $\mathrm{Ag}^{+}$by the aging gases. Especially, for $\mathrm{NO}$ and $\mathrm{NO}_{2}$ aged $\mathrm{Ag}^{0} \mathrm{Z}$ samples, $\mathrm{Ag}^{0}$ was completely oxidized resulting in XRD patterns similar to that of $\mathrm{AgZ}$. However, no $\mathrm{Ag}_{2} \mathrm{O}$ or $\mathrm{AgNO}_{3}$ was observed on the patterns. This could be due to the detection limit of XRD, by which only crystals and element over $1 \mathrm{wt} \%$ are generally detectable. In other words, the produced $\mathrm{Ag}_{2} \mathrm{O}$ or $\mathrm{AgNO}_{3}$ may be amorphous or not on the surfaces of $\mathrm{Ag}^{0} \mathrm{Z}$. It was noted that the $\mathrm{I}_{2}$ adsorption capacity (Figure 6) dropped correspondingly with the decrease of $\mathrm{Ag}^{0}$ in aged $\mathrm{Ag}^{0} \mathrm{Z}$. This indicates that $\mathrm{I}_{2}$ only reacted with the $\mathrm{Ag}^{0}$ in the aged samples, and the oxidized $\mathrm{Ag}^{+}$was somehow inactive to $\mathrm{I}_{2}$.

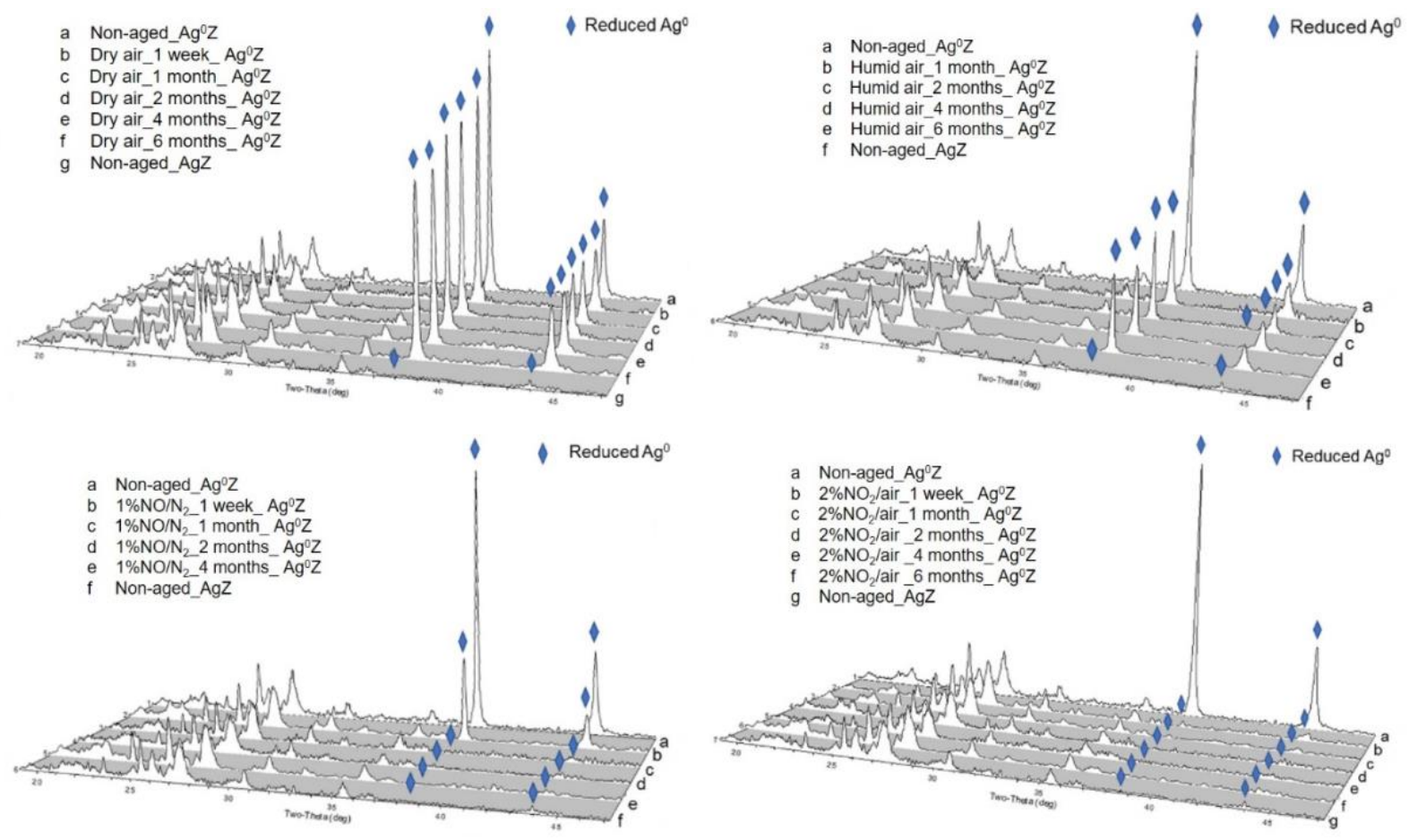

Figure 8. XRD patterns of the non-aged $\mathrm{AgZ}$ and $\mathrm{Ag}^{0} \mathrm{Z}$ and aged $\mathrm{Ag}^{0} \mathrm{Z}$ samples.

\subsubsection{Scanning Electron Microscope}

The SEM (backscattered electron composition, BEC) images of the $\mathrm{AgZ}, \mathrm{Ag}^{0} \mathrm{Z}$ and 1month aged $\mathrm{Ag}^{0} \mathrm{Z}$ samples are displayed in Figure 9. The image of $\mathrm{AgZ}$ indicates that mordenite 
crystals have a uniform elemental distribution. In contrast, small particles are observed on the surface of mordenite crystals in $\mathrm{Ag}^{0} \mathrm{Z}$. The brightness of these small particles in the BEC image is higher than the surrounding surface, indicating that they comprise elements of higher atomic mass. According to the chemical composition of $\mathrm{Ag}^{0} \mathrm{Z}$ and the XRD results, these particles should be $\mathrm{Ag}^{0}$ particles. The diameter of the $\mathrm{Ag}^{0}$ particles ranged from 0.1 to $1.17 \mu \mathrm{m}$. Particles smaller than $0.1 \mu \mathrm{m}$ may also exist but cannot be observed at the image's magnifications.

$\mathrm{Ag}^{0}$ particles are also observed on the surface of dry air and humid air aged $\mathrm{Ag}^{0} \mathrm{Z}$. According to the $\mathrm{I}_{2}$ adsorption tests and XRD results, the amount of the $\mathrm{Ag}^{0}$ in dry air and humid air aged $\mathrm{Ag}^{0} \mathrm{Z}$ decreased. However, a decrease in the number or size of $\mathrm{Ag}^{0}$ particles cannot be observed on the SEM images. For the $\mathrm{NO}$ and $\mathrm{NO}_{2}$ aged $\mathrm{Ag}^{0} \mathrm{Z}$, the images show that $\mathrm{Ag}^{0}$ particles disappeared from the surface of mordenite crystals (a few observed on NO aged $\mathrm{Ag}^{0} \mathrm{Z}$ ). These results are consistent with those of the $\mathrm{I}_{2}$ adsorption tests and XRD. Additionally, no particles of $\mathrm{AgNO}_{3}$ were observed on the crystal surface of the $\mathrm{NO}$ and $\mathrm{NO}_{2}$ aged $\mathrm{Ag}^{0} \mathrm{Z}$.

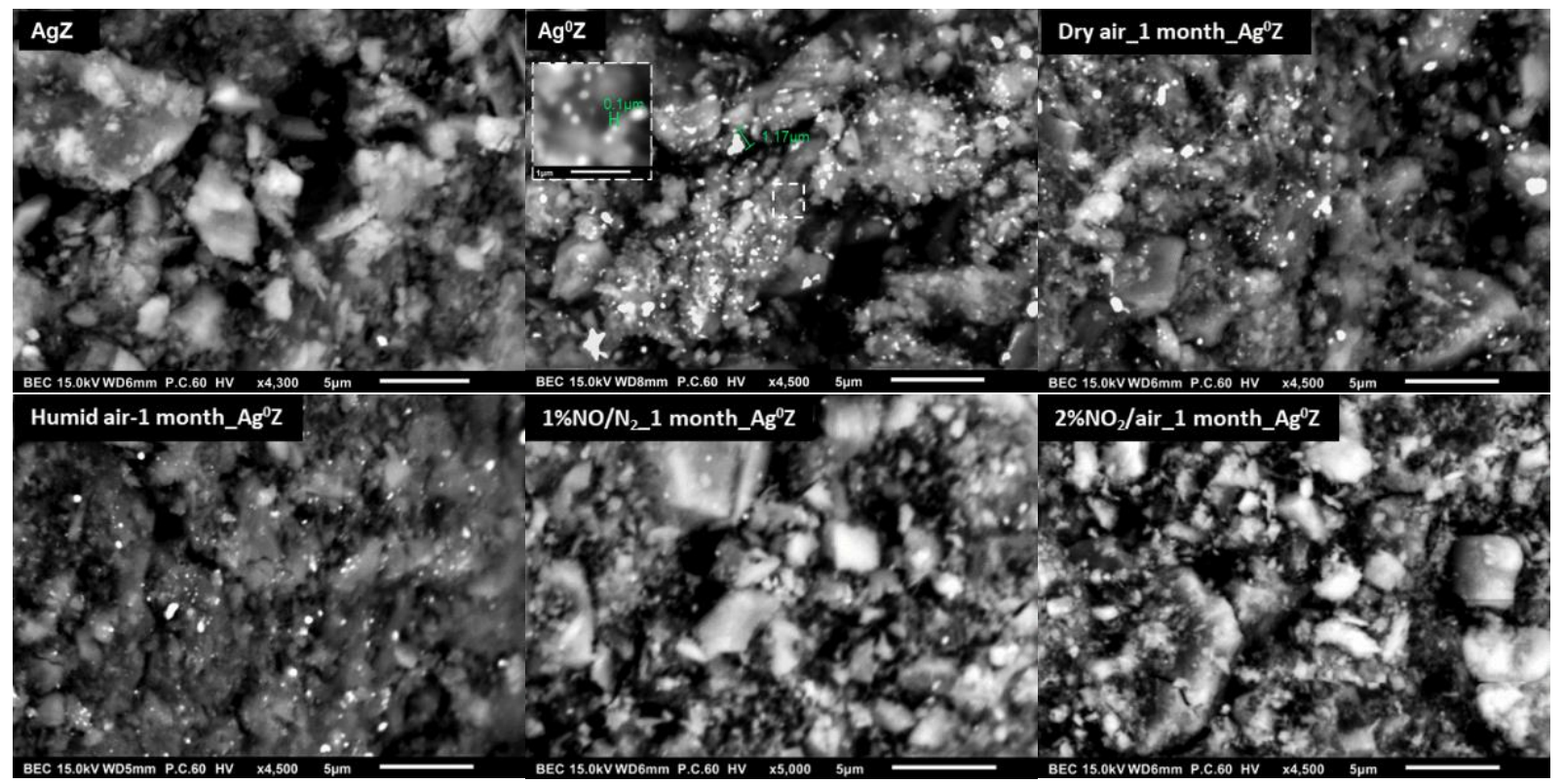

Figure 9. SEM (backscattered electron composition) images of $\mathrm{AgZ}, \mathrm{Ag}^{0} \mathrm{Z}$ and 1-month aged $\mathrm{Ag}^{0} \mathrm{Z}$ samples.

\subsubsection{Energy-Dispersive X-ray Spectroscopy}

Elemental analysis was performed using Energy-Dispersive X-ray Spectroscopy (EDS) to determine the existence of amorphous $\mathrm{Ag}_{2} \mathrm{O}$ and $\mathrm{AgNO}_{3}$ on the aged $\mathrm{Ag}^{0} \mathrm{Z}$ which are not detectable by XRD. However, as shown in Figure 10, no element peak for $\mathrm{N}$ was observed on the EDS spectra of $\mathrm{Ag}^{0} \mathrm{Z}$ aged in $\mathrm{NO}$ and $\mathrm{NO}_{2}$ for 4 months, which suggest that no $\mathrm{AgNO}_{3} / \mathrm{AgNO}_{2}$ was formed or the amount of $\mathrm{N}$ on the $\mathrm{Ag}^{0} \mathrm{Z}$ samples was below the detection limit of EDS. In addition, it is noted that the spectra of the $\mathrm{NO}$ and $\mathrm{NO}_{2}$ aged samples were similar to that of unreduced AgZ. 

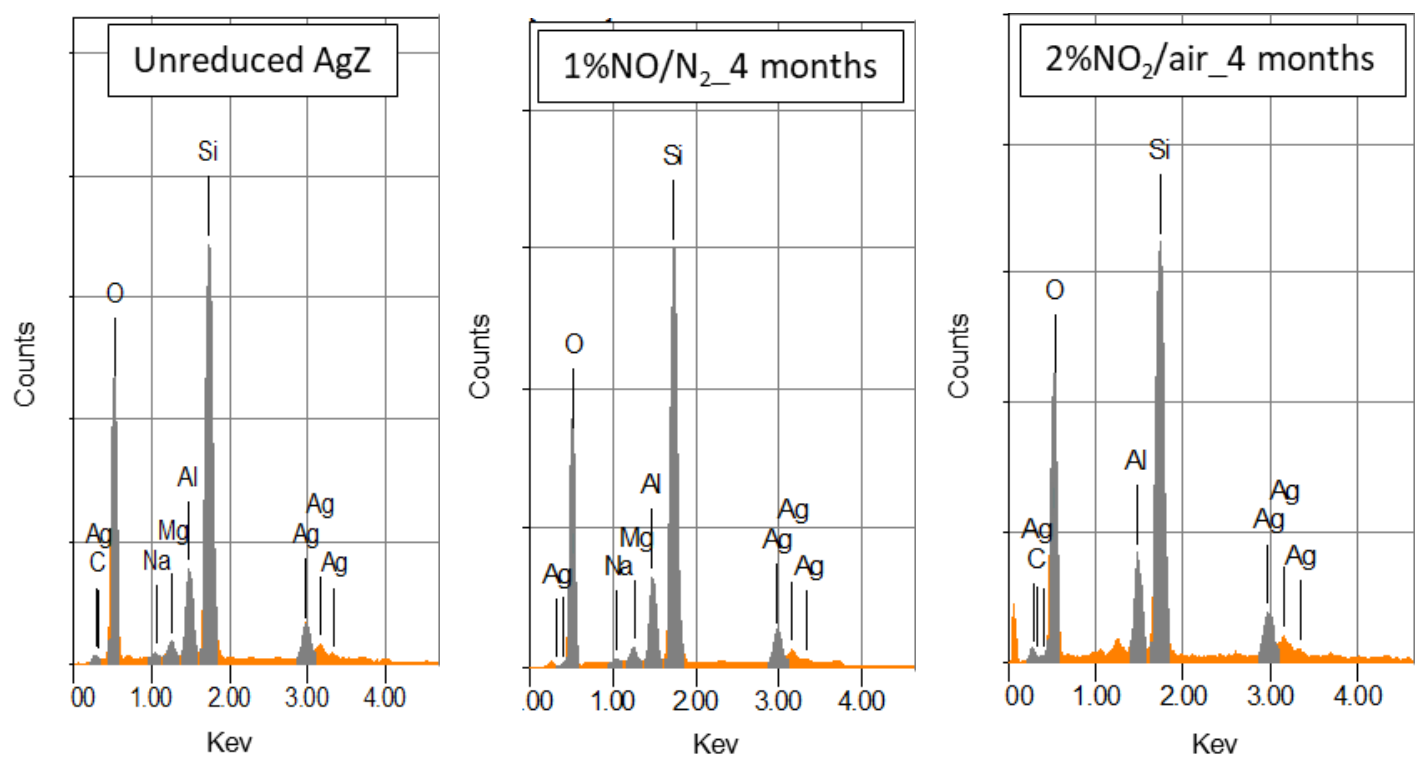

Figure 10. EDS spectra of $\mathrm{AgZ}$ and 4 months aged $\mathrm{Ag}^{0} \mathrm{Z}$ in $\mathrm{NO}$ and $\mathrm{NO}_{2}$.

\subsubsection{X-ray Photoelectron Spectroscopy}

The aged $\mathrm{Ag}^{0} \mathrm{Z}$ samples were also analyzed with XPS to determine the chemical composition and oxidation state of Ag after aging in different aging gases. Spectra of non-aged, 1and 2-month aged $\mathrm{Ag}^{0} \mathrm{Z}$ are shown Figure 11. All samples had similar chemical compositions, and none of the samples had a N peak, which was consistent with the EDS results. The spectra of $\mathrm{Ag}$ (3d core level) for the $\mathrm{Ag}$ standards and Aged $\mathrm{AgZ}$ samples are shown in Figure 12. The binding energy (BE) of $\mathrm{Ag} 3 \mathrm{~d} 5 / 2$ shifted from $368.4 \mathrm{eV}$ to $367.6 \mathrm{eV}$ when the $\mathrm{Ag}^{+}$in $\mathrm{AgZ}$ was reduced and formed $\mathrm{Ag}^{0}$ particles in $\mathrm{Ag}^{0} \mathrm{Z}$. The measured binding energies are in agreement with those measured by Aspromonte. ${ }^{27}$ When $\mathrm{Ag}^{0} \mathrm{Z}$ was exposed to the aging gases, the $\mathrm{BE}$ of $\mathrm{Ag}$ increased, shifting towards the $\mathrm{BE}$ of $\mathrm{AgZ}(368.4 \mathrm{eV}), \mathrm{Ag}_{2} \mathrm{O}(368.3 \mathrm{eV})$ and $\mathrm{AgNO}_{3}(368.1 \mathrm{eV})$. Since no $\mathrm{Ag}_{2} \mathrm{O}$ or $\mathrm{AgNO}_{3}$ were formed on the aged samples, according to the XRD, EDS and XPS results, it can be concluded that the $\mathrm{Ag}^{0} \mathrm{Z}$ was oxidized back to $\mathrm{AgZ}$ when aged in dry air, humid air, $\mathrm{NO}$, and $\mathrm{NO}_{2}$. 


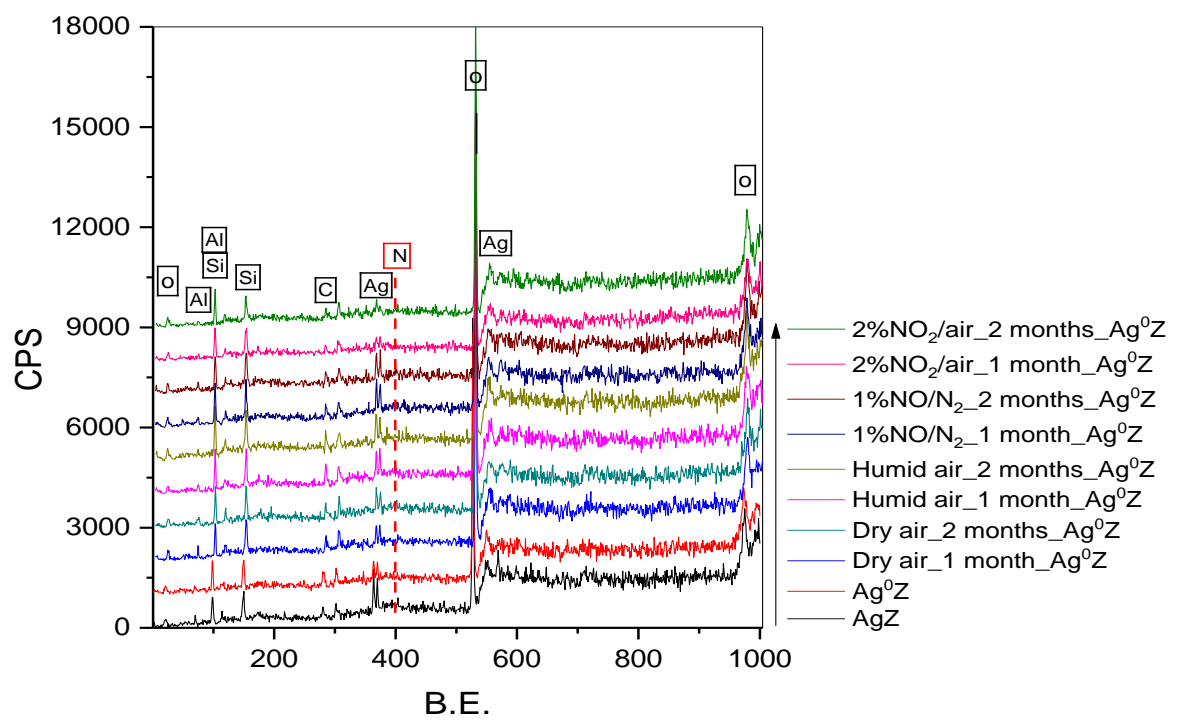

Figure 11. XPS Survey spectra of $\mathrm{Ag}^{0} \mathrm{Z}$ samples

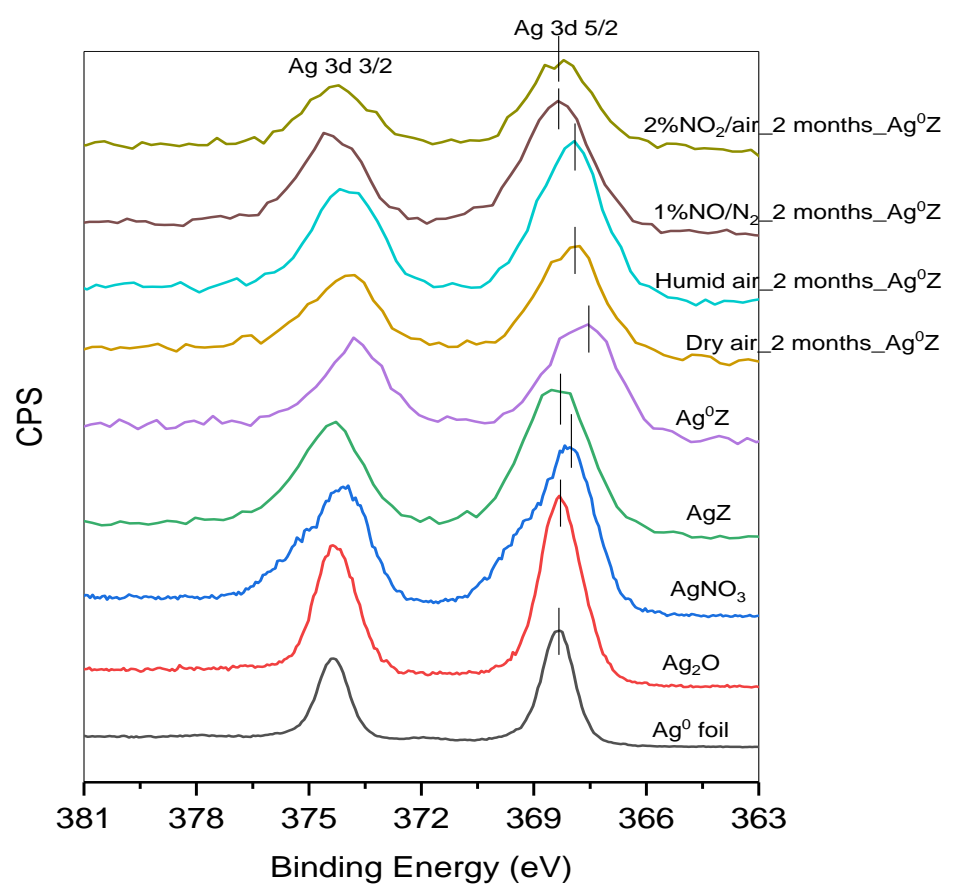

Figure 12. XPS spectra ( $\mathrm{Ag} 3 \mathrm{~d}$ core-level) of $\mathrm{Ag}$ standards and $\mathrm{Ag}^{0} \mathrm{Z}$ samples.

\subsubsection{X-ray Absorption Fine Structure Spectroscopy}

To further determine the oxidation state of $\mathrm{Ag}$ and its chemical environment in the aged $\mathrm{Ag}^{0} \mathrm{Z}$, XAFS analyses on the $\mathrm{Ag}$ in $\mathrm{Ag}^{0} \mathrm{Z}$ samples were conducted. Both XANES (X-ray absorption near edge structure) and EXAFS (Extended X-Ray absorption fine structure) results are shown Figure 13. For the dry air and humid air aged $\mathrm{Ag}^{0} \mathrm{Z}$, the spectra changed upon exposure to air, with humid air having a greater impact than dry air. These results confirmed the decrease in $\mathrm{Ag}^{0}$ on the mordenite crystals as the aging time increased observed by XRD. While the silver particles preserve an oxidation state of 0 in all samples, the change in spectral quadrature suggests 
exposure to air is reducing their size. In addition, both XANES and EXAFS data show a spectral change toward unreduced $\mathrm{AgZ}$ instead of $\mathrm{Ag}_{2} \mathrm{O}$ upon exposure to air and humid air (indicated by the arrows in the plots), which indicate that $\mathrm{Ag}^{0} \mathrm{Z}$ was oxidized back to $\mathrm{AgZ}$ instead of forming oxidized $\mathrm{Ag}\left(\mathrm{Ag}_{2} \mathrm{O}\right)$.

For the $\mathrm{NO}$ and $\mathrm{NO}_{2}$ samples, complete oxidation of $\mathrm{Ag}^{0}$ was observed, which agreed well with the $\mathrm{I}_{2}$ adsorption tests and XRD results. Both the XANES and EXAFS spectra of the aged samples were consistent with the spectrum of $\mathrm{AgZ}$ which also indicate that $\mathrm{Ag}^{0} \mathrm{Z}$ was oxidized back to AgZ.
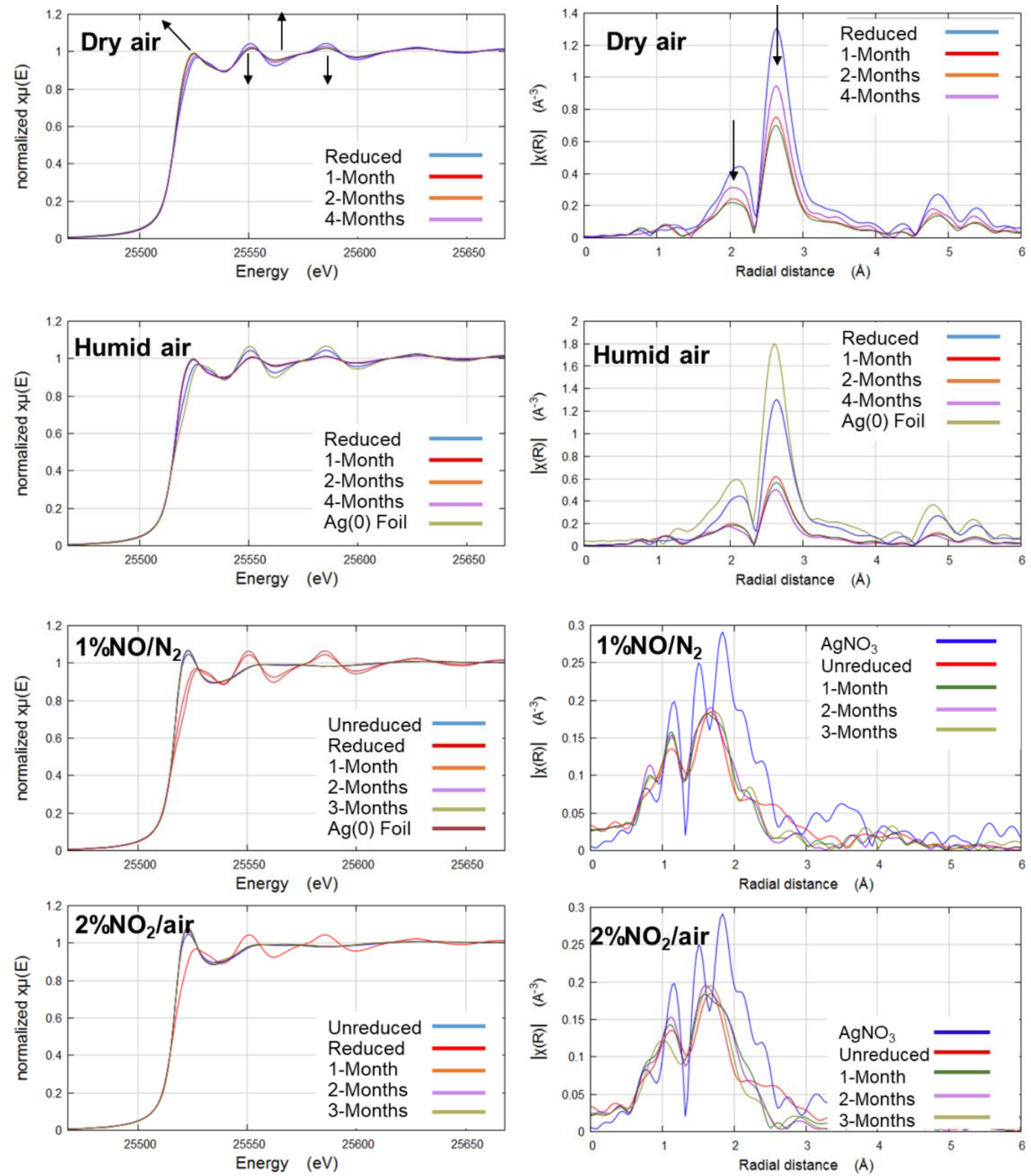

Figure 13. XANES and EXAFS spectra of $\mathrm{Ag}^{0} \mathrm{Z}$ samples. 


\subsubsection{Aging Mechanisms of $\mathrm{Ag}^{0} \mathrm{Z}$}

Consistent results were obtained from $\mathrm{I}_{2}$ adsorption experiments and characterization including XRD, SEM, EDS, XPS, and XAFS. These results led to a conclusion that the mechanism of $\mathrm{Ag}^{0} \mathrm{Z}$ aging in the studied off-gas species was the oxidation of the reduced $\mathrm{Ag}^{0}$ to $\mathrm{Ag}^{+}$followed by the migration of $\mathrm{Ag}^{+}$from the surface to the pores and channels of mordenite crystals, as demonstrated by Figure 14. Similar phenomena of Ag cluster dispersion in microporous zeolites including $\mathrm{MFI}^{24}$ and $\mathrm{Y}$ zeolite ${ }^{26}$ were also observed in previous studies. Thus, the pathways of the aging processes can be expressed as in the following steps; firstly, $\mathrm{Ag}^{0}$ is oxidized to $\mathrm{Ag}^{+}$by oxygen in air gas streams, then the oxidized $\mathrm{Ag}^{+}$migrated from the surface of the mordenite into its crystalline pores. After that, $\mathrm{Ag}^{+}$was bound to the mordenite crystalline structure through substitution with hydrogen. Finally, the generated hydrogen produced water by binding with oxygen or hydroxide.

For example, in dry air as shown in Eqns. (1) (4), $\mathrm{Ag}^{0}$ is oxidized by $\mathrm{O}_{2}$ in dry air to $\mathrm{Ag}^{+}$ on the surface of the mordenite, then $\mathrm{Ag}^{+}$is migrated into the pores and bound to the crystalline structure in mordernite through substitution reaction with $\mathrm{H}^{+}$. The replaced $\mathrm{H}^{+}$was bound to the $\mathrm{O}^{2-}$ in order to produce $\mathrm{H}_{2} \mathrm{O}$. The different influences of the aging gas streams on $\mathrm{Ag}^{0} \mathrm{Z}$ should depend on the different oxidation reactions of $\mathrm{Ag}^{0} \mathrm{Z}$. That is, the aging effects rely on the strength of the oxidants. The subsequent migration process, which is reactions (2) - (4), can be similar for the aging process in all gas streams studied. Considering the similar reactions (2) - (4) in all gas streams and faster aging process in $2 \% \mathrm{NO}_{2} /$ air (Figure 7), which shows the most significant iodine capacity loss after several hours, it can be concluded that the aging processes in all gas streams used in this study are controlled by the oxidation reaction as shown in Eqn. (1) for dry air. The overall reaction, Eqn. (5), is proposed for the oxidation process of Ag cluster which is similar reaction as described by previous study. ${ }^{24}$

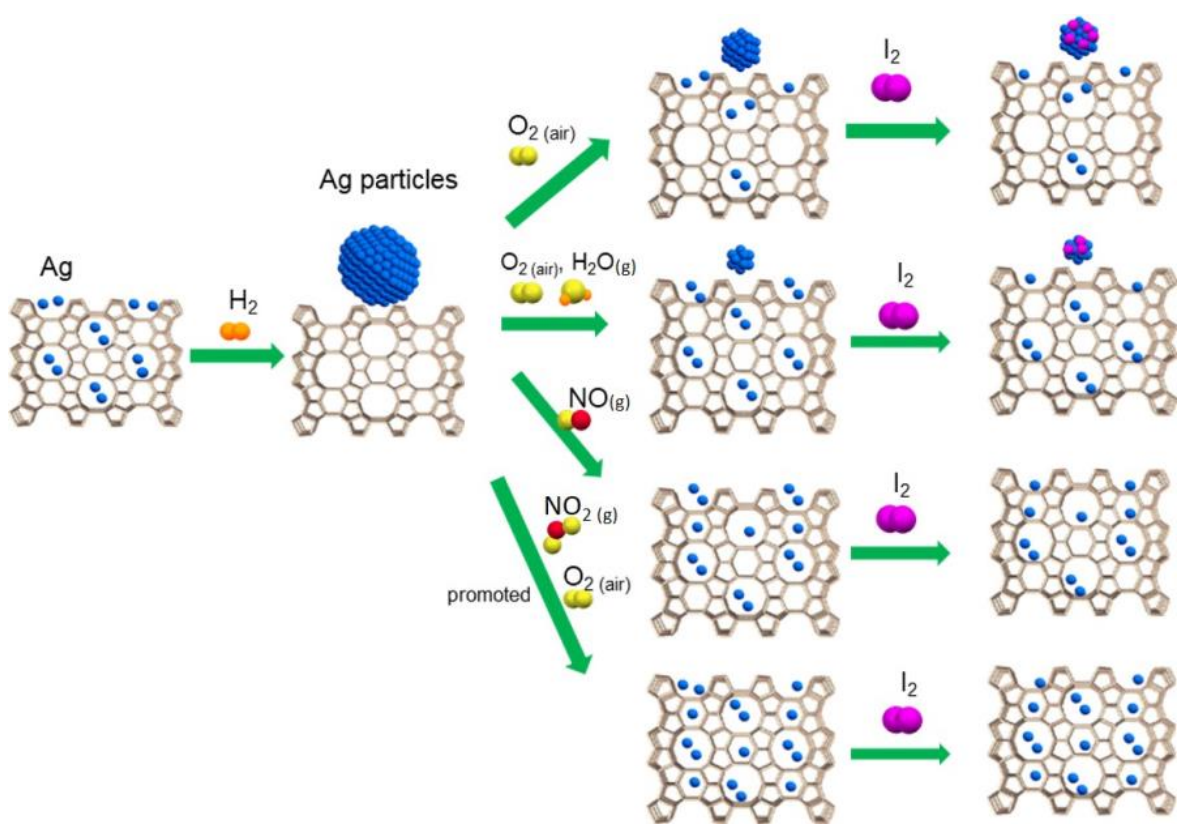

Figure 14. Mechanisms of reduction of $\mathrm{AgZ}$ to $\mathrm{Ag}^{0} \mathrm{Z}$ and aging of $\mathrm{Ag}^{0} \mathrm{Z}$ in different off-gases. 
In dry air:

$$
\begin{aligned}
& \mathrm{O}_{2}+4 \mathrm{Ag} \longleftrightarrow 4 \mathrm{Ag}_{\mathrm{s}}{ }^{+}+2 \mathrm{O}^{2-} \\
& \mathrm{Ag}_{\mathrm{s}}+\stackrel{\text { fast }}{\longrightarrow} \mathrm{Ag}_{\mathrm{p}}{ }^{+} \\
& \mathrm{Ag}_{\mathrm{p}}{ }^{+}+\mathrm{HZ} \stackrel{\text { fast }}{\longrightarrow} \mathrm{AgZ}+\mathrm{H}^{+} \\
& 2 \mathrm{H}^{+}+\mathrm{O}^{2-} \stackrel{\text { fast }}{\longrightarrow} \mathrm{H}_{2} \mathrm{O}
\end{aligned}
$$

Where $\mathrm{Z}$ representes mordenite, the subscript $s$ denotes the $\mathrm{Ag}^{+}$on the external surface and $p$ denotes the $\mathrm{Ag}^{+}$in the pores and channels of mordenite crystals.

In humid air:

$$
\begin{gathered}
2 \mathrm{H}_{2} \mathrm{O}+\mathrm{O}_{2}+4 \mathrm{Ag} \longleftrightarrow 4 \mathrm{Ag}_{\mathrm{s}}{ }^{+}+4 \mathrm{OH}^{-} \\
\mathrm{Ag}_{\mathrm{s}}+\stackrel{\text { fast }}{\longrightarrow} \mathrm{Ag}_{\mathrm{p}}^{+} \\
\mathrm{Ag}_{\mathrm{p}}^{+}+\mathrm{HZ} \stackrel{\text { fast }}{\longrightarrow} \mathrm{AgZ}+\mathrm{H}^{+} \\
\mathrm{H}^{+}+\mathrm{HO}^{-} \stackrel{\text { fast }}{\longrightarrow} \mathrm{H}_{2} \mathrm{O}
\end{gathered}
$$

Overall reaction: $2 \mathrm{NO}+4 \mathrm{Ag}+4 \mathrm{HZ} \longleftrightarrow 4 \mathrm{AgZ}+2 \mathrm{H}_{2} \mathrm{O}+\mathrm{N}_{2}$

In NO: $\quad 2 \mathrm{NO}_{2}+8 \mathrm{Ag} \longleftrightarrow 8 \mathrm{Ag}_{\mathrm{s}}{ }^{+}+4 \mathrm{O}^{2-}+\mathrm{N}_{2}$ 


$$
\begin{gathered}
\mathrm{Ag}_{\mathrm{s}}+\stackrel{\text { fast }}{\longrightarrow} \mathrm{Ag}_{\mathrm{p}}^{+} \\
\mathrm{Ag}_{\mathrm{p}}^{+}+\mathrm{HZ} \stackrel{\text { fast }}{\longrightarrow} \mathrm{AgZ}+\mathrm{H}^{+} \\
2 \mathrm{H}^{+}+\mathrm{O}^{2-} \stackrel{\text { fast }}{\longrightarrow} \mathrm{H}_{2} \mathrm{O} \\
\text { Overall reaction: } 2 \mathrm{NO}_{2}+8 \mathrm{Ag}+8 \mathrm{HZ} \longleftrightarrow 8 \mathrm{AgZ}+4 \mathrm{H}_{2} \mathrm{O}+\mathrm{N}_{2}
\end{gathered}
$$

\subsubsection{Kinetics for Aging Processes on $\mathrm{Ag}^{0} \mathrm{Z}$}

The aging effects of dry air, humid air, $1 \% \mathrm{NO} / \mathrm{N}_{2}$, and $2 \% \mathrm{NO}_{2} /$ air on $\mathrm{Ag}^{0} \mathrm{Z}$ at $150{ }^{\circ} \mathrm{C}$ for up to 6 months were reported through a previous work. ${ }^{26} \mathrm{Ag}^{0} \mathrm{Z}$ aged in dry air, humid air (d.p. -15 ${ }^{\circ} \mathrm{C}$ ), $1 \% \mathrm{NO} / \mathrm{N}_{2}$, and $2 \% \mathrm{NO}_{2}$ /air each had reduced iodine loading capacities. The most adverse impact on iodine capacity was observed for $\mathrm{Ag}^{0} \mathrm{Z}$ aged in the $2 \% \mathrm{NO}_{2} /$ air stream. In the $2 \% \mathrm{NO}_{2} /$ air gas stream at $150{ }^{\circ} \mathrm{C}, \mathrm{Ag}^{0} \mathrm{Z}$ lost $>90 \%$ of its initial iodine capacity within 1 month.

To obtain insight into the aging kinetics of $\mathrm{Ag}^{0} \mathrm{Z}$, aging experiments in dry air, humid air, $1 \% \mathrm{NO} / \mathrm{N}_{2}$, and $2 \% \mathrm{NO}_{2}$ /air with different aging times ( 1 day to 1 month), temperatures $\left(100{ }^{\circ} \mathrm{C}\right.$ to $200{ }^{\circ} \mathrm{C}$ ), and water vapor concentrations (d.p. $-40{ }^{\circ} \mathrm{C}$ to $+15^{\circ} \mathrm{C}$ ) were performed. Figure 15 shows the kinetic data for iodine loading on $\mathrm{Ag}^{0} \mathrm{Z}$ aged in different gas streams including dry air, humid air (d.p. $-40{ }^{\circ} \mathrm{C},-15{ }^{\circ} \mathrm{C}$, and $+15{ }^{\circ} \mathrm{C}$ ), $1 \% \mathrm{NO} / \mathrm{N}_{2}$, and $2 \% \mathrm{NO}_{2} /$ air at different temperatures $\left(100{ }^{\circ} \mathrm{C}, 150{ }^{\circ} \mathrm{C}\right.$, and $200{ }^{\circ} \mathrm{C}$ ) for up to 1 month. Iodine loading capacities on $\mathrm{Ag}^{0} \mathrm{Z}$ aged in dry air (Figure 15 (A)) decreased by $15.5 \%, 34.8 \%$, and $36.4 \%$ at $100{ }^{\circ} \mathrm{C}, 150{ }^{\circ} \mathrm{C}$, and $200{ }^{\circ} \mathrm{C}$ after 1 month, respectively. Iodine loading capacities on $\mathrm{Ag}^{0} \mathrm{Z}$ aged in humid air (d.p. $-15^{\circ} \mathrm{C}$, Figure 15 (B)) decreased by $42.4 \%, 44.8 \%$, and $58.2 \%$ at $100{ }^{\circ} \mathrm{C}, 150{ }^{\circ} \mathrm{C}$, and $200{ }^{\circ} \mathrm{C}$ after 3 days, respectively. Figure 15 (C) indicates the effect of the water vapor concentration on $\mathrm{Ag}^{0} \mathrm{Z}$ 's iodine loading capacity; iodine loading capacities were decreased by $34.8 \%$ (d.p. $-40{ }^{\circ} \mathrm{C}$ ), $44.8 \%$ (d.p. $15^{\circ} \mathrm{C}$ ), and $56.3 \%$ (d.p. $+15^{\circ} \mathrm{C}$ ) at $150{ }^{\circ} \mathrm{C}$ after 3 days. The results in Figures $15(\mathbf{B})$ and $(\mathbf{C})$ show that the effect of humid air increases with increasing temperature and water vapor concentration. Iodine loading capacities on $\mathrm{Ag}^{0} \mathrm{Z}$ aged in $1 \% \mathrm{NO} / \mathrm{N}_{2}$ (Figure 15 (D)) decreased by $60.8 \%, 59.0 \%$, and $62.4 \%$ at $100{ }^{\circ} \mathrm{C}, 150{ }^{\circ} \mathrm{C}$, and $200{ }^{\circ} \mathrm{C}$ after 1 month, respectively. Figure 15 (E) shows that iodine loading capacities on $\mathrm{Ag}^{0} \mathrm{Z}$ aged in $2 \% \mathrm{NO}_{2} /$ air decreased by $87.5 \%, 88.9 \%$, and $91.2 \%$ at $100{ }^{\circ} \mathrm{C}, 150{ }^{\circ} \mathrm{C}$, and $200{ }^{\circ} \mathrm{C}$ after 5 hours, respectively. These results indicated that the iodine capacity of aged $\mathrm{Ag}^{0} \mathrm{Z}$ decreases with increasing aging temperature and increasing aging time when exposed to off-gas streams. This means that dry air, humid air, $1 \% \mathrm{NO} / \mathrm{N}_{2}$, and 2\% $\mathrm{NO}_{2} /$ air have a negative impact on the iodine loading capacity of $\mathrm{Ag}^{0} \mathrm{Z}$. 

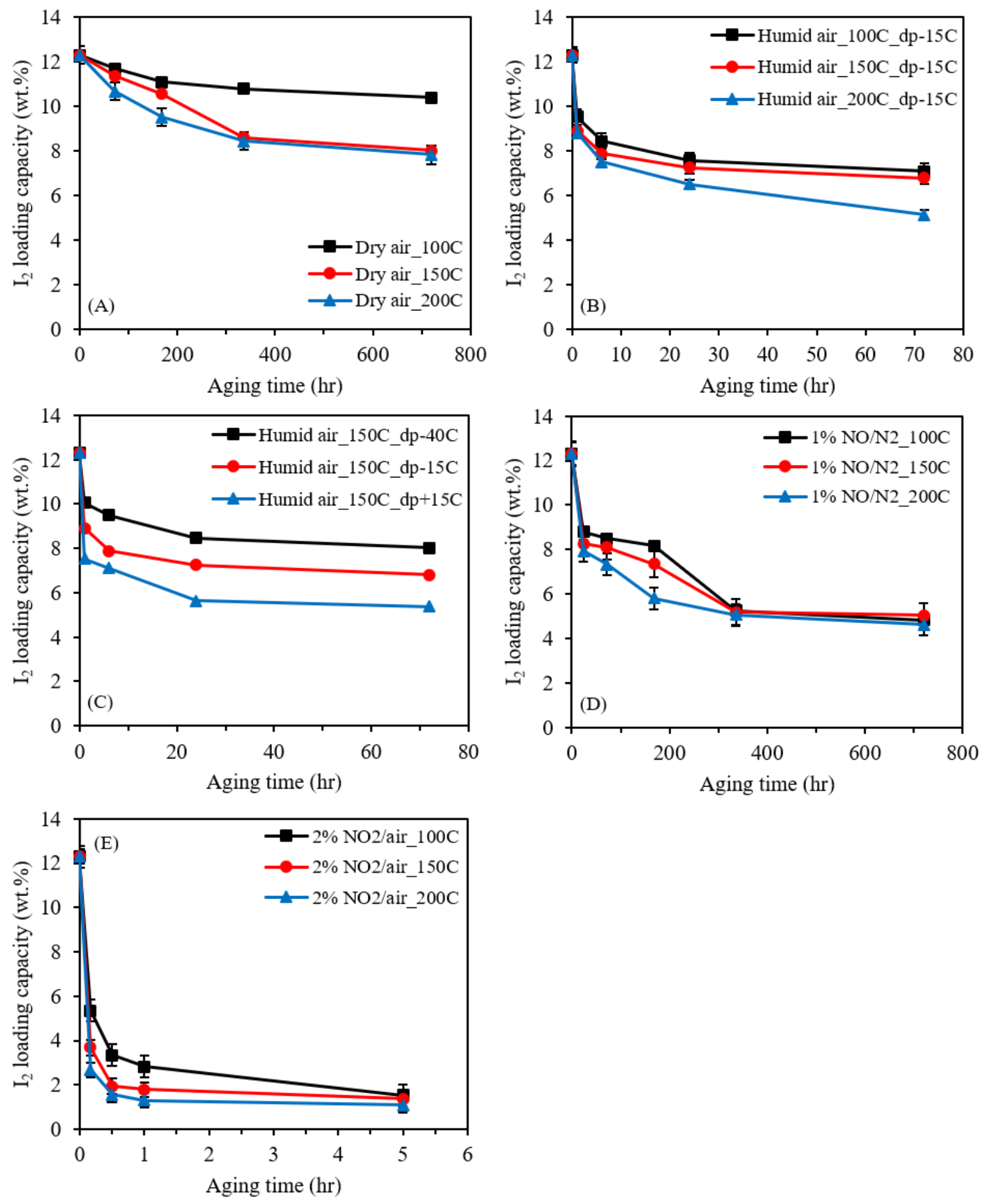

Figure 15. Kinetic data on $\mathrm{I}_{2}$ adsorption capacity of $\mathrm{Ag}^{0} \mathrm{Z}$ aged in dry air (A), humid air (B), humid air with different water vapor concentrations at constant temperature (C), $1 \% \mathrm{NO} / \mathrm{N}_{2}(\mathrm{D})$, and $2 \%$ $\mathrm{NO}_{2} /$ air (E) at different aging times and temperatures. 


\subsubsection{Modeling}

As discussed above, the aging process is controlled by the oxidation reaction for all the gas streams examined in this study. Aging experiments were conducted using a continuous flow system such that the gas concentrations in the streams were constant during the experiment. Accordingly, the pseudo reaction model was applied to describe the kinetics of the aging process for $\mathrm{Ag}^{0} \mathrm{Z}$. For the modeling work, the correlation coefficient $\left(\mathrm{R}^{2}\right.$, Eqn. (21)) was used to evaluate the goodness of fit between experimental data and model results. In Eqn. (21), $x$ represents sample data from experimental results, $\bar{x}$ represents the average of the sample data set from experimental results, $y$ stands for sample data from model results, and $\bar{y}$ represents the average of the sample data set from model results. In general, a correlation cofficient close to 1 indicates strong correlation between experimental data and model results.

$$
\text { Correlation coefficient }\left(R^{2}\right)=\frac{\sum(x-\bar{x})(y-\bar{y})}{\sqrt{(x-\bar{x})^{2}(y-\bar{y})^{2}}}
$$

Results from the pseudo reaction models for aged $\mathrm{Ag}^{0} \mathrm{Z}$ in dry air, humid air with different water vapor concentrations (d.p. $-40{ }^{\circ} \mathrm{C},-15^{\circ} \mathrm{C}$, and $+15^{\circ} \mathrm{C}$ ) , $1 \% \mathrm{NO} / \mathrm{N}_{2}$, and $2 \% \mathrm{NO}_{2} /$ air at different aging temperatures $\left(100^{\circ} \mathrm{C}, 150^{\circ} \mathrm{C}\right.$, and $\left.200{ }^{\circ} \mathrm{C}\right)$ for up to 2 weeks are plotted in Figure $\mathbf{1 6}$ and are combined with the kinetic data shown in Figure 15.

Modeling results for the $\mathrm{Ag}^{0} \mathrm{Z}$ aged in dry air at different temperatures for different aging times are shown in Figure 16 (A). Eqn. (22) represents a reaction equation for the kinetic model with $\mathrm{Ag}^{0} \mathrm{Z}$ aged in dry air shown in Figure $16(\mathbf{A}) . C_{A g}$ is the normalized concentration of silver, which indicates the amount of $\mathrm{I}_{2}$ loaded on the aged $\mathrm{Ag}^{0} \mathrm{Z}, C_{\mathrm{O}_{2}}$ is the concentration of oxygen in dry air, $C_{\mathrm{Ag}^{+}}$is the concentration of silver oxidized by oxygen in dry air, $n$ is the reaction order, $k_{1}$ is the forward reaction rate constant, and $k_{-1}$ is the reverse reaction rate constant. Here, $k_{1}$ and $C_{\mathrm{O}_{2}}$ are lumped into $k_{1}{ }^{*}$ because the gas concentration was constant at all times during the aging experiment. $C_{\mathrm{Ag}^{+}}$can be calculated by substracting the amount of $\mathrm{I}_{2}$ loaded on the aged $\mathrm{Ag}^{0} \mathrm{Z}$ from the amount of $\mathrm{I}_{2}$ loaded on the unaged $\mathrm{Ag}^{0} \mathrm{Z}$. The model parameters for all reaction models and the correlation coefficients $\left(\mathrm{R}^{2}\right)$ between experimental data and model results are shown in Table 1. These results indicate the model is well fitted to experimental data, with a strong correlation coefficient $\left(\mathrm{R}^{2}=0.988\right.$ at $\left.150^{\circ} \mathrm{C}\right)$ attained using Eqn. (21), when $\mathrm{n} \geq 1$. Thus, the Pseudo $1^{\text {st }}$ order reversible reaction model fits the experimental data (Figure $16(\mathrm{~A})$ ). These results are consistent with the experimental data (Figure 15), which show that the aging effects of gas streams on $\operatorname{Ag}^{0} \mathrm{Z}$ increase with increasing aging time and temperature.

$$
\begin{gathered}
\mathrm{Ag} \stackrel{\mathrm{O}_{2}}{\longrightarrow} \mathrm{Ag}_{\mathrm{s}}{ }^{+} \\
\mathrm{v}=\frac{\mathrm{dC}_{\mathrm{Ag}}}{\mathrm{dt}}=-\mathrm{k}_{1} \mathrm{C}_{\mathrm{O}_{2}} \mathrm{C}_{\mathrm{Ag}}{ }^{\mathrm{n}}+\mathrm{k}_{-1} \mathrm{C}_{\mathrm{Ag}^{+}}{ }^{\mathrm{n}} \\
\mathrm{k}_{1}{ }^{*}=\mathrm{k}_{1} \mathrm{C}_{\mathrm{O}_{2}} \\
\mathrm{v}=\frac{\mathrm{dC} \mathrm{Ag}}{\mathrm{dt}}=-\mathrm{k}_{1}{ }^{*} \mathrm{C}_{\mathrm{Ag}}+\mathrm{k}_{-1} \mathrm{C}_{\mathrm{Ag}^{+}} \quad(\text { for } \mathrm{n}=1)
\end{gathered}
$$


Modeling results for $\mathrm{Ag}^{0} \mathrm{Z}$ aged in humid air at different temperatures, aging times, and water vapor concentrations are plotted in Figures $16(B)$ and $16(C)$. A reaction equation for the model is provided in Eqn. (23). Considering the correlation coefficients for each order model, model results show good fitting to experimental data when $\mathrm{n} \geq 1 . C_{\mathrm{H}_{2} \mathrm{O}}$ and $C_{\mathrm{O}_{2}}$ are the concentrations of water vapor and oxygen in humid air, $k_{1}$ is the reaction rate constant, $k_{-1}$ is the reverse reaction rate constant, and $n$ is the reaction order. Here, $k_{1}, C_{\mathrm{H}_{2} \mathrm{O}}$, and $C_{\mathrm{O}_{2}}$ are lumped into $k_{1}{ }^{*}$, and $\mathrm{m}$ is the power of the water vapor concentration determined by an exponential curve expressed by $k_{1}{ }^{*}$ versus $C_{\mathrm{H}_{2} \mathrm{O}}$ as shown in Figure $17(m=0.20)$. These modeling results indicate that the pseudo $1^{\text {st }}$ order reversible reaction model fits well the experimental data $\left(\mathrm{R}^{2}=0.985\right.$ at $150{ }^{\circ} \mathrm{C}$ ) using an approach that is similar to the model for dry air aged $\mathrm{Ag}^{0} \mathrm{Z}$.

$$
\begin{gathered}
\mathrm{Ag} \stackrel{\mathrm{H}_{2} \mathrm{O}, \mathrm{O}_{2}}{\longrightarrow} \mathrm{Ag}_{\mathrm{s}}{ }^{+} \\
\mathrm{v}=\frac{\mathrm{dC}_{\mathrm{Ag}}}{\mathrm{dt}}=-\mathrm{k}_{1}{ }^{*} \mathrm{C}_{\mathrm{Ag}}{ }^{\mathrm{n}}+\mathrm{k}_{-1} \mathrm{C}_{\mathrm{Ag}^{+}}{ }^{\mathrm{n}} \\
\mathrm{k}_{1}{ }^{*}=\mathrm{k}_{1} \mathrm{C}_{\mathrm{H}_{2} \mathrm{O}}{ }^{\mathrm{m}} \mathrm{C}_{\mathrm{O}_{2}} \\
\mathrm{v}=\frac{\mathrm{dC}_{\mathrm{Ag}}}{\mathrm{dt}}=-\mathrm{k}_{1}{ }^{*} \mathrm{C}_{\mathrm{Ag}}+\mathrm{k}_{-1} \mathrm{C}_{\mathrm{Ag}^{+}} \quad(\text { for } \mathrm{n}=1)
\end{gathered}
$$

Modeling results for $\mathrm{Ag}^{0} \mathrm{Z}$ aged in $1 \% \mathrm{NO} / \mathrm{N}_{2}$ at different temperatures and aging times are plotted in Figure 16 (D). A reaction equation for the model is provided in Eqn. (24). Considering the correlation coefficient for each order model, modeling results show good fitting to experimental data when $\mathrm{n} \geq 1$. Here, $C_{N O}$ is the concentration of NO, and $k_{1}$ and $C_{N O}$ are lumped into $k_{1}{ }^{*}$. These modeling results indicate that the pseudo $1^{\text {st }}$ order reversible reaction model fits well the experimental data $\left(\mathrm{R}^{2}=0.985\right.$ at $\left.150{ }^{\circ} \mathrm{C}\right)$ using an approach that is similar to the model for dry air and humid air aged $\mathrm{Ag}^{0} \mathrm{Z}$.

$$
\begin{gathered}
\mathrm{Ag} \stackrel{\mathrm{NO}}{\longrightarrow} \mathrm{Ag}_{\mathrm{s}}{ }^{+} \\
\mathrm{v}=\frac{\mathrm{dC}_{\mathrm{Ag}}}{\mathrm{dt}}=-\mathrm{k}_{1}{ }^{*} \mathrm{C}_{\mathrm{Ag}}{ }^{\mathrm{n}}+\mathrm{k}_{-1} \mathrm{C}_{\mathrm{Ag}^{+}}{ }^{\mathrm{n}} \\
\mathrm{k}_{1}{ }^{*}=\mathrm{k}_{1} \mathrm{C}_{\mathrm{NO}} \\
\mathrm{v}=\frac{\mathrm{dC}_{\mathrm{Ag}}}{\mathrm{dt}}=-\mathrm{k}_{1}{ }^{*} \mathrm{C}_{\mathrm{Ag}}+\mathrm{k}_{-1} \mathrm{C}_{\mathrm{Ag}^{+}} \quad(\text { for } \mathrm{n}=1)
\end{gathered}
$$

Modeling results for $\mathrm{Ag}^{0} \mathrm{Z}$ aged in $2 \% \mathrm{NO}_{2} /$ air at different temperatures and aging times are plotted in Figure $16(\mathbf{E})$. A reaction equation for the model is provided in Eqn. (25). A pseudo irreversible reaction model was employed to describe the kinetics of the $2 \% \mathrm{NO}_{2}$ aging process for $\mathrm{Ag}^{0} \mathrm{Z}$. Here, $C_{\mathrm{NO}_{2}}$ is the concentration of $\mathrm{NO}_{2}$, and $k_{1}$ and $C_{\mathrm{NO}_{2}}$ are lumped into $k_{1}{ }^{*}$. Modeling results indicate that the model is well fitted $\left(\mathrm{R}^{2}=0.988\right.$ at $\left.150{ }^{\circ} \mathrm{C}\right)$ to experimental data when $\mathrm{n} \geq$ 2 , which means that the pseudo $2^{\text {nd }}$ order irreversible reaction model fits the experimental data.

$$
\begin{gathered}
\mathrm{Ag} \stackrel{\mathrm{NO}_{2}}{\longleftrightarrow} \mathrm{Ag}_{\mathrm{s}}{ }^{+} \\
\mathrm{v}=\frac{\mathrm{dC}_{\mathrm{Ag}}}{\mathrm{dt}}=-\mathrm{k}_{1}{ }^{*} \mathrm{C}_{\mathrm{Ag}}{ }^{\mathrm{n}}
\end{gathered}
$$




$$
\begin{aligned}
\mathrm{k}_{1}{ }^{*}=\mathrm{k}_{1} \mathrm{C}_{\mathrm{NO}_{2}} \\
\mathrm{v}=\frac{\mathrm{dC}_{\mathrm{Ag}}}{\mathrm{dt}}=-\mathrm{k}_{1}{ }^{*} \mathrm{C}_{\mathrm{Ag}}{ }^{2} \quad(\text { for } \mathrm{n}=2)
\end{aligned}
$$
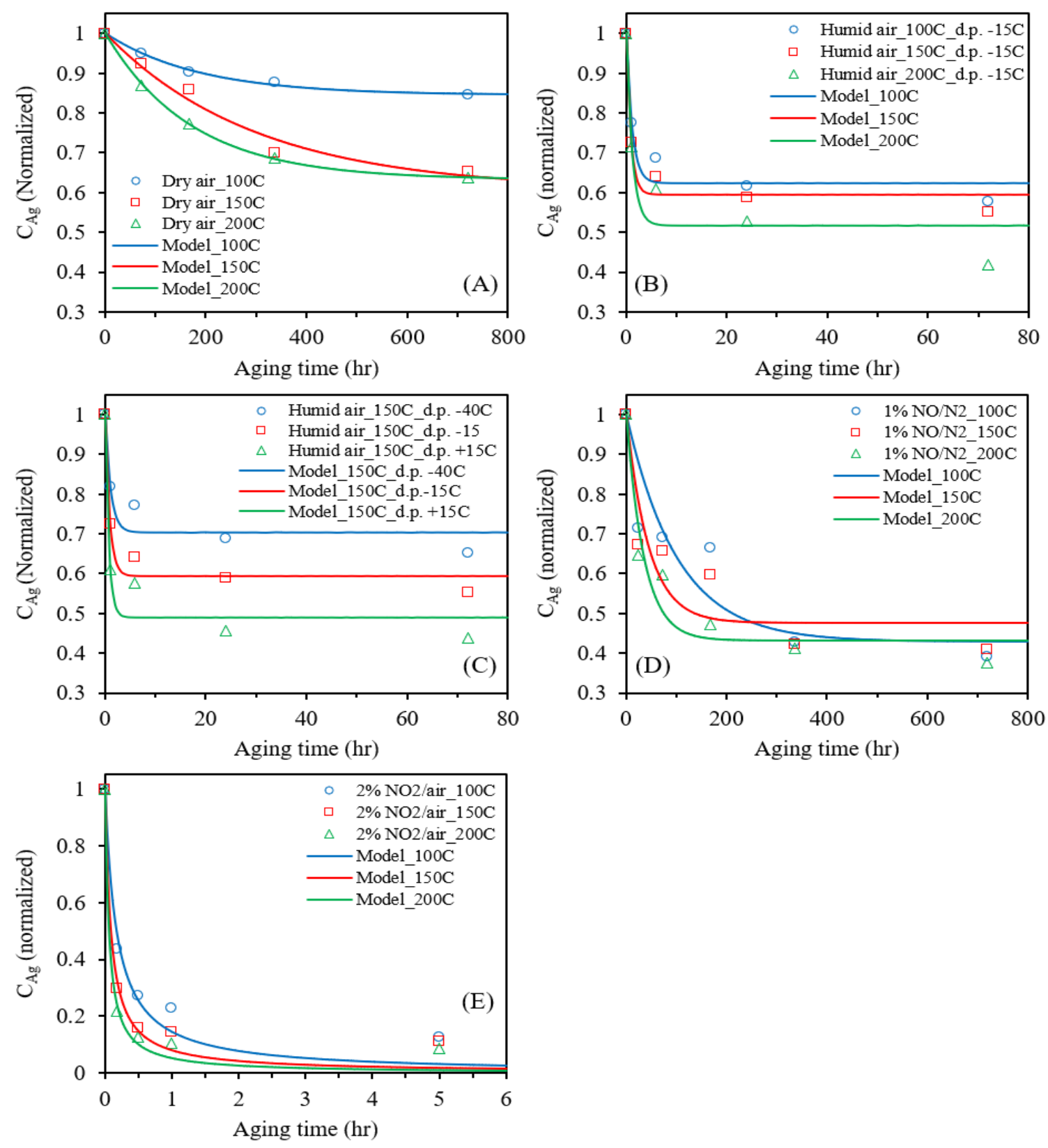

Figure 16. Pseudo reaction models for $\mathrm{Ag}^{0} \mathrm{Z}$ aged in dry air (A), humid air (B), humid air with different water vapor concentrations (C), $1 \% \mathrm{NO} / \mathrm{N}_{2}(\mathrm{D})$, and $2 \% \mathrm{NO}_{2} /$ air (E) at different aging temperatures and times. 


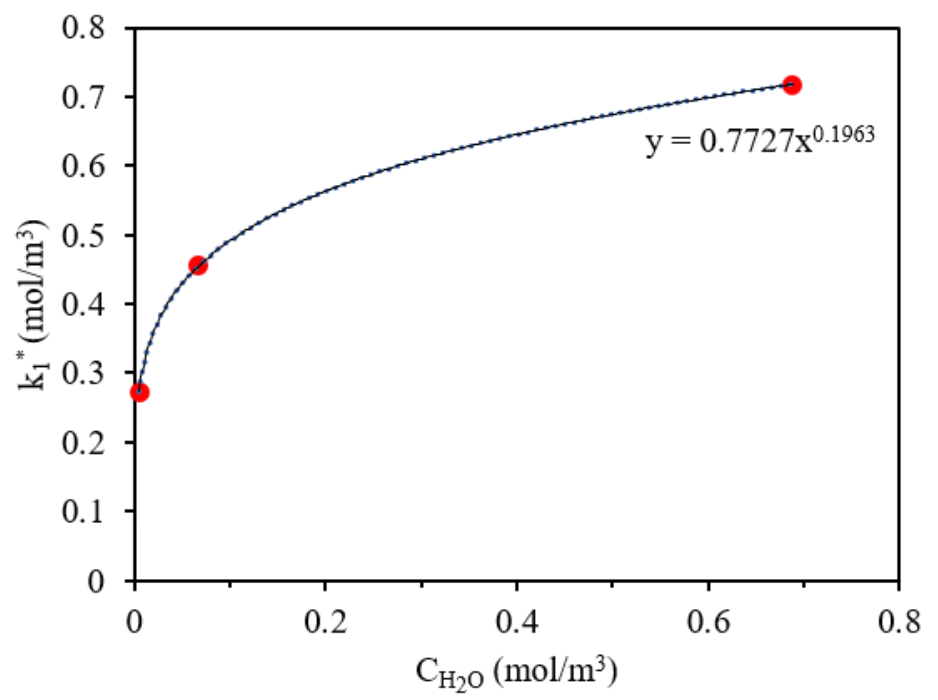

Figure 17. Power function curve between reaction rate constant $\left(k_{1}{ }^{*}\right)$ and water vapor concentration $\left(C_{\mathrm{H}_{2} \mathrm{O}}\right)$.

Table 1. Variables and Model Parameters for the Pseudo Reaction Model

\begin{tabular}{|c|c|c|c|c|c|c|c|c|c|}
\hline $\begin{array}{c}\mathrm{T} \\
\left({ }^{\circ} \mathrm{C}\right)\end{array}$ & $\begin{array}{l}\text { D.P. } \\
\left({ }^{\circ} \mathrm{C}\right)\end{array}$ & $\begin{array}{c}\mathrm{C}_{\mathrm{H}_{2} \mathrm{O}} \\
\left(\mathrm{mol} / \mathrm{m}^{3}\right)\end{array}$ & $\begin{array}{c}\mathrm{C}_{\mathrm{O}_{2}} \\
\left(\mathrm{~mol} / \mathrm{m}^{3}\right)\end{array}$ & $\begin{array}{c}\mathrm{C}_{\mathrm{NO}} \\
\left(\mathrm{mol} / \mathrm{m}^{3}\right)\end{array}$ & $\begin{array}{c}\mathrm{C}_{\mathrm{NO}_{2}} \\
\left(\mathrm{~mol} / \mathrm{m}^{3}\right)\end{array}$ & $\begin{array}{l}\mathrm{k}_{1}^{*} \\
\left(\mathrm{hr}^{-1}\right)\end{array}$ & $\begin{array}{c}\mathrm{k}_{1} \\
\left(\left(\mathrm{~mol} / \mathrm{m}^{3}\right)^{-1} \cdot \mathrm{hr}^{-1}\right)^{\mathrm{a}}\end{array}$ & $\begin{array}{c}\mathrm{k}_{-1} \\
\left(\mathrm{hr}^{-1}\right)\end{array}$ & $\mathrm{R}^{2}$ \\
\hline \multicolumn{10}{|l|}{ Dry air } \\
\hline 100 & -70 & - & 8.59 & - & - & 8.36E-4 & $9.73 \mathrm{E}-5$ & $4.55 \mathrm{E}-3$ & $0.997^{\mathrm{b}}$ \\
\hline 150 & -70 & - & 8.59 & - & - & $1.32 \mathrm{E}-3$ & $1.53 \mathrm{E}-4$ & $2.01 \mathrm{E}-3$ & $0.988^{b}$ \\
\hline 200 & -70 & - & 8.59 & - & - & $2.14 \mathrm{E}-3$ & $2.4 \mathrm{E}-4$ & $3.68 \mathrm{E}-3$ & $0.999^{b}$ \\
\hline \multicolumn{10}{|c|}{ Humid air } \\
\hline 100 & -15 & 0.067 & 8.59 & - & - & 0.323 & $0.064^{\mathrm{a}}$ & 0.537 & $0.974^{\mathrm{b}}$ \\
\hline 150 & -40 & 0.005 & 8.59 & - & - & 0.272 & $0.090^{\mathrm{a}}$ & 0.644 & $0.982^{\mathrm{b}}$ \\
\hline 150 & -15 & 0.067 & 8.59 & - & - & 0.456 & $0.090^{\mathrm{a}}$ & 0.667 & $0.985^{\mathrm{b}}$ \\
\hline 150 & +15 & 0.687 & 8.59 & - & - & 0.716 & $0.090^{\mathrm{a}}$ & 0.688 & $0.982^{\mathrm{b}}$ \\
\hline 200 & -15 & 0.067 & 8.59 & - & - & 0.403 & $0.080^{\mathrm{a}}$ & 0.429 & $0.953^{\mathrm{b}}$ \\
\hline \multicolumn{10}{|l|}{$1 \% \mathrm{NO}$} \\
\hline 100 & - & - & - & 0.409 & - & $5.63 \mathrm{E}-3$ & 0.014 & 4.22E-3 & $0.920^{\mathrm{b}}$ \\
\hline 150 & - & - & - & 0.409 & - & 0.012 & 0.029 & 0.011 & $0.920^{\mathrm{b}}$ \\
\hline 200 & - & - & - & 0.409 & - & 0.016 & 0.039 & 0.012 & $0.965^{\mathrm{b}}$ \\
\hline \multicolumn{10}{|l|}{$2 \% \mathrm{NO}_{2}$} \\
\hline 100 & - & - & - & - & 0.818 & 3.168 & 3.873 & - & $0.995^{\mathrm{c}}$ \\
\hline 150 & - & - & - & - & 0.818 & 6.238 & 7.626 & - & $0.994^{\mathrm{c}}$ \\
\hline 200 & - & - & - & - & 0.818 & 8.427 & 10.302 & - & $0.986^{\mathrm{c}}$ \\
\hline
\end{tabular}

${ }^{\mathrm{a}}\left(\mathrm{mol} / \mathrm{m}^{3}\right)^{-1.20} \cdot \mathrm{hr}^{-1}$ for humid air; $\quad{ }^{\mathrm{b}}$ for $\mathrm{n}=1$ in Eqns. (22), (23), and (24); $\quad{ }^{\mathrm{c}}$ for $\mathrm{n}=2$ in Eqn. (25) 


\subsection{Aging Processes on Aged $\mathrm{Ag}^{0}$-Aerogel}

\subsubsection{Aging Effects and $\mathrm{I}_{2}$ Adsorption on Aged $\mathbf{A g}^{0}$-Aerogel}

The aging of $\mathrm{Ag}^{0}$-aerogel under the studied conditions resulted in different physical and chemical changes compared to $\mathrm{Ag}^{0} \mathrm{Z}$. As shown in Figure 18, the original $\mathrm{Ag}^{0}$-aerogel particles are black with yellow spots. The $\mathrm{Ag}^{0}$-aerogel aged in dry air, humid air, and $1 \% \mathrm{NO} / \mathrm{N}_{2}$ changed to black with traces of gray, while the $\mathrm{Ag}^{0}$-aerogel aged in $2 \% \mathrm{NO}_{2} /$ air turned to a white color after 1 month of aging. It was noted that the change in color following $\mathrm{NO}$ exposure in $\mathrm{Ag}^{0}$-aerogel was different to that of $\mathrm{Ag}^{0} \mathrm{Z}$ which changed from dark brown to white. In addition, the inconsistent color change of $\mathrm{NO}_{2}$ aged $\mathrm{Ag}^{0}$-aerogel particles should be due to the chemical and physical nonuniformity of the original $\mathrm{Ag}^{0}$-aerogel particles.

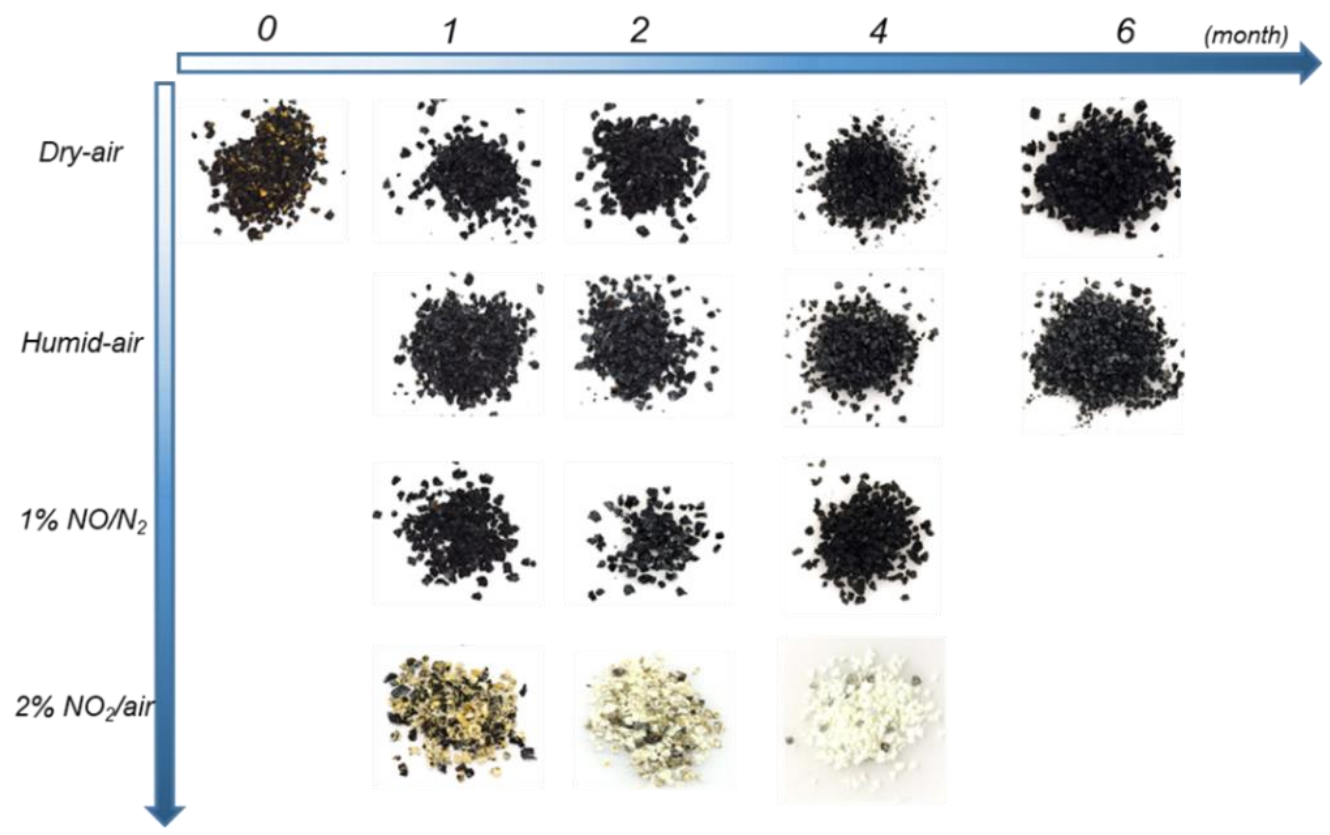

Figure 18. Pictures of $\mathrm{Ag}^{0}$-aerogel samples.

$\mathrm{I}_{2}$ adsorption performance for $\mathrm{Ag}^{0}$-aerogel is shown in Figure 19. The results indicate that $\mathrm{Ag}^{0}$-aerogel was more resistant to the aging gases than $\mathrm{Ag}^{0} \mathrm{Z}$. $\mathrm{Ag}^{0}$-aerogel maintained a greater portion of its $\mathrm{I}_{2}$ adsorption capacity when exposed to dry air, humid air and $1 \% \mathrm{NO} / \mathrm{N}_{2}$ up to 4 or 6 months. However, $\mathrm{Ag}^{0}$-aerogel still lost the majority of its $\mathrm{I}_{2}$ capacity after 1-month of exposure to the $\mathrm{NO}_{2}$ containing gas stream. The plot of capacity loss over time shown in Figure 20 indicates that the capacity equilibrated at $70 \%-90 \%$ in the dry air, humid air, and NO streams, and dropped to $<20 \%$ in the $\mathrm{NO}_{2}$ stream within 1 month. This revealed an aging effect of $\mathrm{NO}_{2}>\mathrm{NO}=$ humid air >dry air (in terms of capacity loss), which is different to that of $\mathrm{Ag}^{0} \mathrm{Z}$. Even though $\mathrm{Ag}^{0}$-aerogel also lost most of the $\mathrm{I}_{2}$ adsorption capacity after one month of aging in $\mathrm{NO}_{2}$, it was significantly more tolerant to $\mathrm{NO}_{2}$ than $\mathrm{Ag}^{0} \mathrm{Z}$ which lost most of the capacity within 1 hour. 

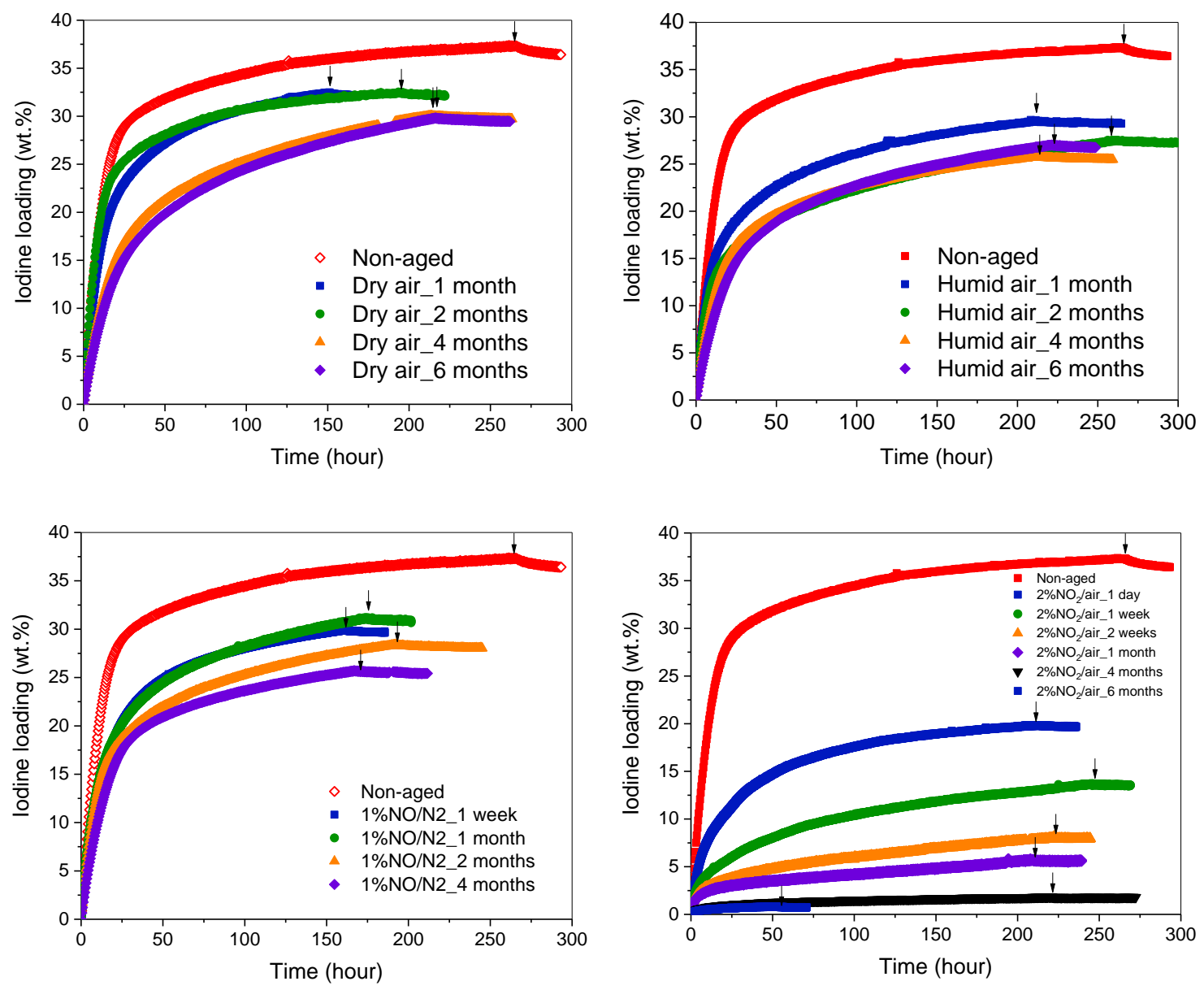

Figure 19. $\mathrm{I}_{2}$ adsorption on aged $\mathrm{Ag}^{0}$-aerogel at $150^{\circ} \mathrm{C}$.

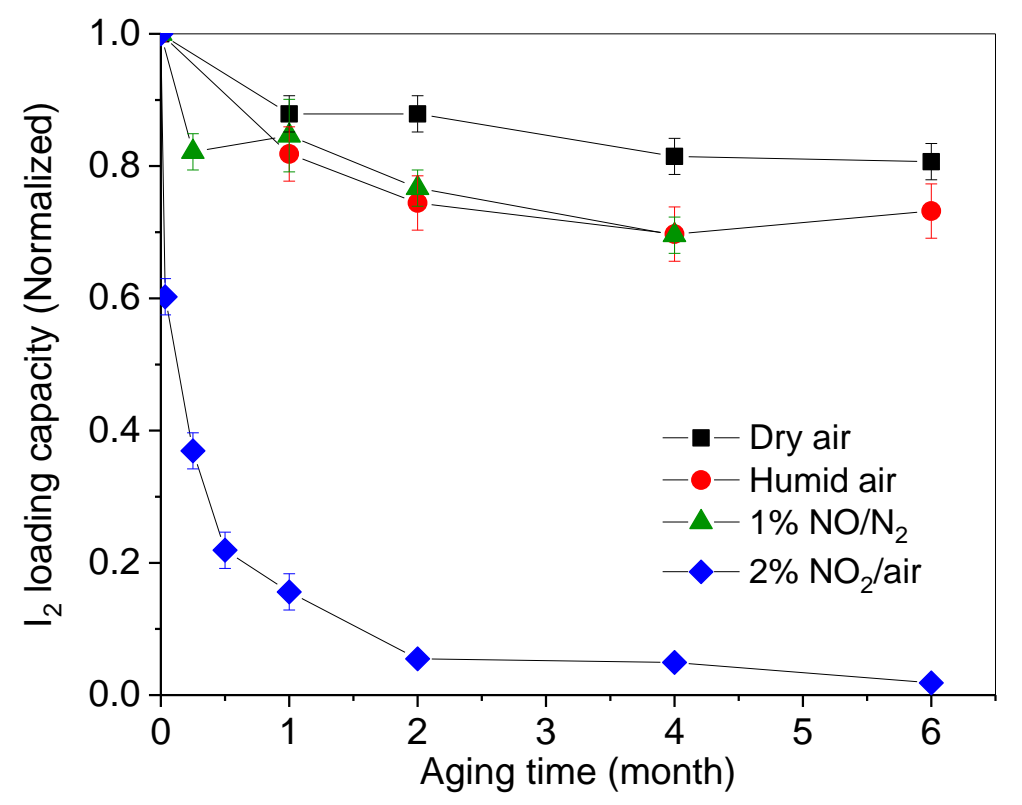

Figure 20. Change of $\mathrm{I}_{2}$ adsorption capacity of $\mathrm{Ag}^{0}$-aerogel over aging time at $150{ }^{\circ} \mathrm{C}$. 


\subsubsection{Characterizations of Aged $\mathbf{A g}^{0}$-Aerogel}

\subsubsection{X-ray Powder Diffraction}

Results of the XRD analysis on the non-aged and aged $\mathrm{Ag}^{0}$-aerogel samples at $150{ }^{\circ} \mathrm{C}$ are shown in Figure 21. The patterns show shifts from $\mathrm{Ag}^{0}$ crystals to $\mathrm{Ag}_{2} \mathrm{~S}$ crystals when the sample is aged in dry air, humid air, and $\mathrm{NO}$, and shifts to $\mathrm{Ag}_{2} \mathrm{SO}_{4}$ when it is aged in $\mathrm{NO}_{2}$. The formation of $\mathrm{Ag}_{2} \mathrm{~S}$ and $\mathrm{Ag}_{2} \mathrm{SO}_{4}$ should be caused by the oxidation of the $\mathrm{SH}^{-}$(thiol functional group) on the surface of aerogel and consequent reactions of $\mathrm{S}^{2-}$ and $\mathrm{SO}^{4-}$ with the $\mathrm{Ag}^{0} \mathrm{or} \mathrm{Ag}^{+}$. The intensity of the $\mathrm{Ag}_{2} \mathrm{~S}$ peaks on the dry air sample patterns were not as significant as those on the humid and $\mathrm{NO}$ aged sample patterns, due to the lighter aging effect of dry air on $\mathrm{Ag}^{0}$-aerogel. In addition, there were no $\mathrm{Ag}_{2} \mathrm{O}$ or $\mathrm{AgNO}_{3}$ observed on the patterns.
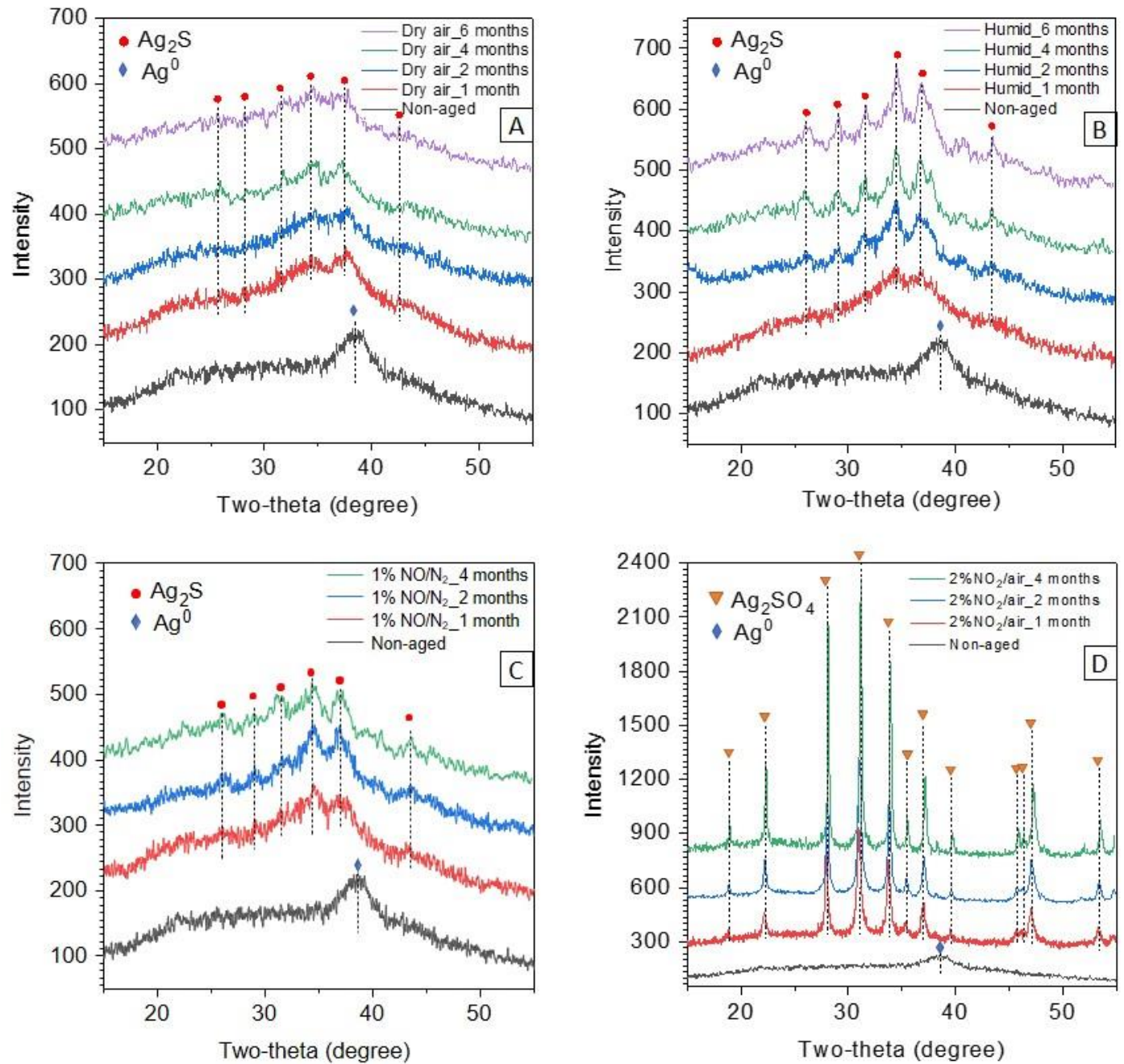

Figure 21. XRD patterns of non-aged $\mathrm{Ag}^{0}$-aerogel and aged $\mathrm{Ag}^{0}$-aerogel in dry air (A), humid air (d.p. $\left.-15^{\circ} \mathrm{C},(\mathrm{B})\right), 1 \% \mathrm{NO} / \mathrm{N}_{2}(\mathrm{C})$, and $2 \% \mathrm{NO}_{2} /$ dry air (D) at $150{ }^{\circ} \mathrm{C}$. 


\subsubsection{Scanning Electron Microscope}

The SEM (backscattered electron composition) images of the aged $\mathrm{Ag}^{0}$-aerogel (Figure 22) show the formation of particles on the surface of aerogels aged in humid air, $\mathrm{NO}$, and $\mathrm{NO}_{2}$. No obvious particles were observed on the dry air aged samples, which could be due to the small size/amount of the particles. ${ }^{29}$ For the humid air and NO aged samples, the small particles were observed regionally on the aerogel surface (not found on the entire aerogel surface). For the $\mathrm{NO}_{2}$ aged $\mathrm{Ag}^{0}$-aerogel, the surface was entirely covered by the particles.

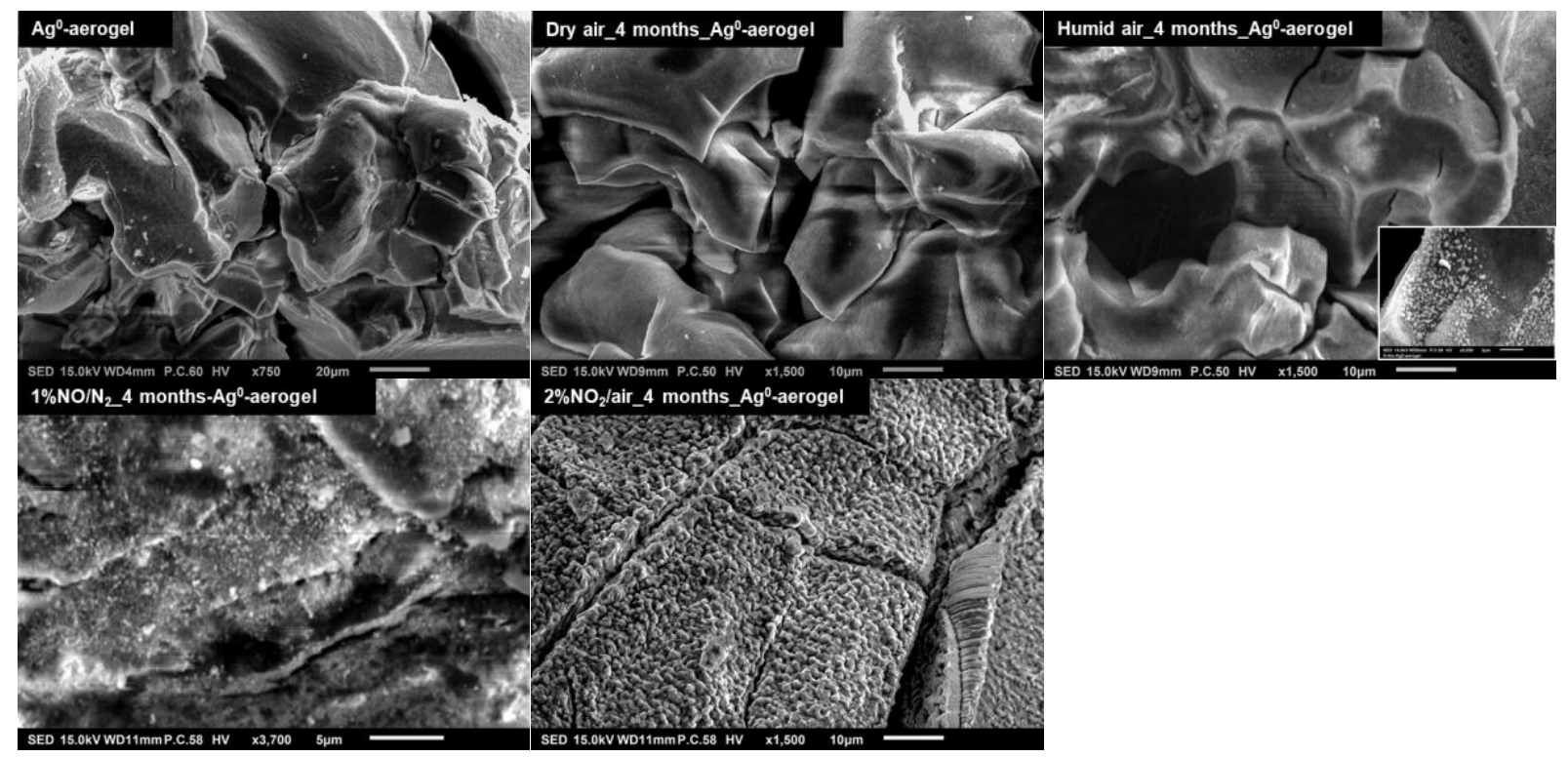

Figure 22. SEM (backscattered electron composition) images of $\mathrm{Ag}^{0}$-aerogel and 4-month aged $\mathrm{Ag}^{0}$-aerogel samples at $150{ }^{\circ} \mathrm{C}$.

\subsubsection{Energy-Dispersive X-ray Spectroscopy}

Energy-Dispersive X-ray Spectroscopy (EDS) analyses were performed on the particles to determine their chemical compositions. As shown in Figure 23, different Ag and S contents were obtained by scanning the area shown in the SEM images. The humid air aged $\mathrm{Ag}^{0}$-aerogel had an increased $\mathrm{Ag}$ and $\mathrm{S}$ contents (14.44\% and 9.19\%, respectively) compared to the non-aged $\mathrm{Ag}^{0}$ aerogel (5.7\% and $4.3 \%$, respectively). The atomic ratio of $\mathrm{Ag}$ to $\mathrm{S}(\mathrm{Ag} / \mathrm{S})$ also increased from 1.33 to 1.57 , which suggested that the particles observed on the surface were $\mathrm{Ag}_{2} \mathrm{~S}$. Similar results were observed on the NO aged $\mathrm{Ag}^{0}$-aerogel, which had an even higher $\mathrm{Ag} / \mathrm{S}$ value due to a denser particle formation on the surface. The EDS data of the $\mathrm{NO}_{2}$ sample showed an increase in the $\mathrm{O}$, $\mathrm{Ag}$ and $\mathrm{S}$ contents, as well as a $\mathrm{Ag} / \mathrm{S}$ value of about 2, which was consistent with the chemical composition of $\mathrm{Ag}_{2} \mathrm{SO}_{4}$. These EDS results confirmed the conclusions from XRD. 

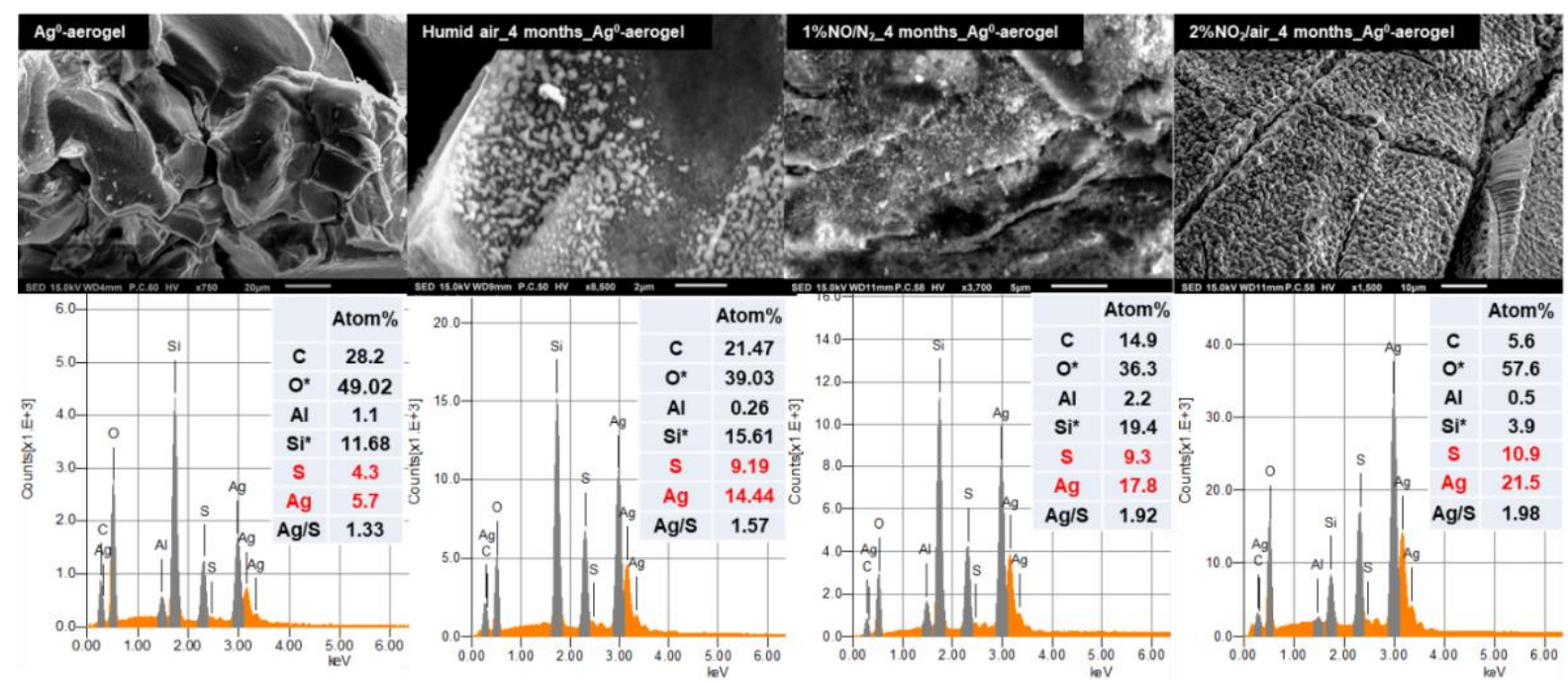

Figure 23. EDS results of $\mathrm{Ag}^{0}$-aerogel samples.

\subsubsection{X-ray Photoelectron Spectroscopy}

Changes in the Ag oxidation state of the aged $\mathrm{Ag}^{0}$-aerogel at $150{ }^{\circ} \mathrm{C}$ determined by XPS are shown in Figure 24. The $\mathrm{Ag}^{0}$-aerogel aged in dry air, humid air and $\mathrm{NO}$ had similar shifts in $\mathrm{Ag}$ binding energy from $368.2 \mathrm{eV}$ to $368.1 \mathrm{eV}$, which are the $\mathrm{BE}$ of the $\mathrm{Ag}$ and $\mathrm{Ag}_{2} \mathrm{~S}$ standards. ${ }^{28}$ The $\mathrm{NO}_{2}$ aged $\mathrm{Ag}^{0}$-aerogel had a more significant spectral shift to $367.8 \mathrm{eV}$, which was consistent with the $\mathrm{BE}$ of the $\mathrm{Ag}_{2} \mathrm{SO}_{4}$ standard. ${ }^{28,31,32}$ These results agreed well with the XRD and EDS results.

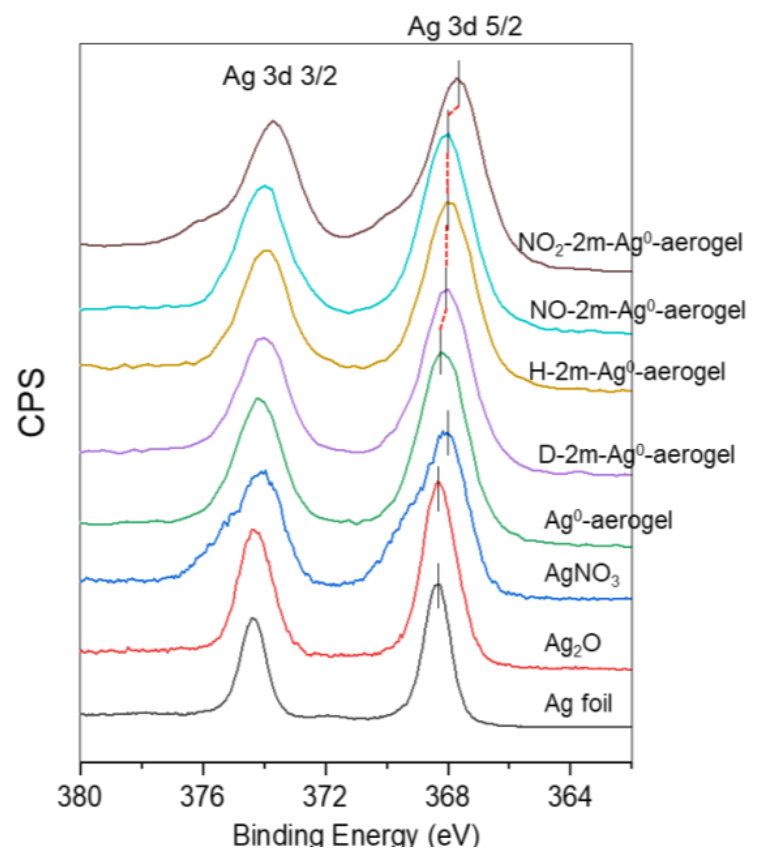

Figure 24. XPS spectra of $\mathrm{Ag}^{0}$-aerogel samples. 


\subsubsection{X-ray Absorption Fine Structure Spectroscopy}

Consistent results were also obtained from XAFS tests. The XANES data (Figure 25) show that there is a spectral change in the dry air, humid air and $\mathrm{NO}$ aged samples towards the $\mathrm{Ag}_{2} \mathrm{~S}$ standard. The slight changes indicate that only small portion of the $\mathrm{Ag}^{0}$ was oxidized to $\mathrm{Ag}_{2} \mathrm{~S}$, and the majority of the silver remained in the form of $\mathrm{Ag}^{0}$. The spectra of $\mathrm{NO}_{2}$ aged samples show a rapid and complete oxidation of $\mathrm{Ag}^{0}$ to $\mathrm{AgSO}_{4}$ upon exposure to $\mathrm{NO}_{2}$.
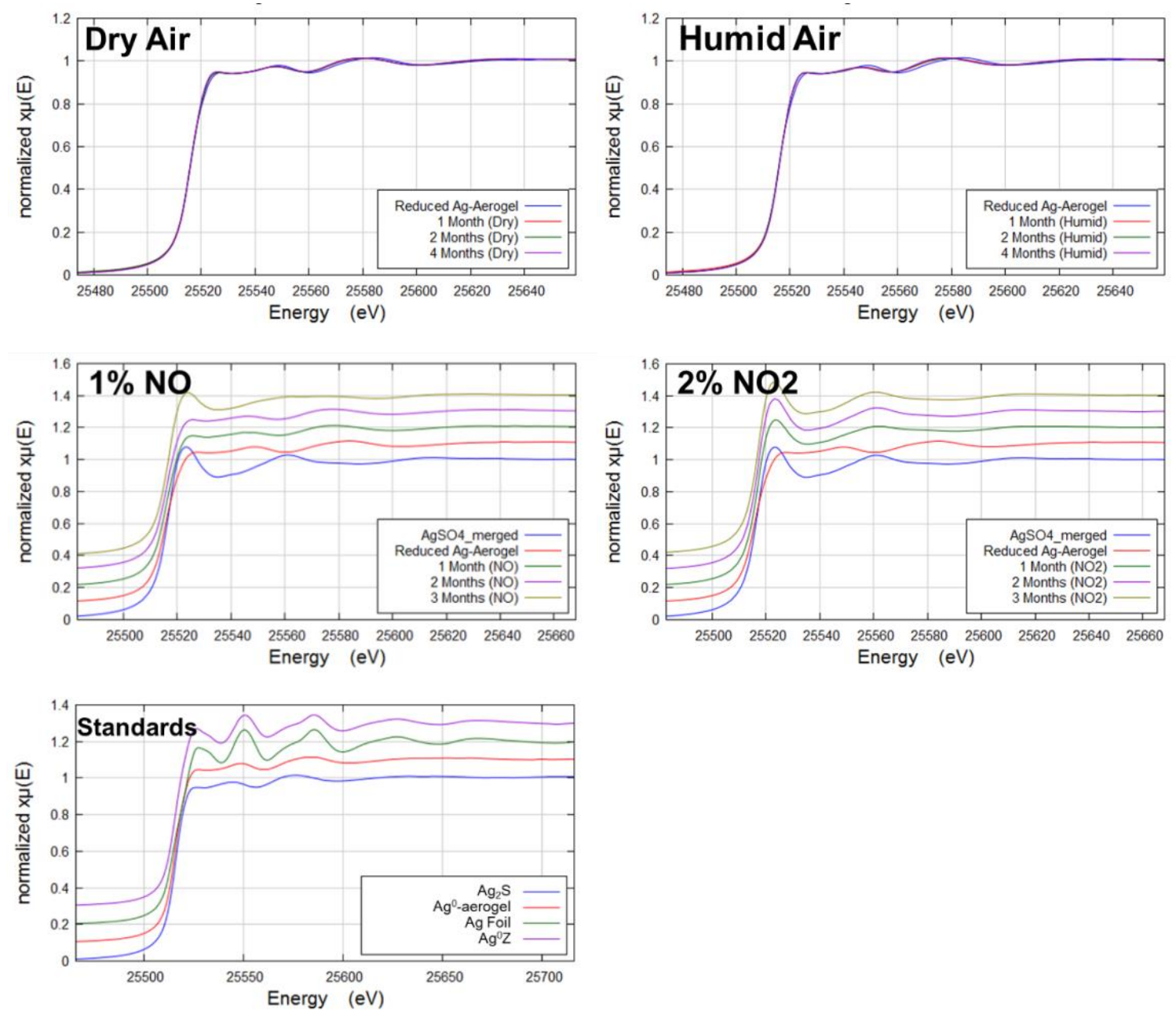

Figure 25. XANES spectra of $\mathrm{Ag}^{0}$-aerogel samples.

\subsubsection{Aging Mechanisms of $\mathrm{Ag}^{0}$-Aerogel}

Results from experiments and material analyses above suggest that the aging processes of the $\mathrm{Ag}^{0}$-aerogel in dry air, humid air (d.p. $-15^{\circ} \mathrm{C}$ ), $1 \% \mathrm{NO} / \mathrm{N}_{2}$, and $2 \% \mathrm{NO}_{2} /$ dry air take place through the oxidation of $\mathrm{Ag}^{0}$ to $\mathrm{Ag}_{2} \mathrm{~S}$ or $\mathrm{Ag}_{2} \mathrm{SO}_{4}$. Similar phenomena of $\mathrm{Ag}^{0}$ oxidation in the aging process of the $\mathrm{Ag}^{0}$-aerogel were observed in a previous study. ${ }^{30}$ The pathway of the aging processes can be expressed using oxidation reactions for both Ag particles and HS- functional groups, which were attached to aerogel surface. The HS- groups were oxidized under the aging 
conditions and reacted with the $\mathrm{Ag}^{+}$to form $\mathrm{Ag}_{2} \mathrm{~S}$ or $\mathrm{Ag}_{2} \mathrm{SO}_{4}$. The processes of reduction of $\mathrm{Ag}$ aerogel, aging of $\mathrm{Ag}^{0}$-aerogel, and $\mathrm{I}_{2}$ adsorption on aged $\mathrm{Ag}^{0}$-aerogel are demonstrated in Figure 26.

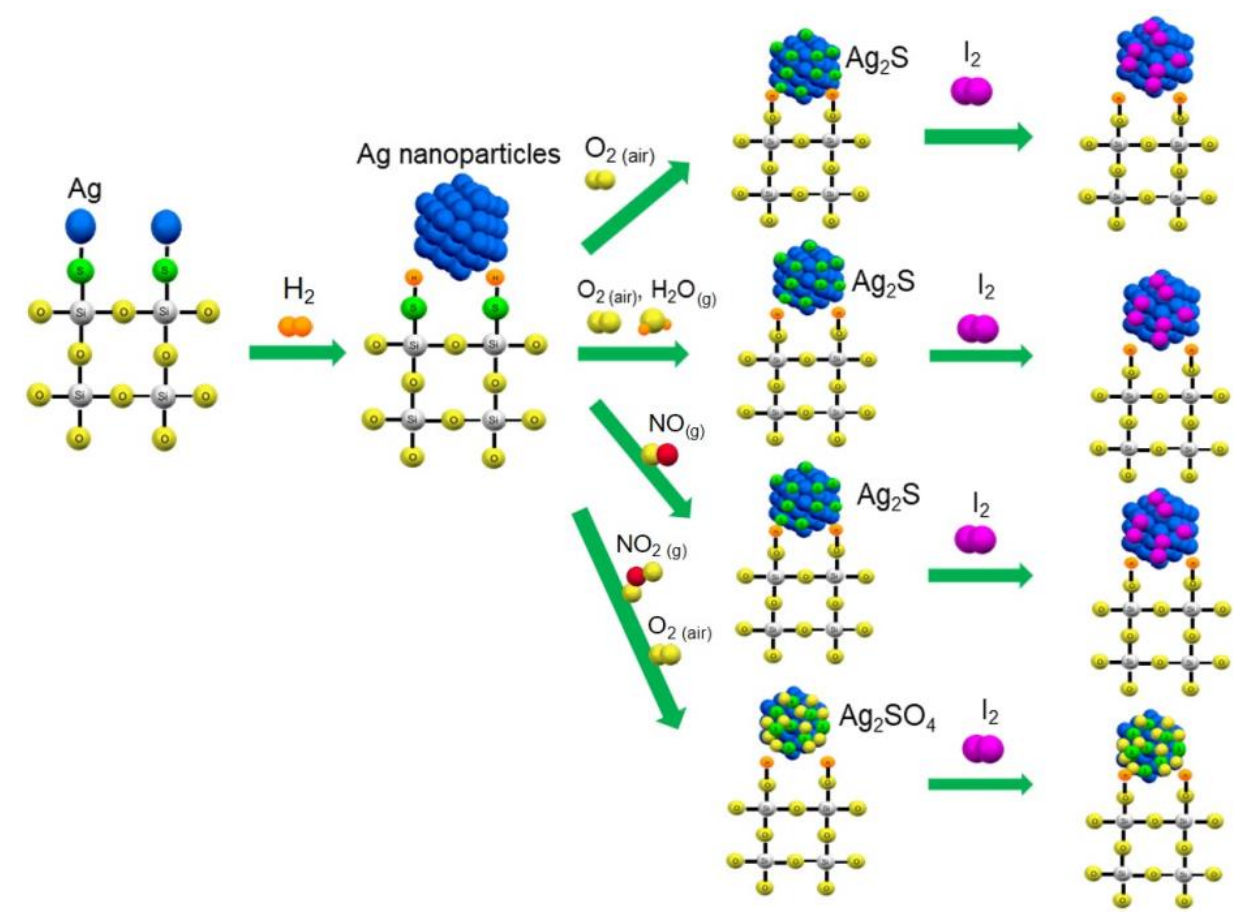

Figure 26. Mechanisms of reduction of $\mathrm{Ag}^{0}$-aerogel, aging of $\mathrm{Ag}^{0}$-aerogel, and $\mathrm{I}_{2}$ adsorption on aged $\mathrm{Ag}^{0}$-aerogel.

The chemical reactions for the aging process in each gas are shown below. In dry air and humid air shown in Eqns. (26) and (27), $\mathrm{HS}^{-}$on the surface of aerogel structure is oxidized by $\mathrm{O}_{2}$ in dry air or humid air. Consequent reaction of $\mathrm{S}^{2-}$ with $\mathrm{Ag}^{+}$, which is oxidized from $\mathrm{Ag}^{0}$ by $\mathrm{O}_{2}$ in dry air or humid air, occurs to form $\mathrm{Ag}_{2} \mathrm{~S}$. In $1 \% \mathrm{NO} / \mathrm{N}_{2}$ shown in Eqn. (28), HS- is oxidized by $\mathrm{NO}$ gas, and then $\mathrm{S}^{2-}$ reacts with $\mathrm{Ag}^{+}$, which is formed from $\mathrm{Ag}^{0}$ oxidized by $\mathrm{NO}$ gas, to form $\mathrm{Ag}_{2} \mathrm{~S}$. In $2 \% \mathrm{NO}_{2} /$ dry air shown in Eqn. (29), $\mathrm{HS}^{-}$is oxidized by $\mathrm{NO}_{2}$ gas, followed by reaction of $\mathrm{SO}_{4}{ }^{2-}$ with $\mathrm{Ag}^{+}$, which is oxidized from $\mathrm{Ag}^{0}$ by $\mathrm{NO}_{2}$ gas, to produce $\mathrm{Ag}_{2} \mathrm{SO}_{4}$. These mechanisms are suggested from the results of XRD and XPS which indicated the product, $\mathrm{Ag}_{2} \mathrm{~S}$ and $\mathrm{Ag}_{2} \mathrm{SO}_{4}$. Also, it was suggested that a $\mathrm{OH}^{-}$was produced from the oxidation of a $\mathrm{HS}^{-}$.

In dry air:

$$
\mathrm{O}_{2}+4 \mathrm{Ag}+2 \mathrm{HS}^{-} \longleftrightarrow 2 \mathrm{Ag}_{2} \mathrm{~S}+2 \mathrm{HO}^{-}
$$

In humid air:

$$
\mathrm{O}_{2}+4 \mathrm{Ag}+2 \mathrm{HS}^{-} \stackrel{\mathrm{H}_{2} \mathrm{O}}{\longleftrightarrow} 2 \mathrm{Ag}_{2} \mathrm{~S}+2 \mathrm{HO}^{-}
$$

In $1 \% \mathrm{NO} / \mathrm{N}_{2}:$

$$
2 \mathrm{NO}+4 \mathrm{Ag}+2 \mathrm{HS}^{-} \longleftrightarrow 2 \mathrm{Ag}_{2} \mathrm{~S}+\mathrm{N}_{2}+2 \mathrm{HO}^{-}
$$

In $2 \% \mathrm{NO}_{2} /$ dry air: 


$$
2 \mathrm{NO}_{2}+4 \mathrm{Ag}+3 \mathrm{O}_{2}+2 \mathrm{HS}^{-} \longleftrightarrow 2 \mathrm{Ag}_{2} \mathrm{SO}_{4}+\mathrm{N}_{2}+2 \mathrm{HO}^{-}
$$

\subsubsection{Kinetics for Aging Processes on $\mathbf{A g}^{\mathbf{0}}$-Aerogel}

The effects of dry air, humid air, $1 \% \mathrm{NO} / \mathrm{N}_{2}$, and $2 \% \mathrm{NO}_{2} /$ air on the performance of $\mathrm{Ag}^{0}-$ aerogel aged at $150^{\circ} \mathrm{C}$ for up to 6 months were discussed above. Aging $\mathrm{Ag}^{0}$-aerogel in dry air, humid air $\left(\right.$ d.p. $\left.-15^{\circ} \mathrm{C}\right), 1 \% \mathrm{NO} / \mathrm{N}_{2}$, and $2 \% \mathrm{NO}_{2} /$ air reduces the material's iodine loading capacity. The most significant impact on iodine capacity for $\mathrm{Ag}^{0}$-aerogel was observed for samples aged in $2 \% \mathrm{NO}_{2} /$ air. For instance, the $\mathrm{Ag}^{0}$-aerogel aged in $2 \% \mathrm{NO}_{2} /$ air at $150{ }^{\circ} \mathrm{C}$ lost $>80 \%$ of its iodine capacity within 1 month. To obtain insight into the kinetics of $\mathrm{Ag}^{0}$-aerogel aging, experiments were performed at different temperatures $\left(100{ }^{\circ} \mathrm{C}\right.$ to $150{ }^{\circ} \mathrm{C}$ ) for various periods of time (1 day to 1 month).

Iodine loading data for each aged $\mathrm{Ag}^{0}$-aerogel sample were obtained and compared with the deactivation data from the chemical analyses discussed above since the iodine capacity loss should be consistent with the amount of Ag oxidized. Figure 27 shows the kinetic data for the iodine loading capacities on $\mathrm{Ag}^{0}$-aerogel aged in different gas streams including dry air, humid air, $1 \% \mathrm{NO} / \mathrm{N}_{2}$, and $2 \% \mathrm{NO}_{2} /$ air at different temperatures $\left(100^{\circ} \mathrm{C}, 125^{\circ} \mathrm{C}\right.$, and $\left.150^{\circ} \mathrm{C}\right)$ for aging times between 1 day and 1 month. The kinetic data shown in Figure 27 indicate that the iodine loading capacity of aged $\mathrm{Ag}^{0}$-aerogel decreases with increasing aging temperatures and aging times. This means that dry air, humid air, $1 \% \mathrm{NO}$, and $2 \% \mathrm{NO}_{2}$ have a negative impact on the iodine loading capacity of $\mathrm{Ag}^{0}$-aerogel. For example, the iodine loading capacities for $\mathrm{Ag}^{0}$-aerogel aged in dry air (Figure 27 (A)) were reduced by $7.5 \%, 14.9 \%$, and $19.7 \%$ at $100{ }^{\circ} \mathrm{C}, 125^{\circ} \mathrm{C}$, and $150{ }^{\circ} \mathrm{C}$ after 1 month, respectively. Iodine loading capacities for $\mathrm{Ag}^{0}$-aerogel aged in humid air (d.p. $-15^{\circ} \mathrm{C}$, Figure $27(\mathbf{B})$ ) dropped by $11 \%, 15.3 \%$, and $18.2 \%$ at $100{ }^{\circ} \mathrm{C}, 125^{\circ} \mathrm{C}$, and $150{ }^{\circ} \mathrm{C}$ after 1 month, respectively. Iodine loading capacities for $\mathrm{Ag}^{0}$-aerogel aged in $1 \% \mathrm{NO}$ (Figure 27 (C)) decreased by $12.3 \%, 12.8 \%$, and $22.9 \%$ at $100{ }^{\circ} \mathrm{C}, 125^{\circ} \mathrm{C}$, and $150{ }^{\circ} \mathrm{C}$, respectively, after 1 month. Iodine loading capacities for $\mathrm{Ag}^{0}$-aerogel aged in $2 \% \mathrm{NO}_{2}$ (Figure 27 (D)) declined by 44.6\%, 58.8\%, and $78.2 \%$ at $100{ }^{\circ} \mathrm{C}, 125^{\circ} \mathrm{C}$, and $150{ }^{\circ} \mathrm{C}$, respectively, after 2 weeks. These results revealed an aging effect of $\mathrm{NO}_{2}>\mathrm{NO}=$ humid air = dry air in terms of capacity loss, which shows $\mathrm{NO}_{2}$ has

the most adverse impact on the iodine loading capacity of $\mathrm{Ag}^{0}$-aerogel over all aging times and temperatures. 

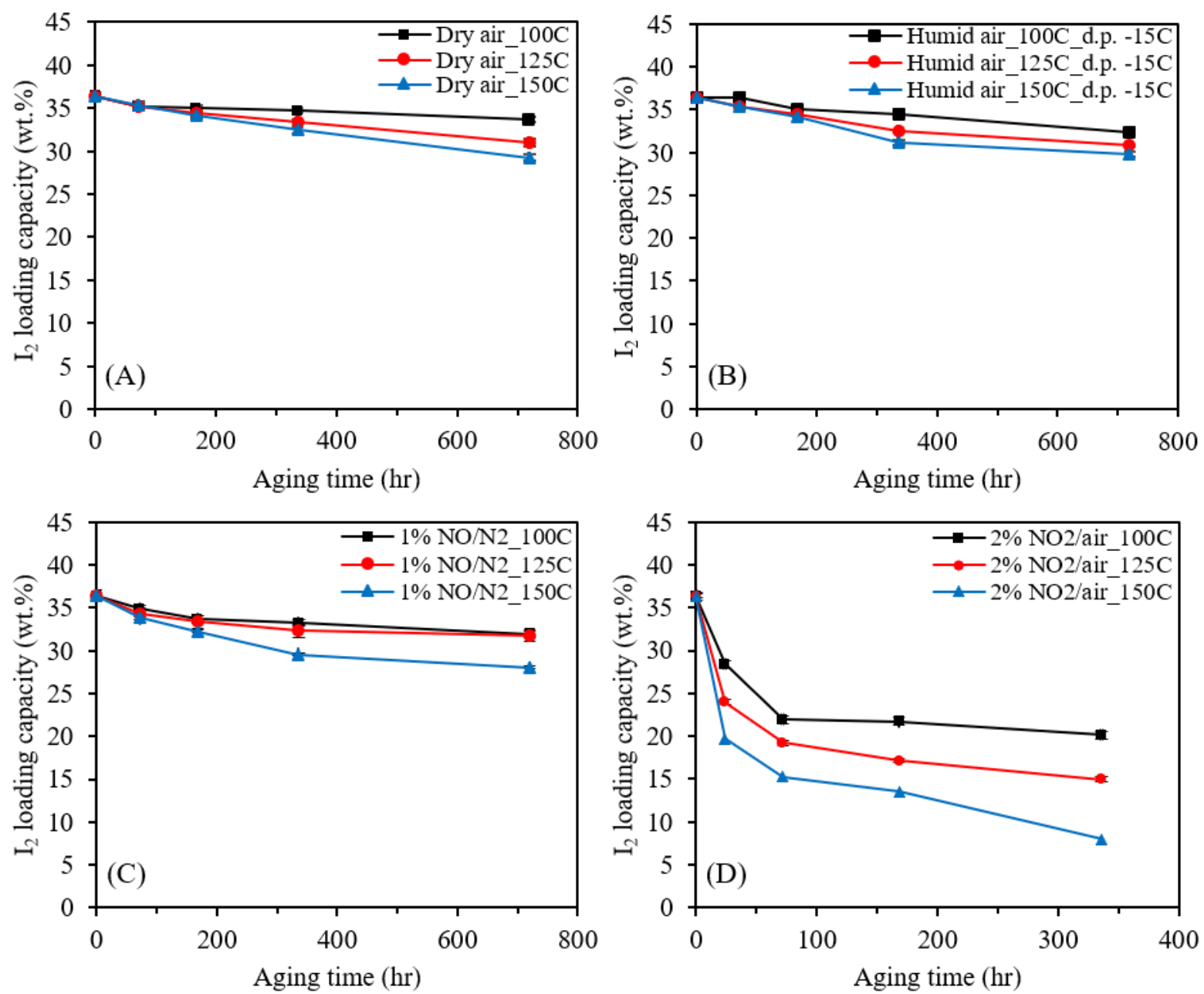

Figure 27. Kinetic data on $\mathrm{I}_{2}$ adsorption capacity of $\mathrm{Ag}^{0}$-aerogel aged in dry air (A), humid air (B), $1 \% \mathrm{NO} / \mathrm{N}_{2}(\mathrm{C})$, and $2 \% \mathrm{NO}_{2} /$ air (D) at different aging time and temperature.

\subsubsection{Modeling}

The kinetic data, chemical analyses, and mechanisms discussed above showed that the aging processes for $\mathrm{Ag}^{0}$-aerogel in all gas streams are controlled by the oxidation of $\mathrm{Ag}^{0}$ to $\mathrm{Ag}_{2} \mathrm{~S}$ or $\mathrm{Ag}_{2} \mathrm{SO}_{4}$. This involves the oxidation of both $\mathrm{Ag}^{0}$ particles and HS- functional groups attached to the aerogel. The aging experiments in this study were conducted under a continuous flow system such that the gas concentrations in each stream were constant throughout the aging process. Therefore, the pseudo reversible reaction model was applied to describe the kinetics of the aging process on $\mathrm{Ag}^{0}$-aerogel. Modeling results for aged $\mathrm{Ag}^{0}$-aerogel in dry air, humid air, $1 \% \mathrm{NO} / \mathrm{N}_{2}$, and $2 \% \mathrm{NO}_{2}$ /air at different aging temperatures $\left(100{ }^{\circ} \mathrm{C}, 125^{\circ} \mathrm{C}\right.$, and $\left.150{ }^{\circ} \mathrm{C}\right)$ for up to 1 month are plotted in Figure 28 which includes the kinetic data shown in Figure 27.

Modeling results for the $\mathrm{Ag}^{0}$-aerogel aged in dry air at different temperatures for different aging times are shown in Figure 28 (A). Eqn. (30) represents a reaction equation for the kinetic model on the aging $\mathrm{Ag}^{0}$-aerogel in dry air shown in Figure 28 (A). $C_{A g}$ is the normalized concentration of silver which indicates the amount of $\mathrm{I}_{2}$ loaded on the aged $\mathrm{Ag}^{0}$-aerogel, $C_{\mathrm{O}_{2}}$ is the 
concentration of oxygen in dry air, $C_{A g^{+}}$is the concentration of silver oxidized by oxygen in dry air, $n$ is the reaction order, $k_{1}$ is the forward reaction rate constant, and $k_{-1}$ is the reverse reaction rate constant. Also, $C_{H^{-}}$and $C_{S^{-}}$are the concentration of $\mathrm{HS}^{-}$functional groups attached to aerogel surface and the concentration of $\mathrm{S}^{-}$oxidized by oxygen in dry air, respectively. Here, $k_{1}$ and $C_{\mathrm{O}_{2}}$ are lumped into $k_{1}{ }^{*}$ because the gas concentration was constant at all the times during the aging experiment. $C_{H S^{-}}$and $C_{S^{-}}$can be calculated using the stoichiometry in Eqn. (30) in terms of $\mathrm{Ag}^{0} . C_{\mathrm{Ag}^{+}}$can also be calculated by substracting the amount of $\mathrm{I}_{2}$ loaded on the aged $\mathrm{Ag}^{0}-$ aerogel from the amount of $\mathrm{I}_{2}$ loaded on the unaged $\mathrm{Ag}^{0}$-aerogel. The model parameters for all reaction models and the correlation coefficients $\left(\mathrm{R}^{2}\right)$ between experimental data and model results are shown in Table 2. These results indicate that the model is well fitted $\left(\mathrm{R}^{2}=0.988\right.$ at $\left.150^{\circ} \mathrm{C}\right)$ to experimental data when $\mathrm{n} \geq 1$, which means the Pseudo $1^{\text {st }}$ order reversible reaction model fits the experimental data (Figure 28 (A)). These results are consistent with experimental data (Figure 27 (A)), which show that the effect of aging on the $\mathrm{Ag}^{0}$-aerogel's iodine capacity increases with increasing aging time and temperature.

$$
\begin{gathered}
\mathrm{O}_{2}+4 \mathrm{Ag}+2 \mathrm{HS}^{-} \longleftrightarrow 2 \mathrm{Ag}_{2} \mathrm{~S}+2 \mathrm{HO}^{-} \\
\mathrm{v}=\frac{\mathrm{dC}_{\mathrm{Ag}}}{\mathrm{dt}}=-\mathrm{k}_{1}{ }^{*} \mathrm{C}_{\mathrm{HS}^{-}} \mathrm{C}_{\mathrm{Ag}}{ }^{\mathrm{n}}+\mathrm{k}_{-1} \mathrm{C}_{\mathrm{S}^{-}} \mathrm{C}_{\mathrm{Ag}^{+}}{ }^{\mathrm{n}} \\
\mathrm{k}_{1}{ }^{*}=\mathrm{k}_{1} \mathrm{C}_{\mathrm{O}_{2}} \\
1-\mathrm{C}_{\mathrm{HS}^{-}}=\mathrm{C}_{\mathrm{S}^{-}} \\
\mathrm{C}_{\mathrm{S}^{-}}=2 \mathrm{C}_{\mathrm{Ag}^{+}} \\
\mathrm{C}_{\mathrm{Ag}^{+}}=1-\mathrm{C}_{\mathrm{Ag}} \\
\mathrm{v}=\frac{\mathrm{dC}_{\mathrm{Ag}}}{\mathrm{dt}}=-\mathrm{k}_{1}{ }^{*} \mathrm{C}_{\mathrm{HS}^{-}} \mathrm{C}_{\mathrm{Ag}}+\mathrm{k}_{-1} \mathrm{C}_{\mathrm{S}^{-}} \mathrm{C}_{\mathrm{Ag}^{+}} \quad(\text { for } \mathrm{n}=1)
\end{gathered}
$$

Using a similar approach to the one used for $\mathrm{Ag}^{0}$-aerogel aged in dry air, modeling results for $\mathrm{Ag}^{0}$-aerogel aged in humid air, $1 \% \mathrm{NO} / \mathrm{N}_{2}$, and $2 \% \mathrm{NO}_{2} /$ air at different temperatures and aging times are shown in Figures 28 (B), (C), and (D). Reaction equations for each model are provided in Eqns. (31), (32), and (33). Comparing the correlation coefficient of each order model to the modeling results, the model is shown to be in good agreement with experimental data when $\mathrm{n} \geq 1$ for humid air and $1 \% \mathrm{NO} / \mathrm{N}_{2}$ aged $\mathrm{Ag}^{0}$-aerogel, and when $\mathrm{n} \geq 2$ for $2 \% \mathrm{NO}_{2} /$ air aged $\mathrm{Ag}^{0}$-aerogel. These modeling results indicate that the pseudo $1^{\text {st }}$ order reversible reaction models fit the experimental data for humid air aged $\mathrm{Ag}^{0}$-aerogel $\left(\mathrm{R}^{2}=0.985\right.$ at $\left.150^{\circ} \mathrm{C}\right)$ and $1 \% \mathrm{NO} / \mathrm{N}_{2}$ aged $\mathrm{Ag}^{0}-$ aerogel $\left(\mathrm{R}^{2}=0.985\right.$ at $\left.150^{\circ} \mathrm{C}\right)$, and that the pseudo $2^{\text {nd }}$ order reversible reaction model fits the experimental data for $2 \% \mathrm{NO}_{2} /$ air aged $\mathrm{Ag}^{0}$-aerogel $\left(\mathrm{R}^{2}=0.985\right.$ at $\left.150^{\circ} \mathrm{C}\right)$.

$$
\begin{aligned}
& \mathrm{O}_{2}+4 \mathrm{Ag}+2 \mathrm{HS}^{-} \stackrel{\mathrm{H}_{2} \mathrm{O}}{\longleftrightarrow} 2 \mathrm{Ag}_{2} \mathrm{~S}+2 \mathrm{HO}^{-} \\
& \mathrm{v}=\frac{\mathrm{dC}_{\mathrm{Ag}}}{\mathrm{dt}}=-\mathrm{k}_{1}{ }^{*} \mathrm{C}_{\mathrm{HS}^{-}} \mathrm{C}_{\mathrm{Ag}}{ }^{\mathrm{n}}+\mathrm{k}_{-1} \mathrm{C}_{\mathrm{S}^{-}} \mathrm{C}_{\mathrm{Ag}^{+}}{ }^{\mathrm{n}} \\
& \mathrm{k}_{1}{ }^{*}=\mathrm{k}_{1} \mathrm{C}_{\mathrm{H}_{2} \mathrm{O}} \mathrm{C}_{\mathrm{O}_{2}} \\
& \mathrm{v}=\frac{\mathrm{dC}}{\mathrm{Ag}}=-\mathrm{k}_{1}{ }^{*} \mathrm{C}_{\mathrm{HS}^{-}} \mathrm{C}_{\mathrm{Ag}}+\mathrm{k}_{-1} \mathrm{C}_{\mathrm{S}^{-}} \mathrm{C}_{\mathrm{Ag}^{+}} \quad(\text { for } \mathrm{n}=1)
\end{aligned}
$$




$$
\begin{aligned}
& 2 \mathrm{NO}+4 \mathrm{Ag}+2 \mathrm{HS}^{-} \longleftrightarrow 2 \mathrm{Ag}_{2} \mathrm{~S}+\mathrm{N}_{2}+2 \mathrm{HO}^{-} \\
& \mathrm{v}=\frac{\mathrm{dC}_{\mathrm{Ag}}}{\mathrm{dt}}=-\mathrm{k}_{1}{ }^{*} \mathrm{C}_{\mathrm{HS}^{-}} \mathrm{C}_{\mathrm{Ag}}{ }^{\mathrm{n}}+\mathrm{k}_{-1} \mathrm{C}_{\mathrm{S}^{-}} \mathrm{C}_{\mathrm{Ag}^{+}}{ }^{\mathrm{n}} \\
& \quad \mathrm{k}_{1}{ }^{*}=\mathrm{k}_{1} \mathrm{C}_{\mathrm{NO}} \\
& \mathrm{v}=\frac{\mathrm{dC}_{\mathrm{Ag}}}{\mathrm{dt}}=-\mathrm{k}_{1}{ }^{*} \mathrm{C}_{\mathrm{HS}^{-}} \mathrm{C}_{\mathrm{Ag}}+\mathrm{k}_{-1} \mathrm{C}_{\mathrm{S}^{-}} \mathrm{C}_{\mathrm{Ag}^{+}} \quad(\text { for } \mathrm{n}=1)
\end{aligned}
$$

$$
\begin{gathered}
2 \mathrm{NO}_{2}+4 \mathrm{Ag}+3 \mathrm{O}_{2}+2 \mathrm{HS}^{-} \longleftrightarrow 2 \mathrm{Ag}_{2} \mathrm{SO}_{4}+\mathrm{N}_{2}+2 \mathrm{HO}^{-} \\
\mathrm{v}=\frac{\mathrm{dC} \mathrm{Ag}}{\mathrm{dt}}=-\mathrm{k}_{1}{ }^{*} \mathrm{C}_{\mathrm{HS}^{-}} \mathrm{C}_{\mathrm{Ag}}{ }^{\mathrm{n}}+\mathrm{k}_{-1} \mathrm{C}_{\mathrm{S}^{-} \mathrm{C}_{\mathrm{Ag}^{+}}{ }^{\mathrm{n}}} \\
\mathrm{k}_{1}{ }^{*}=\mathrm{k}_{1} \mathrm{C}_{\mathrm{NO}_{2}} \\
\mathrm{v}=\frac{\mathrm{dC}_{\mathrm{Ag}}}{\mathrm{dt}}=-\mathrm{k}_{1}{ }^{*} \mathrm{C}_{\mathrm{HS}^{-}} \mathrm{C}_{\mathrm{Ag}^{2}}{ }^{2}+\mathrm{k}_{-1} \mathrm{C}_{\mathrm{S}^{-}} \mathrm{C}_{\mathrm{Ag}^{+}}{ }^{2} \quad(\text { for } \mathrm{n}=2)
\end{gathered}
$$
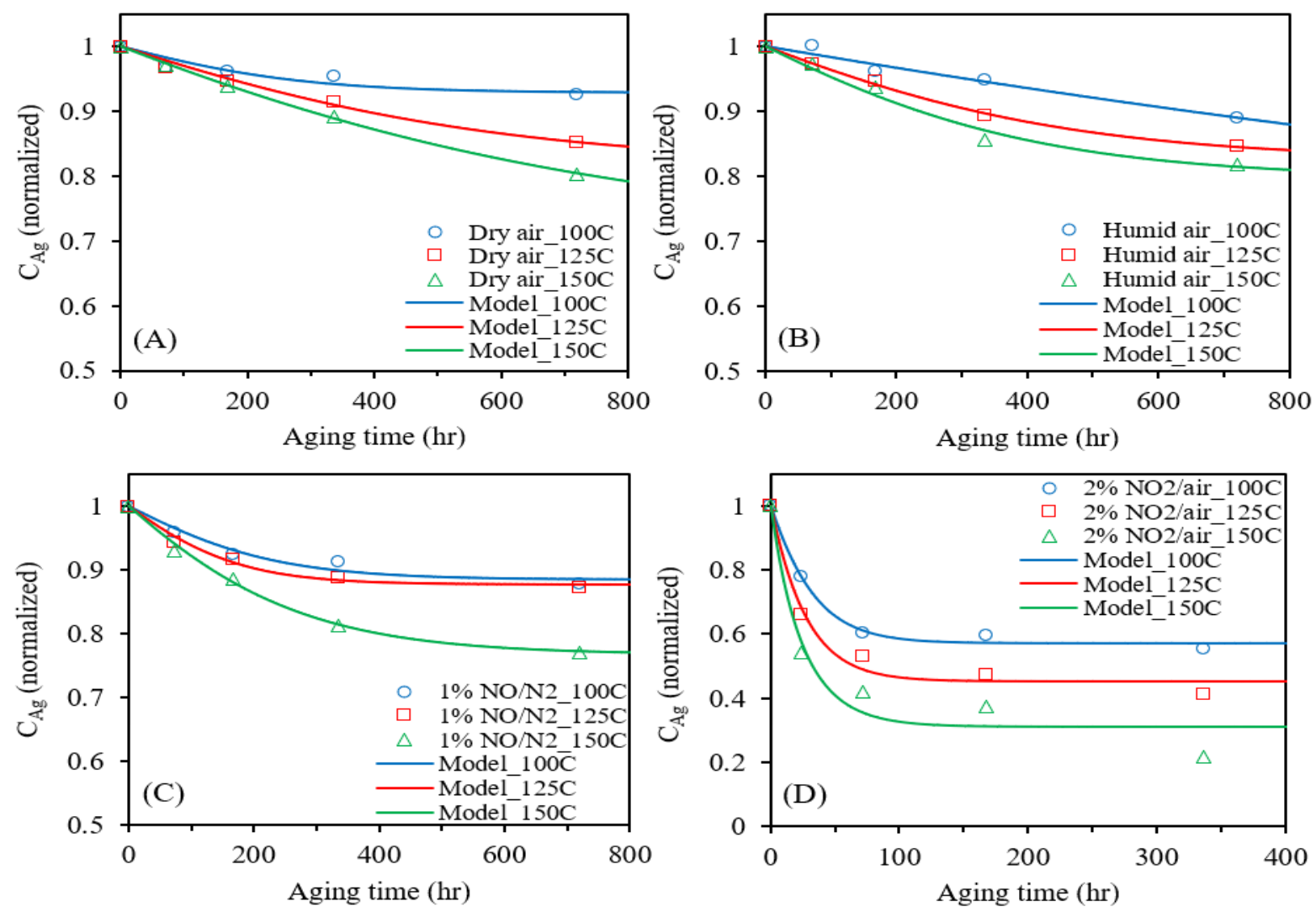

Figure 28. Pseudo reaction models on $\mathrm{Ag}^{0}$-aerogel aged in dry air (A), humid air (B), $1 \% \mathrm{NO} / \mathrm{N}_{2}$ (C), and 2\% $\mathrm{NO}_{2} /$ air (D) at different aging temperatures and time. 
Table 2. Variables and Model Parameters for the Pseudo Reaction Model

\begin{tabular}{|c|c|c|c|c|c|c|c|c|c|}
\hline $\begin{array}{c}\mathrm{T} \\
\left({ }^{\circ} \mathrm{C}\right)\end{array}$ & $\begin{array}{l}\text { D.P. } \\
\left({ }^{\circ} \mathrm{C}\right)\end{array}$ & $\begin{array}{c}\mathrm{C}_{\mathrm{H}_{2} \mathrm{O}} \\
\left(\mathrm{mol} / \mathrm{m}^{3}\right)\end{array}$ & $\begin{array}{c}\mathrm{C}_{\mathrm{O}_{2}} \\
\left(\mathrm{~mol} / \mathrm{m}^{3}\right)\end{array}$ & $\begin{array}{c}\mathrm{C}_{\mathrm{NO}} \\
\left(\mathrm{mol} / \mathrm{m}^{3}\right)\end{array}$ & $\begin{array}{c}\mathrm{C}_{\mathrm{NO}_{2}} \\
\left(\mathrm{~mol} / \mathrm{m}^{3}\right)\end{array}$ & $\begin{array}{c}\mathrm{k}_{1}{ }^{*} \\
\left(\mathrm{hr}^{-1}\right)\end{array}$ & $\begin{array}{c}\mathrm{k}_{1} \\
\left(\left(\mathrm{~mol} / \mathrm{m}^{3}\right)^{-1} \cdot \mathrm{hr}^{-1}\right)\end{array}$ & $\begin{array}{c}\mathrm{k}_{-1} \\
\left(\mathrm{hr}^{-1}\right)\end{array}$ & $\mathrm{R}^{2}$ \\
\hline \multicolumn{10}{|l|}{ Dry air } \\
\hline 100 & -70 & - & 8.59 & - & - & $8.28 \mathrm{E}-5$ & $9.73 \mathrm{E}-5$ & 0.022 & $0.940^{\mathrm{a}}$ \\
\hline 125 & -70 & - & 8.59 & - & - & $1.04 \mathrm{E}-4$ & $3.33 \mathrm{E}-3$ & $3.33 \mathrm{E}-3$ & $0.996^{\mathrm{a}}$ \\
\hline 150 & -70 & - & 8.59 & - & - & $1.26 \mathrm{E}-4$ & $2.4 \mathrm{E}-4$ & $1.27 \mathrm{E}-3$ & $0.999^{\mathrm{a}}$ \\
\hline \multicolumn{10}{|c|}{ Humid air } \\
\hline 100 & -15 & 0.067 & 8.59 & - & - & $5.69 \mathrm{E}-5$ & 0.064 & $3.26 \mathrm{E}-4$ & $0.982^{\mathrm{a}}$ \\
\hline 125 & -15 & 0.067 & 8.59 & - & - & $1.26 \mathrm{E}-4$ & 0.090 & $4.57 \mathrm{E}-3$ & $0.998^{\mathrm{a}}$ \\
\hline 150 & -15 & 0.067 & 8.59 & - & - & $1.66 \mathrm{E}-4$ & 0.080 & $4.20 \mathrm{E}-3$ & $0.992^{\mathrm{a}}$ \\
\hline \multicolumn{10}{|l|}{$1 \% \mathrm{NO}$} \\
\hline 100 & - & - & - & 0.409 & - & $1.67 \mathrm{E}-4$ & 0.014 & 0.015 & $0.979^{\mathrm{a}}$ \\
\hline 125 & - & - & - & 0.409 & - & $2.36 \mathrm{E}-4$ & 0.029 & 0.019 & $0.993^{\mathrm{a}}$ \\
\hline 150 & - & - & - & 0.409 & - & $2.88 \mathrm{E}-4$ & 0.039 & 0.005 & $0.965^{\mathrm{a}}$ \\
\hline \multicolumn{10}{|l|}{$2 \% \mathrm{NO}_{2}$} \\
\hline 100 & - & - & - & - & 0.818 & $4.05 \mathrm{E}-3$ & 3.873 & 0.014 & $0.997^{\mathrm{b}}$ \\
\hline 125 & - & - & - & - & 0.818 & $6.51 \mathrm{E}-3$ & 7.626 & $9.39 \mathrm{E}-3$ & $0.994^{\mathrm{b}}$ \\
\hline 150 & - & - & - & - & 0.818 & $9.79 \mathrm{E}-3$ & 10.302 & $5.24 \mathrm{E}-3$ & $0.986^{\mathrm{b}}$ \\
\hline
\end{tabular}

${ }^{a}$ for $\mathrm{n}=1$ in Eqns. (30), (31), and (32)

${ }^{b}$ for $n=2$ in Eqn. (33)

\subsection{Aging Effects of Off-Gas Mixture on $\mathrm{Ag}^{0} \mathrm{Z}$ and $\mathrm{Ag}^{0}$-Aerogel}

Both $\mathrm{Ag}^{0} \mathrm{Z}$ and $\mathrm{Ag}^{0}$-aerogel lost iodine capacity when aged in dry air, humid air, $1 \% \mathrm{NO} / \mathrm{N}_{2}$, and $2 \% \mathrm{NO}_{2}$ /air, and the magnitute of these losses increased with increasing aging time and temperature, as discussed above. The most significant impact on iodine capacity was observed for $2 \% \mathrm{NO}_{2}$ /air aged $\mathrm{Ag}^{0} \mathrm{Z}$ and $\mathrm{Ag}^{0}$-aerogel. Since a gas mixture of humid air, $\mathrm{NO}$, and $\mathrm{NO}_{2}$ will be formed to a $\mathrm{NO}_{2}$ gas $^{33}$, the kinetics of the aging process for $\mathrm{Ag}^{0} \mathrm{Z}$ in that gas mixture will be similar to that of $\mathrm{Ag}^{0} \mathrm{Z}$ aged in $2 \% \mathrm{NO}_{2} /$ air. To validate the impact of the humid air and $\mathrm{NO}_{\mathrm{x}}$ gas mixture, the effects of the gas mixture on both $\mathrm{Ag}^{0} \mathrm{Z}$ and $\mathrm{Ag}^{0}$-aerogel were investigated. To produce the gas mixture, the experimental system for aging was revised as shown in Figure 2, while using the same experimental systems (Figure 4) for iodine loading.

\subsubsection{Kinetics for Aging Processes on $\mathrm{Ag}^{0} \mathrm{Z}$}

Figure 29 shows the kinetic data for iodine loading on $\mathrm{Ag}^{0} \mathrm{Z}$ aged in the $0.25 \% \mathrm{NO}, 0.5 \%$ $\mathrm{NO}_{2}$ in humid air (d.p. $-15^{\circ} \mathrm{C}$ ) gas mixture prepared by diluting $1 \% \mathrm{NO} / \mathrm{N}_{2}$ and $2 \% \mathrm{NO}_{2} /$ air in humid air (d.p. $-15^{\circ} \mathrm{C}$ ) at $150^{\circ} \mathrm{C}$ for aging times between 10 minutes and 5 hours. The kinetic data in Figure 29 show that iodine loading capacities on the gas-mixture aged $\mathrm{Ag}^{0} \mathrm{Z}$ decreases substantially with increasing aging time. The iodine capacity of the gas-mixture aged $\mathrm{Ag}^{0} \mathrm{Z}$ 
dropped by $86.5 \%$ at $150{ }^{\circ} \mathrm{C}$ after 5 hours, for example. These results revealed the effect of aging for the gas mixture is greater than the aging effect of any of the component gases individually since $\mathrm{Ag}^{0} \mathrm{Z}$ aged in the gas mixture has similar $\mathrm{I}_{2}$ capacity losses to $2 \% \mathrm{NO}_{2}$ /air aged $\mathrm{Ag}^{0} \mathrm{Z}$ despite having a lower concentration of $\mathrm{NO}$ and $\mathrm{NO}_{2}$ in the gas mixture.

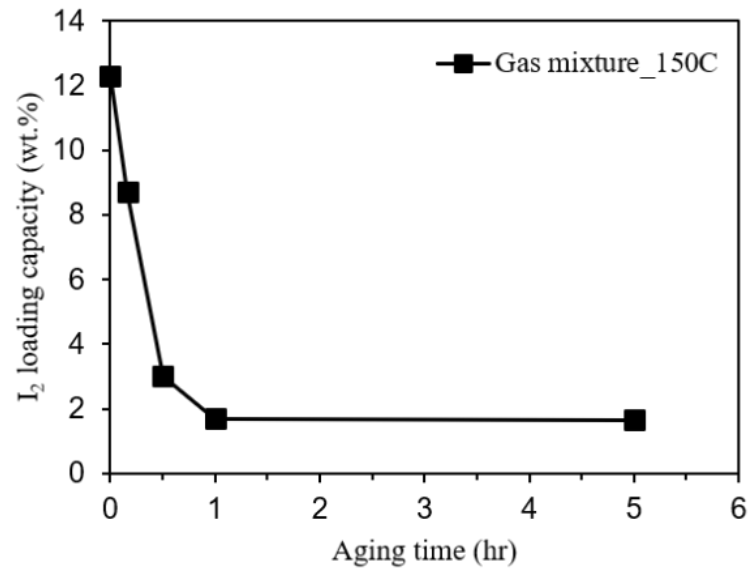

Figure 29. Kinetic data on $\mathrm{I}_{2}$ loading capacity of $\mathrm{Ag}^{0} \mathrm{Z}$ aged in gas mixture, containing $99.25 \%$ humid-air (dew point of $-15{ }^{\circ} \mathrm{C}$ ), $0.25 \% \mathrm{NO}$, and $0.5 \% \mathrm{NO}_{2}$, at $150{ }^{\circ} \mathrm{C}$ for different aging time.

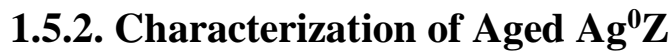

\subsubsection{Scanning Electron Microscope}

SEM (backscattered electron composition) images of $\mathrm{Ag}^{0} \mathrm{Z}$ and aged $\mathrm{Ag}^{0} \mathrm{Z}$ samples are displayed in Figure 30. Small particles (white dots) are observed on the surface of the mordenite crystals. According to the SEM analyses discussed above, these particles should be $\mathrm{Ag}^{0} \mathrm{particles}$ The images show that $\mathrm{Ag}^{0}$ particles disappeared from the surface of the aged mordenite crystals. These results are consistent with those of the $\mathrm{I}_{2}$ adsorption tests that showed the $\mathrm{I}_{2}$ loading capacity of gas-mixture aged $\mathrm{Ag}^{0} \mathrm{Z}$ decreasing with increasing aging time as shown in Figure 29. Additionally, these results suggest that there are no other chemical composites compared to SEM images of the aged $\mathrm{Ag}^{0} \mathrm{Z}$ in gas streams discussed above (Figure 9). 

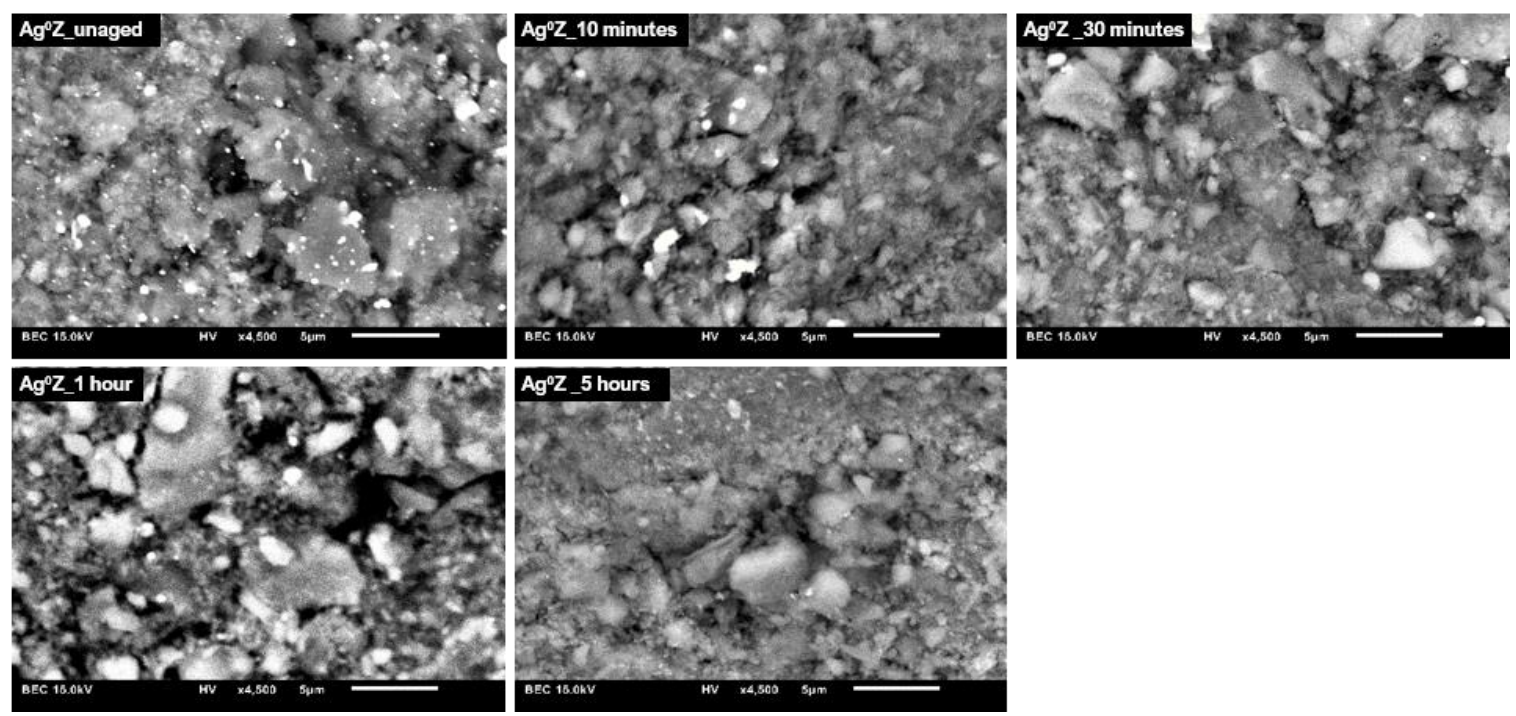

Figure 30. SEM images of $\mathrm{Ag}^{0} \mathrm{Z}$ and aged $\mathrm{Ag}^{0} \mathrm{Z}$ samples in gas mixture, containing $99.25 \%$ humid air (dew point of $-15^{\circ} \mathrm{C}$ ), $0.25 \% \mathrm{NO}$, and $0.5 \% \mathrm{NO}_{2}$, for 10 minutes, 30 minutes, 1 hour, and 5 hours at $150{ }^{\circ} \mathrm{C}$.

\subsubsection{X-ray Powder Diffraction}

The XRD patterns for unaged and aged $\mathrm{Ag}^{0} \mathrm{Z}$ samples in the gas mixture at $150{ }^{\circ} \mathrm{C}$ are shown in Figure 31. A decrease in the intensity of the $\mathrm{Ag}^{0}$ peaks was observed when $\mathrm{Ag}^{0} \mathrm{Z}$ was exposed to the gas mixture which was expected given the $\mathrm{Ag}^{0} \mathrm{Z}$ aged in the gas mixture has similar features to $\mathrm{Ag}^{0} \mathrm{Z}$ aged in $2 \% \mathrm{NO}_{2}$. This is because a gas mixture of humid air, $\mathrm{NO}$, and $\mathrm{NO}_{2}$ will be formed to a $\mathrm{NO}_{2} \mathrm{gas}^{33}$. The decrease in $\mathrm{Ag}^{0}$ should be due to the oxidation of $\mathrm{Ag}^{0}$ to $\mathrm{Ag}+$ by the aging gas mixture. It was shown that $\mathrm{Ag}^{0}$ was totally oxidized resulting in XRD patterns similar to that of $\mathrm{AgZ}$ as discussed above. It was noted that the $\mathrm{I}_{2}$ adsorption loading capacity (Figure 29) decreased correspondingly with the decrease in $\mathrm{Ag}^{0}$ resulting from the oxidation of $\mathrm{Ag}^{0}$ to $\mathrm{Ag}^{+}$by the aging gases. This explains that $\mathrm{I}_{2}$ only reacted with the $\mathrm{Ag}^{0}$ in the aged $\mathrm{Ag}^{0} \mathrm{Z}$, and the oxidized $\mathrm{Ag}^{+}$was somehow inactive to $\mathrm{I}_{2}$.

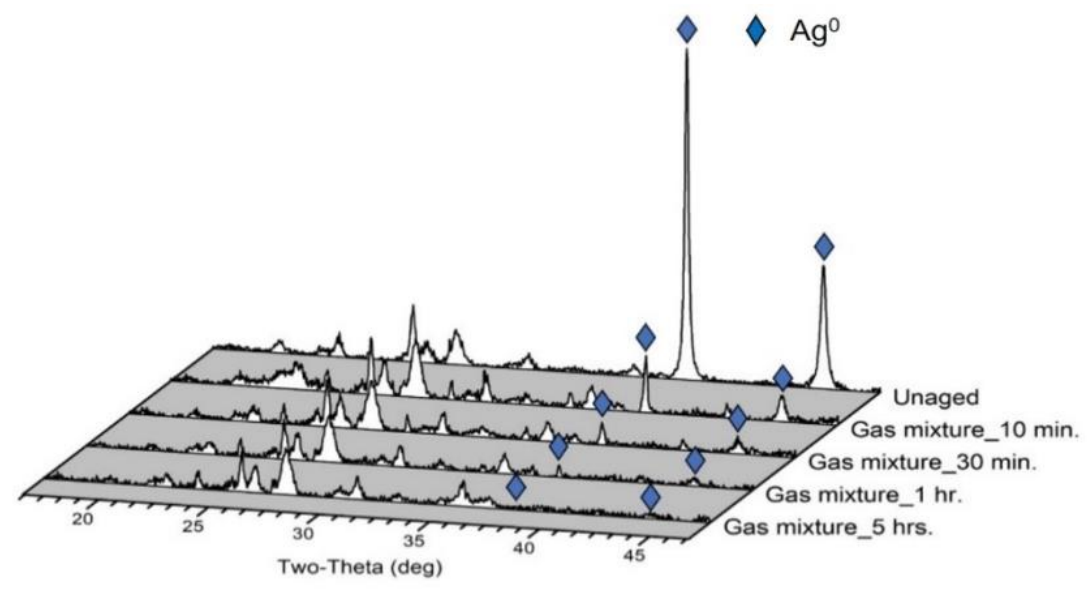

Figure 31. XRD patterns of the unaged $\mathrm{AgZ}$ and aged $\mathrm{Ag}^{0} \mathrm{Z}$ in gas mixture, containing 99.25\% humid air (dew point of $-15{ }^{\circ} \mathrm{C}$ ), $0.25 \% \mathrm{NO}$, and $0.5 \% \mathrm{NO}_{2}$, at $150{ }^{\circ} \mathrm{C}$. 


\subsubsection{Modeling for Aged $\mathrm{Ag}^{0} \mathrm{Z}$}

Using a similar approach to the one used for aged $\mathrm{Ag}^{0} \mathrm{Z}$ that is mentioned above, modeling results for the gas-mixture aged $\mathrm{Ag}^{0} \mathrm{Z}$ for different aging times at $150^{\circ} \mathrm{C}$ are shown in Figure 32 . Eqn. (34) represents an overall oxidation reaction for the kinetic model of $\mathrm{Ag}^{0} \mathrm{Z}$ aged in the gas mixture shown in Figure 32. Reactions of gas components in the gas mixture will occur via intermediate reactions, Eqns (35) - (37) ${ }^{33}$, which form a $\mathrm{NO}_{2}$ gas. Considering that the gas mixture produces the $\mathrm{NO}_{2}$ gas, a reaction equation for the kinetic model can be represented as shown in Eqn. (38), which is similar to Eqn. (25). $C_{\mathrm{O}_{2}}$ is the concentration of oxygen in gas mixture, $C_{\mathrm{H}_{2} \mathrm{O}}$ is the concentration of water in gas mixture, $C_{\mathrm{NO}}$ is the concentration of $\mathrm{NO}$ in gas mixture, $\mathrm{C}_{\mathrm{NO}_{2}}$ is the concentration of $\mathrm{NO}_{2}$ in gas mixture. Here, $k_{1}, C_{\mathrm{O}_{2}}, C_{\mathrm{H}_{2} \mathrm{O}}, C_{\mathrm{NO}}$, and $\mathrm{C}_{\mathrm{NO}_{2}}$ are lumped into $k_{1}{ }^{*}$ because the gas mixture will produce the $\mathrm{NO}_{2}$ gas and the gas concentration was constant at all times during the aging experiment. The parameters for the reaction model and the correlation coefficients $\left(\mathrm{R}^{2}\right)$ between experimental data and model results are shown in Table 3. These results indicate that the model is well fitted $\left(\mathrm{R}^{2}=0.988\right)$ to experimental data when $\mathrm{n} \geq 1$, which means the Pseudo $1^{\text {st }}$ order irreversible reaction model fits the experimental data. These results are consistent with experimental data (Figure 29) that the effect of aging from the gas mixture on $\mathrm{Ag}^{0} \mathrm{Z}$ increases with increasing aging time and temperatures.

$$
\begin{gathered}
\mathrm{O}_{2}+5 \mathrm{H}_{2} \mathrm{O}+\mathrm{NO}+\mathrm{NO}_{2}+10 \mathrm{Ag} \longleftrightarrow 10 \mathrm{Ag}_{\mathrm{s}}{ }^{+}+10 \mathrm{HO}^{-}+\mathrm{N}_{2} \\
2 \mathrm{NO}+\mathrm{O}_{2} \longrightarrow 2 \mathrm{NO}_{2} \\
\mathrm{NO}_{2}+\mathrm{NO} \longrightarrow \mathrm{N}_{2} \mathrm{O}_{3} \\
\mathrm{~N}_{2} \mathrm{O}_{3}+\mathrm{H}_{2} \mathrm{O} \longrightarrow 2 \mathrm{NO}_{2}{ }^{-}+2 \mathrm{H}^{+} \\
\mathrm{v}=\frac{\mathrm{dC} \mathrm{Ag}}{\mathrm{dt}}=-\mathrm{k}_{1}{ }^{*} \mathrm{C}_{\mathrm{Ag}}{ }^{\mathrm{n}} \\
\mathrm{k}_{1}{ }^{*}=\mathrm{k}_{1} \mathrm{C}_{\mathrm{NO}_{2}{ }^{*}} \\
\mathrm{C}_{\mathrm{NO}_{2}}{ }^{*}=\mathrm{C}_{\mathrm{O}_{2}} \mathrm{C}_{\mathrm{H}_{2} \mathrm{O}_{\mathrm{NO}} \mathrm{C}_{\mathrm{NO}_{2}}} \\
\mathrm{v}=\frac{\mathrm{dC} \mathrm{Ag}_{\mathrm{Ag}}}{\mathrm{dt}}=-\mathrm{k}_{1}{ }^{*} \mathrm{C}_{\mathrm{Ag}} \quad(\text { for } \mathrm{n}=1)
\end{gathered}
$$

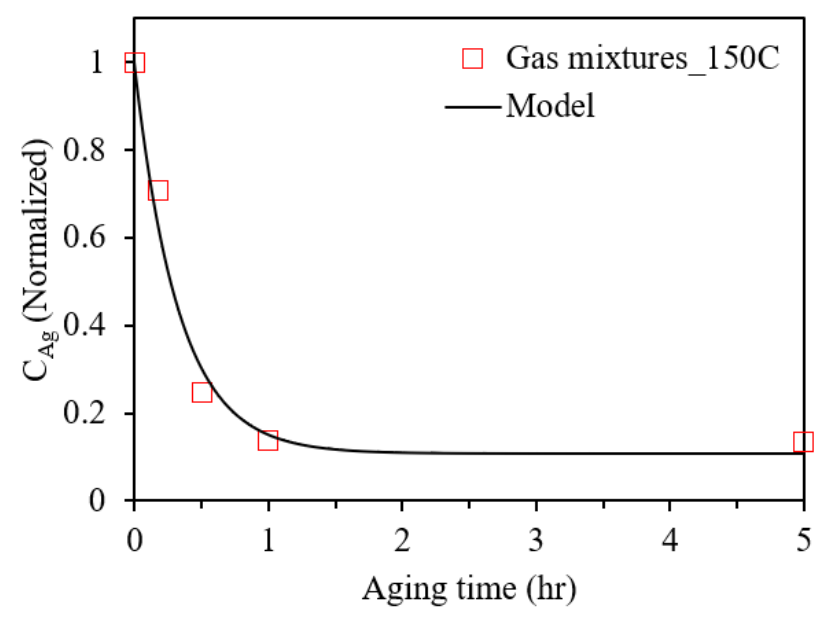

Figure 32. Pseudo reaction model on $\mathrm{Ag}^{0} \mathrm{Z}$ aged in gas mixture, containing $99.25 \%$ humid-air (dew point of $\left.-15{ }^{\circ} \mathrm{C}\right), 0.25 \% \mathrm{NO}$, and $0.5 \% \mathrm{NO}_{2}$, at $150{ }^{\circ} \mathrm{C}$ for different aging time. 
Table 3. Variables and Model Parameters for the Pseudo Reaction Model

\begin{tabular}{|c|c|c|c|c|c|c|c|c|}
\hline $\begin{array}{c}\mathrm{T} \\
\left({ }^{\circ} \mathrm{C}\right)\end{array}$ & $\begin{array}{l}\text { D.P. } \\
\left({ }^{\circ} \mathrm{C}\right)\end{array}$ & $\begin{array}{c}\mathrm{C}_{\mathrm{H}_{2} \mathrm{O}} \\
\left(\mathrm{mol} / \mathrm{m}^{3}\right)\end{array}$ & $\begin{array}{c}\mathrm{C}_{\mathrm{O}_{2}} \\
\left(\mathrm{~mol} / \mathrm{m}^{3}\right)\end{array}$ & $\begin{array}{c}\mathrm{C}_{\mathrm{NO}} \\
\left(\mathrm{mol} / \mathrm{m}^{3}\right)\end{array}$ & $\begin{array}{c}\mathrm{C}_{\mathrm{NO}_{2}} \\
\left(\mathrm{~mol} / \mathrm{m}^{3}\right)\end{array}$ & $\begin{array}{c}\mathrm{k}_{1}{ }^{*} \\
\left(\mathrm{hr}^{-1}\right)\end{array}$ & $\begin{array}{c}\mathrm{k}_{1} \\
\left(\left(\mathrm{~mol} / \mathrm{m}^{3}\right)^{-4} \cdot \mathrm{hr}^{-1}\right)\end{array}$ & $\mathrm{R}^{2}$ \\
\hline \multicolumn{9}{|c|}{ Gas Mixture } \\
\hline 150 & $-70^{a} /-15^{b}$ & 0.067 & 8.59 & 0.102 & 0.205 & 2.707 & 224.9 & $0.993^{\mathrm{c}}$ \\
\hline
\end{tabular}

\subsubsection{Kinetics for Aging Processes on Aged $\mathrm{Ag}^{0}$-Aerogel}

Figure 33 shows the kinetic data for iodine loading on $\mathrm{Ag}^{0}$-aerogel aged in the gas mixture that includes humid air $\left(\right.$ d.p. $\left.-15{ }^{\circ} \mathrm{C}\right), 0.25 \% \mathrm{NO}$, and $0.5 \% \mathrm{NO}_{2}$ which is prepared by diluting $1 \%$ $\mathrm{NO} / \mathrm{N}_{2}$ and $2 \% \mathrm{NO}_{2} /$ air in humid air (d.p. $-15^{\circ} \mathrm{C}$ ) at $150{ }^{\circ} \mathrm{C}$ for aging times between 1 day and 1 month. This kinetic data indicates that the iodine capacity of the aged $\mathrm{Ag}^{0}$-aerogel decreased with increasing aging time when exposed to the gas mixture. For example, the iodine capacity of $\mathrm{Ag}^{0}$ aerogel aged in the gas mixture (Figure 33) decreased by $86.7 \%$ at $150{ }^{\circ} \mathrm{C}$ after 1 month. These results show that the aging effect from the gas mixture is higher than that of the individual single gas streams because gas-mixture aged $\mathrm{Ag}^{0}$-aerogel loses more of its $\mathrm{I}_{2}$ capacity than $2 \% \mathrm{NO}_{2} /$ air aged $\mathrm{Ag}^{0}$-aerogel, despite having a lower concentration of $\mathrm{NO}$ and $\mathrm{NO}_{2}$.

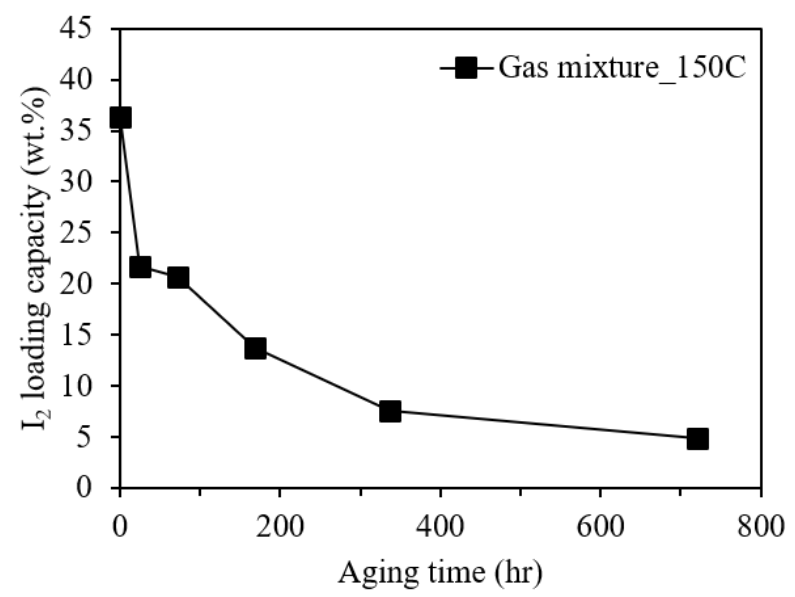

Figure 33. Kinetic data on $\mathrm{I}_{2}$ loading capacity of $\mathrm{Ag}^{0}$-aerogel aged in gas mixture, containing $99.25 \%$ humid air (dew point of $-15^{\circ} \mathrm{C}$ ), $0.25 \% \mathrm{NO}$, and $0.5 \% \mathrm{NO}_{2}$, at $150{ }^{\circ} \mathrm{C}$ for different aging time.

\subsubsection{Characterization of Aged $\mathbf{A g}^{0}$-Aerogel}

\subsubsection{Scanning Electron Microscope}

SEM (secondary electron detector, SED) images of aged $\mathrm{Ag}^{0}$-aerogel (Figure 34) show the formation of particles on the aerogel surface after aging in the gas mixture. Images show that the $\mathrm{Ag}^{0}$-aerogel surface was entirely covered by these particles. Compared to SEM analyses discussed in this report (Figure 22), these particles are assumed to be $\mathrm{Ag}_{2} \mathrm{SO}_{4}$ which is very similar to that of $2 \% \mathrm{NO}_{2} /$ air aged $\mathrm{Ag}^{0}$-aerogel. The images show that the presence of $\mathrm{Ag}_{2} \mathrm{SO}_{4}$ increases 
with increasing aging time. Additionally, these results are consistent with those of the I 2 adsorption tests (Figure 33), which showed that the $\mathrm{I}_{2}$ loading capacity of $\mathrm{Ag}^{0}$-aerogel aged in the gas mixture decreased with increasing aging time.
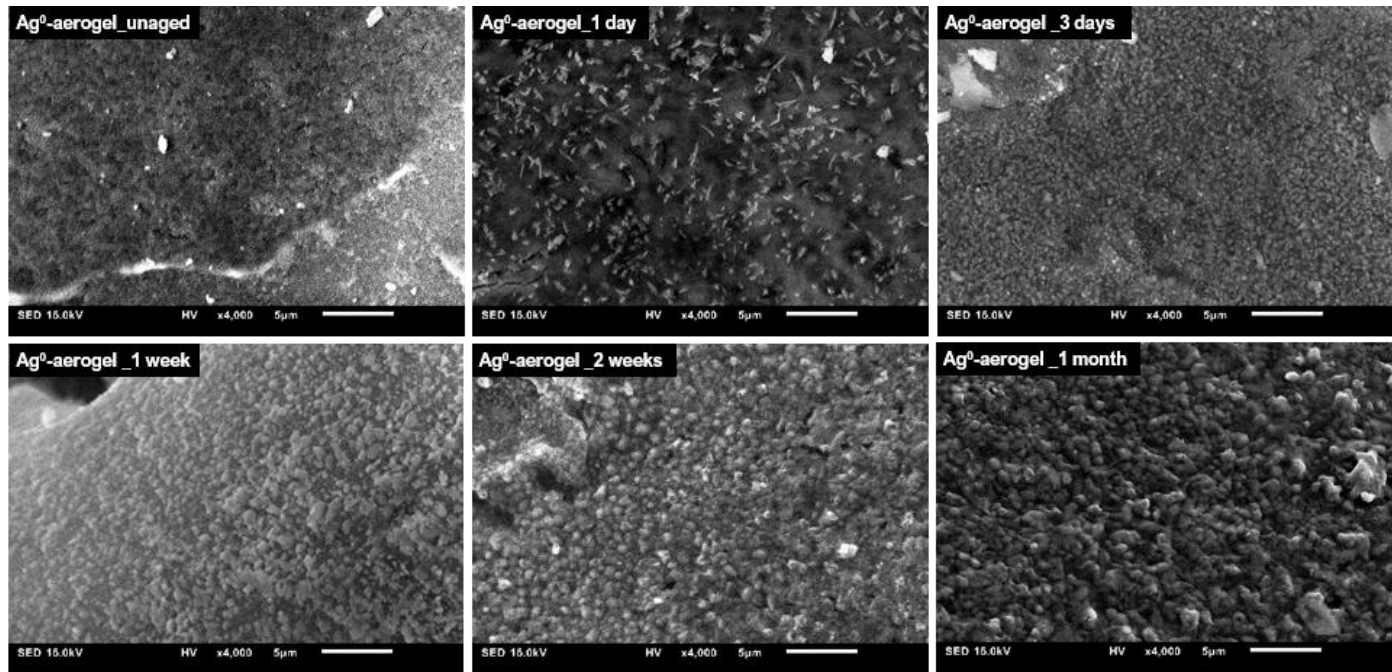

Figure 34. SEM images of $\mathrm{Ag}^{0}$-aerogel and aged $\mathrm{Ag}^{0}$-aerogel samples for 1 day, 3 days, 1 week, 2 weeks, and 1 month at $150{ }^{\circ} \mathrm{C}$.

\subsubsection{X-ray Powder Diffraction}

Results of XRD analysis on the unaged $\mathrm{Ag}^{0}$-aerogel and aged $\mathrm{Ag}^{0}$-aerogel in gas mixture are presented in Figure 35. The XRD patterns show shifts from $\mathrm{Ag}^{0}$ crystals to $\mathrm{Ag}_{2} \mathrm{SO}_{4}$ crystals when exposed to gas mixture. The formation of $\mathrm{Ag}_{2} \mathrm{SO}_{4}$ should be caused by the oxidation of the $\mathrm{SH}^{-}$on the surface of aerogel structure which is very similar to the aged $\mathrm{Ag}^{0}$-aerogel in $2 \% \mathrm{NO}_{2}$ because the gas mixture used in this study should produce $\mathrm{NO}_{2}$ species.

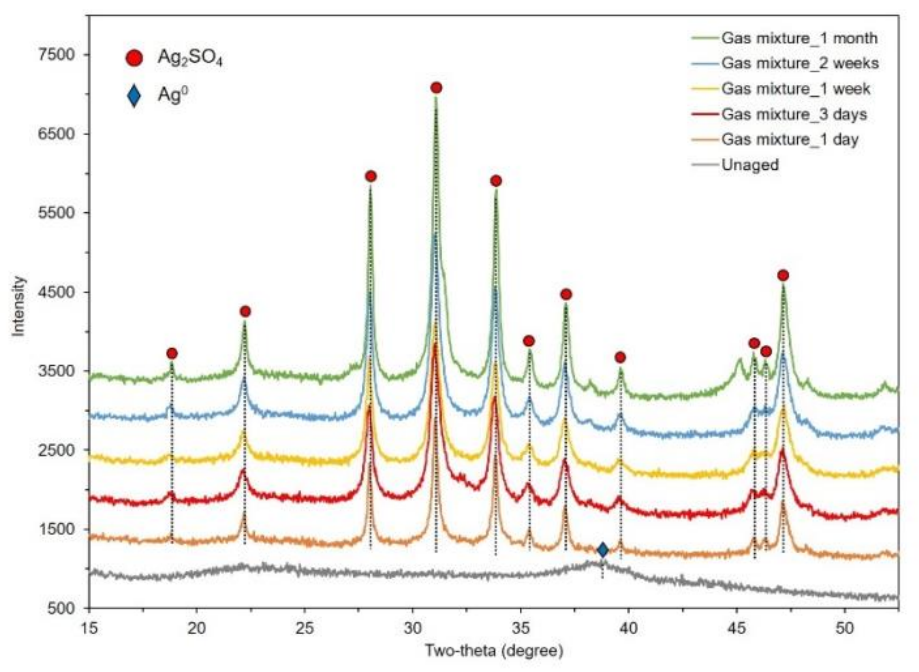

Figure 35. XRD patterns of unaged $\mathrm{Ag}^{0}$-aerogel and aged $\mathrm{Ag}^{0}$-aerogel. 


\subsubsection{Modeling for Aged Ag0-Aerogel}

The pseudo reversible reaction model was employed to describe the kinetics of the aging process for $\mathrm{Ag}^{0}$-aerogel aged in the gas mixture. Modeling results for aged $\mathrm{Ag}^{0}$-aerogel in the gas mixture at $150^{\circ} \mathrm{C}$ for up to 1 month are shown in Figure 36 which also includes the kinetic data shown in Figure 33. Eqns. (39) and (40) represent reaction equations for a kinetic model on the aging of $\mathrm{Ag}^{0}$-aerogel in the gas mixture shown in Figure 36. Considering that the gas mixture produces the $\mathrm{NO}_{2}$ gas, a reaction equation for the kinetic model can be represented as shown in Eqn. (40), which is similar to Eqn. (33). $C_{A g}$ is the normalized concentration of silver which indicates the amount of $\mathrm{I}_{2}$ loaded on the aged $\mathrm{Ag}^{0}$-aerogel, $C_{\mathrm{O}_{2}}$ is the concentration of oxygen in gas mixture, $C_{\mathrm{H}_{2} \mathrm{O}}$ is the concentration of water in gas mixture, $C_{\mathrm{NO}}$ is the concentration of NO in gas mixture, $\mathrm{C}_{\mathrm{NO}_{2}}$ is the concentration of $\mathrm{NO}_{2}$ in gas mixture. $C_{\mathrm{Ag}^{+}}$is the concentration of silver oxidized by gas mixture, $n$ is the reaction order, $k_{1}$ is the forward reaction rate constant, and $k_{-1}$ is the reverse reaction rate constant. Also, $C_{H S^{-}}$and $C_{S^{-}}$are the concentration of $\mathrm{HS}^{-}$functional groups attached to the aerogel surface and the concentration of $\mathrm{S}^{-}$oxidized by oxygen in dry air, respectively. Here, $k_{1}, C_{\mathrm{O}_{2}}, C_{\mathrm{H}_{2} \mathrm{O}}, C_{\mathrm{NO}}$, and $C_{\mathrm{NO}_{2}}$ are lumped into $k_{1}{ }^{*}$ because the gas concentration was constant at all times during the aging experiment and the gas mixture will be formed to a $\mathrm{NO}_{2}$ gas through the reactions similar to Eqns. (35) - (37). $C_{H S^{-}}$and $C_{S^{-}}$can be calculated by re-writing the stoichiometry in Eqn. (39) in terms of $\mathrm{Ag}^{0} \cdot \mathrm{C}_{\mathrm{Ag}^{+}}$can also be calculated by substracting the amount of $\mathrm{I}_{2}$ loaded on the aged $\mathrm{Ag}^{0}$-aerogel from the amount of $\mathrm{I}_{2}$ loaded on the unaged $\mathrm{Ag}^{0}$-aerogel. The model parameters for all reaction models and the correlation coefficients $\left(\mathrm{R}^{2}\right)$ between experimental data and model results are shown in Table 4. These results indicate the model is fitted well to the experimental data when $n \geq 2$, with a strong correlation coefficient $\left(\mathrm{R}^{2}=0.988\right)$, which means the Pseudo $2^{\text {nd }}$ order reversible reaction model fits the experimental data. These results are consistent with the experimental data (Figure 33) that show the effect of aging on $\mathrm{Ag}^{0}$-aerogel increasing with increasing aging time and temperatures.

$$
\begin{aligned}
& 3 \mathrm{O}_{2}+3 \mathrm{H}_{2} \mathrm{O}+\mathrm{NO}+2 \mathrm{NO}_{2}+4 \mathrm{Ag}+2 \mathrm{HS}^{-} \longleftrightarrow 2 \mathrm{Ag}_{2} \mathrm{SO}_{4}+\mathrm{N}_{2}+2 \mathrm{HO}^{-} \\
& \mathrm{v}=\frac{\mathrm{dC}_{\mathrm{Ag}}}{\mathrm{dt}}=-\mathrm{k}_{1}{ }^{*} \mathrm{C}_{\mathrm{HS}^{-}} \mathrm{C}_{\mathrm{Ag}}{ }^{\mathrm{n}}+\mathrm{k}_{-1} \mathrm{C}_{\mathrm{S}^{-}} \mathrm{C}_{\mathrm{Ag}^{+}}{ }^{\mathrm{n}} \\
& \mathrm{k}_{1}{ }^{*}=\mathrm{k}_{1} \mathrm{C}_{\mathrm{NO}_{2}}{ }^{*} \\
& \mathrm{C}_{\mathrm{NO}_{2}}{ }^{*}=\mathrm{C}_{\mathrm{O}_{2}} \mathrm{C}_{\mathrm{H}_{2} \mathrm{O}} \mathrm{C}_{\mathrm{NO}} \mathrm{C}_{\mathrm{NO}_{2}} \\
& \mathrm{v}=\frac{\mathrm{dC}_{\mathrm{Ag}}}{\mathrm{dt}}=-\mathrm{k}_{1}{ }^{*} \mathrm{C}_{\mathrm{HS}^{-}} \mathrm{C}_{\mathrm{Ag}}{ }^{2}+\mathrm{k}_{-1} \mathrm{C}_{\mathrm{S}^{-}} \mathrm{C}_{\mathrm{Ag}^{+}}{ }^{2} \quad(\text { for } \mathrm{n}=2)
\end{aligned}
$$




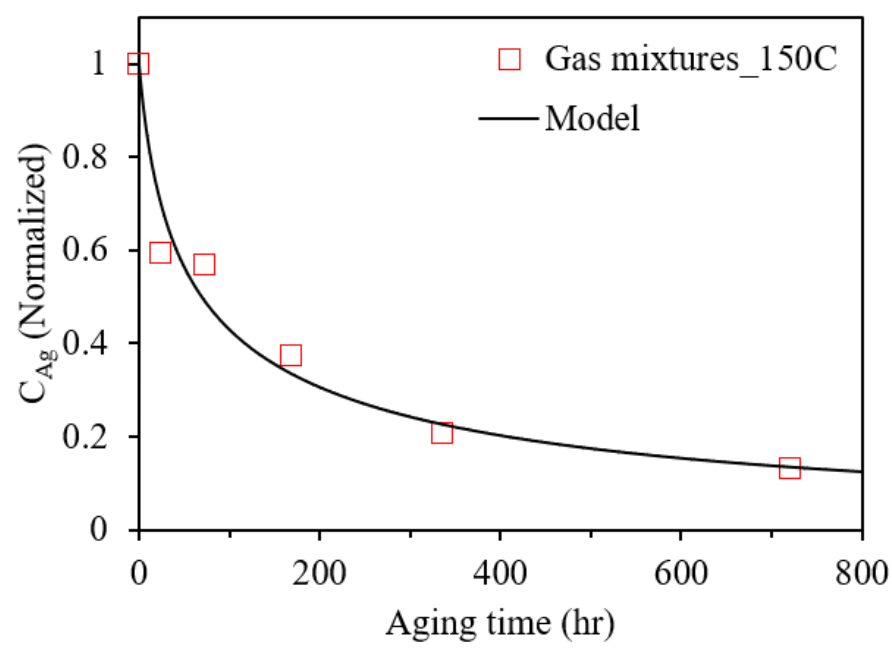

Figure 36. Pseudo reaction model on $\mathrm{Ag}^{0}$-aerogel aged in gas mixture, containing $99.25 \%$ humid air (dew point of $-15^{\circ} \mathrm{C}$ ), $0.25 \% \mathrm{NO}$, and $0.5 \% \mathrm{NO}_{2}$, at $150{ }^{\circ} \mathrm{C}$ for different aging time.

Table 4. Variables and Model Parameters for the Pseudo Reaction Model

\begin{tabular}{|c|c|c|c|c|c|c|c|c|c|}
\hline $\begin{array}{c}\mathrm{T} \\
\left({ }^{\circ} \mathrm{C}\right)\end{array}$ & $\begin{array}{l}\text { D.P. } \\
\left({ }^{\circ} \mathrm{C}\right)\end{array}$ & $\begin{array}{c}\mathrm{C}_{\mathrm{H}_{2} \mathrm{O}} \\
\left(\mathrm{mol} / \mathrm{m}^{3}\right)\end{array}$ & $\begin{array}{c}\mathrm{C}_{\mathrm{O}_{2}} \\
\left(\mathrm{~mol} / \mathrm{m}^{3}\right)\end{array}$ & $\begin{array}{c}\mathrm{C}_{\mathrm{NO}} \\
\left(\mathrm{mol} / \mathrm{m}^{3}\right)\end{array}$ & $\begin{array}{c}\mathrm{C}_{\mathrm{NO}_{2}} \\
\left(\mathrm{~mol} / \mathrm{m}^{3}\right)\end{array}$ & $\begin{array}{c}\mathrm{k}_{1}^{*} \\
\left(\mathrm{hr}^{-1}\right)\end{array}$ & $\begin{array}{c}\mathrm{k}_{1} \\
\left(\left(\mathrm{~mol} / \mathrm{m}^{3}\right)^{-4} \cdot \mathrm{hr}^{-1}\right)\end{array}$ & $\begin{array}{c}\mathrm{k}_{-1} \\
\left(\mathrm{hr}^{-1}\right)\end{array}$ & $\mathrm{R}^{2}$ \\
\hline \multicolumn{10}{|c|}{ Gas Mixture } \\
\hline 150 & $-70^{\mathrm{a}} /-15^{\mathrm{b}}$ & 0.067 & 8.59 & 0.102 & 0.205 & $3.93 \mathrm{E}-3$ & 0.327 & $6.44 \mathrm{E}-4$ & $0.922^{\circ}$ \\
\hline
\end{tabular}

\subsection{Conclusions}

The aging processes of $\mathrm{Ag}^{0} \mathrm{Z}$ and $\mathrm{Ag}^{0}$-aerogel in different aging gas streams including dry air, humid air, $1 \% \mathrm{NO} / \mathrm{N}_{2}$ and $2 \% \mathrm{NO}_{2}$ /air, at proposed aging times and temperature were studied. It was found that $\mathrm{Ag}^{0} \mathrm{Z}$ had significant $\mathrm{I}_{2}$ adsorption capacity losses when exposed to these gas streams. At $150{ }^{\circ} \mathrm{C}$ of aging temperature, $\mathrm{Ag}^{0}$-aerogel was more resistant to the aging gas streams than $\mathrm{Ag}^{0} \mathrm{Z} . \mathrm{Ag}^{0}$-aerogel can maintain $\sim 80 \%$ of its capacity in dry air, humid air and $\mathrm{NO}, \mathrm{but}^{\mathrm{Ag}} \mathrm{Z}^{0}$ can only maintain $\sim 60 \%$ (dry air), $\sim 40 \%$ (humid air: d.p. $-15{ }^{\circ} \mathrm{C}$ ), and $<10 \%\left(1 \% \mathrm{NO} / \mathrm{N}_{2}\right)$ of its $\mathrm{I}_{2}$ loading capacity. Both $\mathrm{Ag}^{0} \mathrm{Z}$ and $\mathrm{Ag}^{0}$-aerogel lost $>90 \%$ of the capacity when exposed to $2 \%$ $\mathrm{NO}_{2}$ /air, and $\mathrm{Ag}^{0} \mathrm{Z}$ lost the capacity much more rapidly than $\mathrm{Ag}^{0}$-aerogel.

The aging processes for $\mathrm{Ag}^{0} \mathrm{Z}$ and $\mathrm{Ag}^{0}$-aerogel in dry air, humid air, $1 \% \mathrm{NO} / \mathrm{N}_{2}, 2 \% \mathrm{NO}_{2} /$ air, and a gas mixture were also studied. The iodine loading capacity of $\mathrm{Ag}^{0} \mathrm{Z}$ and $\mathrm{Ag}^{0}$-aerogel aged for up to 1 month in gas streams including dry air, humid air (d.p. $-40^{\circ} \mathrm{C},-15^{\circ} \mathrm{C}$, and $+15^{\circ} \mathrm{C}$ ) at $100^{\circ} \mathrm{C}$, $150^{\circ} \mathrm{C}$, and $200^{\circ} \mathrm{C}$ were obtained. These results showed that the iodine loading capacity of aged $\mathrm{Ag}^{0} \mathrm{Z}$ and $\mathrm{Ag}^{0}$-aerogel decreases with increasing aging temperature, time, and water concentration. $\mathrm{Ag}^{0} \mathrm{Z}$ and $\mathrm{Ag}^{0}$-aerogel aged in the $2 \% \mathrm{NO}_{2}$ /air gas stream experienced the most severe impacts though the capacity loss of $\mathrm{Ag}^{0}$-aerogel is less substantial. $\mathrm{NO}_{2}$ aged $\mathrm{Ag}^{0} \mathrm{Z}$ lost $87.5 \%, 88.9 \%$, and 
$91.2 \%$ of its iodine capacity at $100^{\circ} \mathrm{C}, 150{ }^{\circ} \mathrm{C}$, and $200^{\circ} \mathrm{C}$ after 5 hours, respectively. $\mathrm{Ag}^{0}$-aerogel, on the other hand, lost $44.6 \%, 58.8 \%$, and $78.2 \%$ of its iodine capacity at $100{ }^{\circ} \mathrm{C}, 125{ }^{\circ} \mathrm{C}$, and 150 ${ }^{\circ} \mathrm{C}$ after 2 weeks, respectively. The aging process for $\mathrm{Ag}^{0} \mathrm{Z}$ and $\mathrm{Ag}^{0}$-aerogel in a gas mixture of $0.25 \% \mathrm{NO}, 0.5 \% \mathrm{NO}_{2}$ in humid air (d.p. $-15{ }^{\circ} \mathrm{C}$ ) were also studied. Both $\mathrm{Ag}^{0} \mathrm{Z}$ and $\mathrm{Ag}^{0}$-aerogel aged in the gas mixture showed similar iodine capacity losses to those of $2 \% \mathrm{NO}_{2} /$ air aged $\mathrm{Ag}^{0} \mathrm{Z}$ and $\mathrm{Ag}^{0}$-aerogel even though lower concentraions of $\mathrm{NO}$ and $\mathrm{NO}_{2}$ were used in the gas mixture. This means that the gas mixture has a significant impact on the performance of both $\mathrm{Ag}^{0} \mathrm{Z}$ (lost $87 \%$ of its initial iodine capacity after 5 hours) and $\mathrm{Ag}^{0}$-aerogel (lost $86 \%$ of its initial capacity after 1 month).

The mechanisms of $\mathrm{Ag}^{0} \mathrm{Z}$ and $\mathrm{Ag}^{0}$-aerogel aging processes in the different aging gases were determined. For $\mathrm{Ag}^{0} \mathrm{Z}$, the mechanism was found to be a four-step process: (i) oxidation of $\mathrm{Ag}^{0}$ to $\mathrm{Ag}^{+}$, (ii) migration of $\mathrm{Ag}^{+}$from the surface into the pores/channels of mordenite crystals, (iii) binding of $\mathrm{Ag}^{+}$to the crystal structure by replacing the $\mathrm{H}$ already present, and (iv) binding of the generated $\mathrm{H}^{+}$with $\mathrm{O}^{2-}$ or $\mathrm{HO}^{-}$producing $\mathrm{H}_{2} \mathrm{O}$. For $\mathrm{Ag}^{0}$-aerogel, it was found that the aging mechanism is governed by the oxidation of $\mathrm{Ag}^{0}$ forming $\mathrm{Ag}_{2} \mathrm{~S}$ or $\mathrm{AgSO}_{4}$.

Furthermore, pseudo reaction models based on the $\mathrm{Ag}^{0}$ oxidation reaction for all of the aging processes were employed to describe the kinetics of $\mathrm{Ag}$ deactivation on $\mathrm{Ag}^{0} \mathrm{Z}$ and $\mathrm{Ag}^{0}$ aerogel. The results of the iodine loading capacity experiments and model fitting revealed that the $\mathrm{Ag}^{0} \mathrm{Z}$ and $\mathrm{Ag}^{0}$-aerogel lost a significant iodine capacity when they were exposed to off-gas streams.

\subsection{References for Part 1}

1. Haefner, D. R.; Tranter, T. J., Methods of gas phase capture of iodine from fuel reprocessing off-gas: a literature survey. Idaho National Laboratory, Idaho Falls, ID 2007.

2. Jubin, R. T.; DelCul, G. D.; Patton, B. D.; Owens, R. S.; Ramey, D. W.; Spencer, B. B., Advanced fuel cycle initiative coupled end-to-end research, development, and demonstration project: integrated off-gas treatment system design and initial performance-9226, WM2009 Conference, Phoenix, AZ, 2009.

3. Scheele, R. D.; Wend, C. F.; Buchmiller, W. C.; Kozelisky. A. E.; Sell, R. L., Preliminary evaluation of spent silver mordenite disposal forms resulting from gaseous radioiodine control at Hanford's Waste Treatment Plant; PNWD-3225, WTP-RPT-039; Pacific Northwest Laboratory: Richland, WA, 2002.

4. Chapman, K. W.; Chupas, P. J.; Nenoff, T. M., Radioactive iodine capture in silver containing mordenites through nanoscale silver iodide formation. J Am Chem Soc 2010, 132 (26), 88979.

5. Matyáš, J.; Fryxell, G. E.; Busche, B. J.; Wallace, K.; Fifield, L. S., Functionalized silica aerogels: Advanced materials to capture and immobilize radioactive iodine (2011). Ceramic Engineering and Science Proceedings, 32 (9), pp. 23-32. 
6. Matyáš, J.; Canfield, N.; Sulaiman, S.; Zumhoff, M., Silica-based waste form for immobilization of iodine from reprocessing plant off-gas streams, J. Nucl. Mater. 476 (2016) 255-261.

7. Amonette, J. E.; Matyáš, J., Functionalized silica aerogels for gas-phase purification, sensing, and catalysis: a review, Microporous Mesoporous Materials. 250 (2017) 100-119.

8. Strachan, D. M.; Chun, J.; Matyáš, J.; Lepry, W. C.; Riley, B. J.; Ryan, J. V.; Thallapally, P. K., Summary Report on the Volatile Radionuclide and Immobilization Research for FY2011 at $P N N L$, Pacific Northwest National Laboratory (PNNL), Environmental Molecular Sciences Laboratory (EMSL), Richland, WA (US), 2011.

9. Bruffey, S. H.; Jubin, R. T.; Anderson, K. K.; Walker, J. F., Aging and Iodine Loading of Silver Functionalized Aerogels. FCRD-SWF-2012-000256, (2012).

10. Bruffey, S. H.; Anderson, K. K.; Jubin, R. T.; Walker, J. F., Humid Aging and Iodine Loading of Silver-Functionalized Aerogels. FCRD-SWF-2013-000258. (2013).

11. Jubin, R. T.; Bruffey, S. H.; Patton, K. K., Humid Aging and Iodine Loading of SilverFunctionalized Aerogels. FCRD-SWF-2014-000594, (2014).

12. Bruffey, S. H.; Patton, K. K.; Jubin, R. T., Complete Iodine Loading of NO-Aged Ag ${ }^{0}$ functionalized Aerogel. ORNL/LTR--2015/258, (2015).

13. Patton, K. K.; Bruffey, S. H.; Walker, J. F.; Jubin, R. T., $\mathrm{NO}_{2}$ Aging and Iodine Loading of Silver-Functionalized Aerogels. ORN L/LTR-2014/271, (2014).

14. Jubin, R. T.; Ramey, D. W.; Spencer, B. B.; Anderson, K. K.; Robinson, S. M., Impact of Pretreatment and Aging on the Iodine Capture Performance of Silver-Exchanged Mordenite WM2012 Conference, Phoenix, AZ (United States), Phoenix, AZ (United States), 2012.

15. Patton, K. K.; Bruffey, S. H.; Jubin, R. T.; Walker, J. F., Effects of Extended In-Process Aging of Silver-Exchanged Mordenite on Iodine Capture Performance, 33rd Nuclear Air Cleaning Conference, St Louis, MO (United States), St Louis, MO (United States), 2014.

16. Bruffey, S. H.; Jubin, R. T.; Anderson, K. K.; Walker, J. F., Aging of iodine-loaded silver mordenite in NO2; ORNL/LTR-2014/153; Oak Ridge National Laboratory (ORNL): Oak Ridge, TN (United States), 2014.

17. Patton, K. K.; Bruffey, S. H.; Jubin, R. T.; Walker, J. F., Iodine Loading of NO Aged Silver Exchanged Mordenite; ORNL/LTR-2014/425; Oak Ridge National Laboratory (ORNL): Oak Ridge, TN (United States), 2014.

18. Bruffey, S. H.; Jubin, R. T., Initial Evaluation of Effects of NOx on Iodine and Methyl Iodide Loading of AgZ and Aerogels; ORNL/SPR-2015/125; Oak Ridge National Laboratory (ORNL): Oak Ridge, TN (United States), 2015; p 125. 
19. Bruffey, S. H.; Patton, K. K.; Walker, J. F.; Jubin, R. T., Complete NO and NO2 Aging Study for AgZ; ORNL/SPR-2015/128; Oak Ridge National Laboratory (ORNL): Oak Ridge, TN (United States), 2015; p 128.

20. Jordan, J. A.; Bruffey, S. H., Preparation of NO2-Aged Silver-Functionalized Silica-Aerogel and Silver Mordenite Samples; Oak Ridge National Laboratory (ORNL), Oak Ridge, TN (United States): 2016.

21. Nan, Y.; Liu, J.; Tang, S.; Lin, R.; Tavlarides, L. L., Silver-Exchanged Mordenite for Capture of Water Vapor in Off-Gas Streams: A Study of Adsorption Kinetics, Industrial \& Engineering Chemistry Research 2018, 57 (3), 1048-1058.

22. Nan, Y.; Choi, S.; Ladshaw, A. P.; Yiacoumi, S.; Tsouris, C.; Tavlarides. L. L., Determination of Mechanisms and Kinetics of AgOZ and AgO-Aerogel Aging in Nuclear Off-Gases, Transactions of the American Nuclear Society, Vol. 118, Philadelphia, Pennsylvania, June 1721,2018

23. Nan, Y.; Tavlarides. L. L., Adsorption of iodine on hydrogen-reduced silver-exchanged mordenite: Experiments and modeling, AIChE Journal 2017, 63 (3), 1024-1035.

24. Shimizu, K.; Sugino, K.; Kato, K.; Yokota, S.; Okumura, K.; Satsuma, A., Formation and Redispersion of Silver Clusters in Ag-MFI Zeolite as Investigated by Time-Resolved QXAFS and UV-Vis. The Journal of Physical Chemistry C 2007, 111 (4), 1683-1688.

25. Nan, Y.; Abney, C.; Liu, J.; Choi, S.; Tavlarides, L. L., Aging Processes of Ag-Exchanged Mordenite and Ag-Functionalized Silica Aerogel in Spent Nuclear Fuel Reprocessing Off Gases. 2017 AIChE Annual Meeting, Minneapolis, MN, 2017

26. Beyer H,; Jacobs P.A,; Uytterhoeven J.B., Redox behaviour of transition metal ions in zeolites. Part 2.-Kinetic study of the reduction and reoxidation of silver-Y zeolites. Journal of the Chemical Society, Faraday Transactions 1: Physical Chemistry in Condensed Phases. 1976;72:674-685.

27. Aspromonte S.G,; Mizrahi M.D,; Schneeberger F.A.; Lopez J.M.; Boix A.V., Study of the nature and location of silver in Ag-exchanged mordenite catalysts. Characterization by spectroscopic techniques. The Journal of Physical Chemistry C. 2013;117(48):25433-25442.

28. Naumkin, A. V.; Kraut-Vass, A.; Gaarenstroom, S. W.; Powell, C. J., NIST X-ray photoelectron spectroscopy database, Measurement Services Division of the National Institute of Standards and Technology (NIST) Technology Services, 2012.

29. Matyáš, J.; Fryxell, G. E.; Robinson, M. J., Characterization of Dry-Air Aged Granules of Silver Functionalized Silica Aerogel, FCRD-SWF-2012-000214, Pacific Northwest National Laboratory (PNNL), Richland, WA, 2012.

30. Matyáš, J.; Ilton, E. S.; Kovařík, L., Silver-functionalized silica aerogel: Towards an understanding of aging on iodine sorption performance, RSC Adv., 2018, 8, 31843-31852. 
31. Bensebaa, F.; Zhou, Y.; Deslandes, Y.; Kruus, E.; Ellis, T. H., XPS study of metal-sulfur bonds in metal-alkanethiolate materials, Surface Science Letters, 1998, 405, L472-L476.

32. Moulder, J. F.; Stickle, W. F.; Sobol, P. E.; Bomben, K. D., Handbook of X-Ray Photoelectron Spectroscopy, Perkin-Elmer, Eden Prairie, MN, 1992.

33. Kharitonov, V. G.; Sundquist, A. R.; Sharma, V. S., Kinetics of Nitrosation of Thiols by Nitric Oxide in the Presence of Oxygen, The Journal of Biology Chemistry. 1995;270(47):2815828164. 


\section{Part 2: Capture of Iodine from Nuclear-Fuel-Reprocessing Off-Gas: Influence of Aging on Reduced Silver Mordenite Adsorbent after Exposure to NO/NO}

\subsection{Abstract}

Iodine radioisotopes released during nuclear fuel reprocessing must be removed from the off-gas stream before discharge. One promising material for iodine capture is reduced silver mordenite $\left(\mathrm{Ag}^{0} \mathrm{Z}\right)$. Nevertheless, the adsorbent's capacity will degrade, or age, over time when the material is exposed to other off-gas constituents. Though the overall impact of aging is known, the underlying physical and chemical processes are not. To examine these processes, $\mathrm{Ag}^{0} \mathrm{Z}$ samples were prepared and aged in $2 \% \mathrm{NO}_{2}$ in dry air and in $1 \% \mathrm{NO}$ in $\mathrm{N}_{2}$ gas streams at $150^{\circ} \mathrm{C}$ for up to six months. Aged samples were then characterized using Scanning Electron Microscopy, X-ray Diffraction, Raman Spectroscopy, and X-ray Absorption Spectroscopy. These techniques show that aging involves two overarching processes: (i) oxidation of the silver nanoparticles present in $\mathrm{Ag}^{0} \mathrm{Z}$ and (ii) migration of oxidized silver into the mordenite's inner network. Silver on the nanoparticle's surface is oxidized through adsorption of $\mathrm{O}_{2}, \mathrm{NO}$, and $\mathrm{NO}_{2}$. Raman Spectroscopy and X-ray Absorption Spectroscopy indicate that nitrates are the primary products of this adsorption. Most of these nitrates migrate into the interior of the mordenite and exchange at framework binding sites, returning silver to its unreduced state (AgZ). The remaining nitrates exist at a persistent concentration without aggregating into bulk phase $\mathrm{AgNO}_{3}$. X-ray Absorption Spectroscopy results further indicate that iodine adsorption occurs on not just $\mathrm{Ag}^{0} \mathrm{Z}$ but also on $\mathrm{AgZ}$ and a portion of the nitrates in the system. $\mathrm{AgZ}$ adsorbs a sizable quantity of iodine early in the aging process but its capacity drops rapidly over time. For well-aged samples, nitrates are responsible for up to $95 \%$ of mordenite's iodine capacity. These results have enhanced our understanding of the aging process in silver mordenite and are expected to guide the development of superior adsorbents for the capture of radioactive iodine from reprocessing off-gas.

\subsection{Introduction}

Over the next twenty years, the global energy generating capacity of nuclear power is expected to see an increase of as much as $63 \%$ relative to global production in $2017 .{ }^{1}$ This growing capacity will, necessarily, require not only the development of new nuclear fuel resources but also the expansion and refinement of existing resources. The reprocessing of spent nuclear fuel (SNF) offers one potential avenue to increase the availability of nuclear fuel resources. Additionally, the recovery of usable materials from SNF reduces waste from and increases the sustainability of nuclear energy. SNF, nevertheless, contains a number of radioactive fission byproducts which are volatilized during reprocessing including iodine-129 in both organic and inorganic forms, tritium, carbon-14, krypton-85, and xenon- $135 .{ }^{2}$ Of these species, iodine is the most important as a result of its long half-life ( 15.7 million years) which allows for accumulation in the environment. Furthermore, radioactive iodine emissions are regulated by both the US Environmental Protection Agency and Nuclear Regulatory Commission under the US Code of Federal Regulations Title 40 Part $190^{3}$ and Title 10 Part $20,{ }^{4}$ respectively. As such, reprocessing off-gas must be treated to capture volatilized iodine.

Since the 1960s, silver (Ag) based solid adsorbents including various Ag zeolites (mordenite, faujasite, etc.), Ag nitrate impregnated alumina and silica, and more recently Ag 
functionalized aerogels have been considered for iodine off-gas capture. ${ }^{5-7}$ Among these materials, silver mordenite ( $\mathrm{AgZ})$ adsorbents, and particularly reduced silver mordenite $\left(\mathrm{Ag}^{0} \mathrm{Z}\right)$, have been examined extensively and are considered promising for their high iodine adsorption capacity, thermodynamic stability, and regenerative capabilities. ${ }^{7}$ Recently, a renewed emphasis has been placed on the development of $\mathrm{Ag}^{0} \mathrm{Z}$ from commercially available $\mathrm{AgZ}$ for iodine capture with several studies attempting to provide a greater fundamental understanding of adsorbent activation, ${ }^{8}$ the mechanisms of organic and inorganic iodine adsorption, ${ }^{9-14}$ and adsorbent regeneration. ${ }^{15}$ This shift in emphasis away from $\mathrm{AgZ}$ and towards $\mathrm{Ag}^{0} \mathrm{Z}$ is primarily a consequence of $\mathrm{Ag}^{0} \mathrm{Z}$ having a significantly higher adsorption capacity for both organic and inorganic iodine. ${ }^{16}$ Another significant area of interest is the impact that exposure to off-gas constituents including oxygen $\left(\mathrm{O}_{2}\right)$, water vapor $\left(\mathrm{H}_{2} \mathrm{O}\right)$, nitric oxide $(\mathrm{NO})$, and nitrogen dioxide $\left(\mathrm{NO}_{2}\right)$ has on $\mathrm{Ag}^{0} \mathrm{Z}$ 's inorganic iodine ( $\mathrm{I}_{2}$ ) adsorption capacity. ${ }^{17-21}$ The net effect of these off-gas constituents on $\mathrm{Ag}^{0} \mathrm{Z}$ performance is known as aging. Additionally, while all four of the aforementioned gases can substantially degrade the adsorbent's $\mathrm{I}_{2}$ capacity, the impact of the $\mathrm{NO}_{\mathrm{x}}$ gases on $\mathrm{Ag}^{0} \mathrm{Z}$ performance is the most significant. For instance, the aging effect from exposure to $1 \% \mathrm{NO}$ in a balance of nitrogen $\left(\mathrm{N}_{2}\right)$ yields an $85 \%$ reduction in the adsorbent's I 2 capacity after one month. ${ }^{19}$ This is significantly more than the $40 \%$ reduction observed after six months in dry air. ${ }^{17}$ Nevertheless, while exposure to $\mathrm{NO}$ and $\mathrm{NO}_{2}$ is known to dramatically reduce adsorbent performance, the physical and chemical processes that produce these dramatic changes have not yet been investigated.

Thus, the purpose of this study is to examine $\mathrm{Ag}^{0} \mathrm{Z}$ aging with the intent of elucidating the underlying physicochemical processes involved that result in the observed $\mathrm{I}_{2}$ capacity $\operatorname{losses} \mathrm{Ag}^{0} \mathrm{Z}$ samples were aged in gas streams of $1 \% \mathrm{NO}$ in $\mathrm{N}_{2}$ and of $2 \% \mathrm{NO}_{2}$ in dry air at $150^{\circ} \mathrm{C}$ for up to six months. Aged samples were characterized using Scanning Electron Microscopy (SEM), X-ray Diffraction (XRD), Raman Spectroscopy, and X-ray Absorption Spectroscopy (XAS) to help determine how adsorbent aging influences the material properties and Ag speciation. With this information, potential mechanisms for adsorbent aging are explored and discussed. Finally, based on the proposed processes, a predictive model for $\mathrm{Ag}^{0} \mathrm{Z}$ aging has been developed based on the Discontinuous Galerkin Off-gas Separation and Recovery (DG-OSPREY) modeling framework.

\subsection{Methodology}

\subsubsection{Materials}

$\mathrm{Ag}^{0} \mathrm{Z}$ samples were prepared from commercially available AgZ (IONEX-Type Ag-900) with a Ag content of 11.9 w.t. \% and a silicon-aluminum ratio of 5:1 purchased from Molecular Products Inc. As Nan previously determined using inductively coupled plasma optical emission spectroscopy, the degree of $\mathrm{Ag}$ exchange in the as received $\mathrm{AgZ}$ was $\sim 50 \%$. $^{22} \mathrm{In}$ addition to $\mathrm{Ag}$, the material also contains notable impurities of potassium $(\mathrm{K})$, sodium $(\mathrm{Na})$, calcium $(\mathrm{Ca})$, and iron $(\mathrm{Fe})$ which represent $0.74,0.4,0.33$, and 0.98 w.t. $\%$ of the material, respectively. Since the use of commercially available AgZ in off-gas treatment is expected, we did not attempt to remove the impurities present in the mordenite as received from the manufacturer. AgZ samples were delivered as cylindrical pellets with an average diameter of $1.6 \mathrm{~mm}$, manufactured from mordenite microcrystals supported by a clay binding material. The quantity of clay binder used in pellet preparation was not disclosed by the manufacturer since they consider this property of the material 
to be confidential. Pellet diameter variance was $\pm 0.4 \mathrm{~mm}$ based on the distribution of pellets between 10 -mesh $(2.00 \mathrm{~mm})$ and 16 -mesh $(1.18 \mathrm{~mm})$ stainless steel screens. This variation was narrowed using a 12 -mesh $(1.70 \mathrm{~mm})$ screen to remove smaller pellets yielding a final average diameter of $1.8 \mathrm{~mm}$. A complete description of the properties of this $\mathrm{AgZ}$ was provided in a previous work. ${ }^{16} \mathrm{AgZ}$ was reduced to $\mathrm{Ag}^{0} \mathrm{Z}$ in $10 \mathrm{~g}$ batches by exposing the samples to a $4 \%$ hydrogen $\left(\mathrm{H}_{2}\right)$ in argon (Ar) gas stream with a flow rate of $500 \mathrm{~mL} / \mathrm{min}$ at $400^{\circ} \mathrm{C}$ for 24 hours. Before and after reduction, samples were treated in a pure $\mathrm{N}_{2}$ gas stream at the same temperature and flow rate used in reduction for four hours. This was done to desorb excess moisture before reduction and to remove any physisorbed $\mathrm{H}_{2}$ once reduction was completed. These reduction conditions ensure that all $\mathrm{Ag}$ in the mordenite microcrystals is reduced to metallic silver $\left(\mathrm{Ag}^{0}\right)$, which then migrates to the mordenite's surface forming $\mathrm{Ag}^{0}$ nanoparticles. ${ }^{15,16}$ The size of the nanoparticles formed under these reduction conditions will be greater than $3 \mathrm{~nm}$, as Zhao and coworkers previously reported. ${ }^{8}$ Nevertheless, the exact size of the nanoparticles formed in the $\mathrm{Ag}^{0} \mathrm{Z}$ prepared for this study must be determined through characterization. All gases provided from cylinders were purchased form Airgas Inc. and were Certified Standard Grade, with the exception of compressed dry air which was Ultra Zero Grade. This included the $4 \% \mathrm{H}_{2}$ in Ar mixture and pure $\mathrm{N}_{2}$ used in $\mathrm{AgZ}$ reduction, $1 \% \mathrm{NO}$ in $\mathrm{N}_{2}$ and 2\% $\mathrm{NO}_{2}$ in dry air mixtures used for aging experiments, and the compressed dry air ( 1.58 ppm by weight $\left.\mathrm{H}_{2} \mathrm{O}\right)$ used during $\mathrm{I}_{2}$ loading.

\subsubsection{Aging and Adsorption Experiments}

$\mathrm{Ag}^{0} \mathrm{Z}$ samples were aged by exposing them to gas stream mixtures of $1 \% \mathrm{NO}$ in $\mathrm{N}_{2}$ and of $2 \% \mathrm{NO}_{2}$ in dry air for various periods of time (i.e., one day, one week, one month) at a constant temperature of $150^{\circ} \mathrm{C}$. Before this exposure, samples were dried in a $\mathrm{N}_{2}$ flow for four hours at the exposure temperature. Glass columns with an internal diameter of $2.5 \mathrm{~cm}$ and a total height of 7.0 $\mathrm{cm}$, divided equally into four chambers, were used to hold the $\mathrm{Ag}^{0} \mathrm{Z}$ samples. For both gas mixtures, two of these columns were placed in series and each chamber was loaded with $1 \mathrm{~g}$ of $\mathrm{Ag}^{0} \mathrm{Z}$ allowing for up to eight samples to be tested simultaneously in each gas mixture. Compressed gas cylinders were used to provide a steady gas stream to the system with a flow rate of $500 \mathrm{ml} / \mathrm{min}$ regulated using a Cole-Parmer gas mass flow controller (Item \# EW-32907). Two ovens (Thermo Scientific Heratherm) were used to ensure that both the sample columns and the incoming gas maintained a constant temperature. Thermal monitors were placed at the entrance of each glass column to verify that the influent gas stream was at the desired temperature. All parts of the system were connected to one another using stainless steel tubing. A complete diagram of the system used for the aging experiments is given in Figure 1. 


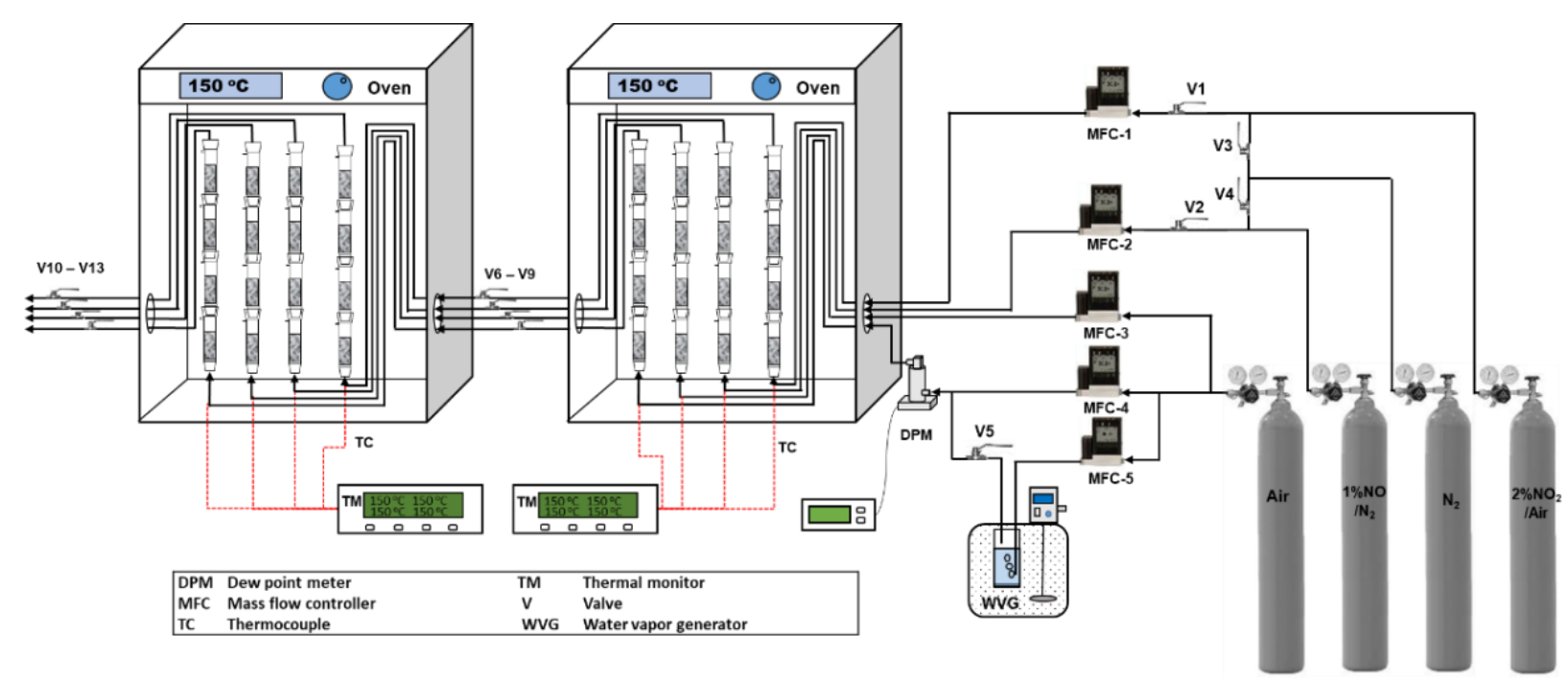

Figure 1. Complete schematic of continuous flow aging system; $1 \% \mathrm{NO}$ in $\mathrm{N}_{2}, 2 \% \mathrm{NO}_{2}$ in Air, and pure $\mathrm{N}_{2}$ lines were used in this study.

Once the $\mathrm{Ag}^{0} \mathrm{Z}$ sample had been exposed to either the $\mathrm{NO}$ or the $\mathrm{NO}_{2}$ mixture for a long enough period of time, it was either stored for later characterization or transferred to the $\mathrm{I}_{2}$ adsorption system to determine its capacity. The adsorption system and experimental equipment used were identical to a system previously described. ${ }^{16}$ In this system, about $0.2 \mathrm{~g}$ of aged $\mathrm{Ag}^{0} \mathrm{Z}$ was loaded onto a steel screen suspended from a microbalance with a sensitivity of $0.1 \mu \mathrm{g}$. This suspended sample of aged $\mathrm{Ag}^{0} \mathrm{Z}$ was then exposed to a stream of dry air with an $\mathrm{I}_{2}$ concentration of $50 \mathrm{ppmv}$ at $150^{\circ} \mathrm{C}$. Mass gain taken from microbalance measurements was used to quantify the $\mathrm{I}_{2}$ adsorption capacity. When the sample mass stabilized, the $\mathrm{I}_{2}$ supply was shut off and a clean stream of dry air was allowed to flow through the aged sample to desorb any physisorbed I 2 . The $\mathrm{I}_{2}$ loaded samples were then stored until they were needed for characterization. All aged and $\mathrm{I}_{2}$ loaded samples were stored under an inert atmosphere of pure Ar at all times when they were not being actively characterized or being prepared for characterization. Additionally, the packaging of the samples ensured that they were not exposed to light at any time during storage. These steps were taken to prevent potential contamination of the samples between the aging and characterization experiments.

\subsubsection{Characterization Methods}

Aged and unaged $\mathrm{Ag}^{0} \mathrm{Z}$ samples were characterized through a combination of several complementary techniques including SEM, XRD, Raman spectroscopy, and XAS to evaluate the physical and chemical changes to the material after the aging experiments. For the SEM analysis, backscattered electron images were captured using a JEOL JSM-5600 instrument to obtain information regarding the topography and chemical composition of the surface of the mordenite samples. XRD was performed using a Bruker D8 Advance ECO powder diffractometer with $\mathrm{Cu}$ $\mathrm{K} \alpha$ radiation $(\lambda=1.54056 \AA)$ at $40 \mathrm{kV}$ and $25 \mathrm{~mA}$. The diffraction patterns attained though this investigation were collected along a $2 \theta$-range from $15^{\circ}$ to $60^{\circ}$ and analyzed with version 9.0 of MDI's Jade software. Raman spectroscopy was performed using a Renishaw InVia confocal Raman microscope equipped with a 785-nm continuous-wave diode laser combined with a Leica DM2700P microscope to provide spectra between 100 and $2500 \mathrm{~cm}^{-1}$ at room temperature. A near- 
infrared excitation wavelength was chosen for this analysis to avoid potential interference from fluorescence emissions. Biria and Hosein provide a detailed description of the Raman methodology used in this work. ${ }^{23}$

XAS was used to determine how $\mathrm{Ag}^{0} \mathrm{Z}$ 's chemical composition changes during aging and how aged samples adsorb I2. This analysis was performed at Argonne National Laboratory's Advanced Photon Source using beamline 10-ID-B after completing the three characterization techniques mentioned in the previous paragraph. ${ }^{24}$ Aged $\mathrm{Ag}^{0} \mathrm{Z}$ samples were ground with a mortar and pestle to achieve a uniform particle size. From each ground sample, a mass of approximately $10 \mathrm{mg}$ was loaded into a self-supported pallet and tested at the $\mathrm{Ag} \mathrm{K}$-edge of $25514 \mathrm{eV}$ in transmission mode. Data were also collected from Ag foil simultaneously to serve as a reference for energy calibration and data alignment. All samples were held under a pure Ar atmosphere at all times, from the completion of the initial aging or $\mathrm{I}_{2}$ loading of the material until the XAS investigations began. Analysis of the XAS data, which included spectra normalization, analysis of the X-ray Absorption Near Edge Structure (XANES) region, and linear combination fitting, was performed with Athena, a component of the Demeter software package. ${ }^{25}$ Linear combination fitting was performed on normalized $\mu(\mathrm{E})$ spectra from $30 \mathrm{eV}$ below to $100 \mathrm{eV}$ above the edge for all samples. Reference standards for unaged $\mathrm{Ag}^{0} \mathrm{Z}$ and $\mathrm{AgZ}$, silver nitrate $\left(\mathrm{AgNO}_{3}\right)$, and silver oxide $\left(\mathrm{Ag}_{2} \mathrm{O}\right)$ were used in combination fitting. From a proportional combination of these selected standards, an approximate XANES spectrum can be simulated and compared against the results obtained experimentally. The approximate spectrum was optimized based on the R-factor and reduced $\chi^{2}$ fit parameters with the combination of references resulting in the smallest fit parameters used as the most probable representation of the sample. Best fit results for each spectrum are included in the supporting information.

\subsubsection{Adsorption Modeling}

Aging simulations are performed with the DG-OSPREY model which is developed at the Georgia Institute of Technology. ${ }^{2}$ DG-OSPREY is, in turn, built within the Multiphysics Object Oriented Simulation Environment (MOOSE) modeling framework developed at the Idaho National Laboratory. ${ }^{26}$ The MOOSE framework, itself, is responsible for discretization of spatial domains and iteratively solving non-linear systems of equations. Domain discretization may be performed using either continuous or discontinuous finite element methods. Discontinuous methods are less oscillatory for problems derived from conservation laws and, as such, are used in DG-OSPREY. ${ }^{2}$ The non-linear system of equations produced from domain discretization is solved iteratively using the Preconditioned Jacobi Free-Newton Krylov (PJFNK) method. This method incorporates both a non-linear solver based on Newton type methods and a linear Krylov subspace method nested within the non-linear solver. Linear iterations are preconditioned using incomplete lower and upper triangular fractionalization. Line search methods, Back-Tracking for example, are used to control the convergence of the non-linear iterations. DG-OSPREY establishes the mass and energy conservation equations, formulated in the weak form and defined as piecewise discontinuous, needed to perform column adsorption modeling calculations.

Conservation of mass (Equation 1) is defined with respect to each gas species $\left(C_{i}\right)$ and its accumulation $\left(d C_{i} / d t\right)$ in the void space of the column as defined by the bulk bed porosity $(\varepsilon)$. Accumulation of each species is, in turn, further dependent upon advection, based on an advective velocity of $v$ through the column, dispersion $\left(D_{\mathrm{i}}\right)$, and the net adsorption rate $\left(d q_{i} / d t\right)$ multiplied by 
the adsorbent material's packing density $\left(\rho_{b}\right)$. The adsorption rate itself (Equation 2) is defined using a chemical reaction model where the forward and reverse rate constants are defined by $k_{f}$ and $k_{r}$, respectively. The reaction order with respect to each reactant $\left(v_{j}{ }^{*}\right)$ and product $\left(v_{k}{ }^{*}\right)$ species is considered to be independent of the species' stoichiometry $\left(v_{i}\right)$ in the chemical reaction. For solid species, mass conservation is significantly simplified since advection and diffusion do not need to be considered. Rather, adsorption represented through the net rate of adsorption which is the only component of Equation 1 that needs to be considered for non-gas phase species.

$$
\begin{gathered}
\varepsilon \frac{\partial C_{i}}{\partial t}+\nabla \cdot\left(\varepsilon v C_{i}\right)=\nabla \cdot\left(\varepsilon D_{i} \nabla C_{i}\right)+\rho_{b} \frac{\partial q_{i}}{\partial t} \\
\frac{\partial q_{i}}{\partial t}=v_{i}\left(k_{f} \prod_{j} C_{j}^{v_{j}^{*}}-k_{r} \prod_{k} C_{k}^{v_{k}^{*}}\right)
\end{gathered}
$$

Conservation of energy (Equation 3) is dependent upon the accumulation of heat $(d T / d t)$ that includes a contribution from the specific heat of the gas phase $\left(h_{g}\right)$ and that of adsorbents $\left(h_{s}\right)$ involving their respective densities $\left(\rho\right.$ and $\rho_{b}$ ). Energy transport as a result of gas advection and material thermal conductivity $(K)$, in addition to heating due to the isosteric heat of adsorption for each gas species $\left(Q_{s t, i}\right)$, is also considered. For fixed bed columns, mass and energy fluxes at the inlet are governed by advective and dispersive transport while at the exit a zero gradient condition is defined. ${ }^{2}$ For the simulations performed in this study, the aging environment was treated as a thin-bed with otherwise the same characteristics as the experimental system.

$$
\left(h_{g} \rho \varepsilon+h_{s} \rho_{b}\right) \frac{\partial T}{\partial t}+\nabla \cdot\left(h_{g} \rho \varepsilon v T\right)=\nabla \cdot(\varepsilon K \nabla T)+\rho_{b} \sum_{i} \frac{\partial\left(Q_{s t, i} q_{i}\right)}{\partial t}
$$

\subsection{Results and Discussion}

\subsubsection{Iodine Capacity Experiments}

Results of the $\mathrm{I}_{2}$ loading experiments on aged $\mathrm{Ag}^{0} \mathrm{Z}$ for $1 \% \mathrm{NO}$ in $\mathrm{N}_{2}$ and for $2 \% \mathrm{NO}_{2}$ in dry air at $150^{\circ} \mathrm{C}$ are shown in Table 1 . The $\mathrm{I}_{2}$ capacity was measured as a percent mass gained at equilibrium from exposure to $50 \mathrm{ppmv} \mathrm{I}_{2}$ in dry air. Thus, $\mathrm{Ag}^{0} \mathrm{Z}$ 's initial, unaged I capacity of 12.3 w.t $\%$ is equivalent to $0.123 \mathrm{~g}$ iodine adsorbed per $\mathrm{g}$ adsorbent. At this capacity, nearly $87 \%$ of the $\mathrm{Ag}$ in the unaged sample is utilized for $\mathrm{I}_{2}$ adsorption. Aging in the $2 \% \mathrm{NO}_{2}$ environment is significantly faster than in $1 \%$ NO, with the adsorbent losing almost $59 \%$ of its initial $\mathrm{I}_{2}$ capacity after only $12 \mathrm{~min} . \mathrm{Ag}^{0} \mathrm{Z}$ aged in just dry air for six months at $150^{\circ} \mathrm{C}$ lost $40 \%$ of its $\mathrm{I}_{2}$ adsorption capacity. ${ }^{17}$ Thus, while the samples are exposed to both $\mathrm{NO}_{2}$ and dry air for the duration of the experiment, the aging effect of dry air is essentially negligible compared to that of $\mathrm{NO}_{2}$. After five hours in $2 \% \mathrm{NO}_{2}$, the adsorbent has an $\mathrm{I}_{2}$ capacity is only 1.4 w.t. \% which amounts to a loss of over $88 \%$ of its initial capacity. The $\mathrm{I}_{2}$ capacity in $2 \% \mathrm{NO}_{2}$ aged samples continues to decline after one month, two months, and four months of aging with a final six-month aged capacity of 0.35 w.t. $\%$ which is about $2.8 \%$ of the $\mathrm{Ag}^{0} \mathrm{Z}$ 's initial capacity. In the $1 \% \mathrm{NO}$ environment, the $\mathrm{I}_{2}$ capacity drops to 7.48 w.t. $\%$ after one day and then to 4.95 w.t. $\%$ after one week from the initial 12.3 w.t. $\%$ on the unaged adsorbent. After one month in $1 \% \mathrm{NO}$, the $\mathrm{I}_{2}$ capacity declines to 1.4 w.t. \% which is the same as the $\mathrm{NO}_{2}$ aged sample's five hours capacity. The NO aged sample's 
capacity further drops to 1.27 w.t. $\%$ after four months and finally to 0.45 w.t. $\%$ after six months. As such, while aging in $2 \% \mathrm{NO}_{2}$ is significantly faster than in $1 \% \mathrm{NO}$, the degree of aging over the long term is roughly comparable.

Table 1: Equilibrium $\mathrm{I}_{2}$ capacity measured in weight percent gained after aging $\mathrm{Ag}^{0} \mathrm{Z}$ for a variety of times in the $1 \% \mathrm{NO}$ in $\mathrm{N}_{2}$ and in the $2 \% \mathrm{NO}_{2}$ in dry air aging environments at $150^{\circ} \mathrm{C}$.

\begin{tabular}{|c|c|c|c|}
\hline \multicolumn{2}{|c|}{$\mathbf{1 \%}$ NO in N2 } & \multicolumn{2}{c|}{ 2\% NO in Dry Air } \\
\hline Aging Time & $\mathrm{I}_{2}$ Capacity (w.t. \%) & Aging Time & $\mathrm{I}_{2}$ Capacity (w.t. \%) \\
\hline Unaged & 12.3 & Unaged & 12.3 \\
\hline 1 day & 7.48 & 12 min & 5.10 \\
\hline 1 week & 4.95 & 5 hour & 1.40 \\
\hline 1 month & 1.40 & 1 month & 0.98 \\
\hline 2 month & 1.62 & 2 month & 0.66 \\
\hline 4 month & 1.27 & 4 month & 0.30 \\
\hline 6 month & 0.47 & 6 month & 0.35 \\
\hline
\end{tabular}

These results clearly show that exposure to either $\mathrm{NO}$ or $\mathrm{NO}_{2}$ significantly impacts the $\mathrm{I}_{2}$ capacity of $\mathrm{Ag}^{0} \mathrm{Z}$. The $\mathrm{I}_{2}$ capacity loss from aging in the $1 \% \mathrm{NO}$ environment is in line with findings from a previous study on $\mathrm{Ag}^{0} \mathrm{Z}$ aging conducted by Patton and coworkers. ${ }^{19}$ Previous analyses of $\mathrm{I}_{2}$ capacity losses in $2 \% \mathrm{NO}_{2}$ were performed using a static atmosphere and, as such, are not comparable to the results obtained here in a continuous flow system. ${ }^{21}$ The $\mathrm{I}_{2}$ adsorption capacity alone does not, however, give sufficient insight to adequately ascertain the underlying processes that govern adsorbent aging, thus requiring further characterization of the material.

\subsubsection{Adsorbent Characterization}

\subsubsection{Scanning Electron Microscopy}

Representative SEM backscattered electron images for $\mathrm{AgZ}, \mathrm{Ag}^{0} \mathrm{Z}$, and $\mathrm{Ag}^{0} \mathrm{Z}$ aged for one month in $1 \% \mathrm{NO}$ in $\mathrm{N}_{2}$ and $2 \% \mathrm{NO}_{2}$ in dry air at $150^{\circ} \mathrm{C}$ are displayed in Figure 2. Irregularly shaped mordenite crystals are observed in all four images indicating that the mordenite's surface topography does not change as a result of either the reduction of $\mathrm{AgZ}$ to $\mathrm{Ag}^{0} \mathrm{Z}$ or the subsequent aging of $\mathrm{Ag}^{0} \mathrm{Z}$. When $\mathrm{AgZ}$ is reduced to $\mathrm{Ag}^{0} \mathrm{Z}$ using the $4 \% \mathrm{H}_{2}$ in $\mathrm{Ar}$ gas stream as discussed previously, small bright particles can be seen on the mordenite's surface (Figure $\mathbf{2 b}$ ). The high brightness of these particles in the backscattered electron image indicates that they are composed of elements with an atomic mass higher than that of the mordenite's framework elements of aluminum, silicon, and oxygen. These particles are composed of $\mathrm{Ag}^{0}$ that has migrated from the interior of the mordenite to its surface and coalesced into aggregate clusters during $\mathrm{H}_{2}$ reduction of $\mathrm{AgZ}$ as previously established. ${ }^{8,15,16}$ The diameter of the $\mathrm{Ag}^{0}$ particles observed on the mordenite's surface ranges from 0.1 to $1.2 \mu \mathrm{m}$. Nanoparticles with a diameter smaller than $0.1 \mu \mathrm{m}$ are also expected but cannot be observed at this magnification. ${ }^{15}$ After the $\mathrm{Ag}^{0} \mathrm{Z}$ is aged in either the $1 \% \mathrm{NO}$ or the $2 \% \mathrm{NO}_{2}$ gas stream, the number of $\mathrm{Ag}^{0}$ particles that are observable on the mordenite's surface is substantially reduced. This suggests that at least one component of material aging arises from the breakup of the large $\mathrm{Ag}^{0}$ particles formed during the reduction of $\mathrm{AgZ}$. Additionally, the uniform brightness of the mordenite crystals after aging shows that large particles (diameter $>0.1 \mu \mathrm{m}$ ) comprised of other $\mathrm{Ag}$ species, such as $\mathrm{AgNO}_{3}$ or $\mathrm{Ag}_{2} \mathrm{O}$, do not form on the 
mordenite's surface. Further characterization of the material is, nevertheless, still needed to precisely identify the processes governing particle breakup and the ultimate form of Ag after aging.
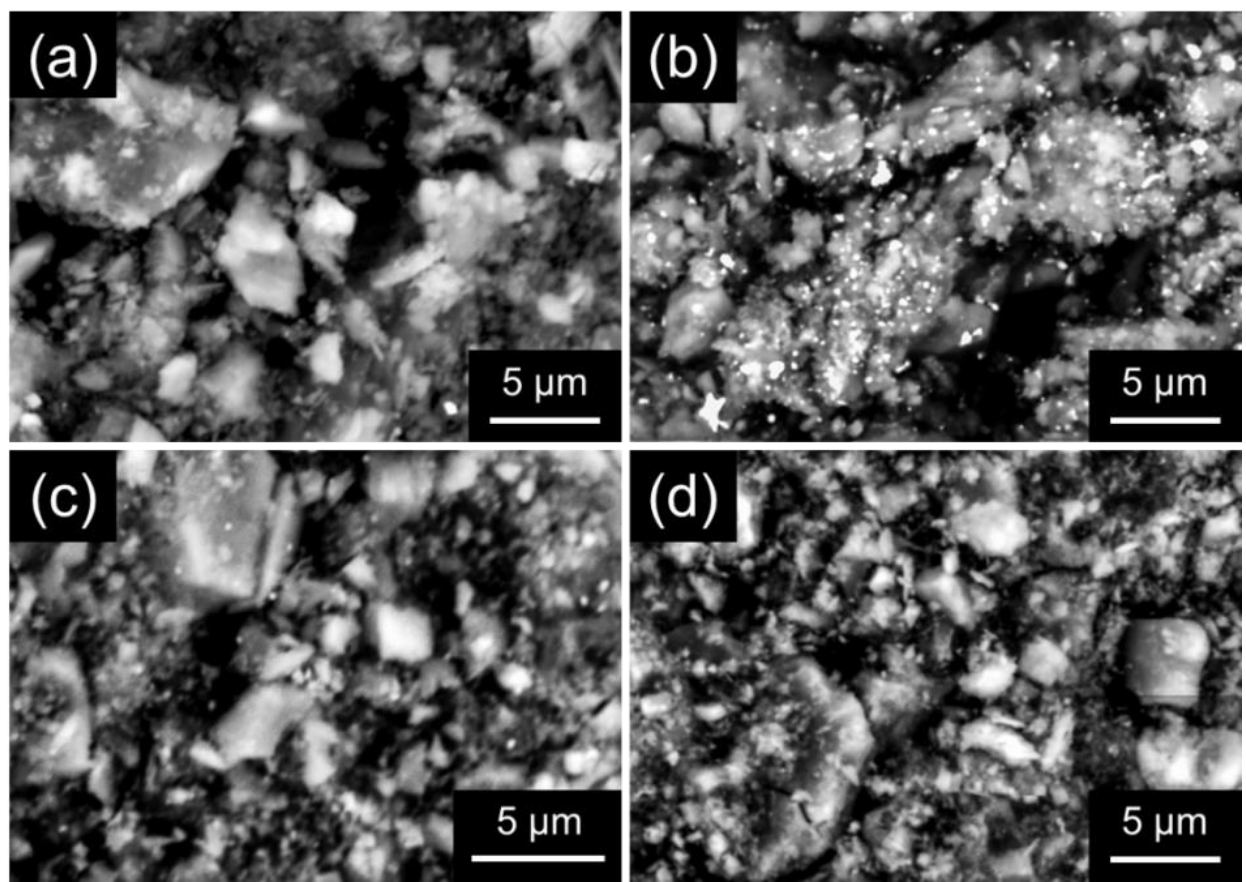

Figure 2. SEM images for (a) $\mathrm{AgZ}$; (b) $\mathrm{Ag}^{0} \mathrm{Z}$; (c) $\mathrm{Ag}^{0} \mathrm{Z}$ aged in $1 \% \mathrm{NO}$ in $\mathrm{N}_{2}$ for one month at $150^{\circ} \mathrm{C}$; (d) $\mathrm{Ag}^{0} \mathrm{Z}$ aged in $2 \% \mathrm{NO}_{2}$ in dry air for one month at $150^{\circ} \mathrm{C}$. Scale bars are $5 \mu \mathrm{m}$ in each image.

\subsubsection{X-ray Diffraction}

XRD patterns for $\mathrm{Ag}^{0} \mathrm{Z}$ samples aged in $1 \% \mathrm{NO}$ and $2 \% \mathrm{NO}_{2}$ at $150^{\circ} \mathrm{C}$ are summarised in Figures $3 \mathbf{a}$ and $\mathbf{3 b}$, respectively. Patterns for unaged $\mathrm{Ag}^{0} \mathrm{Z}$ and $\mathrm{AgZ}$ are also shown in both figures. Each of the samples examined exhibited a pattern at $2 \theta$ between $10^{\circ}$ and $36^{\circ}$ that is typical for mordenite crystals. In the pattern for unaged $\mathrm{Ag}^{0} \mathrm{Z}$, two peaks associated with $\mathrm{Ag}^{0}$ are observed at $2 \theta=38.2^{\circ}$ and $2 \theta=44.3^{\circ}$ in addition to the typical mordenite peaks. These peaks are associated with the (110) and (200) miller indices, respectively. The appearance of these two $\mathrm{Ag}^{0}$ peaks is to be expected given that the formation of metallic Ag particles was observed on the mordenite's surface following $\mathrm{AgZ}$ reduction to $\mathrm{Ag}^{0} \mathrm{Z}$ in the backscattered electron images discussed previously. Using the Scherrer equation, the mean size of the $\mathrm{Ag}$ particles on unaged $\mathrm{Ag}^{0} \mathrm{Z}$ was determined to be $3.65 \mathrm{~nm}$. This is consistent with the work of Zhao and coworkers who reported that the size of the Ag nanoparticles formed under the reduction conditions used in this study would be greater than $3 \mathrm{~nm} .{ }^{8}$ Additionally, the pores in the mordenite pellet are between $0.5 \mathrm{~nm}$ and 40 $\mathrm{nm}$ in size. Thus, while the particles tend to migrate towards the surface of the mordenite pellets, as our SEM results show, many of the smaller Ag particles are likely located in the pellet's pores. As the $\mathrm{Ag}^{0} \mathrm{Z}$ samples are aged, the intensity of the $\mathrm{Ag}^{0}$ peaks declines indicating that the amount

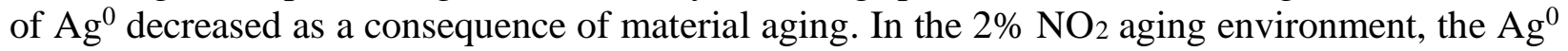
peak disappears completely within the first five hours of aging at $150^{\circ} \mathrm{C}$. For samples exposed to the $1 \% \mathrm{NO}$ aging environment, the peaks associated with $\mathrm{Ag}^{0}$ were still present after one week of aging at $150^{\circ} \mathrm{C}$ and had disappeared entirely after one month. Ag particles still present in the NO 
aged sample after one week had a mean size of $3.77 \mathrm{~nm}$ which was slightly larger than the mean size for Ag particles in the unaged sample. It should also be noted that all aged samples retain the patterns between $10^{\circ}$ and $36^{\circ}$ that are characteristic of mordenite crystals indicating that aging has no impact of the mordenite's crystalline structure. These results clearly suggest that the dramatic decline in the adsorbent's $\mathrm{I}_{2}$ capacity is largely a consequence of $\mathrm{Ag}$ oxidation converting $\mathrm{Ag}^{0}$ into other chemical forms that are unavailable for $\mathrm{I}_{2}$ adsorption. Neither $\mathrm{NO}$ or $\mathrm{NO}_{2}$ aged $\mathrm{Ag}^{0} \mathrm{Z}$ exhibits any additional characteristic peaks. Given that the instrument used for this analysis has a detection limit of one Angstrom, the absence of any additional peaks indicates that the Ag species formed as a result of aging do not coalesce into bulk phase species with identifiable crystalline structures. Instead, the oxidized Ag species formed from aging likely exist as either small molecular clusters or isolated surface species that are undetectable using XRD.

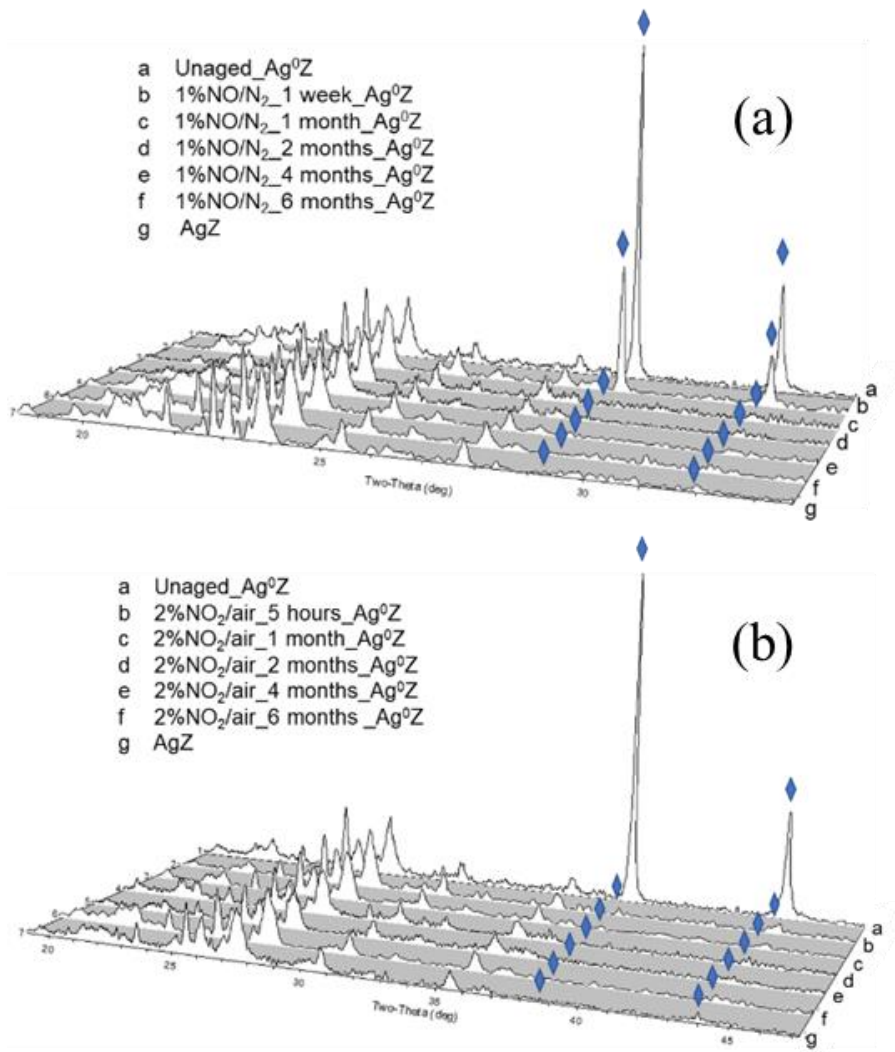

Figure 3. XPS patterns for $\mathrm{AgZ}, \mathrm{Ag}^{0} \mathrm{Z}$, and $\mathrm{Ag}^{0} \mathrm{Z}$ aged at $150^{\circ} \mathrm{C}$ in (a) $1 \% \mathrm{NO}$ in $\mathrm{N}_{2}$ for one week, one month, two months, four months, and six months and (b) $2 \% \mathrm{NO}_{2}$ in dry air for five hours, one month, two months, four months, and six months. Marks are provided on each spectrum to indicate characteristic peaks for $\mathrm{Ag}^{0}$.

\subsubsection{Raman Spectroscopy}

In an attempt to more precicely identify how $\mathrm{Ag}$ speciation changes as a result of $\mathrm{Ag}^{0} \mathrm{Z}$ aging, Raman spectra for $\mathrm{AgZ}, \mathrm{Ag}^{0} \mathrm{Z}$, and aged $\mathrm{Ag}^{0} \mathrm{Z}$ were collected. The results from these measurments are summarized in Figures $4 \mathbf{a}$ and $\mathbf{4 b}$ for samples aged in $1 \%$ NO in $\mathrm{N}_{2}$ and $2 \%$ $\mathrm{NO}_{2}$ in dry air, repectively. A broad band between $100 \mathrm{~cm}^{-1}$ and $400 \mathrm{~cm}^{-1}$ with its peak at $193 \mathrm{~cm}^{-}$ ${ }^{1}$ is observed on the spectrum for the as received AgZ. This band can likely be attributed to Ag that is incorporated into the mordenite crystal since peaks in this region are commonly associated with 
the vibrational modes of the Ag lattice. ${ }^{27}$ The intensity of the band between 100 and $400 \mathrm{~cm}^{-1}$ increases signitifantly after $\mathrm{AgZ}$ is reduced to $\mathrm{Ag}^{0} \mathrm{Z}$ sugesting a greater conentration of $\mathrm{Ag}$ on the mordenite's surface. Additionally, a new peak at $166 \mathrm{~cm}^{-1}$ is observed alongside the peak at 193 $\mathrm{cm}^{-1}$ on the sepctrum for $\mathrm{Ag}^{0} \mathrm{Z}$. These two developments can be attributed to the formation of the $\mathrm{Ag}$ particles previously observed, which entails the reduction of $\mathrm{Ag}$ to $\mathrm{Ag}^{0}$, migration of $\mathrm{Ag}^{0}$ to the surface, and then aggregation of $\mathrm{Ag}^{0}$ into nanoparticles. ${ }^{8,15,16}$

After one month in either aging environment, the intensity of the $\mathrm{Ag}$ band between 100 $\mathrm{cm}^{-1}$ and $400 \mathrm{~cm}^{-1}$ decreases dramatically. Since the peaks at $166 \mathrm{~cm}^{-1}$ and $193 \mathrm{~cm}^{-1}$ are of roughly equal intensity before aging, the declining intensity of the $\mathrm{Ag}$ band can largely be attributed to the reduced intensity of the peak at $166 \mathrm{~cm}^{-1}$ after one month of aging. An additional month of aging does not result in any signitifanct change to the $\mathrm{Ag}$ band in either aging environment. These results suggest, in agreement with our XRD findings, that $\mathrm{Ag}^{0}$ oxidation is one of the key components of aging. Additionally, the reduced intensity of the $\mathrm{Ag}$ band between $100 \mathrm{~cm}^{-1}$ and $400 \mathrm{~cm}^{-1}$ indicates $\mathrm{Ag}$ is migrating into the interior of the mordenite. The migration of $\mathrm{Ag}$ in this fashion would necessitate the breakup of Ag particles as previously observed in our SEM results. Thus, the aging of $\mathrm{Ag}^{0} \mathrm{Z}$ can broadly be broken into three overaching processes including: (i) oxidation of $\mathrm{Ag}^{0}$ on the Ag particle's surface, (ii) separation of oxidized Ag from the Ag particle, and (iii) migration of oxidized Ag off of the mordenite's surface without forming large aggregates. Agostini and coworkers document a similar phenomenon when Ag nanopaticles are oxidized by $\mathrm{O}_{2}$ at elevated temperatures. ${ }^{28}$ A notable band at $1045 \mathrm{~cm}^{-1}$ corresponding to $\mathrm{AgNO}_{3}$ that is evident for $\mathrm{Ag}^{0} \mathrm{Z}$ samples aged in both the $\mathrm{NO}$ and $\mathrm{NO}_{2}$ gas streams gives us some insight into the process by which $\mathrm{Ag}^{0}$ is oxidized.
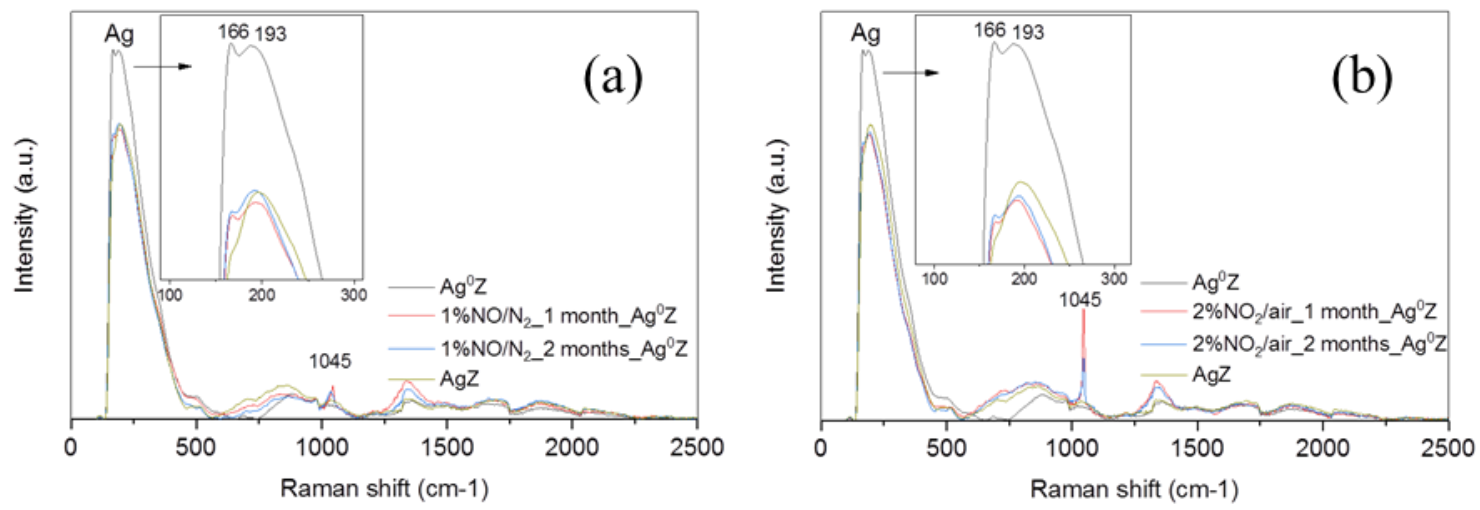

Figure 4. Raman spectra of $\mathrm{AgZ}, \mathrm{Ag}^{0} \mathrm{Z}$, and $\mathrm{Ag}^{0} \mathrm{Z}$ aged at $150^{\circ} \mathrm{C}$ in (a) $1 \% \mathrm{NO}$ in $\mathrm{N}_{2}$ at $150^{\circ} \mathrm{C}$ for one and two months and in (b) $2 \% \mathrm{NO}_{2}$ in dry air at $150^{\circ} \mathrm{C}$ for one and two months.

Considering the major gas species in each aging stream and their potential interactions with metallic Ag that can lead to the formation of $\mathrm{AgNO}_{3}$ in some form, we may begin to delineate the starting point for $\mathrm{Ag}^{0} \mathrm{Z}$ aging. Since $\mathrm{N}_{2}$ is an inert gas in this system, the only significant gas species that may react with the Ag nanoparticle at the experimental temperature are $\mathrm{O}_{2}, \mathrm{NO}$, and $\mathrm{NO}_{2}$. At the experimental temperature of $150^{\circ} \mathrm{C}$, dissociative adsorption of $\mathrm{O}_{2}$ is known to occur on metallic Ag, forming an adsorbed oxide species with the net reaction shown in Equation 4. ${ }^{29-}$ 31 This is a well-established reaction but the absence of an appropriate peak on the Raman spectra of aged $\mathrm{Ag}^{0} \mathrm{Z}$ demonstrates that this oxide species is only an intermediate product on the path to nitrate formation. Another potential reaction for oxide formation is given in Equation 5 where 
$\mathrm{NO}_{2}$ dissociatively adsorbs to the Ag surface, forming an adsorbed oxide and releasing $\mathrm{NO}$ gas. ${ }^{32}$ From this point, $\mathrm{NO}_{2}$ can then adsorb on the oxide species, yielding an adsorbed nitrate on the $\mathrm{Ag}$ nanoparticle through the reaction described in Equation 6. ${ }^{33,34} \mathrm{NO}$, by itself, does not adsorb to bare metallic $\mathrm{Ag}$ at temperatures above $\sim 20^{\circ} \mathrm{C} .{ }^{35,36}$ The formation of an adsorbed oxide species can, however, occur through $\mathrm{Na}$ catalyzed dissociative adsorption of $\mathrm{NO}$ on the Ag nanoparticle as described in Equation 7. ${ }^{37} \mathrm{Na}$ is present in the mordenite as a metal impurity with a $\mathrm{Ag}-\mathrm{Na}$ molar ratio of 6.4:1. Further adsorption of $\mathrm{NO}$ on the adsorbed oxide can then lead to the formation of an adsorbed nitrate on the Ag surface (Equation 8). ${ }^{38,39}$

$$
\begin{aligned}
& 4 \mathrm{Ag}^{0}+\mathrm{O}_{2} \leftrightarrow 2\left(\mathrm{Ag}_{2} \mathrm{O}\right)_{\mathrm{ads}} \\
& 2 \mathrm{Ag}^{0}+\mathrm{NO}_{2} \leftrightarrow\left(\mathrm{Ag}_{2} \mathrm{O}\right)_{\mathrm{ads}}+\mathrm{NO} \\
& \mathrm{Ag}_{2} \mathrm{O}+\mathrm{NO}_{2} \leftrightarrow\left(\mathrm{AgNO}_{3}\right)_{\mathrm{ads}}+\mathrm{Ag}^{0} \\
& (\mathrm{Na})_{\mathrm{ads}}+2 \mathrm{Ag}^{0}+\mathrm{NO} \rightarrow(\mathrm{Na})_{\mathrm{ads}}+\left(\mathrm{Ag}_{2} \mathrm{O}\right)_{\mathrm{ads}}+0.5 \mathrm{~N}_{2} \\
& \left(\mathrm{Ag}_{2} \mathrm{O}\right)_{\mathrm{ads}}+2 \mathrm{NO} \rightarrow\left(\mathrm{AgNO}_{3}\right)_{\mathrm{ads}}+\mathrm{Ag}^{0}+0.5 \mathrm{~N}_{2}
\end{aligned}
$$

These adsorbed nitrates are not the final form of $\mathrm{Ag}$ in the system. Instead, the formation of these nitrates results in the dissolution of the Ag nanoparticles, allowing oxidized Ag to migrate into the mordenite's interior. This should ultimately result in Ag migrating into the mordenite's channels where it will exchange at protonated binding sites (HZ), thus returning Ag to its original state prior to $\mathrm{H}_{2}$ reduction (Equation 9). The persistence of the peak at $1045 \mathrm{~cm}^{-1}$, however, indicates that not all $\mathrm{Ag}$ in the system will exchange at binding sites, leaving some portion as nitrates on the mordenite's surface. Based on the results from our SEM and XRD analyses, these nitrates are not in the form of bulk phase $\mathrm{AgNO}_{3}$ but, instead, likely exist in the form of molecular surface species.

$$
\left(\mathrm{AgNO}_{3}\right)_{\mathrm{abs}}+\mathrm{HZ} \rightarrow \mathrm{AgZ}+\mathrm{HNO}_{3}
$$

Thus, at any given time, there are three significant forms of Ag that may exist in either the $\mathrm{NO}$ or $\mathrm{NO}_{2}$ aged sample. Aging could be easily represented if we only needed to consider $\mathrm{I}_{2}$ adsorption on the $\mathrm{Ag}^{0}$ nanoparticles. This, unfortunately, is simply not the case. While the reaction pathway is unknown, there is, nevertheless, clear evidence that a notable quantity of $\mathrm{I}_{2}$ is adsorbed on unreduced $\mathrm{AgZ}$ in the form of $\alpha$-phase $\mathrm{AgI} .{ }^{9,15,18}$ Based on the analysis of Patton and coworkers, the Ag utilization rate for $\mathrm{I}_{2}$ adsorption on $\mathrm{AgZ}$ can be as much as $27 \%$ at $150^{\circ} \mathrm{C}{ }^{18}$ Though far lower than the $87 \%$ Ag utilization rate achieved for unaged $\mathrm{Ag}^{0} \mathrm{Z}$, this utilization rate is still higher than the $9.7 \%$ achieved by aged $\mathrm{Ag}^{0} \mathrm{Z}$ after five hours in the $2 \% \mathrm{NO}_{2}$ and one month in the $1 \% \mathrm{NO}$ gas streams. As such, material aging must also involve a secondary effect that influences $\mathrm{I}_{2}$ adsorption in the $\alpha$-phase.

\subsubsection{X-ray Absorption Spectroscopy}

To further investigate $\mathrm{Ag}$ speciation as a function of aging time and to determine the contribution of each Ag species to $\mathrm{I}_{2}$ adsorption, several aged samples were characterized before and after $\mathrm{I}_{2}$ adsorption using XAS analysis. In this case the XANES, which includes the region of the XAS spectrum starting before the absorption edge and continuing to 50-100 eV beyond, was analyzed. The XANES is sensitive to metal oxidation states and the geometry of coordination due to selection rules dictating the probability of X-ray absorption. XANES of unreduced $\mathrm{AgZ}, \mathrm{Ag}^{0} \mathrm{Z}$, and mordenite aged in $1 \% \mathrm{NO}$ and $2 \% \mathrm{NO}_{2}$ are shown in Figure 5. The spectrum of the as received 
$\mathrm{AgZ}$ shows an absorption edge with the inflection point occurring at $25520 \mathrm{eV}$ and white line at $25525 \mathrm{eV}$, but it is otherwise devoid of any significant features. In contrast, $\mathrm{Ag}^{0} \mathrm{Z}$ has a spectrum that is similar to $\mathrm{Ag}$ foil due to the formation of $\mathrm{Ag}^{0}$ nanoparticles on the mordenite's surface after reduction by $\mathrm{H}_{2}{ }^{9,15,16,40}$ This agrees well with our findings from SEM, XRD, and Raman spectroscopy. The spectra for samples aged in $\mathrm{NO}$ and $\mathrm{NO}_{2}$ are very similar to the spectrum for $\mathrm{AgZ}$, in that they show a dominant white line without any significant subsequent oscillations. These conspicuous differences apparent in the spectra allow for straightforward analysis by linear combination fitting, affording a means by which the ratio of $\mathrm{Ag}$ species present in the aged mordenite can also be quantified.
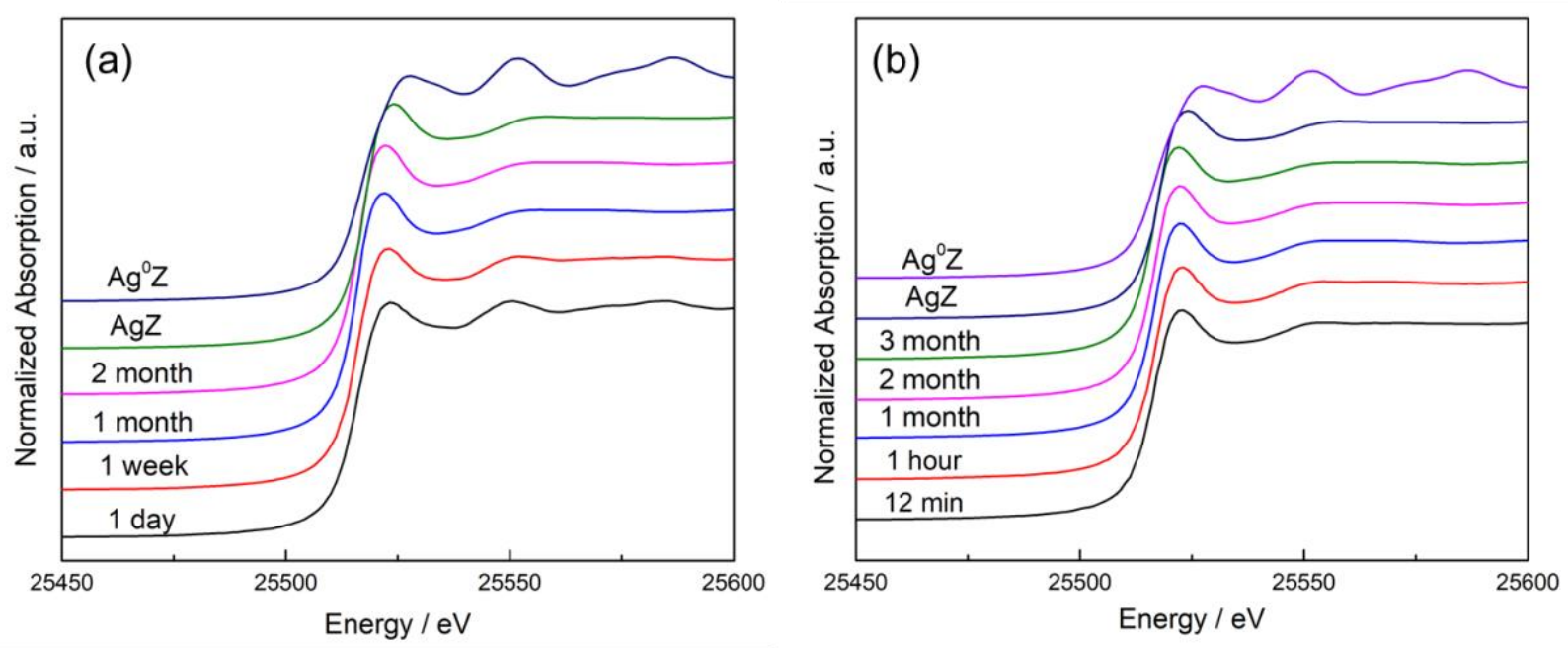

Figure 5. Normalized Ag K-edge XANES of AgZ aged in (a) $1 \% \mathrm{NO}_{\text {in }} \mathrm{N}_{2}$ and (b) $2 \% \mathrm{NO}_{2}$ in dry air.

Four different Ag standards were used throughout the linear combination fitting analysis including: (i) $\mathrm{AgZ}$ to represent unreduced $\mathrm{Ag}$ bound at mordenite binding sites, (ii) $\mathrm{Ag}^{0} \mathrm{Z}$ as a representation of $\mathrm{Ag}^{0}$ in the form of nanoparticles, (iii) $\mathrm{Ag}_{2} \mathrm{O}$ for oxides in the system, and (iv) $\mathrm{AgNO}_{3}$ for nitrates. A fifth standard for silver iodide (AgI) was used when examining samples exposed to $\mathrm{I}_{2}$. Linear combination fits are shown in the supporting information for samples aged in $2 \% \mathrm{NO}_{2}$ before (Figure S1) and after $\mathrm{I}_{2}$ adsorption (Figure S2), and for samples aged in $1 \%$ NO before (Figure S3) and after $\mathrm{I}_{2}$ adsorption (Figure S4). From these fits, the breakdown of Ag species as a percentage of total $\mathrm{Ag}$ is determined for samples aged in both the $2 \% \mathrm{NO}_{2}$ (Figure 6) and the $1 \% \mathrm{NO}$ (Figure 7) environments. For samples aged in the $2 \% \mathrm{NO}_{2}$ stream, $\mathrm{Ag}^{0}$ is rapidly oxidized leaving only about $1 \%$ of $\mathrm{Ag}$ in the reduced state after $12 \mathrm{~min}$. After one hour, $\mathrm{all}^{\mathrm{Ag}^{0} \mathrm{Z}}$ in the $\mathrm{NO}_{2}$ aged system had been oxidized, leaving about $67.5 \%$ of $\mathrm{Ag}$ in the form of $\mathrm{AgZ}$, while the remaining $32.5 \%$ was in the form of surface nitrates. There is an increase in the percentage of $\mathrm{Ag}$ in the form of nitrates after one month of aging in $2 \% \mathrm{NO}_{2}$, which can be attributed primarily to material non-uniformity. The remaining $2 \% \mathrm{NO}_{2}$ aging times of two months and three months have the same proportion of $\mathrm{Ag}$ in the form of $\mathrm{AgZ} \mathrm{(71 \% )} \mathrm{and} \mathrm{surface} \mathrm{nitrates} \mathrm{(29 \% ).}$ 

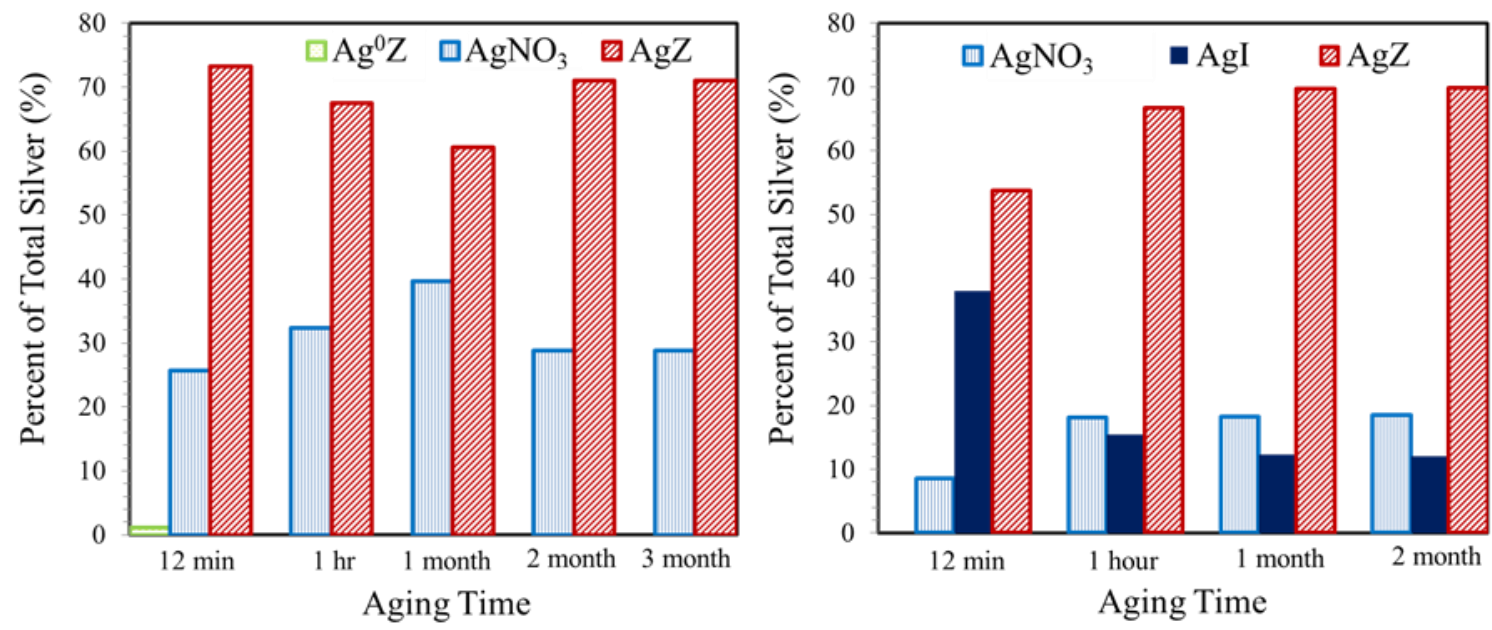

Figure 6. Proportion of each $\mathrm{Ag}$ species present in $2 \% \mathrm{NO}_{2}$ aged mordenite samples as a percent of total Ag before (left) and after (right) I2 adsorption determined from linear combination fitting of XANES data.

No oxides were observed for any of the $2 \% \mathrm{NO}_{2}$ aging times. This is not particularly surprising since the vast majority of $\mathrm{Ag}^{0} \mathrm{Z}$ has been oxidized within the first 12 min in $2 \% \mathrm{NO}_{2}$. As previously discussed in Section 3.2.3, oxides are only formed as an adsorbed surface species on the Ag nanoparticle in the $2 \% \mathrm{NO}_{2}$ environment through the reactions described in Equations 4 and 5. This adsorbed oxide serves as an intermediate product in the formation of the adsorbed nitrates that ultimately induce the migration of oxidized Ag off the surface of the Ag nanoparticle. Thus, we would only expect to see a noticeable concentration of oxides form when a reasonably large amount of $\mathrm{Ag}^{0} \mathrm{Z}$ is present in the system and disappear when $\mathrm{Ag}^{0} \mathrm{Z}$ has been exhausted. While the reactions are different for $1 \%$ NO aging, a similar effect is observed where a small oxide concentration is maintained early on, when a significant concentration of $\mathrm{Ag}^{0} \mathrm{Z}$ persists. Another interesting feature observed here is the persistent nitrate concentration, also observed in the Raman spectra, that remains even in samples aged in $\mathrm{NO}_{2}$ for more than two months. As previously described, all nitrates should, ideally, migrate into the mordenite crystals and exchange at protonated sites as described in Equation 9. Thus, it would be reasonable to expect that nitrates would make up a large proportion of the total Ag early on and then decline over time as a result of migration. Instead, the percentage of $\mathrm{Ag}$ in the form of nitrates does not significantly change between 12 min (25.7\%) and three months (29\%) in the $\mathrm{NO}_{2}$ environment.

The most likely explanation for this behavior lies in the structure of the mordenite crystal. Binding sites are located in the main channels, side channels, and side pockets of the mordenite with a roughly 50/50 split between the main and side areas. ${ }^{41,42}$ The distribution of binding sites is, nevertheless, somewhat variable leading to a certain amount of non-uniformity between mordenite samples. In this study, the mordenite crystal contains 12 -member main $(7.0 \times 6.5 \AA)$ channels, one set of 8 -member side channels $(5.7 \times 2.6 \AA)$ that run parallel to the main channels, and another set of 8 -member side channels $(3.4 \times 4.8 \AA)$ that connect the previous two types of channels. ${ }^{10}$ Small 5 -member side pockets are also present and can be found between the main and side channels (Figure S5). The size of the side channels and side pockets may, therefore, simply be too small to allow for nitrate migration. This is known to occur with larger molecules that are only able to diffuse through the crystals main channels and will not enter the side areas. ${ }^{10}$ Another, 
more likely, possibility is that the structure of the side spaces alters the site exchange reaction pathway to make the process less favorable and thus prevents the reaction from occurring. A similar phenomenon is observed in the adsorption of $\mathrm{I}_{2}$ on $\mathrm{AgZ}$ where main-channel sites interact strongly enough with $\mathrm{I}_{2}$ to cleave the I-I bond, while on side-channel sites $\mathrm{I}_{2}$ is outcompeted by $\mathrm{H}_{2} \mathrm{O} .{ }^{12}$ In either case, the persistent nitrate concentration can be attributed to their inability to exchange at protonated sites in the mordenite's side channels and side pockets.

After $\mathrm{I}_{2}$ adsorption, the percentage of total $\mathrm{Ag}$ in the form of $\mathrm{AgI}$ is $37.9 \%, 15.4 \%, 12.3 \%$, and $12.0 \%$ for samples aged in $2 \% \mathrm{NO}_{2}$ for 12 min, one hour, one month, and two months, respectively. By considering the concentration of each $\mathrm{Ag}$ form before and after $\mathrm{I}_{2}$ adsorption, the contribution of these species to the formation of $\mathrm{AgI}$ can be estimated. For 12 min aging in $\mathrm{NO}_{2}$ (Figure 6), the AgZ and nitrate concentrations drop by $19.6 \%$ (73.2\% to 53.6\%) and $17.3 \%$ (25.7\% to $8.4 \%$ ) of total $\mathrm{Ag}$ after $\mathrm{I}_{2}$ adsorption, respectively. Thus, of the $37.9 \%$ of all $\mathrm{Ag}$ in the form of AgI, the adsorption of $\mathrm{I}_{2}$ on $\mathrm{AgZ}$ accounts for $51.5 \%$ (19.6\% out of $37.9 \%$ ) of the AgI formed, while adsorption of $\mathrm{I}_{2}$ on surface nitrates accounts for $45.6 \%(17.3 \%$ out of $37.9 \%)$ of $\mathrm{AgI}$ formation. The remaining $2.6 \%$ arises from the adsorption of $\mathrm{I}_{2}$ on $\mathrm{Ag}^{0} \mathrm{Z}$ for samples aged in the $2 \% \mathrm{NO}_{2}$ environment for $12 \mathrm{~min}$. After one hour of aging, $\mathrm{AgZ}$ 's contribution to $\mathrm{I}_{2}$ adsorption has declined significantly with only $5.8 \%$ of $\mathrm{AgI}$ forming in the $\alpha$-phase, while the remainder is formed through adsorption of $\mathrm{I}_{2}$ on surface nitrates. This is also the case after two months in the $\mathrm{NO}_{2}$ environment with a comparable amount of $\mathrm{I}_{2}$ adsorbed on $\mathrm{AgZ}$. This declining contribution to $\mathrm{I}_{2}$ adsorption from $\mathrm{AgZ}$ is likely related to a persistent nitrate concentration that is seemingly unavailable for $I_{2}$ adsorption.

At an aging time of 12 min in the $\mathrm{NO}_{2}$ environment, nitrates that do not adsorb $\mathrm{I}_{2}$ represent roughly $33 \%$ of the sample's nitrates associated with Ag. This fraction increases to $\sim 64 \%$ of all nitrates after two months of aging. Nitrates unavailable for $\mathrm{I}_{2}$ adsorption could be attributed to the formation of immobile Ag nitrate clusters stabilized within the mordenite crystal's main channels. Interactions that stabilize molecular clusters within the mordenite channels have already been observed. ${ }^{43} \mathrm{AgI}$ in the $\alpha$-phase, for example, is usually only stable above $147^{\circ} \mathrm{C}$ in clusters $>10 \mathrm{~nm}$ in size, but inside the mordenite main channels sub-nanometer clusters are stable to temperatures as low as $95^{\circ} \mathrm{C}$ through mordenite-cluster interactions. ${ }^{9}$ Additionally, the congregation of these immobile clusters within the main channels would obstruct access to the binding sites needed for the formation of $\alpha$-phase AgI, explaining the declining contribution to $\mathrm{I}_{2}$ adsorption from AgZ. Another possible explanation for these phenomena could be the formation of bridged nitrates between $\mathrm{Ag}$ atoms at framework binding sites that are known to be stable up to at least $100{ }^{\circ} \mathrm{C} .{ }^{44}$ Excessive buildup of bridged nitrates in the mordenite main channels would also obstruct gas diffusion in the mordenite's interior, although their interactions with $\mathrm{I}_{2}$ have not been studied. Regardless, nitrate buildup in the mordenite channels is likely the explanation for the persistent nitrate concentration observed and the limited formation of $\alpha$-phase AgI in well-aged samples. 

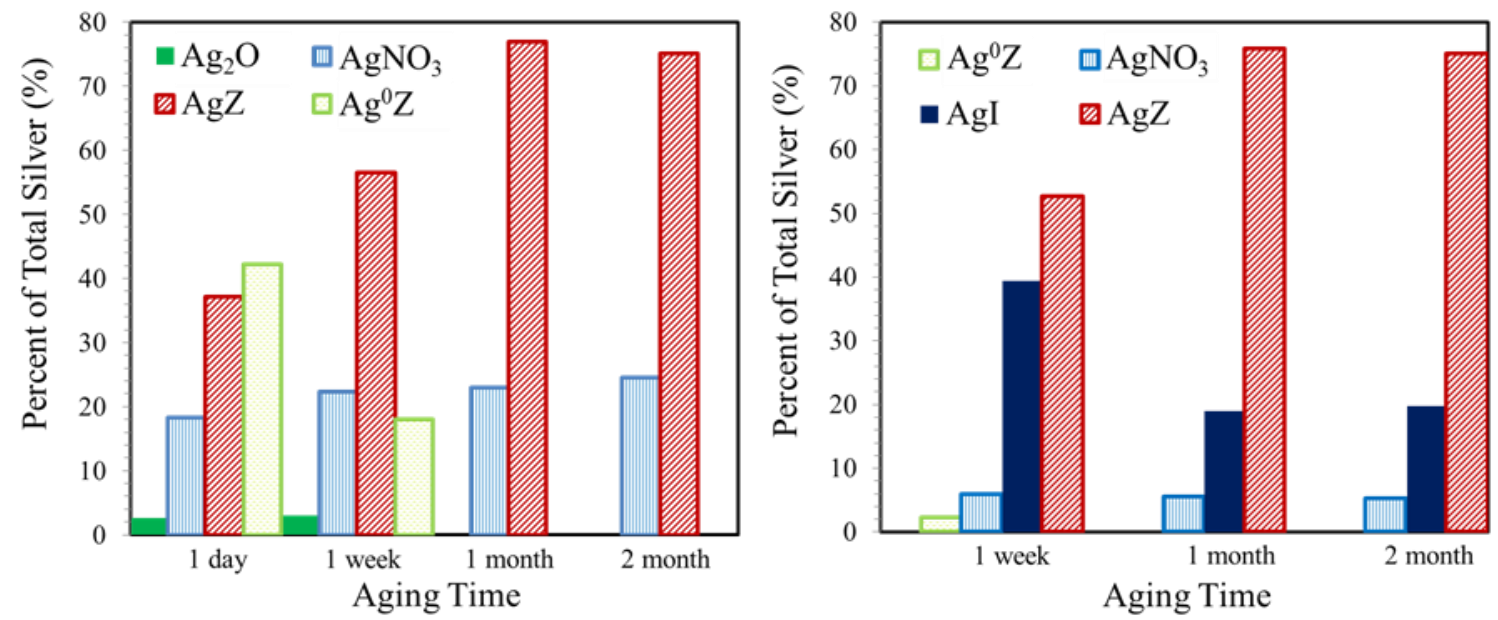

Figure 7. Proportion of each Ag species present in $1 \% \mathrm{NO}$ aged mordenite samples as a percent of total $\mathrm{Ag}$ before (left) and after (right) $\mathrm{I}_{2}$ adsorption determined from linear combination fitting of XANES data.

Aging of the adsorbent in the $1 \% \mathrm{NO}$ environment is also shown to significantly reduce $\mathrm{I}_{2}$ adsorption capacity, though this effect is much slower than the aging effect in $2 \% \mathrm{NO}_{2}$. After a single day of $\mathrm{NO}$ aging, $\mathrm{Ag}^{0} \mathrm{Z}$ has declined drastically representing only $42.3 \%$ of all $\mathrm{Ag}$ in the system. By the end of the first week, the proportion of $\mathrm{Ag}$ in the reduced form has declined even further to $18 \%$ of total $\mathrm{Ag}$, and after one month of aging in $1 \% \mathrm{NO}$, it has vanished entirely. A small portion of $\mathrm{Ag}$ is in the form of oxides ( $3 \%$ of total $\mathrm{Ag}$ ) at both the one day and the one week aging times but disappears from the system after one month alongside $\mathrm{Ag}^{0} \mathrm{Z}$. Oxides are formed in this environment from the dissociative adsorption of NO catalyzed by $\mathrm{Na}$ as previously described through the reaction given in Equation 7. Nitrates make up 18.3\% of total Ag after one day with a slight increase in its proportion of total Ag to $22.4 \%$ after one week and then to $23 \%$ after one month. AgZ makes up 37.2\%, 56.5\%, and 77\% of total Ag after one day, one week, and one month aging in the $1 \%$ NO environment, respectively. Interestingly, nitrate migration to the mordenite's channel binding sites in $1 \% \mathrm{NO}$ seems to be much slower than in $2 \% \mathrm{NO}_{2}$ where the system reached equilibrium after one hour. This may be attributed to a delay in the dissolution of the Ag nanoparticles with the adsorbed nitrates on the nanoparticle's surface residing there for some period of time in $\mathrm{NO}$ since it is significantly less reactive that $\mathrm{NO}_{2}$.

Following $\mathrm{I}_{2}$ exposure, AgI makes up $39.4 \%$ of total Ag on the sample aged for one week and $19 \%$ on the sample aged for one month. For the one-week aged sample, the two largest contributors to $\mathrm{I}_{2}$ adsorption are $\mathrm{Ag}^{0} \mathrm{Z}(\sim 40 \%)$ and surface nitrates $(\sim 42 \%)$ with small contributions from adsorption on oxides $(\sim 8 \%)$ and $\alpha$-phase adsorption on $\mathrm{AgZ}(\sim 10 \%)$. After one month, $\mathrm{Ag}$ in the form of oxides and $\mathrm{Ag}^{0} \mathrm{Z}$ disappear from the system, and adsorption on surface nitrates represents nearly all, about $93.5 \%$, of the $\mathrm{I}_{2}$ adsorption observed. As with $\mathrm{NO}_{2}$ aging, a permanent nitrate concentration that is unavailable for $\mathrm{I}_{2}$ adsorption develops, though it is significantly smaller in this environment. The percentage of total Ag occupied by the unavailable channel nitrate phase is $5.2 \%$ in the $1 \%$ NO stream after two months compared to $18.4 \%$ in $2 \% \mathrm{NO}_{2}$. Nevertheless, there is no significant increase in the contribution to $\mathrm{I}_{2}$ adsorption from the $\alpha$-phase suggesting that the interior AgZ binding sites are still inaccessible. This can be explained through the behavior of Fe impurities, 6.3:1 Ag-Fe molar ratio, present in the material. After $\mathrm{H}_{2}$ reduction, all Fe present 
in the mordenite crystal will be reduced to Fe (II) and will be bound to the mordenite as an uncomplexed ion. ${ }^{45}$ In this state, and without any means of oxidizing to Fe (III) in the $1 \%$ NO environment, $\mathrm{Fe}$ is somewhat mobile and can migrate into the mordenite main-channels where there is sufficient space to form immobile dinitrosyl and trinitrosyl complexes..$^{46,47}$ These nitrosyl complexes, therefore, likely compete for space with the immobile channel nitrates, significantly reducing the concentration of that $\mathrm{Ag}$ phase. A general scheme for adsorbent reduction, aging, and the adsorption of $\mathrm{I}_{2}$ on aged mordenite is provided in Figure 8.
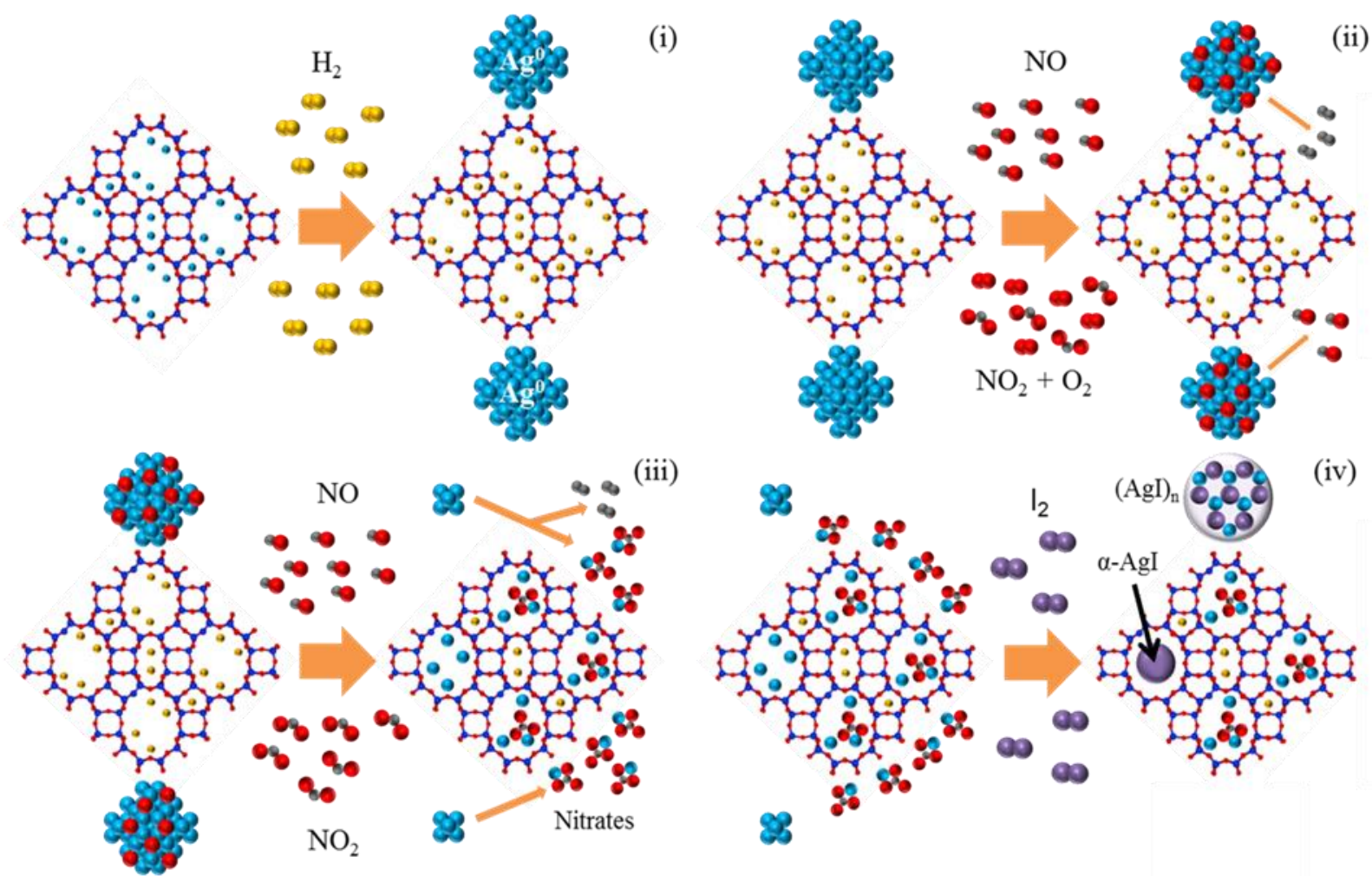

Figure 8. Schematics for (i) the reduction of $\mathrm{AgZ}$ to $\mathrm{Ag}^{0} \mathrm{Z}$ using $\mathrm{H}_{2}$, (ii) the dissociative adsorption of $\mathrm{NO}$ and $\mathrm{NO}_{2} / \mathrm{O}_{2}$ on the $\mathrm{Ag}$ nanoparticle to form adsorbed oxides, (iii) the adsorption of $\mathrm{NO}$ and $\mathrm{NO}_{2}$ onto the adsorbed oxides to form nitrates that then migrate off of the nanoparticle, and (iv) the adsorption of $\mathrm{I}_{2}$ on aged $\mathrm{Ag}^{0} \mathrm{Z}$.

\subsubsection{Aging Modeling}

Utilizing the chemical processes previously discussed and with experimental results as a point of comparison, $\mathrm{Ag}^{0} \mathrm{Z}$ aging simulations were performed for both the $1 \% \mathrm{NO}$ in $\mathrm{N}_{2}$ and the $2 \% \mathrm{NO}_{2}$ in dry air environments. The aging system was simulated as a thin bed with a diameter of $2.5 \mathrm{~cm}$, thickness of $0.1 \mathrm{~cm}$, and porosity of 0.333 which yield an adsorbent mass of $1 \mathrm{~g}$. Simulated $\mathrm{Ag}^{0} \mathrm{Z}$ aging results for $2 \% \mathrm{NO}_{2}$ in dry air at $150^{\circ} \mathrm{C}$ are compared against the XAS data for aging times up to two months in Figure 9. Since no oxides are observed for this environment, Equation 4 or Equation 5 may be combined with Equation 6 to yield a single net reaction for the formation of adsorbed nitrates. Based on this research, we cannot determine which oxide forming reaction will dominate. Therefore, for the purpose of this simulation we will consider oxide formation from the dissociative adsorption of $\mathrm{O}_{2}$ (Equation 4) to be the dominant reaction. Thus, by combining Equations 4 and 6 and assuming an additional irreversible step to represent migration of $\mathrm{Ag}$ off of 
the nanoparticle without migration toward the mordenite channels we are left with the net reaction described in Equation 10. Migration to the channels is ultimately governed by Equation 9. Combining this reaction with the decomposition of nitric acid ${ }^{48}$ and assuming nitrate migration off of the nanoparticle has already occurred yields the net reaction given by Equation 11. Finally, Equation 12 describes the formation of channel nitrates that are unavailable for $\mathrm{I}_{2}$ adsorption, where $\boldsymbol{\theta}$ is a representation of the available sites for channel nitrate formation and is defined as one fourth of the main channel binding sites.

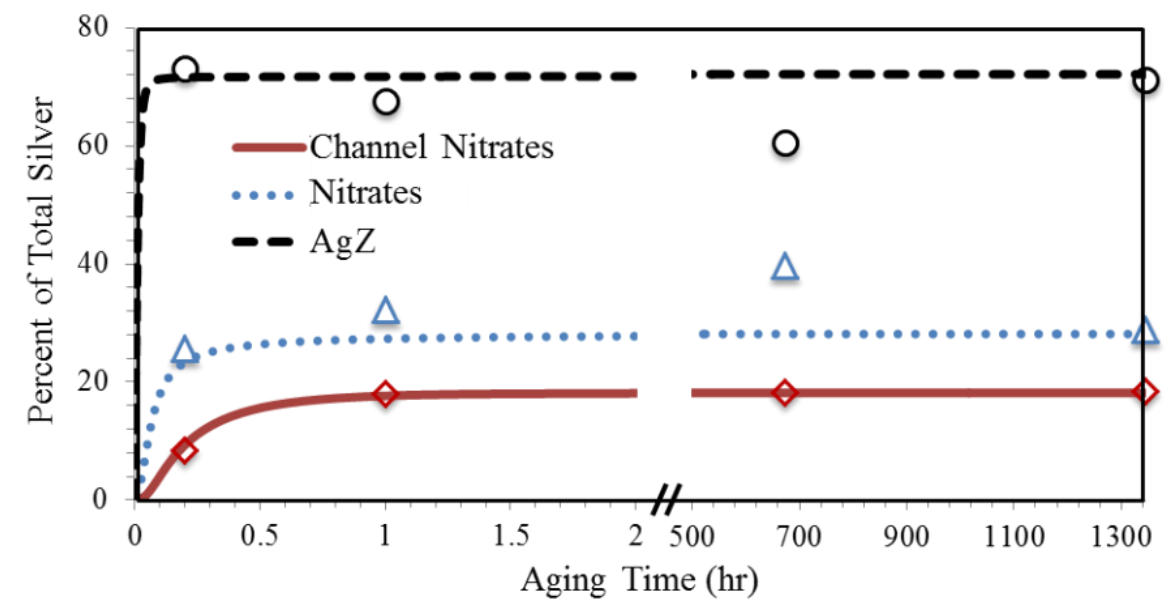

Figure 9. Simulation results compared against XAS combination fitting data for aging at $150^{\circ} \mathrm{C}$ in $2 \% \mathrm{NO}_{2}$ in dry air for aging times up to two months.

$$
\begin{aligned}
& 2 \mathrm{Ag}^{0}+\mathrm{O}_{2}+2 \mathrm{NO}_{2} \rightarrow 2\left(\mathrm{AgNO}_{3}\right)_{\text {surface }} \\
& 4 \mathrm{HZ}+4\left(\mathrm{AgNO}_{3}\right)_{\text {surface }} \rightarrow 4 \mathrm{AgZ}+4 \mathrm{NO}_{2}+2 \mathrm{H}_{2} \mathrm{O}+\mathrm{O}_{2} \\
& \left(\mathrm{AgNO}_{3}\right)_{\text {surface }}+\boldsymbol{\theta} \leftrightarrow\left(\mathrm{AgNO}_{3}\right)_{\text {channel }}
\end{aligned}
$$

As noted previously in Section 3.2.4, binding sites are split between the main channels and side areas on an approximately $50 / 50$ basis. ${ }^{41,42}$ For the mordenite examined in this study, unoccupied binding sites account for, on average, about $10 \%$ of all binding sites. Thus, the percentage of occupied sites in the main channel can generally range from 40 to $50 \%$ of all sites, though in some cases additional variance may be possible based on the main:side site ratio. In the case of $2 \% \mathrm{NO}_{2}$, it was assumed that the number of occupied sites in the main channel represented $41 \%$ of all sites based on the AgZ concentration in well-aged ( $\geq$ two months) samples. Reaction rate constants, which were adjusted until a reasonable fit of the data was attained, are shown in Table 2. To minimize the number of variables being considered, the reaction orders were determined from the stoichiometry and only modified when a reasonable fit could not be attained from adjusting the rate constants alone. No adjustments to the orders of any species were necessary for the reactions involved in aging of the adsorbent in $2 \% \mathrm{NO}_{2}$ in dry air. Generally, good agreement was obtained between experimental data and simulated aging results using this methodology. Some variations were observed, such as at $12 \mathrm{~min}$ where the simulation underpredicts $\mathrm{AgZ}$ as a percentage of total (73.2\% vs. $71.6 \%)$ and at one hour where it overpredicts the data (67.5\% vs. 71.7\%). This is to be expected given that the $\mathrm{Ag}^{0} \mathrm{Z}$ adsorbent is not entirely uniform. Significant deviation between experimental and simulated results is observed only for the 
one-month aging time for $\mathrm{AgZ}$ and nitrates. This can also be attributed to material non-uniformity which is unusually high but not improbable for the one-month aged sample.

For aging in $1 \% \mathrm{NO}$ in $\mathrm{N}_{2}$, the dissociative adsorption of $\mathrm{NO}$ and adsorption of $\mathrm{NO}$ on adsorbed oxides are simulated using the reactions represented by Equations 7 and 8, respectively. Since a small quantity of adsorbed oxides is observed in this system, these reactions may not be combined into a single reaction as was the case in $2 \% \mathrm{NO}_{2}$. Equation 13 , additionally, combines Equation 8 with the irreversible migration of Ag off of the nanoparticle to account for the formation of surface nitrates. Occupied sites in the main channel were assumed to represent $45 \%$ of all binding sites in the mordenite for the NO environment. The concentration of adsorbed Na, which acts as a catalyst for dissociative NO adsorption, was assumed to be constant. Nitrate migration into the mordenite channels is represented using Equation 14 which is a combination of Equation 9, starting from a nitrate on the mordenite's surface, and the decomposition of nitric acid in the presence of NO. ${ }^{49}$ Formation of dinitrosyl complexes, which are a possible competitor to channel nitrates in the main channels, on Fe ions in the mordenite is represented by Equation 15 .

$$
\begin{aligned}
& \left(\mathrm{Ag}_{2} \mathrm{O}\right)_{\mathrm{ads}}+2 \mathrm{NO} \rightarrow\left(\mathrm{AgNO}_{3}\right)_{\text {surface }}+\mathrm{Ag}^{0}+0.5 \mathrm{~N}_{2} \\
& 2 \mathrm{HZ}+2\left(\mathrm{AgNO}_{3}\right)_{\text {surface }}+\mathrm{NO} \rightarrow 2 \mathrm{AgZ}+\mathrm{H}_{2} \mathrm{O}+3 \mathrm{NO}_{2} \\
& \mathrm{Fe}(\mathrm{Z})_{2}+2 \boldsymbol{\theta}+2 \mathrm{NO} \leftrightarrow \mathrm{Fe}(\mathrm{Z})_{2}(\mathrm{NO})_{2}
\end{aligned}
$$

The gas concentration of NO was held constant for the aging simulations shown in Figure 10. Initially, simulations were performed with variable NO concentration but there was not a significant decrease in the concentration over the simulation's run time. Thus, the simulation run time can be notably reduced by holding the concentration constant without affecting the simulation results. In two instances, adjusting the rate constant was not sufficient to achieve a reasonable fit of the data. To account for this, the reaction order was adjusted accordingly for one species per irreversible reaction. All reversible reactions could be fit by adjusting the rate constant alone. As such, the reaction orders for all species in every reversible reaction were determined by stoichiometry. Slight variations are, once again, observed between simulated and experimental results due to slight variations in $\mathrm{Ag}^{0} \mathrm{Z}$ 's properties between each sample. These are not notably more or less significant than the variations already observed in $\mathrm{NO}_{2}$.

With respect to $\mathrm{I}_{2}$ adsorption on $\mathrm{Ag}$ in the form of oxides or nitrates, the contributions to the material's adsorption capacity are easy to determine. All oxides adsorbed on the Ag nanoparticles and all surface nitrates will be replaced by $\mathrm{AgI}$ upon exposure to $\mathrm{I}_{2}$. Adsorption on $\mathrm{Ag}^{0} \mathrm{Z}$ can be estimated using the last reaction given in Table 2 by fitting to the experimental data previously collected by Nan and coworkers. ${ }^{16}$ Thus, as an example, after one week aging in $1 \%$ $\mathrm{NO}$, the simulated $\mathrm{AgI}$ from adsorbed oxide, surface nitrates, and $\mathrm{Ag}^{0} \mathrm{Z}$ is $1.0 \%, 16.3 \%$, and $14.1 \%$ of total Ag, respectively. These results are in line with the experimental results where AgI from adsorbed oxide, surface nitrates, and $\mathrm{Ag}^{0} \mathrm{Z}$ account for $3 \%, 16.5 \%$, and $15.8 \%$ of total $\mathrm{Ag}$, respectively. Predicting $\alpha$-phase adsorption on $\mathrm{AgZ}$ is, however, not possible with the information currently available. 

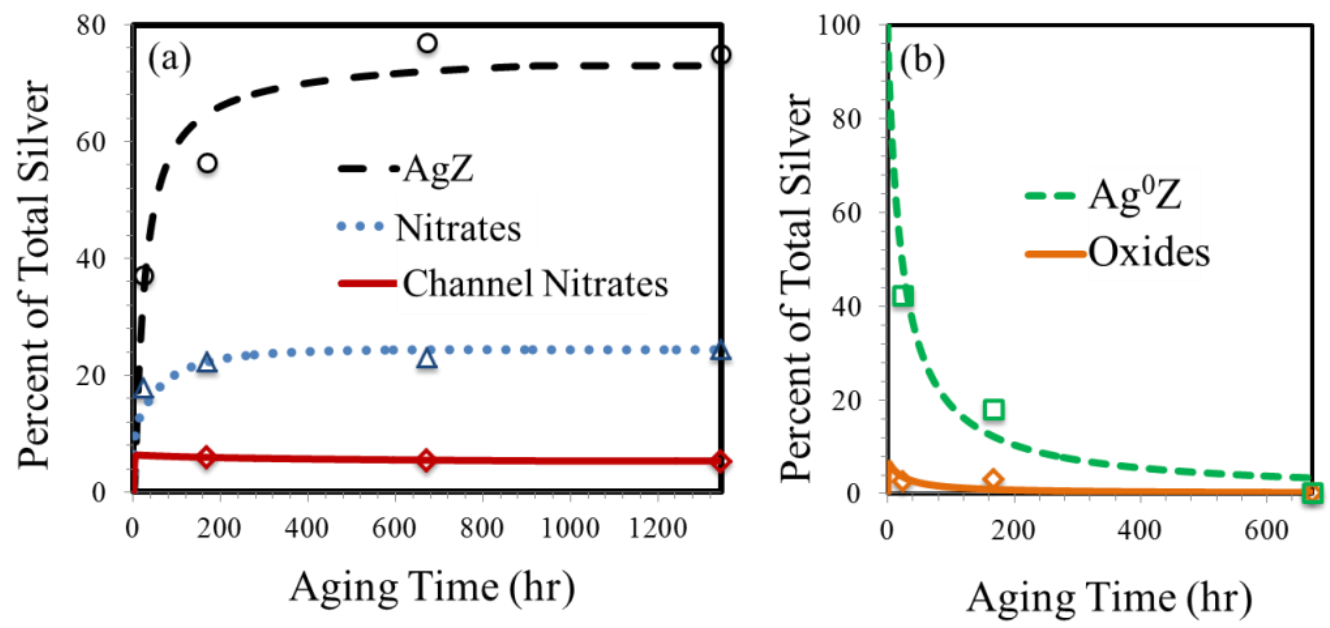

Figure 10. Simulation results compared against XAS combination fitting data for (a) AgZ, all nitrates, and nitrates in the mordenite's main channel and (b) $\mathrm{Ag}^{0} \mathrm{Z}$ and oxides for samples aged up to two months in $1 \% \mathrm{NO}$ in $\mathrm{N}_{2}$ at $150^{\circ} \mathrm{C}$.

Based on a previous analysis, unreduced $\mathrm{AgZ}$ has an $\mathrm{I}_{2}$ capacity of 2.6 w.t. \% at $150^{\circ} \mathrm{C}$ for an unaged adsorbent with a $\mathrm{Ag}$ content of 9.5 w.t. $\%{ }^{18}$ As such, $\alpha$-phase iodine adsorption will yield a Ag utilization rate on main channel binding sites of about $27 \%$ if the channels are unobstructed. Thus, when we consider that $25 \%$ of Ag in our material is not in the main channels, the overall utilization rate for $\alpha$-phase adsorption should drop to about $20 \%$ of the total Ag in the system. At 12 min aging in $2 \% \mathrm{NO}_{2}, \alpha$-phase adsorption accounts for $19.6 \%$ of total Ag suggesting that the channels are not yet obstructed. After one hour of aging, however, $\alpha$-phase AgI only accounts for $\sim 1 \%$ of total $\mathrm{Ag}$ and it remains at this level for each subsequent aging time. This, however, does not give sufficient information to determine a relationship between nitrate accumulation in the main channels, which is already well underway after 12 min in $\mathrm{NO}_{2}$, and site access.

Table 2. Forward $\left(\mathrm{kf}_{\mathrm{f}}\right)$ and reverse $\left(\mathrm{k}_{\mathrm{r}}\right)$ reaction rate constants for all reactions used in aging simulations for $1 \% \mathrm{NO}$ in $\mathrm{N}_{2}$ and for $2 \% \mathrm{NO}_{2}$ in dry air at $150^{\circ} \mathrm{C}$ as well as the reaction for $\mathrm{I}_{2}$ adsorption on $\mathrm{Ag}^{0}$. Reaction orders determined by stoichiometry unless otherwise noted.

\begin{tabular}{|c|c|c|c|}
\hline \multirow[t]{2}{*}{ Reaction } & \multicolumn{2}{|c|}{ Rate Constants } & Notes \\
\hline & $\mathrm{kf}_{\mathrm{f}}$ & $\mathrm{k}_{\mathrm{r}}$ & N/A \\
\hline $2 \mathrm{Ag}^{0}+\mathrm{O}_{2}+2 \mathrm{NO}_{2} \rightarrow 2\left(\mathrm{AgNO}_{3}\right)_{\text {surface }}$ & $2.3 \mathrm{e} 10$ & 0.0 & N/A \\
\hline$(\mathrm{Na})_{\mathrm{ads}}+2 \mathrm{Ag}^{0}+\mathrm{NO} \rightarrow\left(\mathrm{Ag}_{2} \mathrm{O}\right)_{\mathrm{ads}}+0.5 \mathrm{~N}_{2}+(\mathrm{Na})_{\mathrm{ads}}$ & 0.2 & 0.0 & $4^{\text {th }}$ order wrt $\mathrm{Ag}^{0}$ \\
\hline$\left(\mathrm{Ag}_{2} \mathrm{O}\right)_{\mathrm{ads}}+2 \mathrm{NO} \rightarrow \mathrm{Ag}^{0}+\left(\mathrm{AgNO}_{3}\right)_{\text {surface }}+0.5 \mathrm{~N}_{2}$ & 15.0 & 0.0 & N/A \\
\hline $4 \mathrm{HZ}+4\left(\mathrm{AgNO}_{3}\right)_{\text {surface }} \rightarrow 4 \mathrm{AgZ}+4 \mathrm{NO}_{2}+2 \mathrm{H}_{2} \mathrm{O}+\mathrm{O}_{2}$ & $1.0 \mathrm{e} 10$ & 0.0 & N/A \\
\hline $2 \mathrm{HZ}+2\left(\mathrm{AgNO}_{3}\right)_{\text {surface }}+\mathrm{NO} \rightarrow 2 \mathrm{AgZ}+\mathrm{H}_{2} \mathrm{O}+2 \mathrm{NO}_{2}$ & 10.0 & 0.0 & $4^{\text {th }}$ order wrt HZ \\
\hline$\left(\mathrm{AgNO}_{3}\right)_{\text {surface }}+\boldsymbol{\theta} \leftrightarrow\left(\mathrm{AgNO}_{3}\right)_{\text {channel }}$ & 26.5 & 0.3 & $\mathrm{~N} / \mathrm{A}$ \\
\hline $\mathrm{Fe}(\mathrm{Z})_{2}+2 \boldsymbol{\theta}+2 \mathrm{NO} \leftrightarrow \mathrm{Fe}(\mathrm{Z})_{2}(\mathrm{NO})_{2}$ & $1.25 \mathrm{e}-4$ & 12.75 & N/A \\
\hline $2 \mathrm{Ag}^{0}+\mathrm{I}_{2} \leftrightarrow 2 \mathrm{AgI}$ & 16870 & $5.75 e-4$ & N/A \\
\hline
\end{tabular}




\subsection{Conclusions}

Reduced silver mordenite $\left(\mathrm{Ag}^{0} \mathrm{Z}\right)$ is a promising material for iodine capture from nuclear fuel reprocessing off-gas. This material is an effective iodine adsorbent that can utilize up to $87 \%$ of the silver $(\mathrm{Ag})$ in the mordenite for adsorption. Though its iodine capacity is high, the behavior of $\mathrm{Ag}$ mordenites under real off-gas conditions is not well understood. One area of interest is material aging where the adsorbent loses iodine capacity over time from exposure to $\mathrm{O}_{2}, \mathrm{H}_{2} \mathrm{O}, \mathrm{NO}$, and $\mathrm{NO}_{2}$. While the overall effect of aging is known, the underlying processes that explain this loss of capacity have not been explored. To examine these processes, $\mathrm{Ag}^{0} \mathrm{Z}$ samples were aged in gas streams of $2 \% \mathrm{NO}_{2}$ in dry air and of $1 \% \mathrm{NO}$ in $\mathrm{N}_{2}$ at $150^{\circ} \mathrm{C}$ for periods of up to six months and investigated through a combination of different characterization techniques.

Backscattered electron images, obtained through SEM, showed that following the reduction of mordenite to $\mathrm{Ag}^{0} \mathrm{Z}$, small particles of metallic $\mathrm{Ag}$ were observed on the unaged mordenite's surface. After one month of aging at $150^{\circ} \mathrm{C}$, the number of observable nanoparticles was significantly lower for both aging environments. Results from XRD largely corroborate our findings from SEM. Two peaks characteristic of $\mathrm{Ag}^{0}$ are present on the XRD spectra for unaged $\mathrm{Ag}^{0} \mathrm{Z}$ which corresponds to the Ag particles seen through SEM imaging. The intensity of these peaks declines over time as a consequence of adsorbent aging with the peaks disappearing entirely after a certain period of time. This, as well, corresponds to the greatly diminished number of particles observed on the SEM images for aged $\mathrm{Ag}^{0} \mathrm{Z}$. These results suggest that iodine capacity losses are primarily a result of the oxidation of $\mathrm{Ag}$ into other chemical forms that are unavailable for adsorption. The absence of any additional peaks on the spectra for aged $\mathrm{Ag}^{0} \mathrm{Z}$ indicates that these oxidized Ag species are not aggregating into clusters of sufficient size to be detectable by XRD.

The results for our Raman Spectroscopy analysis are largely in agreement with our findings from SEM and XRD. For both the $\mathrm{NO}$ and $\mathrm{NO}_{2}$ aging environments, a peak characteristic of $\mathrm{AgNO}_{3}$ is observed at $1045 \mathrm{~cm}^{-1}$ on the spectra for all aged $\mathrm{Ag}^{0} \mathrm{Z}$ samples. Based on our SEM and $\mathrm{XRD}$ results, this peak does not represent bulk phase $\mathrm{AgNO}_{3}$ but rather molecular nitrates on the surface of the mordenite. These surface nitrates are likely formed through the adsorption of $\mathrm{O}_{2}$, $\mathrm{NO}$, and $\mathrm{NO}_{2}$ onto the surface of the nanoparticle. Nitrates adsorbed on the Ag nanoparticle will then migrate onto the mordenite surface and should eventually undergo Ag exchange at binding sites in the mordenite crystalline framework returning Ag to its unreduced state. The fact that a persistent concentration is observable on the Raman spectra, nevertheless, indicates that Ag exchange is incomplete. This is likely tied to Ag exchange being less favorable at binding sites not located in the main channels of the mordenite crystal. Thus, once all sites in the main channels are occupied, any remaining nitrate will remain in that form permanently.

XAS gives further insight into Ag speciation as a function of aging time. Though an overwhelming majority of the Ag in the aged samples is in the unreduced form, a permanent concentration of nitrates is once again observed. These nitrates are a significant contributor to iodine adsorption and, for well-aged samples, they account for nearly all of the iodine adsorbed. Interestingly, though Ag in the unreduced form is known to adsorb iodine as $\alpha$-phase AgI, very little iodine is actually adsorbed in this phase. Simultaneously, even after iodine adsorption, a persistent nitrate concentration is observed. These nitrates are likely in the mordenite channels where they can be stabilized through interactions with either the mordenite channel walls or 
framework bound cations. The aggregation of these nitrates in the main channels would prohibit diffusion of iodine into the mordenite crystal and could, therefore, explain the lower than expected adsorption of iodine in the $\alpha$-phase.

Based on these processes, aging was simulated and compared against experimental data attaining reasonable approximations. $\mathrm{I}_{2}$ adsorption was also considered, though adsorption in the $\alpha$-phase could not be modeled with the available data. Additional experimental investigations could, therefore, be used to improve the model discussed based on our current understanding of the aging processes. Developing a mechanistic understanding aging is, nevertheless, likely to be very difficult through experimentation alone. In this context, one must be aware of a variety of short lived transient and intermediate species that, while difficult to observe experimentally, are essential to the development of precise aging reaction pathways. As an example, adsorption in the $\alpha$-phase would be exceptionally difficult to examine experimentally since it only proceeds deep within, and as a direct consequence of, the mordenite crystal structure. Molecular modeling, which can be used to determine the transition states and assess the feasibility of potential reactions, is a good complement to experimentation when attempting to examine aging at the mechanistic level.

\subsection{References for Part 2}

1) Energy, Electricity and Nuclear Power Estimates for the Period up to 2015: 2018 Edition. Report IAEA-RDS-1/38; International Atomic Energy Agency, 2018.

2) Ladshaw, A.; Wiechert, A.; Welty, A.; Lyon, K.; Law, J.; Jubin, R.; Tsouris, C.; Yiacoumi, $\mathrm{S}$. Adsorbents and Adsorption Models for Capture of $\mathrm{Kr}$ and $\mathrm{Xe}$ Gas Mixtures in Fixed-bed Columns. Chem. Eng. J. 2019, 375, 122073.

3) EPA, Protection of Environment: Chapter I-Environmental Protection Agency. Part 190Environmental Radiation Protection Standards for Nuclear Power Operations. Agency, U. E. P., Ed. US Environmental Protection Agency: Washington, DC (United States), 2010; Vol. 40 CFR 190.10.

4) NRC, Standards for Protection Against Radiation. US Nuclear Regulatory Commission: Washington, DC (United States), 2012; Vol. 10 CFR 20.

5) Riley, B.; Vienna, J.; Strachan, D.; McCloy, J.; Jerden, J. Material and Processes for the Effective Capture and Immobilization of Radioiodine: A Review. J. Nucl. Mat. 2016, 470, 307-326.

6) Huve, J.; Ryzhikov, A.; Nouali, H.; Lalia, V.; Auge, G.; Daou, T.J. Porous Sorbents for the Capture of Radioactive Iodine Compounds: A Review. RSC Adv. 2018, 8, 29248- 29273.

7) Haefner, D and Tranter, T. Methods of Gas Phase Capture of Iodine from Fuel Reprocessing Off-Gas: A Literature Survey. INL/EXT-07-12299. Idaho National Laboratory, Idaho Falls, ID 2007. 
8) Zhao, H. Y.; Nenoff, T. M.; Jennings, G.; Chupas, P. J.; Chapman, K. W., Determining Quantitative Kinetics and the Structural Mechanism for Particle Growth in Porous Templates. J. Phys. Chem. Let. 2011, 2 (21), 2742-2746.

9) Chapman, K. W.; Chupas, P. J.; Nenoff, T. M., Radioactive Iodine Capture in SilverContaining Mordenites Through Nanoscale Silver Iodide Formation. JACS 2010, 132 (26), 8897-8899.

10) Nenoff, T. M.; Rodriguez, M. A.; Soelberg, N. R.; Chapman, K. W., Silver-mordenite for Radiologic Gas Capture from Complex Streams: Dual Catalytic CH3I Decomposition and I Confinement. Microporous and Mesoporous Materials. 2014, 200, 297-303.

11) Azambre, B.; Chebbi, M. Evaluation of Silver Zeolites Sorbents Towards their Ability to Promote Stable CH3I Storage as AgI Precipitates. ACS Applied Materials \& Interfaces 2017, 9, 25194-25203.

12) Chibani, S.; Chebbi, M.; Lebegue, S.; Cantrel, L.; Badawi, M. Impact of the Si/Al Ratio on the Selective Capture of Iodine Compounds in Silver-mordenite: A Periodic DFT Study. Phys. Chem. Chem. Phys. 2016, 18, 25574-25581.

13) Bucko, T.; Chibani, S.; Paul, J.-F.; Cantrel, L.; Badawi, M. Dissociative Iodomethaneadsorption on Ag-MOR and the Formation of AgI Clusters: An ab initio Molecular Dynamics Study. Phys. Chem. Chem. Phys. 2017, 19, 27530-27543.

14) Jabraoui, H.; Hessou, E.P.; Chibani, S.; Cantrel, L; Lebegue, S. Badawi, M. Adsorption of Volatile Organic and Iodine Compounds over Silver-exchanged Mordenites: A Comparative Periodic DFT Study for Several Silver Loadings. App. Surf. Sci. 2019, 485, 56-63.

15) Abney, C. W.; Nan, Y.; Tavlarides, L. L., X-ray Absorption Spectroscopy Investigation of Iodine Capture by Silver-Exchanged Mordenite. Industrial \& Engineering Chemistry Research 2017, 56 (16), 4837-4846.

16) Nan, Y.; Tavlarides, L. L.; DePaoli, D. W., Adsorption of Iodine on Hydrogen-reduced Silverexchanged Mordenite: Experiments and Modeling. AIChE Journal 2017, 63 (3), 1024-1035.

17) Jubin, R. T.; Ramey, D. W.; Spencer, B. B.; Anderson, K. K.; Robinson, S. M. In Impact of Pretreatment and Aging on the Iodine Capture Performance of Silver-Exchanged Mordenite WM2012 Conference, Phoenix, AZ (United States), 2012.

18) Patton, K. K.; Bruffey, S. H.; Jubin, R. T.; Walker, J. F. Effects of Extended In-Process Aging of Silver-Exchanged Mordenite on Iodine Capture Performance, 33rd Nuclear Air Cleaning Conference, St Louis, MO (United States), 2014.

19) Patton, K. K.; Bruffey, S. H.; Jubin, J. T.; Walker, J. F. Iodine Loading of NO Aged Silver Exchanged Mordenite; Oak Ridge National Laboratory (ORNL): Oak Ridge, TN (United States), 2014. 
20) Bruffey, S.; Jubin, R. Initial Evaluation of Effects of NOx on Iodine and Methyl Iodide Loading of AgZ and Aerogels; ORNL/SPR-2015/125; Oak Ridge National Laboratory (ORNL): Oak Ridge, TN (United States), 2015; p 125.

21) Bruffey, S.; Patton, K.; Walker Jr, J.; Jubin, R. Complete NO and NO2 Aging Study for AgZ; ORNL/SPR-2015/128; Oak Ridge National Laboratory (ORNL): Oak Ridge, TN (United States), 2015; p 128.

22) Nan, Y. Adsorption of Iodine and Water on Silver-Exchanged Mordenite. Ph.D. Dissertation, Syracuse University, Syracuse, NY, 2017.

23) Biria, S.; Hosein, I. D. Control of Morphology in Polymer Blends through Light SelfTrapping: An in Situ Study of Structure Evolution, Reaction Kinetics, and Phase Separation. Macromolecules 2017, 50, 3617-3626.

24) Kropf, A. J.; Katsoudas, J.; Chattopadhyay, S.; Shibata, T.; Lang, E. A.; Zyryanov, V. N.; Ravel, B.; McIvor, K.; Kemner, K. M.; Scheckel, K. G.; Bare, S. R.; Terry, J.; Kelly, S. D.; Bunker, B. A.; Segre, C. U., The New MRCAT (Sector 10) Bending Magnet Beamline at the Advanced Photon Source. AIP Conference Proceedings 2010, 1234 (1), 299-302.

25) Ravel, B.; Newville, M., ATHENA, ARTEMIS, HEPHAESTUS: Data Analysis for X-ray Absorption Spectroscopy using IFEFFIT. Journal of Synchrotron Radiation 2005, 12 (4), 537 541.

26) Gaston, D.; Newman, C.; Hansen, G.; Lebrun-Grandié, D. MOOSE: A Parallel Computational Framework for Coupled Systems of Nonlinear Equations, Nuc. Eng. Design, 2009, 239, 17681778.

27) Martina, I.; Wiesinger, R.; Jembrih-Simburger, D.; Schreiner, M. Micro-Raman Characterisation of Silver Corrosion Products: Instrumental Set Up and Reference Database. e-PS 2012, 9, 1-8.

28) Agostini, G.; Usseglio, S.; Groppo, E.; Uddin, M.J.; Prestipino, C.; Bordiga, S.; Zecchina, A.; Solari, P.L.; Lamberti, C. From Isolated $\mathrm{Ag}^{+}$Ions to Aggregated $\mathrm{Ag}^{0}$ Nanoclusters in SilverExchanged Engelhard Titanosilicate (ETS-10) Molecular Sieve: Reversible Behavior. Chem. Mater. 2009, 21, 1343-1353.

29) Campble, C.T. Atomic and Molecular Oxygen Adsorption on Ag(111). Surface Science, 1985, 157, 43-60.

30) Bukhtiyarov, V.I.; Kaichev, V.V.; Prosvirin, I.P. Oxygen Adsorption on Ag(111): X-ray Photoelectron Spectroscopy (XPS), Angular Dependent X-ray Photoelectron Spectroscopy (ADXPS) and Temperature-Programmed Desorption (TPD) Studies. Journal of Chemical Physics 1999, 111, 2169-2175.

31) Backx. C.; De Groot, C.P.M.; Biloen, P. Adsorption of Oxygen on Ag(110) Studied by High Resolution ELS and TPD. Surface Science 1981, 104, 300-317. 
32) Bare, S.R.; Griffiths, K.; Lennard, W.N. Tang, H.T. Generation of Atomic Oxygen on Ag(111) and $\mathrm{Ag}(110)$ Using NO2 a TPD, LEED, HREELS, XPS, and NRA Study. Surface Science, $1995,342,185-198$

33) Zemlyanov, D.Y.; Hornung, A.; Weinberg, G.; Wild, U.; Schlogl, R. Interaction of Silver with a $\mathrm{NO} / \mathrm{O}_{2}$ Mixture: A Combined X-ray Photoelectron Spectroscopy and Scanning Electron Microscopy Study. Langmuir, 1998, 14, 3242-3248.

34) Outka, D.A.; Madix, R.J.; Fisher, G.B.; Dimaggio, C. The Adsorption of Nitrogen Dioxide on the $\operatorname{Ag}(110)$ Surface and Formation of a Surface Nitrate. Surface Science 1987, 179, 1-24.

35) Marbrow, R.A.; Lambert, R.M. Chemisorption and Surface Reactivity of Nitric Oxide on Clean and Sodium-dosed Ag(110). Surface Science 1976, 61, 317-328.

36) Goddard, P.J.; West, J.; Lambert, R.M. Adsorption, Coadsorption, and Reactivity of Sodium and Nitric Oxide on $\operatorname{Ag}(111)$. Surface Science 1978, 71, 447-461.

37) Carley, A.F.; Davies, P.R.; Roberts, M.W.; Santra, A.K.; Thomas, K.K. Coadsorption of Carbon Monoxide and Nitric Oxide at $\mathrm{Ag}(111)$ : Evidence for a CO-NO Surface Complex. Surface Science 1998, 406, L587-L591.

38) Bao, X.; Wild, U.; Muhler, M.; Pettinger, B.; Schlogl, R.; Ertl, G. Co-adsorption of Nitric Oxide and Oxygen on the $\operatorname{Ag}(110)$ Surface. Surface Science, 1999, 425, 224-232.

39) Zemlyanov, D.; Schlogl, R. Effect of Oxygen on NO Adsorption on the $\operatorname{Ag}(111)$ Surface: Evidence for a $\mathrm{NO}_{3}$ Ads Species. Surface Science 2000, 470, L20-L24.

40) Chapman, K. W.; Chupas, P. J.; Kepert, C. J., Selective Recovery of Dynamic Guest Structure in a Nanoporous Prussian Blue through in Situ X-ray Diffraction: A Differential Pair Distribution Function Analysis. Journal of the American Chemical Society 2005, 127 (32), 11232-11233.

41) Martucci, A.; Cruciani, G.; Alberti, A.; Ritter, C.; Ciambelli, P.; Rapacciuolo. Location of Bronsted Sites in D-mordenites by Neutron Powder Diffraction. Microporous and Mesoporous Materials 2000, 35-36, 405-412.

42) Alberti, A.; Location of Bronsted Sites in Mordenite. Zeolites 1997, 19, 411-415.

43) Chebbi, M.; Azambre, B.; Cantrel, L.; Koch, A. A Combined DRIFTS and DR-UV-Vis Spectroscopic In Situ Study on the Trapping of CH3I by Silver-Exchanged Fujasite Zeolite. J. Phys. Chem. C 2016, 120, 18694-18706.

44) Hadjiivanov, K.I. IR Study of CO and NOx Sorption on Ag-ZSM-5. Microporous and Mesoporous Materials, 1998, 24, 41-49.

45) Lobree, L.; Hwang, I.-C.; Reimer, J.; Bell, A. Investigation of the State of Fe in H-ZSM-5. J. Catalysis 1999, 186, 242-253. 
46) Mihaylov, M.; Ivanova, E.; Drenchev, N.; Hadjivanov, K. Coordination Chemistry of Fe ${ }^{2+}$ Ions in Fe, H-ZSM-5 Zeolite as Revealed by the IR Spectra of Adsorbed CO and NO. J. Phys. Chem. C 2010, 114, 1004-1014.

47) Segawa, K.-I.; Chen, Y.; Kubsh, J.; Delgass, W.N.; Dumesic, J.A.; Hall, W. Infrared and Mossbauer Spectroscopic Studies of the Interaction of Nitric Oxide with Fe-Y Zeolite. Journal of Catalysis 1982, 76, 112-132.

48) Thiemann, M.; Scheibler, E.; Wiegand, K.W. Nitric Acid, Nitrous Acid, and Nitrogen Oxides. Ullmann's Encyclopedia of Industrial Chemistry, 2000.

49) McKinnon, I.R.; Mathieson, J.G.; Wilson, I.R. Gas Phase Reaction of Nitric Oxide with Nitric Acid. Journal of Physical Chemistry 1979, 83, 779-780. 


\section{Part 3: Molecular Modeling}

\subsection{Scope}

In the past few decades, numerous researchers have studied the performance of various adsorbents for the capture of iodine including Ag-exchanged zeolites, Ag-functionalized silica aerogels, and metal organic frameworks (MOFs) ${ }^{1,2}$. Significant progress has been made in determining many of the potential factors that affect the performance of these adsorbents for the capture of both molecular iodine and methyl iodide. These factors include but are not limited to the influence of (i) operating temperature, (ii) pretreatment of the adsorbent with hydrogen, and (iii) the presence of water vapor and $\mathrm{NOx}^{1}$. Mechanistic studies of the underlying processes governing the adsorption of molecular iodine, however, have been limited and, as a result, the uptake mechanisms remain obscured. The study of methyl iodide adsorption, or organic iodides adsorption in general, is even less popular. This may be, at least partially, attributed to the fact that traditional characterization techniques such as STM, XRD ${ }^{3}$, DRIFTS ${ }^{4}$, etc. have difficulties handling complexed material systems and identifying reaction intermediates. Alternatively, computational methods can be used to provide theoretical insights into the iodine uptake mechanism governing adsorption. In the following sections, the feasibility of applying density functional theory (DFT), one of the most powerful molecular modeling techniques available, toward the mechanistic understanding of organic iodide capture will be discussed.

\subsection{DFT and its application in determining adsorption mechanisms}

Among the many theoretical techniques developed to enhance our understanding of the properties of matter at the atomic level, density functional theory (DFT) ${ }^{5}$ has achieved phenomenal successes and received a great deal of attention over the last century. As a tool used to solve the fundamental equation that describes the quantum behavior of atoms and molecules, the Schrödinger equation, DFT calculation has been shown to achieve powerful performance by balancing simulation accuracy and computational costs ${ }^{6}$. It is not uncommon to use DFT to calculate reaction energies and to derive structural information in a chemical process. In fact, DFT is one of the most popular tools for the theoretical study of heterogeneous systems which includes the study of adsorption and catalysis ${ }^{7}$.

Since 2015, a number of theoretical studies examining iodine capture have been performed. Chibani, Chebbi and Badawi ${ }^{8-14}$ conducted a series of studies using DFT to examine the mechanisms of iodine adsorption on metal-exchanged zeolites. Chibani et. al. ${ }^{9}$, for example, used DFT to inspect the impact of the $\mathrm{Si} / \mathrm{Al}$ ratio on the selective capture of iodine compounds in silverexchanged mordenite (AgZ). Chebbi et. al. ${ }^{15}$ used DFT to investigate the iodine trapping efficiency of different metals $\left(\mathrm{Cu}^{+}, \mathrm{Ag}^{+}, \mathrm{Na}^{+}\right)$in metal-exchanged faujasite. Bucko et. al. ${ }^{8}$ utilized DFT and $\mathrm{ab}$ initio molecular modeling (AIMD) to study the dissociative adsorption of methyl iodine $\left(\mathrm{CH}_{3} \mathrm{I}\right)$ on $\mathrm{AgZ}$ and to postulate the preferred dissociation pathways of $\mathrm{CH}_{3} \mathrm{I}$ adsorption. Most recently, Rimsza et. al. ${ }^{16}$ also made use of DFT to study the effect of confinement on the structure of $\mathrm{Ag}^{0}$ clusters formed in silica-mordenite and the formation energies of those clusters. While several DFT studies have been performed in this field, nearly all of them have been focus solely on zeolite systems. Other adsorbent materials systems, including aerogels, have not been widely studied. 


\subsection{Software exploration - Quantum Espresso}

Quantum Espresso (QE) is an open source ab-initio package that utilizes DFT, plane waves, and pseudopotentials to perform electronic structure calculations and nanoscale materials modeling. Espresso is an abbreviation of opEn Source Package for Research in Electronic Structure, Simulation, and Optimization ${ }^{17}$. It is capable of identifying a molecular system's optimized structure and the electronic energy of the identified structure. As one of the most popular and reliable first-principles software packages, QE is best used when dealing with periodic systems and when attempting to simulate heterogeneous surface reactions ${ }^{18}$.

\subsubsection{Slab model}

Surfaces are important in studies that examine heterogeneous processes like adsorption and catalysis. DFT has been proved to be a good complement to experimental characterization and has been used alongside STM, TPD, XRD and XPS to determine, among other things, the surface structures of metals and nanoparticles ${ }^{6}$. The main benefit of DFT is its ability to mechanistically examine the chemical processes that occur on various surfaces.

To simulate a surface using DFT, an idealized model, known as the slab model, is utilized. In the slab model, all atom information is defined within one supercell (Figure 1) that is periodically repeated in all three dimensions. A region of empty space along the z-axis, conventionally called vacuum space, is defined in the supercell. This is done to prevent atoms in the representative supercell from interacting with atoms in other cells located above and below the representative cell on the $\mathrm{z}$-axis. Thus, the surface is simulated as an infinite plane along the $\mathrm{x}$ axis and $y$-axis (i.e. the surface plane) while being finite along the z-axis (i.e. the normal plane).

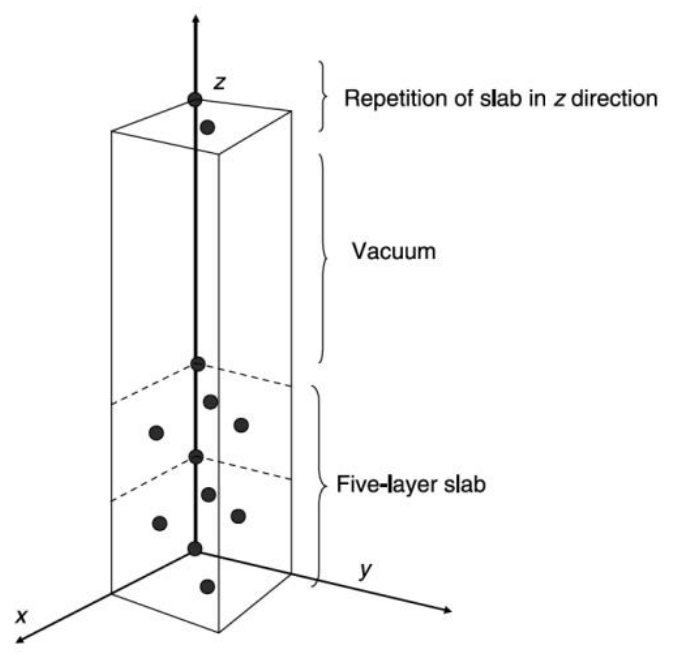

Figure 1. Schematic of slab model used in a periodic DFT calculation. ${ }^{6}$ 


\subsubsection{Potential Energy Surface Diagram}

Deriving a potential energy surface (PES) diagram, example given in Figure 2, is one of the most important objectives of DFT analysis. Mathematically, the valleys of a PES diagram represent minima points where the gradients with respect to all internal coordinates are zero. Minima points correspond to stable or quasi-stable structures, including the reactants (initial states), products (finial states), or intermediates of a chemical reaction. Peak points on the PES diagram, on the other hand, stand for saddle points, which are a maxima in one dimension but a minima in all others. Saddle points represent transition state (TS) structures. By evaluating the PES, one can determine the likely pathway for a chemical reaction and by using statistical mechanics, the reaction rate and rate-limiting step can also be determined.

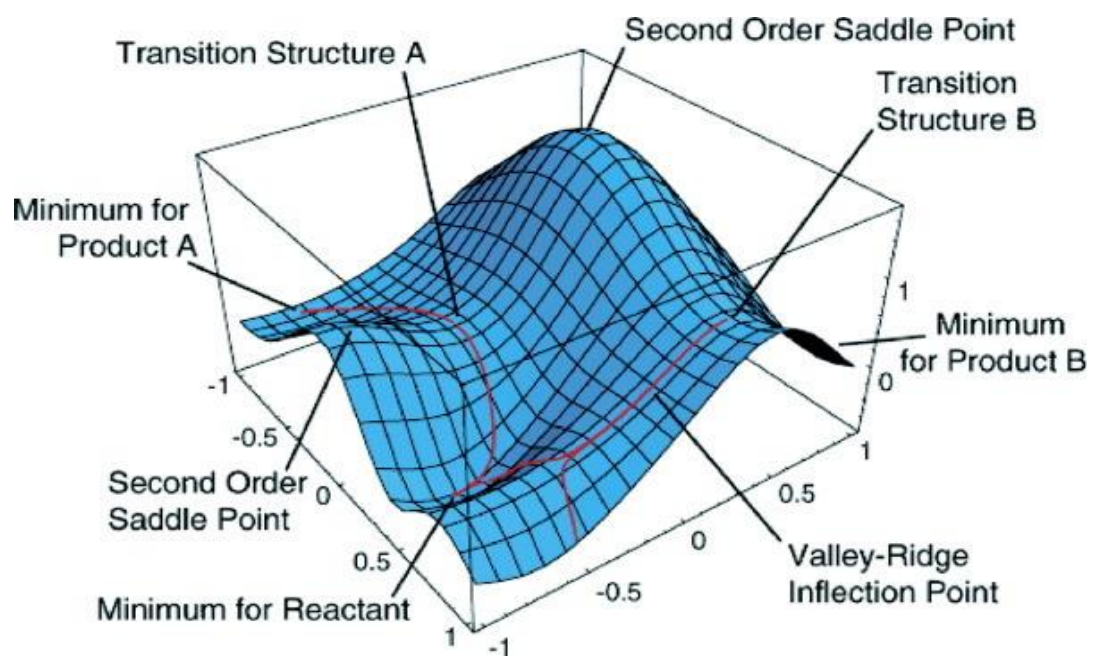

Figure 2. Schematic of a 2-D potential energy surface diagram. ${ }^{19}$

\subsubsection{Case study - Finding reaction mechanism of methane dissociation onto Ni (111)}

To explore the basic functions of $\mathrm{QE}$, and to investigate standard procedures for calculating heterogeneous processes, an established case was selected as an example of study to be used before moving on to the examination of silver adsorbents in the scope of this project.

\subsubsection{System overview}

Steam reforming of natural gas is a conventional technique for hydrogen production and is often accomplished through the decomposition of methane on a metal-based catalysis. Efforts have been made to study the reaction sequence of methane dehydrogenating to $\mathrm{C}$ and $\mathrm{H}$ on nickel surfaces. Because it was hard to track intermediates in these reactions experimentally, DFT served as a crucial tool in determining the reaction mechanisms for methane dehydrogenation ${ }^{20-23}$.

In general, methane dissociation can be divided into four elementary steps (Table 1). This specific system was selected for several reasons. First, methane decomposition is similar to our silver system in that it is a series of heterogeneous reactions between gas phase species and a transition metal surface. Second, silver and nickel have the same crystalline structure (both are 
face-centered cubic). Third, both metals are typically active along the same surface plane [the (111) Miller plane]. Nickel is also a much lighter element than silver, which means that it is exponentially less computationally expensive to simulate. As such, given the similarities between silver and nickel, the methane nickel system is a good model system for learning purposes.

Table 2. Elementary reaction steps for methane dissociation on Ni (111)

\begin{tabular}{cc}
\hline ID & Reactions \\
\hline $\mathbf{1}$ & $\mathrm{CH}_{4}+2 \theta^{*} \leftrightarrow \mathrm{CH}_{3}^{*}+\mathrm{H}^{*}$ \\
\hline $\mathbf{2}$ & $\mathrm{CH}_{3}^{*}+\theta^{*} \leftrightarrow \mathrm{CH}_{2}^{*}+\mathrm{H}^{*}$ \\
\hline $\mathbf{3}$ & $\mathrm{CH}_{2}^{*}+\theta^{*} \leftrightarrow \mathrm{CH}^{*}+\mathrm{H}^{*}$ \\
\hline $\mathbf{4}$ & $\mathrm{CH}^{*}+\theta^{*} \leftrightarrow \mathrm{C}^{*}+\mathrm{H}^{*}$ \\
\hline
\end{tabular}

\subsubsection{Methodology}

To find the PES using QE, a number of different simulations were performed with various QE software packages including (i) geometry relaxation and energy calculation performed using the $P W S C F$ package, (ii) transition state search performed using the $N E B$ package, and (iii) vibrational frequencies calculated using the PHonon package. A three-layer slab with a $12 \AA$ vacuum space was set up to simulate the nickel surface. A $p(2 \times 2)$ super cell was used and the surface Brillouin zone was sampled with a $(6 \times 6 \times 1)$ mesh. A Methfessel-Paxton smearing of 0.01 Ryberg was applied ${ }^{24}$. The total energies of isolated adsorbates were calculated in a cubic box with dimensions of $20 \AA$ and gamma-point k-sampling which is comparable to a $(1 \times 1 \times 1)$ mesh. All calculations were performed using spin polarization to account for the magnetic properties of nickel. Dipole corrections are also included ${ }^{25}$. QE uses pseudopotentials in surface calculation. For this particular set of simulations, a Generalized Gradient Approximation (GGA) coupled with a Perdew-Burke-Ernzerhof (PBE) functional ${ }^{26}$ was used.

To describe the interactions between $\mathrm{CH}_{\mathrm{x}}(\mathrm{x}=0-3), \mathrm{H}$ species, and the nickel surface, the binding energy $\left(E_{b}\right)$ of the adsorbates is defined by subtracting the electronic energy of the bare slab $\left(E_{\text {slab }}\right)$ and the isolated adsorbates $\left(E_{X}, X=C H_{x}, H\right)$ from the electronic energy of the slab with the adsorbates bound to the slab $\left(E_{X-s l a b}\right)$, given in Equation 1:

$$
E_{b}=E_{X-s l a b}-\left(E_{X}+E_{\text {slab }}\right)
$$

For the dissociation of methane into $\mathrm{CH}_{\mathrm{x}}$ and $\mathrm{H}$ on the nickel surface, the dissociation energy $\left(\Delta E_{\text {diss }}\right)$ is defined in Equation 2:

$$
\Delta \mathrm{E}_{\text {diss }}=\left[\mathrm{E}_{\mathrm{CH}_{\mathrm{x}}-\mathrm{slab}}+(4-\mathrm{x}) \mathrm{E}_{\mathrm{H}-\mathrm{slab}}+\mathrm{x} \mathrm{E}_{\text {slab }}\right]-\left[\mathrm{E}_{\mathrm{CH}_{4}}+5 \mathrm{E}_{\text {slab }}\right]
$$




\subsubsection{Results and comparison}

The first step of any DFT calculation is to validate the pseudopotentials and functionals selected for the simulation. This validation is commonly performed by comparing the theoretical lattice constant and bulk modulus of the bulk material (cubic structure) with experimental data. Good agreement between the theoretical and experimental values for these parameters indicates that the pseudopotentials and functional selected are reasonable. The theoretical lattice constant and bulk modulus of nickel in this work were calculated by fitting the Birch-Murnaghan equation, as listed in Table 2.

Table 3. Comparison of calculated lattice constant and bulk modulus with experimental values

\begin{tabular}{lcc}
\hline & This work & Experiment $^{27}$ \\
\hline Lattice constant $(\AA)$ & 3.512 & 3.524 \\
Bulk modulus $(\mathrm{Gpa})$ & 205 & $162-200$ \\
\hline
\end{tabular}

After setting the calculation parameters, we must determine the layout of the adsorbate molecules on topmost layer of the slab model. On any given surface, the adsorbate molecules may theoretically position themselves in an infinite number of unique configurations. The problem is, therefore, conventionally simplified by only focusing on the most stable binding sites. For a facecentered cubic crystal on a (111) plane, the most stable binding sites for adsorbates can be the top, bridge, or hollow (fcc and hcp) sites illustrated in Figure 3. Table 3 reports the binding energies of $\mathrm{CH}_{\mathrm{x}}(x=0-3)$ and $\mathrm{H}$ species on the nickel (111) surface. These results indicate that the most favorable adsorption site for all listed species was the hollow site. This agrees well with observations from other works ${ }^{20,22,28}$.

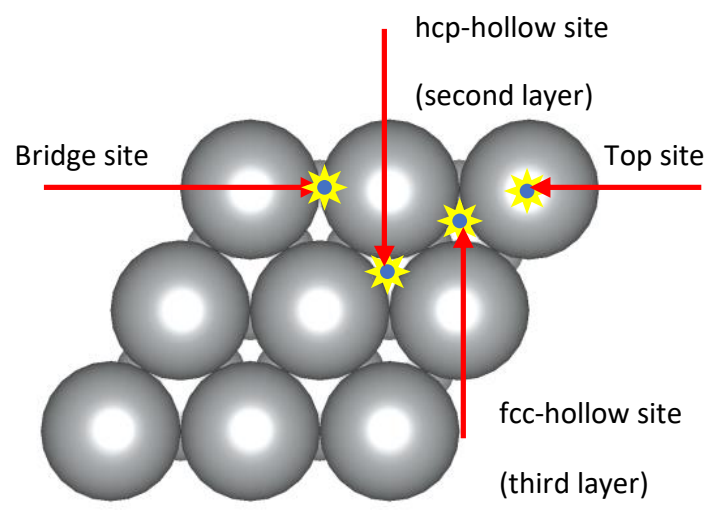

Figure 3. Illustration of the different binding sites on (111) fcc plane. 
Table 3. Binding energies $\left(\mathrm{E}_{\mathrm{b}}\right)$ for adsorbates in each binding site on Ni(111). The most stable binding sites are highlighted.

\begin{tabular}{|c|c|c|c|c|c|}
\hline \multirow[b]{2}{*}{ Adsorbate } & \multirow[b]{2}{*}{ Site } & \multicolumn{3}{|c|}{ Binding energy $\mathrm{E}_{\mathrm{b}}(\mathrm{eV})$} & \multirow[b]{2}{*}{$\operatorname{Ref}^{20}$} \\
\hline & & This work & $\operatorname{Ref1}^{22}$ & $\operatorname{Ref} 2^{28}$ & \\
\hline \multirow{3}{*}{$\mathrm{H}$} & fcc & -2.67 & -2.64 & -2.77 & fcc \\
\hline & hcp & -2.66 & -2.65 & -2.76 & \\
\hline & top & -2.11 & -1.92 & -2.22 & \\
\hline \multirow{3}{*}{$\mathrm{C}$} & fcc & -6.72 & -6.12 & -6.52 & \\
\hline & hcp & -6.80 & -6.22 & -6.61 & hep \\
\hline & top & -4.44 & -4.21 & N/A & \\
\hline \multirow{3}{*}{$\mathrm{CH}$} & fcc & -6.39 & -5.64 & -6.27 & \\
\hline & hcp & -6.44 & -5.7 & -6.35 & hcp \\
\hline & top & -4.30 & -3.8 & N/A & \\
\hline \multirow{3}{*}{$\mathrm{CH} 2$} & fcc & -4.68 & -3.19 & -3.85 & fcc \\
\hline & hcp & -4.67 & -3.21 & -3.83 & \\
\hline & top & -4.67 & -2.48 & -2.78 & \\
\hline \multirow{3}{*}{$\mathrm{CH} 3$} & fcc & -1.85 & -1.31 & -1.81 & fcc \\
\hline & hcp & -1.84 & -1.33 & -1.78 & \\
\hline & top & -1.61 & -1.1 & -1.55 & \\
\hline
\end{tabular}

All following calculations were performed based on the most favorable binding sites identified above. By calculating the electronic energy of initial states (IS), transition states (TS) and final states (FS), the PES of methane dissociation was determined. The calculated PES is shown in Figure 4, with other reported values as a benchmark. The vertical axis is the electronic energies and the horizontal axis is the reaction coordinate. Four transition state structures, TS1, TS2, TS3 and TS4, are identified for the whole reaction pathway. Based on the PES, we can see that all of the elementary steps are endothermic expect reaction 3. Additionally, reaction 4 has the highest energy barrier, via TS4, and represents the breaking of the final C-H bond. The PES provides qualitative information for each elementary reaction, showing that it is the last step that required the most energy. 


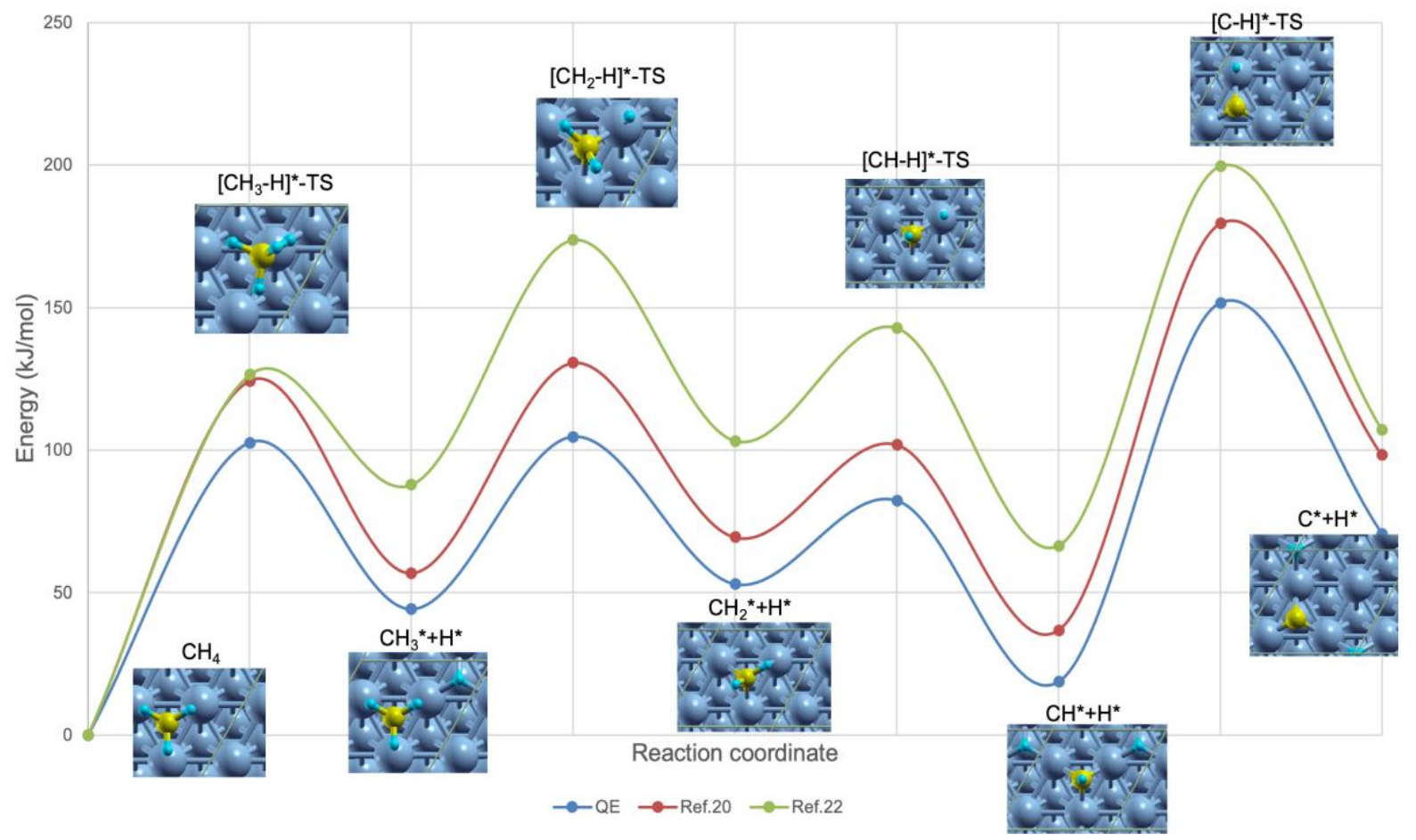

Figure 4. Potential energy surface (PES) diagram of all the elementary steps for methane dissociation, comparing with published data. ${ }^{20,22}$

\subsection{Preliminary investigation on silver system}

DFT, itself, has turned out to be an effective tool for studying certain mechanisms that would be hard to analyze using conventional experimental techniques. Despite the emergence of DFT studies focusing on metal-zeolite systems, few, if any, DFT studies targeted silver functionalized aerogels have been performed. The goal in this work is, therefore, to set up an atomic model that could represent the structure of the silver aerogel and then to apply the technique we learnt from the nickel system to find reaction mechanisms in silver system.

\subsubsection{Silver slab model}

During silver aerogel synthesis, the surface of the aerogel is functionalized with 1propanethiol molecules. Silver is then introduced to the aerogel by installing $\mathrm{Ag}^{+}$ions on these thiols. These silver ions are then reduced forming nanoparticles made of metallic silver on the surface of the aerogel ${ }^{29}$. Based on the fact that thiols can be chemisorbed onto metallic silver through cleavage of the $\mathrm{S}-\mathrm{H}$ bond even at low temperatures ${ }^{30}$, we expect to see the formation of a thiolate layer on the surface of the nanoparticles. This system may be reasonably simplified to a silver (111) surface covered with 1-propanethiol molecules. The (111) plane is selected because it has been proved to be the most active plane of silver surfaces ${ }^{31}$.

As described in the last section, the slab model is usually used to simulate metal surfaces. Based on existing experimental and theoretical studies, 1-propanethiol tends to form a monolayer with $(\sqrt{7} \times \sqrt{7})$ periodicity on silver $(111)$ surfaces $^{32-34}$. Therefore, a silver $(111)(\sqrt{7} \times \sqrt{7}) \mathrm{R}^{\circ} 9^{\circ}$ 
slab model was set up (shown in Figure 5). A vacuum space of $25 \AA$ was created along the normal direction of the slab to avoid interactions between atoms in each supercell.
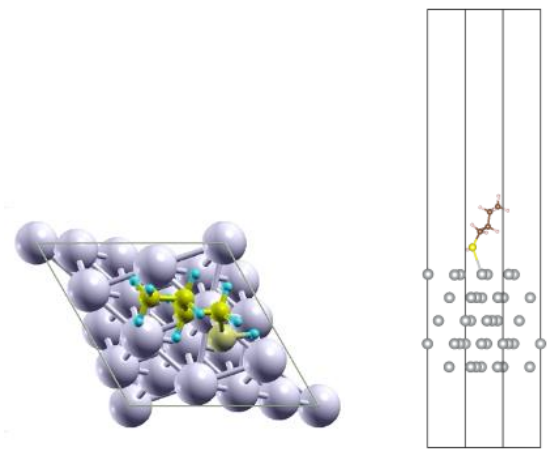

Figure 5. Top view (left) and side view (right) of the $\operatorname{Ag}(111)(\sqrt{7} \times \sqrt{7}) \mathrm{R} 19^{\circ}$ slab model.

\subsubsection{Pseudopotentials and parameters testing}

The pseudopotentials for the silver system were taken from the Standard Solid-State Pseudopotentials (SSSP) database ${ }^{35}$. An $o b t k-88$ functional was used instead of a normal PerdewBurke-Ernzerhof (PBE) functional since better performance was obtained using the obtk-88 functional. The main difference between the two functionals is that the obtk- 88 functional is capable of describing the van der Waals interaction. Geometry relaxation, energy calculation and transition state search were all performed with a $(8 \times 8 \times 1) \mathrm{k}$-space sampling. A Methfessel-Paxton smearing of $0.01 \mathrm{Ry}$ was applied. To cancel the dipole generated by the adsorbates in vacuum space, a dipole correction was also included.

Table 4. Comparison of calculated lattice constant and bulk modulus with experimental values

\begin{tabular}{ccc}
\hline & Bulk modulus $(\mathrm{Gpa})$ & Lattice parameter $(\AA)$ \\
\hline PBE+DFT-D2 & 120 & 4.13 \\
optbk88 & 103.2 & 4.096 \\
experimental & $84-118$ & 4.09 \\
\hline
\end{tabular}

\subsubsection{Preliminary test results}

Before testing the adsorption of 1-propanethiol on the slab, adsorption of a 1-butanethiol was first tested to compare with a published reference ${ }^{34}$. The results of this analysis are given below in Table 5. The disparity between the binding energies obtained in this work and those from the literature could probably be attributed to the different software packages and calculation settings used in this work. Additionally, the geometry of physiosorbed and chemisorbed 1propanethiol and 1-butanethiol are listed in Table 6. Despite the fact that there is little difference between the butanethiol and propanethiol structures, a significant change can be observed between chemisorption and physisorption. It is not surprising to see the chemisorbed thiolates moved towards the center of the hollow adsorption sites given the high degree of symmetry between thiolates after cleavage of the S-H bond. As described in section 3.4.1, only chemisorbed propanethiol will be considered in subsequent simulations since the $\mathrm{S}-\mathrm{H}$ bond will cleave at the experimental temperature. 
Table 5. Binding energies for 1-butanethiol adsorbing to each binding site on Ag (111)

\begin{tabular}{ccc}
\hline & \multicolumn{2}{c}{ Electronic binding energy $(\mathrm{eV})$} \\
\cline { 2 - 3 } Binding Site & QE & Reference $^{34}$ \\
\hline Top (converged between & -0.23 & -0.46 \\
hollow fcc \& bridge) & -0.13 & -0.31 \\
Bridge & -0.10 & -0.30 \\
Hollow fcc & -0.09 & 0.16 \\
Hollow hcp & & \\
\hline
\end{tabular}

Table 6. Binding energies for 1-butanethiol adsorbing to each binding site on $\operatorname{Ag}(111)$

\begin{tabular}{ccccc}
\hline Geometry & But_chem & But_phy & Prop_chem & Prop_phy \\
\hline $\mathrm{dS}-\operatorname{Ag}(\mathrm{A})(+)$ & 2.64 & 3.39 & 2.61 & 3.46 \\
$\mathrm{dS}-\mathrm{Ag}(\mathrm{B})(+)$ & 2.51 & 2.74 & 2.53 & 2.72 \\
$\mathrm{dS}-\mathrm{Ag}(\mathrm{C})(+)$ & 2.52 & 3.54 & 2.53 & 3.55 \\
\hline Tilt angle $\left({ }^{\circ}\right)$ & 41.6 & 37.2 & 47 & 44 \\
\hline
\end{tabular}

\subsection{Conclusions and future plan}

For FY-2020, an in-depth exploration of DFT calculations was performed, and a thorough understanding of QE has been established. So far, we have obtained the basic theoretical tools needed for the study of the reaction mechanisms governing iodine capture. Molecular models of silver mordenite (presented in the report of FY-2019) and silver aerogel have been built up and tested via literature benchmarking. The paths we will focus on going forward are:

1. Using the existing model, we will try to identify the most probable pathway for aerogel aging.

As proposed by Wiechert ${ }^{36}$, different from aging in AgMOR, aging of silver aerogel is most likely attributable to the oxidation of thiol groups on the surface of the $\mathrm{Ag}^{0}$ nanoparticles. This is based on experimental observations that show $\mathrm{Ag}_{2} \mathrm{SO}_{4}$ is formed as a byproduct of aerogel aging. A key point in this process is cleavage of the $\mathrm{C}-\mathrm{S}$ bond that must occur at some point during sulfur oxidation for $\mathrm{Ag}_{2} \mathrm{SO}_{4}$ to form (Equation 3-6). Experimental results from the literature indicate that silver sulfenate (r-SO-Ag) can be formed when a thiolate reacts with atomic oxygen (Equation 3). As shown in Equation 4, sulfur oxidation then likely proceeds by further oxidation of silver sulfenate to silver sulfinate ( $\left.\mathrm{r}-\mathrm{SO}_{2}-\mathrm{Ag}\right)$, which is then oxidized to silver sulfonate $\left(\mathrm{r}-\mathrm{SO} \mathrm{O}_{3}-\mathrm{Ag}\right)$. After that, two possible pathways were postulated for $\mathrm{AgSO}_{4}$ to ultimately form. The first path is that the propyl alkyl is cleaved right after oxidation to r-SO $\mathrm{S}_{3}-\mathrm{Ag}$ forming $\mathrm{Ag}_{2} \mathrm{SO}_{3}$ followed by decomposition of resulting $\mathrm{Ag}_{2} \mathrm{SO}_{3}$ to $\mathrm{Ag}_{2} \mathrm{SO}_{4}, \mathrm{SO}_{2}$ and $\mathrm{Ag}^{0}$ (Equation 5). As a second option, alkyl cleavage occurs after sulfur is completely oxidized to $\mathrm{r}-\mathrm{SO}_{4}-\mathrm{Ag}$ which then directly forms $\mathrm{Ag}_{2} \mathrm{SO}_{4}$ (Equation 6). 


$$
\begin{gathered}
\mathrm{r}-\mathrm{S}-\mathrm{Ag}+\mathrm{O} \rightarrow \mathrm{r}-\mathrm{SO}-\mathrm{Ag} \\
2 \mathrm{r}-\mathrm{SO}_{3}-\mathrm{Ag}+2 \mathrm{Ag}^{0} \rightarrow 2 \mathrm{Ag}_{2} \mathrm{SO}_{3}+\mathrm{r}_{2} \\
2 \mathrm{Ag}_{2} \mathrm{SO}_{3} \rightarrow 2 \mathrm{Ag}^{0}+\mathrm{SO}_{2}+\mathrm{Ag}_{2} \mathrm{SO}_{4} \\
2 \mathrm{r}-\mathrm{SO}_{4}-\mathrm{Ag}+2 \mathrm{Ag}^{0} \rightarrow 2 \mathrm{Ag}_{2} \mathrm{SO}_{4}+\mathrm{r}_{2}
\end{gathered}
$$

Based on existing experimental information, it is not possible to tell which pathway is predominant. In this case, we could take advantage of DFT's unique capability in dealing with such problems. Figure 6 demonstrates a potential result that might be obtained from DFT calculation showing the PESs for both of the reactions postulated above. Path A represents the reaction where alkyl cleavage occurs during oxidation. Path B refers to the reaction pathway where alkyl cleavage occurs after sulfur is fully oxidized to $\mathrm{SO}_{4}$. By looking at this specific case, we might conclude that pathway B is more favorable than pathway A, based on the fact that the energy barrier for each elementary step in path $\mathrm{A}$ is higher than those in path B. However, it's worth noting that this is just a demonstration of how to analyze the results. The real conclusion might differ.

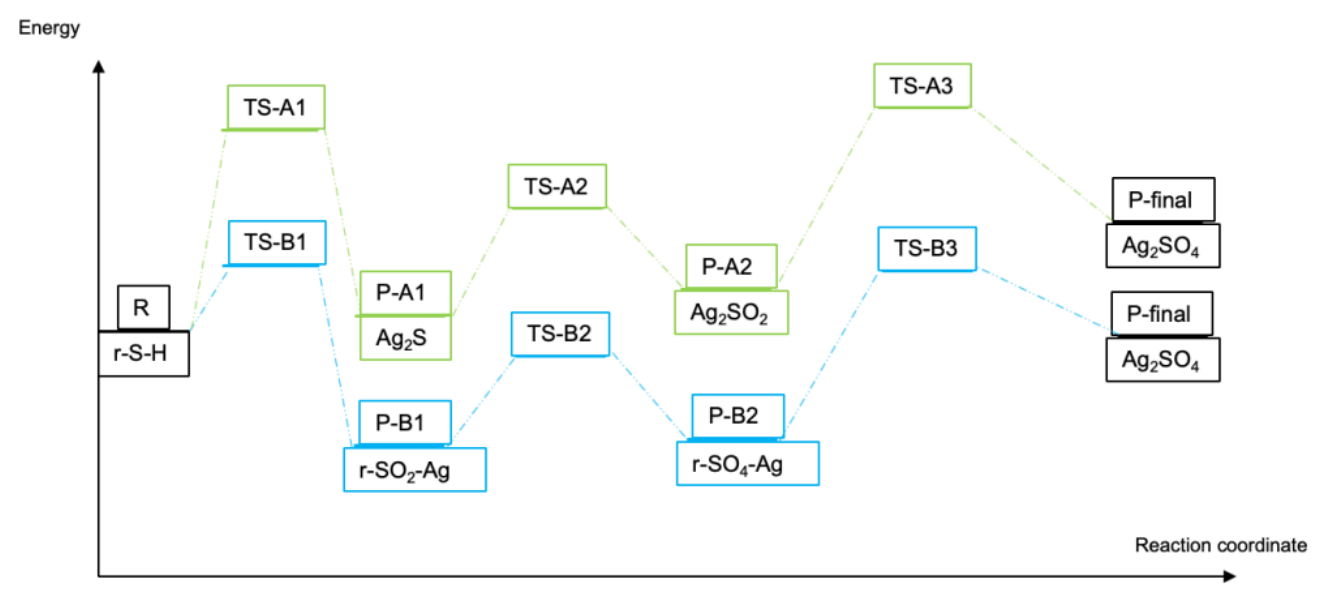

Figure 6. Demonstration of possible PES for two different Ag aging reaction pathways.

2. Further investigation to improve the structural model for silver aerogel

In fact, the exact structure of unaged silver aerogel remains unclear. Preliminary X-ray Absorption Spectroscopy (XAS) results from Syracuse University suggest a $\mathrm{Ag}_{2} \mathrm{~S}$-like structure for unaged silver aerogel while X-ray Photoelectron Spectroscopy (XPS) results, from PNNL, suggest the opposite. More in-depth characterization, such as a combination of XAS and other techniques, XPS or Raman spectroscopy for example, could provide more insights on the structure of the aerogel. The DFT model can also be improved correspondingly. 


\subsection{References for Part 3}

1. Huve, J.; Ryzhikov, A.; Nouali, H.; Lalia, V.; Augé, G.; Daou, T. J., Porous sorbents for the capture of radioactive iodine compounds: a review. RSC Advances 2018, 8 (51), 2924829273.

2. Nandanwar, S. U.; Coldsnow, K.; Utgikar, V.; Sabharwall, P.; Eric Aston, D., Capture of harmful radioactive contaminants from off-gas stream using porous solid sorbents for clean environment - A review. Chemical Engineering Journal 2016, 306, 369-381.

3. Azambre, B.; Chebbi, M., Evaluation of Silver Zeolites Sorbents Toward Their Ability to Promote Stable CH3I Storage as AgI Precipitates. ACS Appl Mater Interfaces 2017, 9 (30), 25194-25203.

4. Chebbi, M.; Azambre, B.; Cantrel, L.; Koch, A., A Combined DRIFTS and DR-UV-Vis Spectroscopic In Situ Study on the Trapping of CH3I by Silver-Exchanged Faujasite Zeolite. The Journal of Physical Chemistry C 2016, 120 (33), 18694-18706.

5. Parr, R. G., Density functional theory of atoms and molecules. In Horizons of quantum chemistry, Springer: 1980; pp 5-15.

6. Sholl, D.; Steckel, J. A., Density functional theory: a practical introduction. John Wiley \& Sons: 2011.

7. Nørskov, J. K.; Studt, F.; Abild-Pedersen, F.; Bligaard, T., Fundamental concepts in heterogeneous catalysis. John Wiley \& Sons: 2014.

8. Bucko, T.; Chibani, S.; Paul, J. F.; Cantrel, L.; Badawi, M., Dissociative iodomethane adsorption on Ag-MOR and the formation of AgI clusters: an ab initio molecular dynamics study. Phys Chem Chem Phys 2017, 19 (40), 27530-27543.

9. Chibani, S.; Chebbi, M.; Lebegue, S.; Cantrel, L.; Badawi, M., Impact of the Si/Al ratio on the selective capture of iodine compounds in silver-mordenite: a periodic DFT study. Phys Chem Chem Phys 2016, 18 (36), 25574-25581.

10. Bučko, T.; Hafner, J., The role of spatial constraints and entropy in the adsorption and transformation of hydrocarbons catalyzed by zeolites. Journal of Catalysis 2015, 329, 32-48.

11. Baltrusaitis, J.; Bučko, T.; Michaels, W.; Makkee, M.; Mul, G., Catalytic methyl mercaptan coupling to ethylene in chabazite: DFT study of the first $\mathrm{C} \mathrm{C}$ bond formation. Applied Catalysis B: Environmental 2016, 187, 195-203.

12. Jabraoui, H.; Hessou, E. P.; Chibani, S.; Cantrel, L.; Lebègue, S.; Badawi, M., Adsorption of volatile organic and iodine compounds over silver-exchanged mordenites: A comparative periodic DFT study for several silver loadings. Applied Surface Science 2019, 485, 56-63. 
13. Chibani, S.; Chiter, F.; Cantrel, L.; Paul, J.-F., Capture of Iodine Species in MIL-53(Al), MIL-120(Al), and HKUST-1(Cu) Periodic DFT and Ab-Initio Molecular Dynamics Studies. The Journal of Physical Chemistry C 2017, 121 (45), 25283-25291.

14. Chibani, S.; Chebbi, M.; Lebegue, S.; Bucko, T.; Badawi, M., A DFT investigation of the adsorption of iodine compounds and water in $\mathrm{H}-, \mathrm{Na}-, \mathrm{Ag}-$, and $\mathrm{Cu}-$ mordenite. J Chem Phys 2016, 144 (24), 244705.

15. Chebbi, M.; Chibani, S.; Paul, J.-F.; Cantrel, L.; Badawi, M., Evaluation of volatile iodine trapping in presence of contaminants: A periodic DFT study on cation exchanged-faujasite. Microporous and Mesoporous Materials 2017, 239, 111-122.

16. Rimsza, J. M.; Chapman, K. W.; Nenoff, T. M., Energetics and Structure of Ag-Water Clusters Formed in Mordenite. The Journal of Physical Chemistry C 2020, 124 (8), 45174524.

17. Giannozzi, P.; Baroni, S.; Bonini, N.; Calandra, M.; Car, R.; Cavazzoni, C.; Ceresoli, D.; Chiarotti, G. L.; Cococcioni, M.; Dabo, I., QUANTUM ESPRESSO: a modular and opensource software project for quantum simulations of materials. Journal of physics: Condensed matter 2009, 21 (39), 395502.

18. Giannozzi, P.; Andreussi, O.; Brumme, T.; Bunau, O.; Nardelli, M. B.; Calandra, M.; Car, R.; Cavazzoni, C.; Ceresoli, D.; Cococcioni, M., Advanced capabilities for materials modelling with Quantum ESPRESSO. Journal of Physics: Condensed Matter 2017, 29 (46), 465901 .

19. Schlegel, H. B., Exploring potential energy surfaces for chemical reactions: an overview of some practical methods. Journal of computational chemistry 2003, 24 (12), 1514-1527.

20. Blaylock, D. W.; Ogura, T.; Green, W. H.; Beran, G. J., Computational investigation of thermochemistry and kinetics of steam methane reforming on $\mathrm{Ni}$ (111) under realistic conditions. The Journal of Physical Chemistry C 2009, 113 (12), 4898-4908.

21. Yang, H.; Whitten, J. L., Dissociative chemisorption of CH4 on Ni(111). The Journal of Chemical Physics 1992, 96 (7), 5529-5537.

22. Li, J.; Croiset, E.; Ricardez-Sandoval, L., Methane dissociation on Ni (100), Ni (111), and Ni (553): A comparative density functional theory study. Journal of Molecular Catalysis A: Chemical 2012, 365, 103-114.

23. Le, T. N.; Liu, B.; Huynh, L. K., SurfKin: an ab initio kinetic code for modeling surface reactions. J Comput Chem 2014, 35 (26), 1890-9.

24. Monkhorst, H. J.; Pack, J. D., Special points for Brillouin-zone integrations. Physical review $B$ 1976, 13 (12), 5188.

25. Makov, G.; Payne, M., Periodic boundary conditions in ab initio calculations. Physical Review B 1995, 51 (7), 4014. 
26. Perdew, J. P.; Burke, K.; Ernzerhof, M., Generalized gradient approximation made simple. Physical review letters 1996, 77 (18), 3865.

27. Kittel, C.; McEuen, P.; McEuen, P., Introduction to solid state physics. Wiley New York: 1996; Vol. 8.

28. Wang, S.-G.; Cao, D.-B.; Li, Y.-W.; Wang, J.; Jiao, H., CH4 dissociation on Ni surfaces: density functional theory study. Surface science 2006, 600 (16), 3226-3234.

29. Matyas, J.; Fryxell, G. E.; Busche, B. J.; Wallace, K.; Fifield, L. S. Functionalized Silica Aerogels: Advanced Materials To Capture And Immobilize Radioactive Iodine; United States, 2011; p v.

30. Rodriguez, L. M.; Gayone, J. E.; Sanchez, E. A.; Grizzi, O.; Blum, B.; Salvarezza, R. C., Room-temperature kinetics of short-chain alkanethiol film growth on $\mathrm{Ag}(111)$ from the vapor phase. J Phys Chem B 2006, 110 (14), 7095-7.

31. Wang, B.; Liu, M.; Wang, Y.; Chen, X., Structures and Energetics of Silver and Gold Nanoparticles. The Journal of Physical Chemistry C 2011, 115 (23), 11374-11381.

32. Vericat, C.; Vela, M. E.; Benitez, G.; Carro, P.; Salvarezza, R. C., Self-assembled monolayers of thiols and dithiols on gold: new challenges for a well-known system. Chem Soc Rev 2010, 39 (5), 1805-34.

33. Woodruff, D. P., The interface structure of n-alkylthiolate self-assembled monolayers on coinage metal surfaces. Phys Chem Chem Phys 2008, 10 (48), 7211-21.

34. Li, A.; Piquemal, J.-P.; Richardi, J.; Calatayud, M., Butanethiol adsorption and dissociation on Ag (111): A periodic DFT study. Surface Science 2016, 646, 247-252.

35. Prandini, G.; Marrazzo, A.; Castelli, I. E.; Mounet, N.; Marzari, N., Precision and efficiency in solid-state pseudopotential calculations. npj Computational Materials 2018, 4 (1), 72 .

36. Wiechert, A. I. ADSORPTION PROCESSES IN NUCLEAR FUEL RESOURCE RECOVERY. Ph.D. Thesis, Georgia Institute of Technology, 2020. 


\section{Part 4: Fixed Bed Modeling}

\subsection{Scope}

As the ultimate goal of this research, a scalable adsorption model will be developed to enable accurate prediction of column performance for silver-based adsorbents used in the capture of organic iodides. To accomplish this goal, a clear understanding of the transport mechanism and reaction processes during adsorption is required. In this section, we will discuss the feasibility of using computational tools developed at Georgia Tech to simulate the methyl iodide adsorption performance.

\subsection{Modeling Methodology}

Fixed bed column simulations are performed using the Catalytic After Treatment System (CATS) modeling framework. CATS is a successor to the Discontinuous Galerkin Off-gas Separation and Recovery model (DG-OSPREY) framework developed at the Georgia Institute of Technology ${ }^{1}$. CATS is built on top of the Multiphysics Object Oriented Simulation Environment (MOOSE) modeling framework developed at Idaho National Laboratory ${ }^{2}$. The MOOSE framework is designed to handle discretization of spatial domains and iterative solving of nonlinear systems of equations. Domain discretization in MOOSE is performed using either continuous or discontinuous Galerkin finite element methods. In this case, the discontinuous Galerkin (DG) method is used since, in the context of problems derived from conservation laws, it is more stable and less oscillatory than the continuous method. ${ }^{3,4}$ Domain discretization produces a non-linear system of equations which MOOSE solves iteratively using the Preconditioned Jacobian Free-Newton Krylov (PJFNK) method. ${ }^{5}$ This method incorporates both a non-linear solver based on Newton type methods and a linear Krylov subspace method which is nested within the non-linear solver, typically the generalized minimal residual (GMRES) method. Convergence of non-linear iterations is controlled through the use of line search methods, such as BackTracking. ${ }^{6}$ For each linear iteration, preconditioning is performed with incomplete lower and upper triangular fractionalization to improve computational efficiency. Integration in time is carried using either a first-order accurate Backwards Euler method or a second-order accurate Backwards Differentiation method. ${ }^{7}$ CATS, on the other hand, establishes the conservation equations needed to preform column adsorption modeling.

Compared with its ancestor DG-OSPERY, CATS, itself, offers more modularity in coding and creates more flexibility for users to create the input files. Specifically, CATS provides the ability to specify and calculate material/gas properties independently from the embedded MOOSE framework. In general, the equations for modeling fixed-bed column adsorption are derived from the gas phase mass and energy conservation equations. ${ }^{8,9}$ In a packed column, the accumulation of mass for any gas species (Equation 1) is based on the concentration of that species $\left(C_{i}\right)$ and the bulk bed porosity $(\varepsilon)$ which defines the void space where the gas may exist. The gas mixture can move in the void space of the column through advection, at an advective velocity of $v$, and dispersion $\left(D_{i}\right)$ transport mechanisms. Adsorption represents a loss to the gas phase based on the net adsorption rate $\left(d q_{i} / d t\right)$ multiplied by the packing density of the adsorbent material $\left(\rho_{b}\right)$. For solid species, mass conservation is significantly simplified since advection and diffusion do not need to be considered. Rather, adsorption represented through the net rate of adsorption is the only 
component of Equation 1 that needs to be considered for non-gas phase species. In terms of energy balance in the column, CATS is, different from DG-OSPREY, built based on the conservation of internal energy density $(E)$ rather than temperature. This change ensures the most conservative form of the energy balance, which not only captures the impact of temperature variations on the system energy, but also captures how density and specific heat variations impact the energy density. In this case, the energy density of the fluid phase $\left(E_{f}\right)$ and solid phase $\left(E_{S}\right)$ are to be considered (Equation 2-5). Those energy densities are related to the temperatures of each phase $\left(T_{f}\right.$ and $\left.T_{s}\right)$ through their respective densities $\left(\rho_{f}\right.$ and $\left.\rho_{s}\right)$ and heat capacities $\left(c_{p f}\right.$ and $\left.c_{p s}\right)$. Heat is accumulated in the column, then transferred through both gas advection $(v)$ and the thermal conductivity of the solid/gas $(\mathrm{K})$ in the packed column. In addition to the transport of thermal energy, the adsorption process will also contribute to the generation or removal of heat from the system through the heat of reaction for each adsorbing gas $\left(\Delta H_{i}\right)^{8,9}$.

$$
\begin{gathered}
\varepsilon \frac{\partial \mathrm{C}_{\mathrm{i}}}{\partial \mathrm{t}}+\nabla \cdot\left(\varepsilon \mathbf{v} \mathrm{C}_{\mathrm{i}}\right)=\nabla \cdot\left(\varepsilon \mathrm{D}_{\mathrm{i}} \nabla \mathrm{C}_{\mathrm{i}}\right)-\rho_{\mathrm{b}} \frac{\partial \mathrm{q}_{\mathrm{i}}}{\partial \mathrm{t}} \\
\varepsilon \frac{\partial \mathrm{E}_{\mathrm{f}}}{\partial \mathrm{t}}+\nabla \cdot\left(\varepsilon \mathbf{v} \mathrm{E}_{\mathrm{f}}\right)=\nabla \cdot\left(\varepsilon \mathrm{K}_{\mathrm{f}} \nabla \mathrm{T}_{\mathrm{f}}\right)-(1-\varepsilon) \mathrm{hA}_{\mathrm{o}}\left(\mathrm{T}_{\mathrm{f}}-\mathrm{T}_{\mathrm{s}}\right) \\
\frac{\partial \mathrm{E}_{\mathrm{s}}}{\partial \mathrm{t}}=\nabla \cdot\left(\mathrm{K}_{\mathrm{s}} \nabla \mathrm{T}_{\mathrm{f}}\right)-\mathrm{h} \mathrm{A}_{\mathrm{o}}\left(\mathrm{T}_{\mathrm{s}}-\mathrm{T}_{\mathrm{f}}\right)+\rho_{\mathrm{s}} \sum_{\mathrm{i}}\left(-\Delta \mathrm{H}_{\mathrm{i}}\right) \frac{\partial \mathrm{q}_{\mathrm{i}}}{\partial \mathrm{t}} \\
\mathrm{E}_{\mathrm{f}}=\rho_{\mathrm{f}} \mathrm{C}_{\mathrm{pf}} \mathrm{T}_{\mathrm{f}} \\
\mathrm{E}_{\mathrm{s}}=\rho_{\mathrm{s}} \mathrm{c}_{\mathrm{ps}} \mathrm{T}_{\mathrm{s}}
\end{gathered}
$$

The rate of adsorption inside the column $(\mathrm{dq} / \mathrm{dt})$ is theoretically a function of interphase mass transfer, intraparticle diffusion, and surface reactions. ${ }^{8}, 9$ In terms of the simulations performed in this report, the chemisorption model is used which defines adsorption as a reversible chemical reaction (Equation 6-7), where a number of reactant species $\left(C_{i}\right)$ form various product species including the adsorbed species $\left(C_{j}\right)$. From this generic chemical reaction, the adsorption rate for the $i^{\text {th }}$ species is defined by Equation 9 with forward and reverse rate constants of $k_{f}$ and $k_{r}$, respectively. The reaction order with respect to each reactant $\left(r_{j}^{*}\right)$ and product $\left(r_{k}^{*}\right)$ species is considered variable and independent of the species' stoichiometry $\left(v_{i}\right.$ and $\left.v_{j}\right)$ in the chemical reaction. A scaling factor (a) is used as a conversion for the rates of a particular species.

$$
\begin{gathered}
\sum_{\mathrm{i}} \mathrm{v}_{\mathrm{i}} \mathrm{C}_{\mathrm{i}} \leftrightarrow \sum_{\mathrm{j}} \mathrm{v}_{\mathrm{j}} \mathrm{C}_{\mathrm{j}} \\
\frac{\partial \mathrm{q}_{\mathrm{i}}}{\partial \mathrm{t}}=-\mathrm{a}\left(\mathrm{k}_{\mathrm{f}} \cdot \prod_{\text {react }} \mathrm{c}_{\mathrm{i}}^{\mathrm{v}_{\mathrm{i}}}-\mathrm{k}_{\mathrm{r}} \cdot \prod_{\text {prod }} \mathrm{C}_{\mathrm{j}}^{\mathrm{v}_{\mathrm{j}}}\right)
\end{gathered}
$$




\subsection{Preliminary $\mathbf{A g}^{\mathbf{0}}$-aerogel thin-bed simulation}

Despite the fact that not all of the mechanisms for methyl iodide adsorption on silver aerogel are known, it is reasonable to assume most of the uptake will occur via the dissociative adsorption of methyl iodide $\left(\mathrm{CH}_{3} \mathrm{I}\right)$ on the metallic silver $\left(\mathrm{Ag}^{0}\right)$ nanoparticles. Based on available literature, the adsorption of $\mathrm{CH}_{3} \mathrm{I}$ on the $\mathrm{Ag}^{0}$ surface can be described with the reaction given in Equation $8^{10,11}$. This reaction involves the cleavage of the C-I bond on a physisorbed $\mathrm{CH}_{3} \mathrm{I}$ yielding a methyl radical and an atomic iodine. The atomic iodine is subsequently adsorbed onto the $\mathrm{Ag}^{0}$ surface forming silver iodide while the methyl radial desorbs and recombines to form ethane in the gas phase. Under experimental conditions, silver-based materials, including aerogel, showed significant capacity loss over extended periods of time as a consequence of adsorbent aging ${ }^{12}$. Therefore, in order to precisely simulate $\mathrm{CH}_{3} \mathrm{I}$ uptake, material aging cannot be neglected if the operation time is longer than 100 hours. The exact aging mechanisms for silver aerogel remain obscure, however, all available experimental observation indicates that 1-propanethiol $\left(\mathrm{CH}_{3} \mathrm{CH}_{2} \mathrm{CH}_{2} \mathrm{SH}\right)^{12}$, the functional groups supporting $\mathrm{Ag}^{0}$ nanoparticles on the aerogel surfaces, likely plays some role in aging. Several postulated thiol-related reactions were discussed in section 3.5. Here, the potential rate-limiting step (Equation 9) is used for describing aging processes to simplify the simulation.

$$
\begin{aligned}
2 \mathrm{Ag}+2 \mathrm{CH}_{3} \mathrm{I}(\mathrm{g}) & \leftrightarrow 2 \mathrm{AgI}+\mathrm{C}_{2} \mathrm{H}_{6}(\mathrm{~g}) \\
2 \mathrm{Ag}^{0}+2 \mathrm{CH}_{3} \mathrm{CH}_{2} \mathrm{CH}_{2} \mathrm{SH}(\mathrm{g}) & \leftrightarrow 2 \mathrm{CH}_{3} \mathrm{CH}_{2} \mathrm{CH}_{2} \mathrm{SAg}+\mathrm{H}_{2}(\mathrm{~g})
\end{aligned}
$$

One other point worth noticing is that based on the deep-bed adsorption test results from $\mathrm{ORNL}^{13}$, silver aerogel, itself, experiences appreciable structural change under adsorption conditions, which subsequently leads to variation in the total volume of packed materials, bulk density of granulates, and the porosity in the column. As such, in this project both bulk density and porosity of adsorbate are considered as variables. For simplicity, we assume the density and porosity change linearly with respect to time. In addition, an average volume is used to account for the structural change.

Kinetic information for the adsorption and aging reactions given above was determined by fitting to experimental data through CATS. The experimental results obtained at ORNL for $\mathrm{CH}_{3} \mathrm{I}$ adsorption at a concentration of $50 \mathrm{ppb}$ (VOG condition) at $150^{\circ} \mathrm{C}$ were used for this simulation. Due to the lack of related experiments at ORNL, data for the effect of aging in dry air was taken from experiments performed at Syracuse University. It is reasonable to apply data from different sources in this case since the aerogel used by the teams at both institutions was produced by the same manufacturer (PNNL) with the experiments being conducted under similar conditions. Figure 1 shows the simulation results for a thin bed $(3.45 \mathrm{~cm}$ inner diameter of the column, 0.25 $\mathrm{cm}$ depth) test. A total adsorbent mass of $1.159 \mathrm{~g}$ and an influent flow rate of $3.99 \mathrm{~L} / \mathrm{min}$ (superficial velocity $=0.167 \mathrm{~m} / \mathrm{s}$ ) were used to simulate the experimental environment. The reaction order with respect to $\mathrm{Ag}^{0}$ was adjusted to provide a reasonable fit of the data. Figure 1a shows the fitting results for aging and while Figure $1 \mathrm{~b}$ shows the adsorption of $\mathrm{CH}_{3} \mathrm{I}$ in a thin bed. Both the aging and $\mathrm{CH}_{3} \mathrm{I}$ adsorption reactions are $5^{\text {th }}$ order with respect to $\mathrm{Ag}^{0}$. The reaction rate constant for aging is $k_{f}=8.10 \times 10^{-11}(\mathrm{~kg} / \mathrm{mol})^{6} / \mathrm{s}$ and the rate constant for $\mathrm{CH}_{3} \mathrm{I}$ adsorption 
is $k_{f}=0.072(\mathrm{~kg} / \mathrm{mol})^{4}\left(\mathrm{~m}^{3} / \mathrm{mol}\right)^{2} / \mathrm{s}$. Kinetic information can be used for further deep-bed simulations.
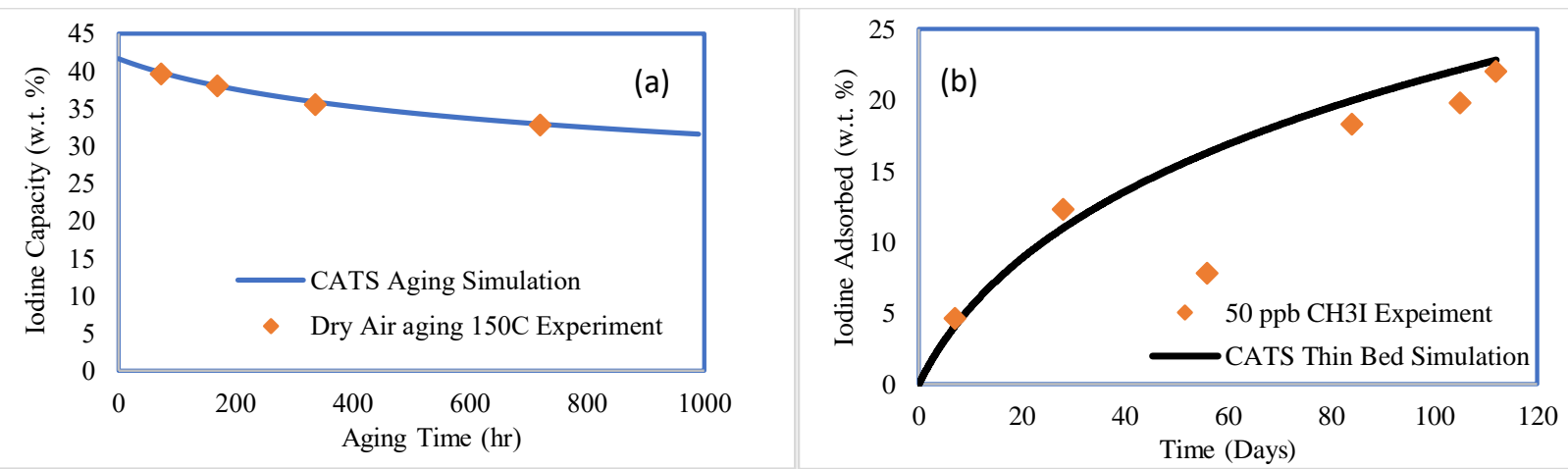

Figure 1. Thin bed simulations for (a) silver aerogel aged in dry air at $150^{\circ} \mathrm{C}$ and (b) adsorption of methyl iodide $\left(\mathrm{CH}_{3} \mathrm{I}\right)$ with a concentration of $50 \mathrm{ppb}$ at $150^{\circ} \mathrm{C}$, aging effect included. Iodine capacity is calculated as weight percentage gained from unloaded adsorbent.

\subsection{Future work}

Continued work will focus on the exploration of proper adsorption mechanisms as well as deep bed simulations. Specifically, the mechanisms of aging and their effect on iodine adsorption will be studied using molecular modeling in conjunction with experimental characterization.

\subsection{References for Part 4}

1. Ladshaw, A. P.; Wiechert, A. I.; Welty, A. K.; Lyon, K. L.; Law, J. D.; Jubin, R. T.; Tsouris, C.; Yiacoumi, S., Adsorbents and adsorption models for capture of $\mathrm{Kr}$ and $\mathrm{Xe}$ gas mixtures in fixed-bed columns. Chemical Engineering Journal 2019, 375, 122073.

2. Gaston, D.; Newman, C.; Hansen, G.; Lebrun-Grandie, D., MOOSE: A parallel computational framework for coupled systems of nonlinear equations. Nuclear Engineering and Design 2009, 239 (10), 1768-1778.

3. Houston, P.; Schwab, C.; Süli, E., Discontinuous hp-finite element methods for advectiondiffusion-reaction problems. SIAM Journal on Numerical Analysis 2002, 39 (6), 2133-2163.

4. Riviere, B., Discontinuous Galerkin methods for solving elliptic and parabolic equations: theory and implementation. SIAM: 2008.

5. Knoll, D. A.; Keyes, D. E., Jacobian-free Newton-Krylov methods: a survey of approaches and applications. Journal of Computational Physics 2004, 193 (2), 357-397.

6. Eckert, S.; Baaser, H.; Gross, D.; Scherf, O., A BDF2 integration method with step size control for elasto-plasticity. Computational Mechanics 2004, 34 (5), 377-386. 
7. Dennis Jr, J. E.; Schnabel, R. B., Numerical methods for unconstrained optimization and nonlinear equations. SIAM: 1996.

8. Ladshaw, A. P.; Yiacoumi, S.; Lin, R.; Nan, Y.; Tavlarides, L. L.; Tsouris, C., A mechanistic modeling framework for gas-phase adsorption kinetics and fixed-bed transport. AIChE Journal 2017, 63 (11), 5029-5043.

9. Simo, M.; Sivashanmugam, S.; Brown, C. J.; Hlavacek, V., Adsorption/desorption of water and ethanol on $3 \mathrm{~A}$ zeolite in near-adiabatic fixed bed. Industrial \& Engineering Chemistry Research 2009, 48 (20), 9247-9260.

10. Zhou, X.-L.; White, J., Thermal decomposition of C 2 H 5 I on Ag (111). Catalysis letters 1989, 2 (6), 375-384.

11. Zhou, X.-L.; Solymosi, F.; Blass, P.; Cannon, K.; White, J., Interactions of methyl halides (Cl, Br and I) with Ag (111). Surface Science 1989, 219 (1-2), 294-316.

12. Matyášs, J.; Ilton, E. S.; Kovařík, L., Silver-functionalized silica aerogel: towards an understanding of aging on iodine sorption performance. RSC Advances 2018, 8 (56), 3184331852 .

13. Stephanie H. Bruffey; Jubin, R. T. Iodine Capture and Mechanical Stability of Modified Silver-Functionalized Silica Aerogel; Oak Ridge National Laboratory: 2019. 


\section{Part 5: List of Products}

\subsection{Related journal publications}

1. Ladshaw, A.P.; Yiacoumi, S.; Lin, R.; Nan, Y.; Tavlarides, L.L.; Tsouris, C. “A Mechanistic Modeling Framework for Gas Phase Adsorption Kinetics and Fixed-Bed Transport," AIChE J., 63, 5029-5043 (2017).

2. Ladshaw, A.P.; Wiechert, A.I.; Welty, A.K.; Lyon, K.L.; Law, J.D.; Jubin, R.T.; Tsouris, C.; Yiacoumi, S. "Adsorbents and adsorption models for capture of $\mathrm{Kr}$ and $\mathrm{Xe}$ gas mixtures in fixed-bed columns," Chemical Engineering Journal, 375, 122073 (2019).

3. Wiechert, Alexander I., et al. "Capture of Iodine from Nuclear-Fuel-Reprocessing Off-Gas: Influence of Aging on a Reduced Silver Mordenite Adsorbent after Exposure to NO/NO2." ACS Applied Materials \& Interfaces, 44, 49680-49693 (2020).

4. Choi, S.; Nan, Y.; Tavlarides, L.L. "Kinetics of Aging Process on Reduced Ag Exchanged Mordenite in Dry Air and Humid Air," AIChE Journal (2020), under review.

5. Wiechert, A.I. "Asorption Processes in Nuclear Fuel Resource Recovery." Ph.D. Thesis, Georgia Institute of Technology, 2020.

6. Ladshaw, A.P. "Complex Adsorption Modeling for Nuclear Energy Applications." Ph.D. Thesis, Georgia Institute of Technology, 2017.

\subsection{Related Presentations}

1. Ladshaw, A.P.; Yiacoumi, S.; Tsouris, C. "Adsorption Modeling for Nuclear Energy Applications," $91^{\text {st }}$ ACS Colloid and Surface Science Symposium, New York, NY, July, 2017.

2. Ladshaw, A.P.; Yiacoumi, S.; Tsouris, C.; Nan, Y.; Lin, R.; Tavlarides, L.L. “Adsorption Models for Treatment of Nuclear Reprocessing Off-Gases," 2017 AIChE Annual Meeting: Solvent Extraction and Adsorption in Spent Fuel Reprocessing and Radioactive Waste Management, Saint Paul, MN, October, 2017.

3. Yiacoumi, S.; Ladshaw, A.P.; Tsouris, T. "Modeling Adsorption Processes in Energy Systems and Resource Recovery," 92 ${ }^{\text {nd }}$ ACS Colloid and Surface Science Symposium, June, 2018.

4. Ladshaw, A.P.; Yiacoumi, S.; Tsouris, C. "A Modeling Framework for Adsorption Processes in Environmental Remediation and Monitoring," 255th ACS National Meeting, New Orleans, LA, March, 2018.

5. Ladshaw, A.P.; Wiechert, A.I.; Welty, A.; Lyon, K.; Law, J.; Nan, Y.; Choi, S.; Tavlarides, L.; Tsouris, C.; Yiacoumi, S. "Developing DG-OSPREY: A Gas-Phase Fixed-bed Adsorption Model Built on MOOSE," Twentieth Symposium on Separations Science and Technology for Energy Applications, Gatlinburg, TN, October 21-24, 2018. 
6. Ladshaw, A.P.; Wiechert, A.I.; Nan, Y.; Choi, S.; Tavlarides, L.L.; Welty, A.; Lyon, K.; Law, J.; Tsouris, C.; Yiacoumi, S.; "DG-OSPREY: A Gas-Phase Fixed-bed Adsorption Model Built on MOOSE," 93 ${ }^{\text {rd }}$ ACS Colloid and Surface Science Symposium, Georgia Institute of Technology, Atlanta, GA, June, 2019.

7. Wiechert, A.I.; Ladshaw, A.P.; Nan, Y.; Choi, S.; Tavlarides, L.L.; Tsouris, C.; Yiacoumi, S.; "Mechanisms of Adsorbent Aging and Its Influence on Iodine Capture from Nuclear Fuel Reprocessing Off-gas," 93 ${ }^{\text {rd }}$ ACS Colloid and Surface Science Symposium, Georgia Institute of Technology, Atlanta, GA, June, 2019.

8. Wiechert, A.I.; Ladshaw, A.P.; Nan, Y.; Choi, S.; Tavlarides, L.L.; Moon, J.; Abney, C.; Tsouris, C.; Yiacoumi, S. "Influence of Aging on the Iodine Adsorption Capacity of Reduced Silver Adsorbents," Southeastern Regional Meeting of the American Chemical Society (SERMACS) Symposium: Advancements in Environmental Chemistry October (2019). Invited

9. Nan, Y.; Choi, S.; Ladshaw, A.P.; Yiacoumi, S.; Tsouris, C.; DePaoli, D.W.; Tavlarides, L. L. "Aging processes of silver mordenite and silver functionalized aerogel in dry air, humid air and NO/N2", 2017 ANS Annual Meeting, San Francisco, CA, June 11-15, 2017.

10. Nan, Y.; Abney, C.; Choi, S.; Tavlarides, L.L. "Aging Processes of Ag-Exchanged Mordenite and Ag-Functionalized Silica Aerogel in Spent Nuclear Fuel Reprocessing Off Gases", 2017 AIChE Meeting, Minneapolis, MN, October 29-November 3, 2017.

11. Nan, Y.; Choi, S.; Ladshaw, A.P.; Yiacoumi, S.; Tsouris, C.; Tavlarides, L.L. "Determination of Mechanisms and Kinetics of Ag0Z and Ag0-Aerogel Aging in Nuclear Off-Gases", 2018 ANS Annual Meeting, Philadelphia, PA, June 17-21, 2018.

12. Nan, Y.; Choi, S.; Ladshaw, A.P.; Yiacoumi, S.; Tsouris, C.; Tavlarides, L.L. "Mechanisms and Kinetics of Ag0Z and Ag0-Aerogel Aging in Nuclear Off-gases", 20th Symposium on Separation Science and Technology for Energy Applications, Gatlinburg, TN, October 21-24, 2018.

13. Choi, S.; Nan, Y.; Wiechert, A.I.; Ladshaw, A.P.; Yiacoumi, S.; Tsouris, C.; Tavlarides, L.L. "Kinetic Study of Ag Mordenite and Ag Functionalized Silica Aerogel Aging in Nuclear Fuel Reprocessing Off-Gases”, 2018 AIChE Annual Meeting, Pittsburgh, PA, October 28 November 2, 2018.

14. Nan, Y.; Choi, S.; Carter, A.; Moon, J.; Liu, J.; Tavlarides, L.L. "Iodine Adsorption in Reduced $\mathrm{AgZ}$ and Ag-Aerogel in Presence of Water and NOx", 2018 AIChE Annual Meeting, October 28 - November 2, 2018.

15. Choi, S.; Nan, Y.; Ladshaw, A.P.; Wiechert, A.I.; Yiacoumi, S.; Tsouris, C.; Tavlarides, L.L. "Mechanisms and Kinetics of Ag0Z and Ag0-Aerogel Aging in Nuclear Off-gases", Material Recovery and Waste Form Development Campaign Working Group Meeting, Richland, WA, March 26-27, 2019. 
16. Choi, S.; Nan, Y.; Wiechert, A.I.; Ladshaw, A.P.; Yiacoumi, S.; Tsouris, C.; Tavlarides, L.L. "Kinetic Study of Ag0Z and Ag0-Aerogel Aged in Off-Gas Streams from Spent Nuclear Fuel Reprocessing System”, 2019 ANS Annual Meeting, Minneapolis, MN, June 9-13, 2019.

17. Choi, S.; Nan, Y.; Wiechert, A.I.; Ladshaw, A.P.; Yiacoumi, S.; Tsouris, C.; Tavlarides, L.L. "Aging Study of Ag0Z and Ag0-Aerogel in the presence of off-gas streams", 2019 Global and Top Fuel, Seattle, WA, September 22-27 2019.

18. Choi, S.; Nan, Y.; Wiechert, A.I.; Ladshaw, A.P.; Yiacoumi, S.; Tsouris, C.; Tavlarides, L.L. "Aging Kinetics of Ag-Exchanged Mordenite and Ag-Functionalized Silica Aerogel in the Presence of Off-Gas Streams", 2019 AIChE Annual Meeting, Orlando, FL, November 10-15, 2019.

19. Choi, S.; Wiechert, A.I.; Yiacoumi, S.; Tsouris, C.; Tavlarides, L.L. "Aging Study of AgExchanged Mordenite and Ag-Functionalized Silica Aerogel in Gas Mixture of Water Vapor and NOx Streams", 2020 Virtual AIChE Annual Meeting, November 16-20, 2020. 


\section{Part 6: Appendix}

\subsection{Supporting Information for Part 2}

Capture of Iodine from Nuclear-Fuel-Reprocessing Off-Gas: Influence of Aging on Reduced Silver Mordenite Adsorbent after Exposure to $\mathrm{NO} / \mathrm{NO}_{2}$
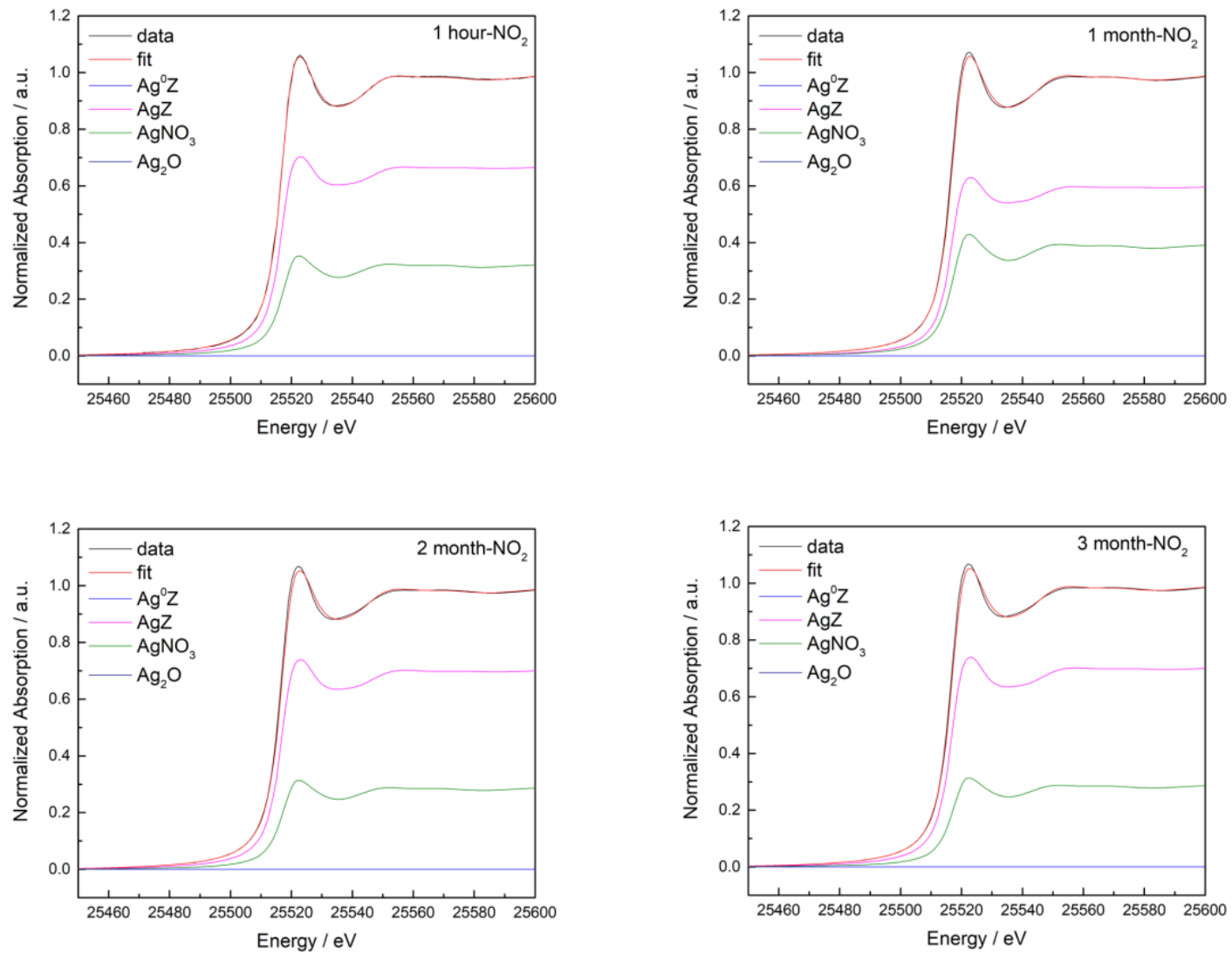

Figure S1. Linear combination fitting (LCF) for $\mathrm{Ag}^{0} \mathrm{Z}$ aged in $2 \% \mathrm{NO}_{2}$ in dry air using reference compounds $\mathrm{Ag}^{0} \mathrm{Z}, \mathrm{Ag}_{2} \mathrm{O}, \mathrm{AgNO}_{3}$, and $\mathrm{AgZ}$. Experimental data are in black and the $\mathrm{LCF}$ is in red. Reference standards used to achieve the LCFs are plotted beneath and scaled according to their contribution to the fit. 

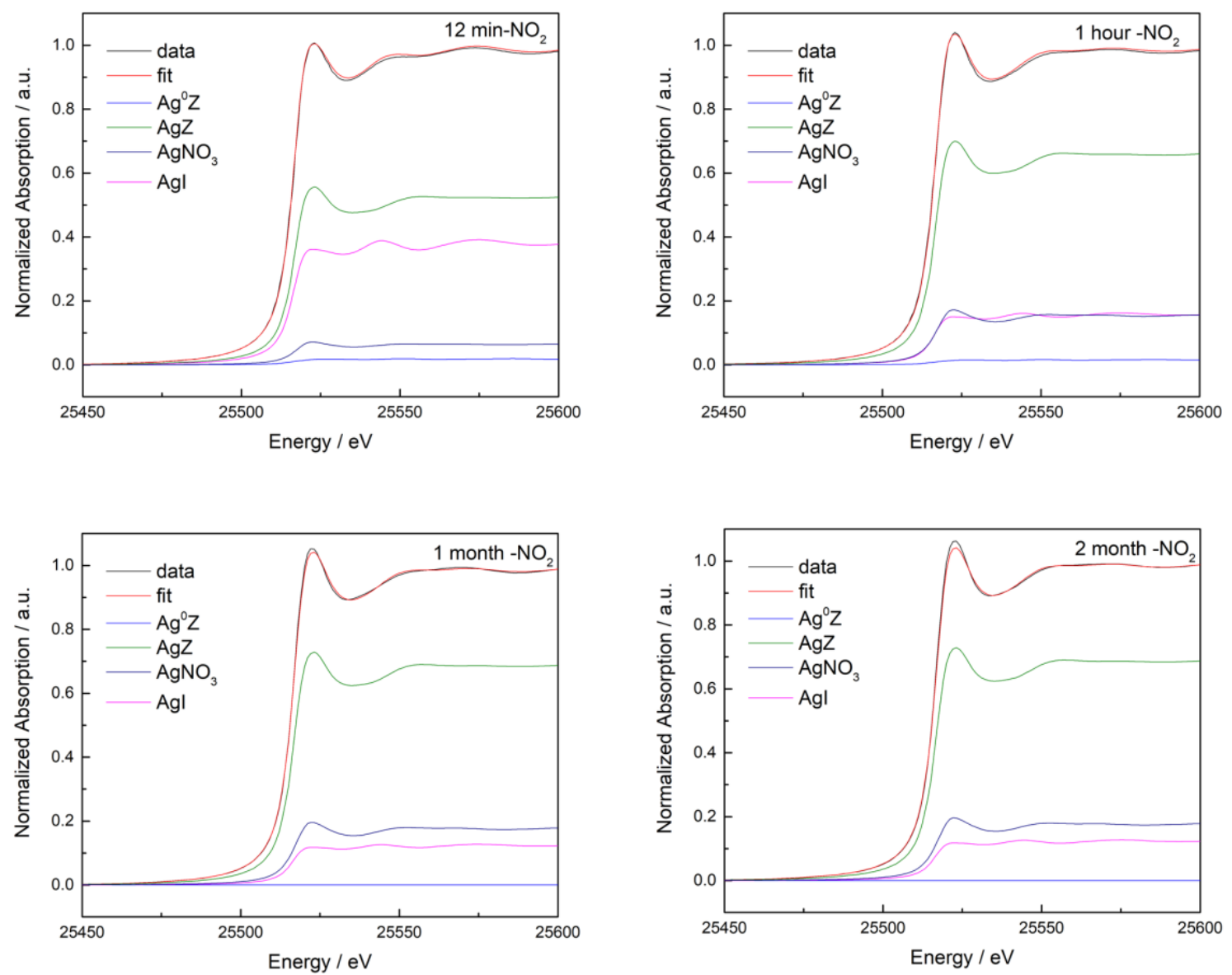

Figure S2. Linear combination fitting (LCF) for $\mathrm{Ag}^{0} \mathrm{Z}$ aged in $2 \% \mathrm{NO}_{2}$ in dry air and then exposed to iodine $\left(\mathrm{I}_{2}\right)$ at a concentration of $50 \mathrm{ppmv}$ in dry air using reference compounds $\mathrm{Ag}^{0} \mathrm{Z}, \mathrm{Ag}_{2} \mathrm{O}$, $\mathrm{AgNO}_{3}, \mathrm{AgZ}$, and AgI. Experimental data are in black and the LCF is in red. Reference standards used to achieve the LCFs are plotted beneath and scaled according to their contribution to the fit. 

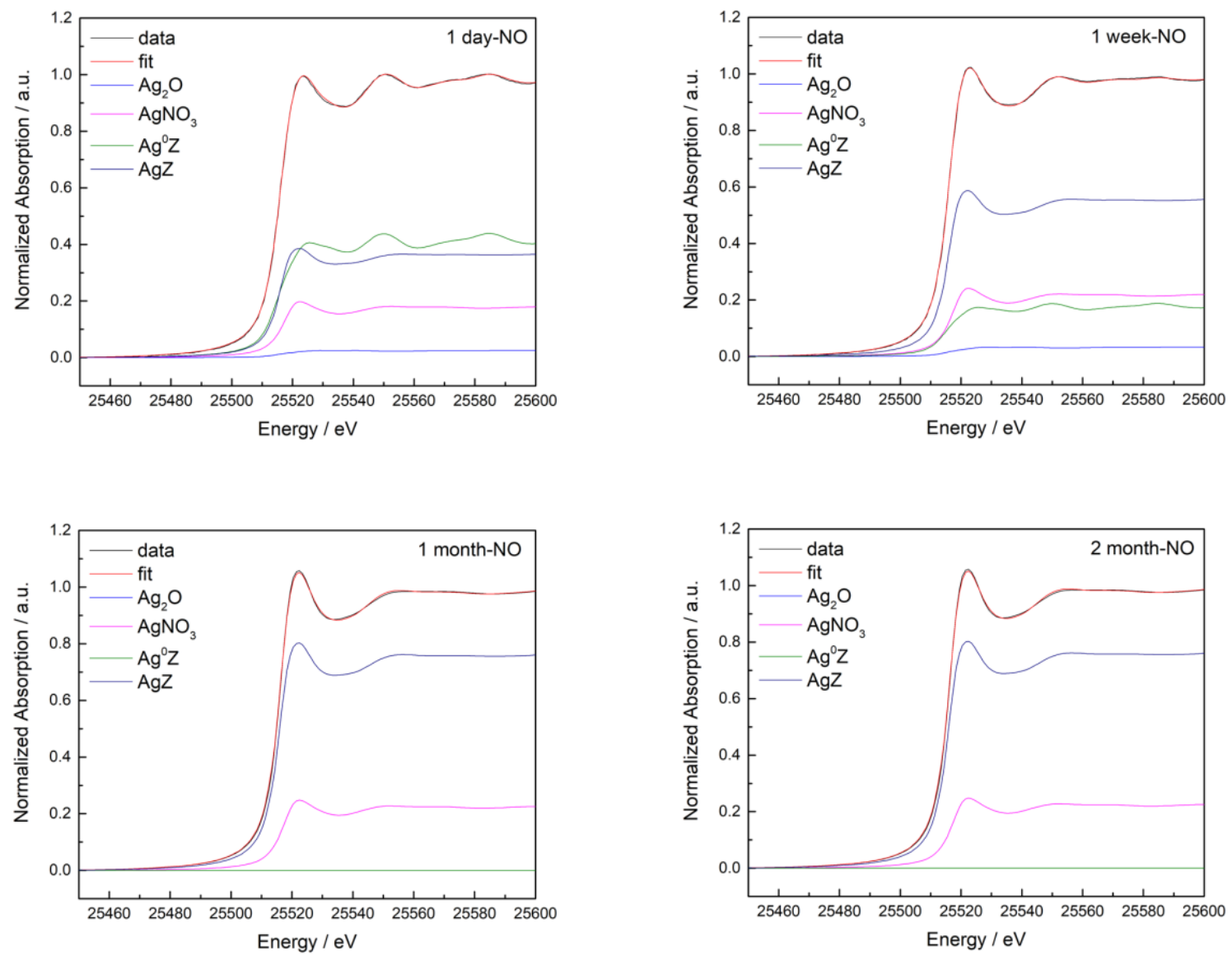

Figure S3. Linear combination fitting (LCF) for $\mathrm{Ag}^{0} \mathrm{Z}$ aged in $1 \% \mathrm{NO}$ in $\mathrm{N}_{2}$ using reference compounds $\mathrm{Ag}^{0} \mathrm{Z}, \mathrm{Ag}_{2} \mathrm{O}, \mathrm{AgNO}_{3}$, and $\mathrm{AgZ}$. Experimental data are in black and the LCF is in red. Reference standards used to achieve the LCFs are plotted beneath and scaled according to their contribution to the fit. 

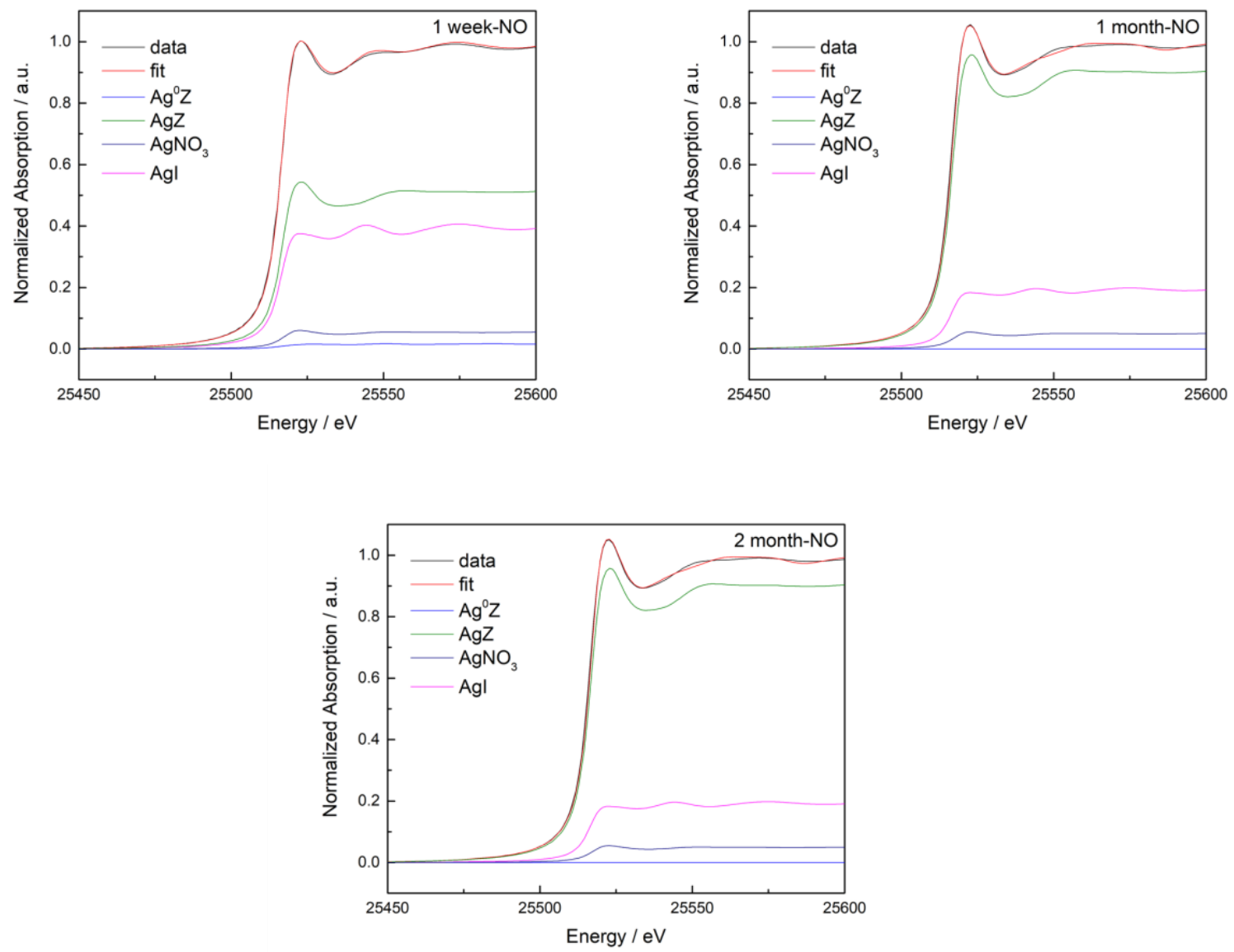

Figure S4. Linear combination fitting (LCF) for $\mathrm{Ag}^{0} \mathrm{Z}$ aged in $1 \% \mathrm{NO}$ in $\mathrm{N}_{2}$ and then exposed to iodine $\left(\mathrm{I}_{2}\right)$ at a concentration of $50 \mathrm{ppmv}$ in dry air using reference compounds $\operatorname{Ag}^{0} \mathrm{Z}, \operatorname{Ag}_{2} \mathrm{O}$, $\mathrm{AgNO}_{3}, \mathrm{AgZ}$, and AgI. Experimental data are in black and the LCF is in red. Reference standards used to achieve the LCFs are plotted beneath and scaled according to their contribution to the fit.

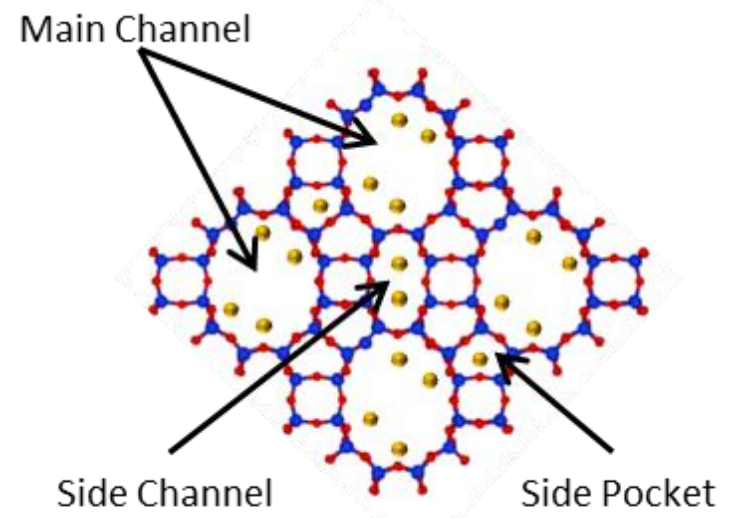

Figure S5. Structure of mordenite crystal where 12-member 7.0 x $6.5 \AA ̊$ main channels, parallel 8member 5.7 × $2.6 \AA$ side channels, and 5-member side pockets with approximate binding sites shown. 